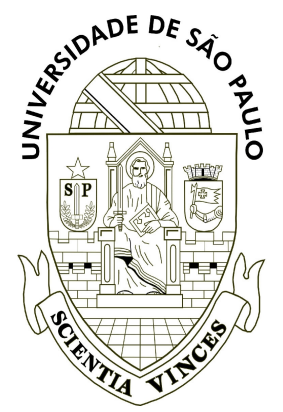

UNIVERSIDADE DE SÃO PAULO

ESCOLA DE COMUNICAÇÕES E ARTES

PROGRAMA DE PÓS-GRADUAÇÃO EM CIÊNCIAS DA COMUNICAÇÃO

MAURÍCIO AUGUSTO PIMENTEL LIESEN NASCIMENTO

\title{
EXCOMMUNICATIO
}

ENSAIO PARA UMA TEORIA NEGATIVA DA COMUNICAÇÃO 


\title{
Excommunicatio
}

\section{Ensaio para uma teoria negativa da comunicação}

\author{
Tese apresentada ao Programa de \\ Pós-Graduação em Ciências da Comunicação \\ da Escola de Comunicações e Artes da \\ Universidade de São Paulo como requisito à \\ obtenção do título de Doutor em Ciências da \\ Comunicação
}

Área de Concentração:

Teoria e Pesquisa em Comunicação

Orientador:

Prof. Dr. Ciro Marcondes Filho

Supervisor (PhD-Sandwich):

Prof. Dr. Dieter Mersch / Universität Potsdam

SÃO PAULO 
O autor autoriza a reprodução e divulgação total ou parcial deste trabalho, por qualquer meio convencional ou eletrônico, para fins de estudo e pesquisa, desde que citada a fonte.

Todas as citações de obras em língua estrangeira, cujas versões em português não foram referenciadas, são traduções livres feitas pelo autor deste trabalho. Eventuais incorreções ou omissões estão sob sua responsabilidade.

Catalogação da Publicação

Serviço de Biblioteca e Documentação

Escola de Comunicações e Artes da Universidade de São Paulo

Dados fornecidos pelo(a) autor(a)

Liesen, Maurício

Excommunicatio: Ensaio para uma teoria negativa da comunicação / Maurício Liesen. -- São Paulo: M. Liesen, 2014.

191 p.: il.

Tese (Doutorado) - Programa de Pós-Graduação em Ciências da Comunicação - Escola de Comunicações e Artes /

Universidade de São Paulo.

Orientador: Ciro J. R. Marcondes Filho

Bibliografia

1. Teoria da Comunicação 2. Filosofia 3. Epistemologia 4.

Negatividade 5. Filosofia dos Media I. Marcondes Filho, Ciro J. R.

II. Título.

CDD 21.ed. - 302.01

Capa:

Montagem sobre a foto da escultura Spreken [1999], de Berlinde de Bruyckere (c)Syb'L. S.-Pictures (C)Coleção MuHKA, Antuérpia, Bélgica

http://www.muhka.be/fr/collectie/work/322/Spreken

Fonte: Linux Biolinum, desenhada por Philipp H. Poll (OFL).

Editor de texto: LibreOffice 4.0.2.2 (LGPLv3).

Gerenciador de referências: Mendelay® 1.8.4. 
LIESEN, Maurício. Excommunicatio: ensaio para uma teoria negativa da comunicação. Tese apresentada ao Programa de Pós-Graduação em Ciências da Comunicação da Escola de Comunicações e Artes da Universidade de São Paulo para obtenção do título de Doutor em Ciências da Comunicação.

Aprovado em:

Banca Examinadora

Prof. Dr. Ciro J. R. Marcondes Filho

Julgamento:

Prof. Dr. José Benjamin Picado

Julgamento:

Prof. Dr. Luís Mauro Sá Martino

Julgamento:

Prof. Dr. Mauro Wilton de Sousa

Julgamento:

Prof. Dra. Mayra Rodrigues Gomes

Julgamento:
Instituição: Universidade de São Paulo

Assinatura:

Instituição: Universidade Federal Fluminense

Assinatura:

Instituição: Faculdade Cásper Líbero

Assinatura:

Instituição: Universidade de São Paulo

Assinatura:

Instituição: Universidade de São Paulo

Assinatura: 
A Katia Fonsaca, cuja presença tece as noites, as promessas e possibilidades. 


\section{AGRADECIMENTOS}

Ao Prof. Dr. Ciro Marcondes Filho, por ter acolhido e amparado esta pesquisa. Obrigado pela amizade, pelas instigantes discussões teóricas, pela sua obra norteadora e pelo exemplo de vida acadêmica. Meus sinceros agradecimentos, com grande respeito e admiração.

Ao Prof. Dr. Dieter Mersch, por ter gentilmente recebido e orientado este trabalho durante os dois anos de pesquisa na Universidade de Potsdam. Obrigado pela suas obras, aulas e conversações inspiradoras que marcaram profundamente a minha atitude como pesquisador.

A Katia Fonsaca, pelo carinho e afeto sem o quais este trabalho não poderia ter sido escrito, por aceitar costuramos juntos nosso "tear de entrexistências", pela paciência e pela revisão do texto.

A meus pais, Mônika Liesen e Maurício Nascimento, e meus irmãos, André, Adriano e Leonardo, pelo bem-querer movente que supera as saudades e as distâncias.

A Cristina Bonfiglioli, pela amizade, pelo apoio e força nos momentos mais difíceis, pelos conselhos, pelas longas e agradáveis conversas teóricas e cotidianas.

A Danielle Naves, pela amizade, pelos diálogos poético-existencias, pela produtiva atmosfera de afinidades filosóficas, pela serenidade.

A Johannes Bennke, pela amizade, pela grande sintonia teórico-filosófica, pela ajuda no cotidiano acadêmico alemão, pelos incontáveis debates inspiradores, pelo suporte não apenas acadêmico, mas existencial.

Ao membros do Centro de Estudos Filosóficos da Comunicação (FiloCom), em especial a Bruna Queiroga, Carol Nehring, Karenine Rocha, Lauren Colvara e Marco Toledo Bastos. Muito obrigado pela amizade, pelos comentários, discussões, orientações, conselhos, provocações e apoio.

Aos meus irmãos eletivos, Arthur Lins, Gledson Oliveira, Pedro Oliveira, Rafael Acioly, Rodrigo Melo e Yuri Ismael. Aos amigos, André de Oliveira, Cícero Alves, Giovane Rodrigues e Vinícius Maracajá.

Agradeço ainda a Carolin Switala, ao Prof. César Guimarães, ao Prof. Denílson Lopes, ao Prof. Frank Hartmann, a Jörg Sternagel, à Prof. Lívia Mathias Simão, Prof. Luíz Mousinho, ao Prof. Norval Baitelo, à Prof. Marília Fiorillo, ao Prof. Michael Mayer e a Peter Müller.

Várias outras pessoas contribuíram direta ou indiretamente para a produção deste trabalho, mas infelizmente não foram citadas nominalmente pela falta da espaço. Peço minhas desculpas e deixo aqui minha sincera gratidão.

Ao Serviço Alemão de Intercâmbio Acadêmico (DAAD), pelo suporte material e financeiro durante os dois últimos anos desta pesquisa, realizados na Universidade de Potsdam entre março de 2012 e março de 2014.

À Fundação de Amparo à pesquisa do Estado de São Paulo (FAPESP), pelo financiamento desta pesquisa entre agosto de 2010 e dezembro de 2011.

À Coordenação de Aperfeiçoamento de Pessoal de Nível Superior (CAPES), pelo apoio financeiro durante os cinco primeiros meses deste trabalho, de março a julho de 2010.

A essas três importantes agências de fomento, meus mais profundos agradecimentos. Sem esse suporte financeiro, material e de capacitação, a realização deste trabalho de doutoramento não teria sido possível. 
Quando eu falo a palavra Futuro, a primeira sílaba já pertence ao passado.

Quando eu falo a palavra Silêncio, o destruo.

Quando eu falo a palavra Nada, crio algo que nenhum não-ser comporta.

"As três palavras mais estranhas" Wisława Szymborska 
LIESEN, Maurício. Excommunicatio: ensaio para uma teoria negativa da comunicação. 2014. 191 p. Tese (Doutorado) - Escola de Comunicações e Artes, Universidade de São Paulo, São Paulo, 2014.

Este trabalho de doutorado esboça uma teoria negativa da comunicação a partir da reelaboração negativa dos seus três conceitos fundamentais: a comunicação, o medium e a comunidade. Grosso modo, a comunicação é figurada como uma experiência radical de alteridade; o medium como a descrição dos modos de percepção desta experiência e a comunidade como a incorporação das possibilidades de sua ocorrência. A comunicação manifesta uma experiência que transforma o 'eu' em 'mim', pois o sujeito não é necessariamente causa ou efeito desta experiência, mas é exposto à ela, como uma ferida aberta. O medium é o modo de percepção que opera esta experiência: ele não é uma ponte entre o abismo que separa o mim do outro, pois ele acentua esse abismo, na medida em que ele se imaterializa no momento da experiência, como uma materialidade que se descorporifica. E quando essa experiência efetua-se, é porque se toma parte em algo comum, em uma comunidade: mesmo que precária ou evanescente, ela incorpora a possibilidade da ocorrência deste fenômeno. Na teoria negativa da comunicação, o medium torna-se transparente, a comunidade torna-se expositória e a comunicação torna-se transcendente. Ponderar sobre a negatividade da comunicação é ir ao encontro de uma ex-comunicação: uma despalavra que busca ex-pôr aquilo que nos fenômenos comunicacionais escapa à discursividade, seja a medialidade do meio, a inefabilidade da relação ou a comunidade daqueles que não constituem qualquer comunidade. O prefixo ex assinala não apenas uma simples negação, mas um deslocamento fundamental: ele é o inegável que se pré-supõe, que constitui a comunicação, mas que resiste à qualquer conceituação. Ao mesmo tempo em que possibilita, o prefixo ex assegura a impossibilidade da sua re-presentação: um comunicar que não se estrutura em signos, mas se mostra - uma comunicação negativa, existencial, intransitiva, inexprimível, mística.

\section{Palavras-chave}

Teoria da Comunicação | Filosofia | Epistemologia | Negatividade | Filosofia dos Media 


\section{ABSTRACT}

LIESEN, Maurício. Excommunicatio: an essay for a negative theory of communication. 2014. 191 pp. Thesis (PhD) - School of Communications and Arts, University of São Paulo (ECA-USP), São Paulo, 2014.

Ex-communication is an «un-word» that emphasizes what eludes in the communicational phenomenon: be it the mediality of the medium, the incomprehensibility of a relation or the community of those who have no community. The «ex» means not only a negation, but also a fundamental drift: it is the irrevocable and the irreconcilable that the communication presupposes and constitutes, although it defies conceptualization. The «ex» guarantees the impossibility of re-presentation. A communication that is not structured by signs, but rather shows itself: it is an existential, intransitive or mystical communication. This PhD thesis aims to establish the general outline for a negative theory of communication. By using the negative and posthermeneutic media philosophy developed by the philosopher Dieter Mersch, this dissertation intends a negative reelaboration of the three main concepts of a communicational theory: media, community and communication. In general, communication is taken as a radical alterity experience, medium as the modes of perception of this experience, and community as the possibility and condition of the communicacional event. In other words: in the negative theory of communication, the medium is transparent, the community is what ex-poses, and communication is transcendent.

\section{Keywords}

Communications Theory | Philosophy | Epistemology | Negativity | Media Philosophy 
LIESEN, Maurício. Excommunicatio: Versuch zu einer negativen Kommunikationstheorie. 2014. 191 S. Dissertation (Doktorarbeit) - Institut für Kommunikation und Künste, Universität São Paulo (ECA-USP), São Paulo, 2014.

Ex-Kommunikation ist ein Ent-Wort, das betont, was sich in den Kommunikationsphänomen entzieht: sei es die Medialität des Mediums, das Unfassbare des Bezugs oder die Gemeinschaft derer, die keine Gemeinschaft haben. Das „Ex-“ bezeichnet nicht nur eine Negation, sondern auch eine fundamentale Verschiebung: es ist das Unwiderrufliche und das Unvereinbare, das die Kommunikation voraus-setzt und mit-konstituiert, obwohl es sich jeder Begrifflichkeit entzieht. Das „Ex“ garantiert die Unmöglichkeit der Re-Präsentation. Ein Kommunizieren, das sich nicht durch Zeichen strukturiert, sondern sich zeigt: eine existenzielle, intransitive oder mystische Kommunikation. Ausgehend von dem Philosophen Dieter Mersch entworfenen negativen und posthermeneutischen Medienphilosophie wurde die generelle Skizze für eine negative Kommunikationstheorie in dieser Doktorarbeit begründet. In dieser Dissertation wurde eine negative Ausarbeitung der drei Hauptbegriffe jener Kommunikationstheorie unterfangen: Kommunikation, Medium und Gemeinschaft. Grob skizziert wird Kommunikation als eine radikale Alteritätserfahrung, Medium als ihre Wahrnehmungsmodi und Gemeinschaft als die Möglichkeit ihres Ereignisses betrachtet, oder anders gesagt: In der negativen Kommunikationstheorie wird das Medium transparent, die Gemeinschaft aus-setzend und die Kommunikation transzendent.

\section{Schlagworte}

Kommunikationstheorie | Philosophie | Erkenntnistheorie| Negativität | Medienphilosophie 


\section{SUMÁRIO}

INTRODUÇÃO

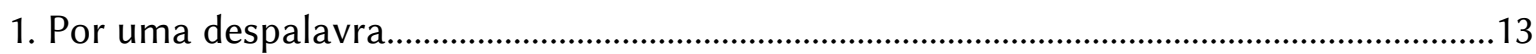

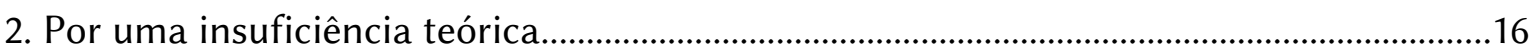

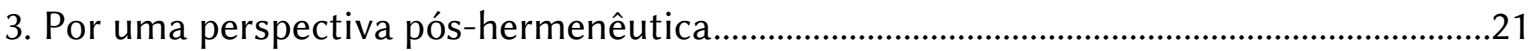

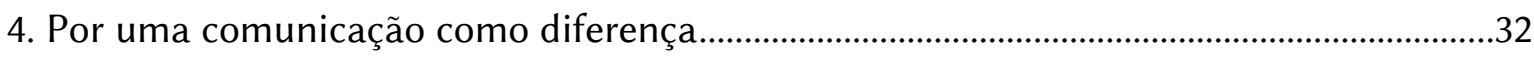

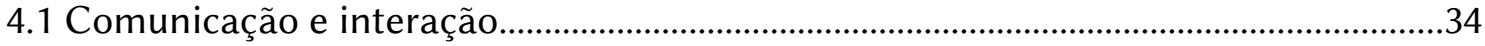

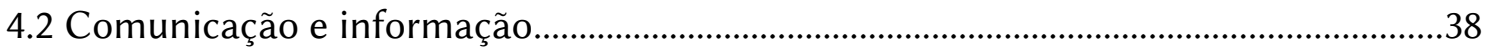

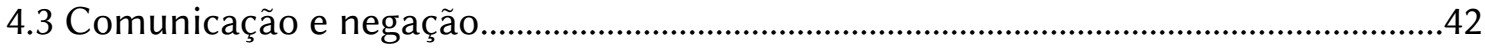

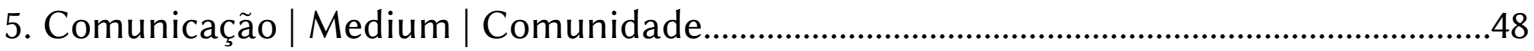

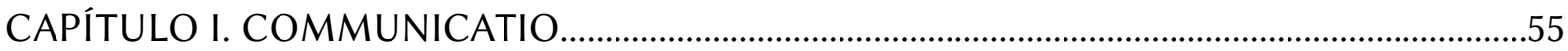

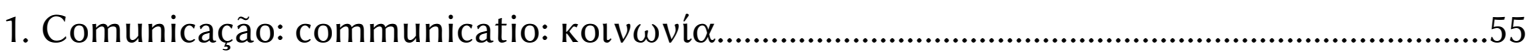

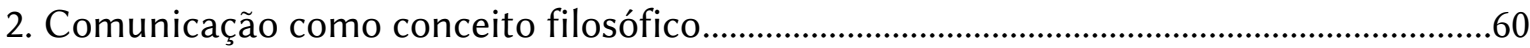

2.1 Søren Kierkegaard e a comunicação indireta...........................................................................64

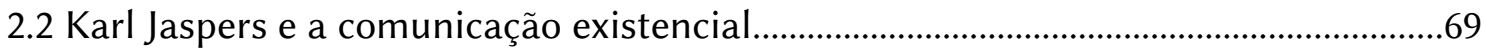

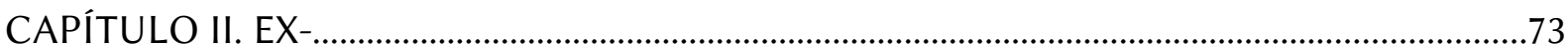

1. Da semelhança, da complementaridade, da diferença.............................................................74

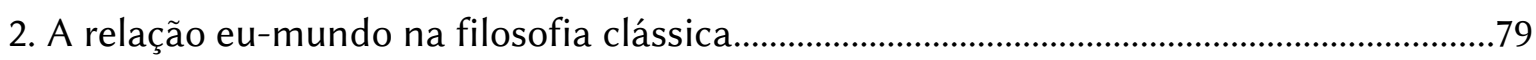

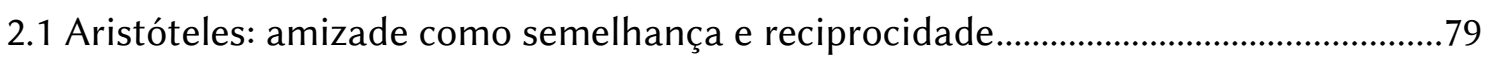

3. Husserl e os primórdios da experiência de alteridade...................................................................

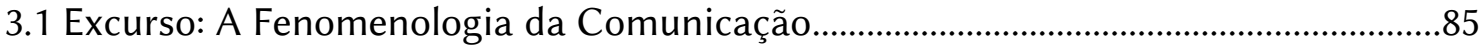

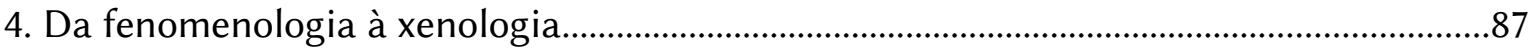

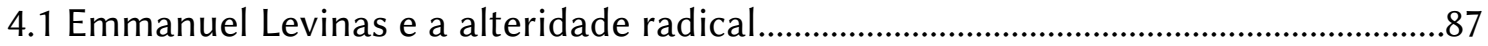

4.2 Bernhard Waldenfels e a fenomenologia da estranheza....................................................91

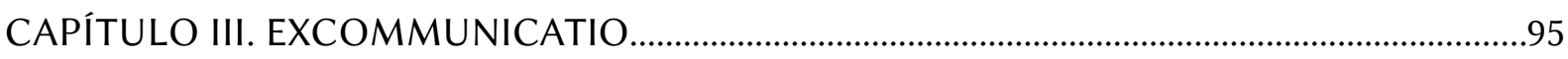

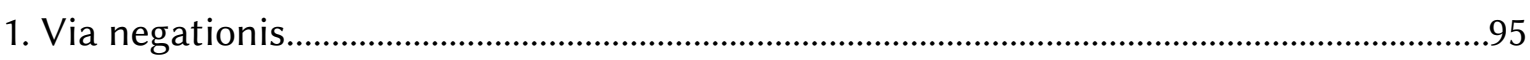

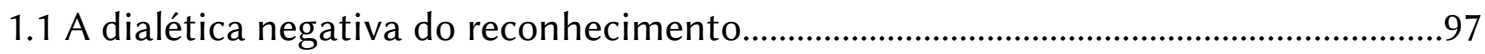


1.2 A inquietude do sentido .103

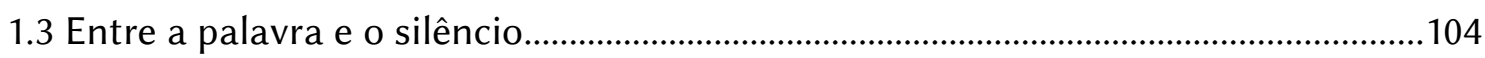

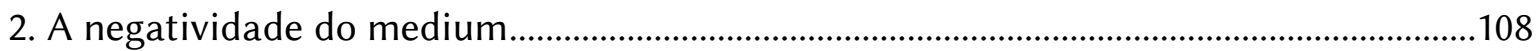

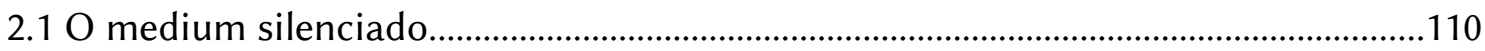

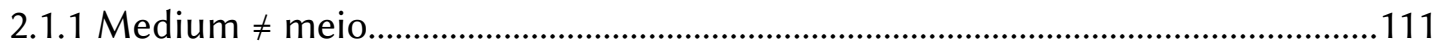

2.1.2 Uma questão de tradução...........................................................................................118

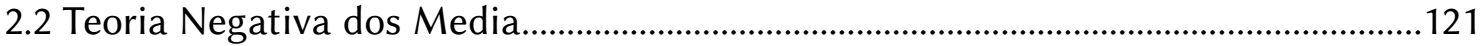

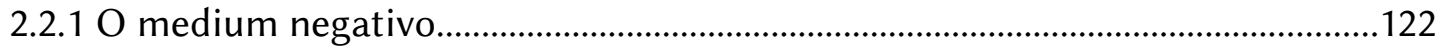

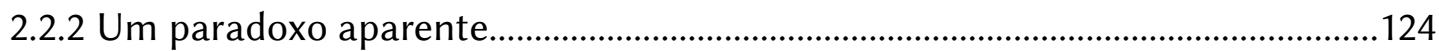

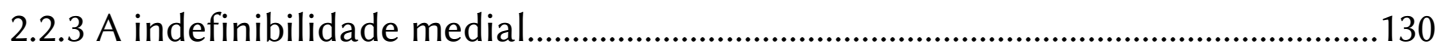

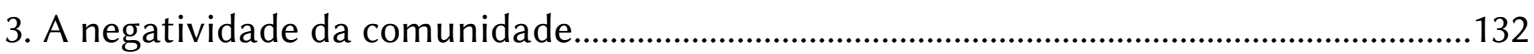

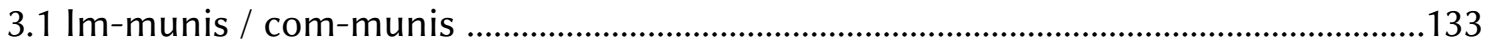

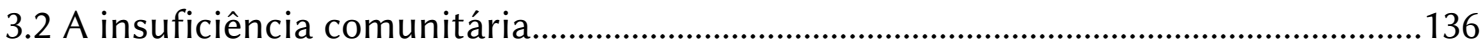

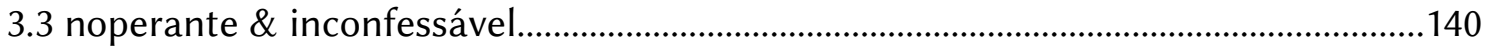

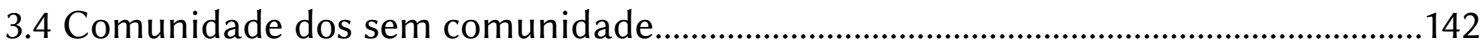

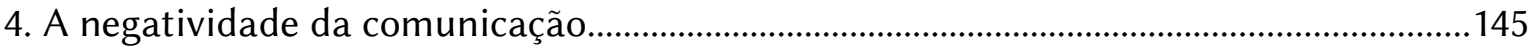

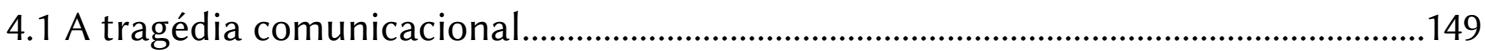

4.1.1 “A existência é comunicação...”.....................................................................................151

4.1.2 A experiência interior, ou uma ilusão necessária ....................................................154

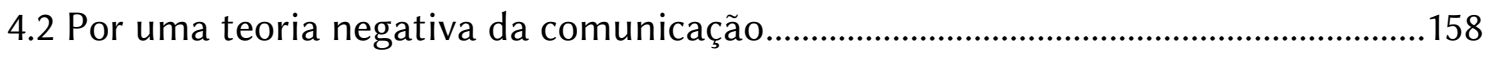

4.2.1 Figurações ético-estéticas de uma teoria negativa da comunicação..................160

4.2.2 Excurso I. Notas sobre uma não comunicação em espaços telemáticos...........163

4.2.3 Excurso II. Ex-comunicação...........................................................................................169

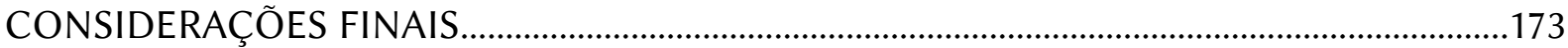

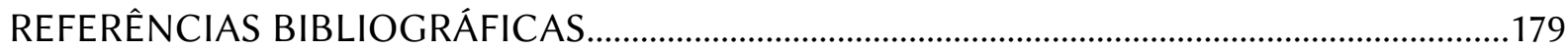


Manoel de Barros

\section{Por uma despalavra}

A proposta deste trabalho é arruar uma despalavra: a ex-comunicação. Paradoxalmente, a ex-comunicação é a própria ex-posição do reino da despalavra. E por ser ela mesma uma despalavra, a ex-comunicação carrega em si uma dupla negatividade: é indefinível e, ao mesmo tempo, incontornável. O prefixo ex assume aqui a mesma função do prefixo des do título do poema de Manoel de Barros: ele atribui não apenas uma simples negação, mas um deslocamento fundamental: ele é o inegável que se pré-supõe, que constitui a comunicação, mas que resiste à qualquer conceituação: ao mesmo tempo em que possibilita, o prefixo ex assegura a impossibilidade da sua re-presentação. Este trabalho é, portanto, uma tentativa de expor um conceito outro de comunicação, de ex-pôr uma alusão capaz de manifestar uma comunicação que não se realiza no nível linguístico e que se nega a qualquer representação adequada. Um comunicar que não se estrutura em signos, mas se mostra: uma comunicação existencial, intransitiva, inexprimível ou mística ${ }^{1}$.

A ex-comunicação no seu manifestar-se é percebida em uma experiência radical de passibilidade. Revelação de uma presença sem a Verdade, sem a plena comunhão com essências e dogmas incontestes, ela se dá na percepção - apreendida como medialidade - a

1 Místico no sentido em que o filósofo austríaco Ludwig Wittgenstein definiu em seu Tratactus Logicus-Philosophicus (WITTGENSTEIN, 1995, p. 85 [6.522]): "Certamente há o inexprimível. Ele se mostra, ele é o místico" [Es gibt allerdings Unaussprechliches. Dies zeigt sich, es ist das Mystische]. 
partir da presença do outro - o além do $\operatorname{mim}$ que atrai e se retrai. A ex-comunicação é a manifestação de uma comunicação sem Deus: não apenas uma negação de qualquer estrutura apriorística, mas também do essencialismo metafísico. Excommunicatio: excomunhão e ex-comunicação. Excomunhão que resiste à comunidade que não permite excomungados. Ex-comunicação que resiste ao apriorismo sígnico que não admite o inexprimível.

Este é o campo de tensões no qual se move esta tese de doutorado. Nele estão as linhas gerais para a proposta de uma teoria negativa da comunicação, cuja defesa será efetivada a partir de uma reelaboração negativa dos seus três conceitos fundamentais: a comunicação, o medium e a comunidade. Estes três termos são o ponto de partida para qualquer teoria que se proponha a descrever o fenômeno comunicacional. Grosso modo, assume-se neste trabalho a comunicação como a figuração de uma experiência radical de alteridade; o medium como a descrição dos modos de percepção desta experiência e a comunidade como a incorporação das possibilidades de sua ocorrência e da superação da intersubjetividade. O pensamento da negatividade auxilia para acolhimento do inexprimível no desenvolvimento desses conceitos - ou quase conceitos, já que atuam mais como modos de descrever fenômenos que escapam à qualquer sedimentação ontológica (a resposta ao "o que é") ou hermenêutica ("tal como"), assumindo antes a característica do pronome relativo "que" (Cf. MERSCH, 2010a, p. 82 ss. e passim). "Que" é a marca da presença de uma ausência fundamental: ele marca o negativo da significação, ou seja, aquilo que não possui nenhum conhecimento de si. A negatividade rabisca o enigma da condição. Ela ressalta algo que se dá com e na comunicação, mas que não se transmite por ela. Ela retrai-se no momento da experiência. A ex-comunicação é inoperante.

Estes termos aparentemente nebulosos são elaborados e reelaborados no decorrer deste trabalho, na esperança de que eles se manifestem de forma mais enfática. Por sua vez, com o intuito de arruar a proposta de uma teoria negativa da comunicação, são necessários três anteparos que constituem a divisão dos capítulos desta tese de doutorado, a saber: a descrição da dimensão existencial e mística do conceito de comunicação; a abordagem da categoria filosófica do outro na constituição da experiência comunicacional; e, por fim, a projeção dos conceitos negativos de medium, comunidade e comunicação.

Como já se deixa perceber, este trabalho não está alinhado aos estudos e teorias da comunicação que partilham dos pressupostos linguístico, mediacional ou sígnico (como sistema de orientação, ponto de partida ou de chegada para as suas reflexões). Ao contrário, 
ele busca atuar no limiar dessas abordagens: uma tentativa de evidenciar os limites de tais apriorismos e mostrar o que - para além ou aquém deles - resta para a comunicação. Mas o local desta tese é bem delimitado: as inquietações, conflitos e diálogos partem daquilo que recentemente foi exposto como o campo pós-hermenêutico (GUMBRECHT, 1998, 2004; MERSCH, 2010a). A ex-comunicação é uma proposta para situar a comunicação - sob a perspectiva de uma filosofia negativa dos media, elaborada principalmente pelo filósofo alemão Dieter Mersch (2002, 2006, 2008, 2010) - dentro de um contexto pós-hermenêutico. A caracterização deste lugar, onde a presente tese vai buscar seus principais referenciais teóricos, é abordado num tópico específico ainda nesta introdução.

Antes deve-se ressaltar que esta proposta não significa, sob qualquer hipótese, uma superação ou necessidade de esquecimento de qualquer outra teoria do chamado campo da comunicação. Muito mais do que uma revisão crítica dessas outras teorias, esta tese propõe apresentar um outro caminho ou uma abordagem suplementar: um outro aparato conceitual para se observar um mesmo fenômeno, ressaltando, contudo, diferentes aspectos. Como apresentado no decorrer deste trabalho, as implicações metodológicas da sua proposta não são concorrentes com qualquer teoria. E as suas implicações éticas e políticas caracterizam-se de outra forma do que aquelas apresentadas pelas teorias do a priori linguístico, mas cuja reflexão é incontornável e necessária para manifestação de um contraponto à atual imposição de uma sociedade da comunicação.

Para exemplificar o posicionamento deste outro olhar, pode-se recorrer à diferenciação entre as perspectivas medial e sígnica das recentes teorias dos media, como proposta pela filósofa alemã Sybille Krämer, em seu livro Medium, Bote, Übertragung [Medium, Mensageiro, Transmissão], publicado em 2008. Krämer aponta para duas abordagens: uma voltada para o que é transmitido signicamente e outra para o que é traduzido medialmente: "Na perspectiva semiológica, o 'oculto' do sentido está atrás do sensual; na perspectiva mediológica, ao contrário, o 'oculto' da sensação está atrás do sentido" (KRÄMER, 2008, p. 34). Em outras palavras, o signo deve ser perceptível, mas o que nele é perceptível, é secundário: o significado é que é importante, ou seja, aquilo que é tomado costumeiramente por ausente, invisível, ou até mesmo imaterial. O signo é em geral concebido como algo que está para uma outra coisa, que indica algo além de sua materialidade. O medium, por sua vez, funciona justamente ao contrário: o que nós percebemos é a própria mensagem, que surge no acontecimento medial. O medium é o secundário: ele se neutraliza, se recolhe no seu uso. Ao contrário da relação sígnica, que 
atrás do sensório encontra-se o sentido, a perspectiva medial propõe que atrás da mensagem visível se esconde o medium invisível (KRÄMER, 2008, p. 35). Tal concepção do medium como algo que se esconde no momento da sua manifestação é desenvolvida extensivamente pela obra do filósofo Dieter Mersch, cuja proposta, como já mencionada, culmina em uma teoria negativa dos media. Para Mersch, os media possuem a capacidade de esconder sua medialidade na medida em que ela ocorre: "Sua presença tem o formato de uma ausência" (MERSCH, 2008, p. 304). A estrutura do medial, portanto, não pode ser mediada. Ela se mostra. O que é passível de observação não é o medium, mas a sua aparição fenomênica como medialidade, pois o medium é algo que torna alguma coisa presente, mas que não se deixa apreender neste processo. Ele não pode ser tematizado. Daí a sua negatividade. A partir dessa perspectiva, este trabalho busca esboçar uma teoria negativa da comunicação.

O insatisfatório é inerente à comunicação. Não é uma falta, como algo que pode ser suprido ou preenchido por outra coisa que estava presente, mas sim, a insuficiência, o inadequado, o irrealizável. Por outro lado, comunicar é algo que ex-cede, que se desdobra não como a busca de um eu para um outro, mas como aquilo que cede, um mim que se abre para o insatisfatório como passibilidade: abertura e escuta. $\mathrm{O}$ desenrolar desta tese busca exibir esta insuficiência fundamental. E dada a sua complexidade fenomenal, qualquer teoria da comunicação reflete impreterivelmente essa insuficiência. Mesmo com o risco de contrair o desgaste desta palavra, o gesto de excomungar a comunicação do seu lugar-comum teórico (semiose, troca ou transmissão), torna-se necessário para ressaltar alguns aspectos em torno deste termo que, se por um lado, foram deixados de lado pela curta tradição das teorias da comunicação no Brasil, por outro lado, está fortemente presente na história do pensamento do século XX em sua tentativa de pensar os limites do próprio pensamento.

\section{II}

\section{Por uma insuficiência teórica}

Aparentemente sem um fora, sem um para além ou aquém de si mesma, desde o 
início do último século a comunicação está sedimentada não apenas nas mais diversas áreas do conhecimento, como também no vocabulário cotidiano, no repertório descritivo e afetivo dos encontros corriqueiros. Nunca se falou tanto sobre comunicação. Por conta do incessante desenvolvimento das tecnologias telemáticas, nunca se afirmou com tanta veemência a disponibilidade ubíqua da comunicação. É uma palavra sedutora: um não conceito ou um quase conceito que impregna com beleza publicitária outros termos distintos tomados irrefletidamente como sinônimos: informação, relação, troca, interação, conexão, disponibilidade, consenso, entendimento, aparatos técnicos, sistema de transportes, transformação, tradução.

Como campo teórico, a comunicação frequentemente dispôs de muletas conceituais emprestadas das ciências sociais, da psicologia, da matemática, da biologia, da psicanálise, da linguística, da semiótica ou dos estudos literários ${ }^{2}$. Isso é tributário da sua formação como curso universitário (cuja expansão nos países ocidentais ocorreu principalmente na década de setenta): os departamentos de ciências da comunicação foram constituídos a partir dos estudos psicológicos e sociológicos da comunicação, dos estudos de suportes específicos (cinema, rádio, televisão, jornal, etc.) e de uma parte das ciências literárias. Por isso, a ciência da comunicação já emergiu integrada como empreendimento interdisciplinar, mantendo esse caráter até seus dias atuais (LAGAAY \& LAUER, 2004, p. 11). Se, por um lado, a sua interdisciplinaridade inata trouxe o benefício de uma produção horizontal de conhecimento complexa e variada, por outro lado, há uma perda significativa na produção conceitual específica que busque o questionamento das fundamentos do próprio liame desta interdisciplinaridade: os conceitos de comunicação e medium.

Uma exemplificação deste cenário: as ementas da disciplina chamada "Teorias da Comunicação", ensinada na maioria dos cursos de "Comunicação Social” espalhados pelo país ${ }^{3}$, carregam até hoje o estigma dos estudos sociológicos do Mass Communication Research, dos modelos matemáticos de transmissão de informações e das chamadas Escolas de Chicago, de Frankfurt e de Toronto, muito mais preocupados com o efeito dos meios

2 Para uma crítica à falta de depuração teórica do termo "comunicação" na academia brasileira, cf. MARCONDES FILHO, 2010a; e ainda o prefácio em MARCONDES FILHO, 2009.

3 Foram consultadas pela internet as ementas da disciplina "Introdução às Teorias da Comunicação/Teorias da Comunicação I" para o ano letivo de 2013 das seguintes universidades brasileiras: USP, UNB, UFC, UFMG, UFRJ, UFF, UERJ, UFBA, UFSC, UFRGS, UFPE, UFJF e UFPR. Das instituições observadas, as únicas cujas ementas apresentaram outro referencial teórico além do citado foram os cursos de Jornalismo da USP, da UFPE e da UFRGS. Último acesso em: 04/06/2013. Para mais detalhes sobre este tema, cf. MARTINO, 2012. Neste artigo, escrito pelo pesquisador Luís Mauro Sá Martino, é apresentada uma análise comparativa dos temas e autores abordados pelos cursos de "Teoria da Comunicação" ministrados em 31 universidades brasileiras. 
massivos de informação na sociedade do que com os questionamentos ontológicos, ético-estéticos e epistemológicos necessários para a constituição de uma teoria ou ainda de uma abordagem teórico-comunicacional ${ }^{4}$.

Mas isso não significa que pouco se escreveu sobre o conceito de comunicação. Ao contrário. Na história do pensamento ocidental, principalmente a partir da segunda metade do século $\mathrm{XIX}^{5}$, a comunicação foi tema de diferentes reflexões teórico-filosóficas. Em alguns momentos, a palavra comunicação desempenhou até mesmo um papel central, como no caso da Existenzphilosophie [Filosofia da Existência], com Søren Kierkegaard e Karl Jaspers, da Begegnungsphilosophie [Filosofia do Encontro] de Martin Buber e da Fenomenologia, com Edmund Husserl e, posteriormente, com Emmanuel Levinas. Este é o primeiro gesto deste trabalho: recolher e refletir sobre os movimentos do pensamento filosófico ocidental nos quais a comunicação foi tratada como categoria ou conceito.

Deve-se ressaltar que este gesto não é solitário, muito menos pioneiro. Há cerca de três décadas tal cartografia do pensamento ocidental vem sendo feita na Alemanha, sob a terminologia Medienphilosophie [Filosofia dos Media] ${ }^{6}$, que não só renovou o debate em torno do conceito de medium a partir da tradição filosófica, como ainda constituiu novas bases para se pensar as teorias dos media contemporaneamente. No cenário brasileiro, o Núcleo de Estudos Filosóficos da Comunicação (FiloCom) sob coordenação do professor Ciro Marcondes Filho, já dialoga há mais de dez anos com esta proposta. Em sua trilogia Nova Teoria da Comunicação, escrita ao longo de vinte anos de pesquisa, Marcondes Filho

4 Para a abordagem e crítica dos aspectos funcionalistas renitentes nas Teorias da Comunicação, cf. SODRÉ, 2012.

5 Não por acaso, à época da expansão dos sistemas informacionais de troca e divulgação massiva, como a expansão da imprensa, as primeiras redes telegráficas a partir do telégrafo elétrico (1833), a fotografia (daguerreótipo, 1837) e o fonógrafo (1877).

6 A Medienphilosophie vem sendo, desde o início da última década, objeto de intenso debate na academia alemã - seja como conceito, disciplina ou mesmo campo. O primeiro momento em que o termo foi utilizado como título de livro foi na obra Medienphilosophie: Musik, Sprache und Schrift bei Friedrich Nietzsche, escrita por Rudolf Fietz e publicada em 1992, que discute o tratamento que Nietzsche deu em sua obra à música, à língua e à escrita (concebidas então como media). De maneira bastante genérica, as correntes medial-filosóficas se dividem atualmente entre aquelas que se ocupam ou do primado do medial (o medium é o próprio sentido) ou da secundidade do medial (ele carrega um sentido que está em outro lugar, que não nela). Ou seja, ou o medium é visto como produtor ou como tradutor (KRÄMER, 2003, p. 80 e ss.).Sobre a legitimação do termo dentro do cenário acadêmico trata-se, de um lado, de uma filosofia dos media em sentido estrito: o que os filósofos (na história da filosofia) têm a dizer sobre os media ou sobre o conceito de medium; por outro lado, trata-se de uma filosofia medial que busca trabalhar filosoficamente questões contemporâneas relacionadas aos media. No primeiro momento, uma releitura de momentos da filosofia de uma problematização não atentada ou não exaustivamente discutida; no segundo, um trabalho de elaboração conceitual para se pensar as novas relações mediais. Nela se inscrevem as revisões de todos os turns (linguistic, iconic, medial, performative etc) do último século. Para um aprofundamento sobre a discussão da pertinência de uma Medienphilosophie, cf. HARTMANN, 2000, 2003; MARGREITER, 2007; ROESLER, 2003; SANDBOTHE \& NAGL, 2005. 
delineou um modelo teórico e metodológico a partir da problematização do conceito de comunicação, fundamentando uma teoria original sobre o acontecimento comunicativo (MARCONDES FILHO, 2002, 2004, 2010a, 2010b, 2011).

Mas não é de se espantar que um dos pioneiros na reivindicação da especificidade do conhecimento teórico comunicacional - ou ainda, do reconhecimento da comunicação como disciplina acadêmica - foi o filósofo tcheco-brasileiro Vilém Flusser ${ }^{7}$, considerado pela própria crítica alemã como um dos pioneiros da Medienphilosophie (GRUBE, 2004, p. 173 ss.; HARTMANN, 2000, p. 279 e ss.; MERSCH, 2006, p. 136 e ss.). Na década de oitenta, Flusser propôs aquilo que ele chamou de comunicologia ${ }^{8}$ [Kommunikologie]: uma disciplina que fosse capaz de lidar com as dimensões existencial e sígnica do processo comunicacional (FLUSSER, 1998). Ao mesmo tempo em que se diferenciou do cânone sociológico das tradicionais teorias da comunicação, a proposta de Flusser delimitou bem as suas questões teóricas. Com isso, sua comunicologia evitou conflitos, principalmente em torno da legitimidade, com outras disciplinas - no mais das vezes, técnicas e orientadas para a prática - que compõem o plural campo das Ciências da Comunicação. ${ }^{9}$

7 De origem judaica, Vilém Flusser ( ${ }^{*} 1920$ †1991) emigrou para o Brasil em 1941 após ter seus pais, irmã e avós mortos nos campos de concentração nazistas. Nove anos depois ele se naturalizou brasileiro. Durante os anos sessenta, foi professor de Filosofia da Ciência, na Escola Politécnica da Universidade de São Paulo e professor de Filosofia da Comunicação na Escola Superior de Cinema e na Escola de Arte Dramática, ambas em São Paulo. Após não ser recontratado como professor da USP, Flusser deixa o Brasil em 1972, iniciando uma fase de intensa produção na Itália, França e Alemanha.

8 Vale ressaltar que o termo "comunicologia" não foi criado por Flusser. A palavra foi usada pela primeira vez em um artigo de Franklin Knower, intitulado A model for Communicology, publicado em 1962 no primeiro volume de The Ohio Speech Journal. Já o cenário do qual emergiu o conceito é anterior, estabelecido em 1951 a partir das abordagens psicanalíticas da comunicação de Jürgen Ruesch e Gregor Bateson, com a publicação da obra Communication: the social matrix of Psychiatry. Mas o primeiro livro a trazer a palavra comunicologia no título só foi publicado em 1978: Communicology - an introduction to the study of communication, escrito por Joseph A. de Vito. Foi somente na década de oitenta, com a obra de Flusser, que o termo ganhou popularidade. Ainda hoje, o termo "comunicologia" é defendido por vários pesquisadores, principalmente norte-americanos. Um dos trabalhos mais profícuos é realizado por Richard Laligan, autor de Phenomenology of Communication: Merleau Ponty's Thematics in Communicology and Semiology (1988) e The Human Science of Communicology: A Phenomenology of Discourse in Foucault and Merleau-Ponty (1992). Seu trabalho influenciou a fundação do Instituto Internacional de Comunicologia, na Southern Illinois University, que atua desde 2000 tanto para a expansão do termo como disciplina, quanto para a formação de um campo de conhecimento: a comunicologia é uma proposta de uma ciência da comunicação humana, a partir de métodos de pesquisa advindos da semiótica e da fenomenologia para explicar a consciência humana e a incorporação de comportamentos como discursos dentro de uma cultura global (Cf. LALIGAN, Richard. Communicology: Lexicon Definition. 2007. In: http://www.communicology.org/conten/definition-communicology. Último acesso: 06/07/2013). Para um aprofundamento sobre a questão, cf. ainda: CATT \& EICHER-CATT, 2010; DEVITO, 1978; LANIGAN, 1992.

9 Se, por um lado, a comunicação como um campo que abrange as várias habilitações voltadas para a crítica e produção de conteúdos mediáticos - sejam eles publicitário, jornalístico, audiovisual, etc. - já possui autonomia a partir de suas práticas, por outro lado, a comunicação como disciplina ainda carece de legitimação, exercida no mais das vezes sob o guarda-chuva teórico das Teorias da Comunicação, ou ainda sob compostos teóricos via o uso do genitivo, como por exemplo, Sociologia da Comunicação, Psicologia da Comunicação, Filosofia da Comunicação, Estética da Comunicação, etc. 
Em sua comunicologia, Flusser buscou um caminho entre a fenomenologia e as teorias informacionais ao conceber o conceito de comunicação a partir de uma constatação existencial. Para o filósofo, a "comunicação humana é um artifício, cujo objetivo é nos fazer esquecer a brutal falta de sentido de uma vida condenada à morte" (FLUSSER, 1998, p. 10). É contra a entropia da morte que um mundo codificado é erigido. Sob este ponto de vista, a comunicação seria um processo necessário de esquecimento de uma existência-para-a-morte pelo qual as informações são armazenadas, processadas, distribuídas e, principalmente, criadas. Assim, a comunicologia renovou a teoria informacional a partir de uma perspectiva existencial: "A tese de que a comunicação humana seja um artifício conta a solidão da morte e a tese de que ela é um processo que corre contra a tendência geral da natureza em direção à entropia, afirmam a mesma coisa" (ibid., p. 13).

Por constituir seu pensamento filosófico a partir do campo comunicacional, Flusser conhecia bem tanto a falta de um cânone teórico quanto a tensão particular de uma teoria da comunicação de ter que refletir sobre uma época tecnocrática, cujo surgimento de sua condição (dos cursos de Comunicação) se deveu à necessidade de mão de obra para as empresas de jornalismo, de publicidade e de audiovisual. Assim, a teoria da comunicação ganhou com Flusser a condição de ser, ao mesmo tempo, sintoma e crítica. Uma situação privilegiada e desafiadora que na época da formação das graduações de comunicação entre os anos 1970 e 1980 - foi assumida por poucos no país.

Entretanto, no âmbito desta pesquisa, o ponto mais importante do pensamento comunicológico de Flusser foi ter, há mais de trinta anos, recolocado o conceito de comunicação como algo intrinsecamente relacionado ao conceito de existência. Neste ponto, partilha desta acepção o segundo gesto desta tese: ressaltar a dimensão existencial da comunicação, pois ela surge como um problema teórico na medida em que a existência humana é tematizada. Por esse motivo, a comunicação não pode ser reduzida à uma visão instrumental.

Contudo, a proposta deste trabalho se distancia da comunicologia flusseriana. Mesmo de caráter filosófico-existencial, o desdobramento de sua proposta não apresenta alternativas à estruturação da comunicação a partir dos estudos dos signos (transmissão e armazenamento) porque, para Flusser, a comunicologia deveria se ocupar de todas as formas e códigos do processo de troca de informações, permanecendo ainda em uma visão estrutural e representacional da comunicação. 
O que se ensaia nesta tese é a relocalização da experiência de comunicação em um campo não linguístico: uma tentativa de repensar o apriorismo do signo e da representação na constituição dos modelos comunicativos. Por esse motivo, situar esta proposta no chamado campo pós-hermenêutico pode fornecer o solo teórico propício para se cultivar uma comunicação negativa, uma figuração que assume a própria insuficiência da palavra comunicação, uma forma que se recolhe à qualquer redução conceitual, mas que se ex-põe e que sempre depende de um "fora" irredutível, seu eks: uma ex-comunicação.

\section{III}

\section{Por uma perspectiva pós-hermenêutica}

Sob uma concepção mais genérica, a pós-hermenêutica atua como uma caixa de ressonância teórica daquilo que se situa para além - ou aquém - de qualquer a priori interpretativo. Termos como alteridade, performativo, excesso, imediaticidade, revelação, testemunho, passibilidade, presença, limiar, atmosfera, sensação, latência, inoperância, materialidade, acontecimento, epifania, místico, súbito, inefável, sublime (para citar apenas alguns), buscam promover o pensamento daquilo que não encontra nenhuma representação ou linguagem apropriada. Por isso, não é de se surpreender que o pensamento pós-hermenêutico tenha como seu locus privilegiado a estética - não em sua acepção

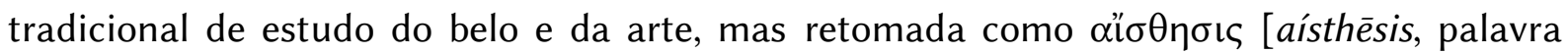
grega para sensação, percepção] ${ }^{10}$, como uma forma de conhecimento que não depende da reelaboração interpretativa.

A hermenêutica é entendida não somente como um esquema que busca a estruturação de um fenômeno para a sua consecutiva interpretação, mas é o próprio meio de produção de sentido, fruto de suas próprias metodologias. Por sua vez, a pós-hermenêutica não significa uma superação ou invalidação da hermenêutica, mas sim a exposição de elementos que não são considerados pelo pensamento hermenêutico ou cuja

10 A apreensão do mundo sem a mediação de conceitos está presente no termo "estética" desde a sua elaboração como disciplina filosófica (como ciência do conhecimento dado através dos sentidos), no século VXIII, pelo filósofo alemão Alexander Gottlieb Baumgarten (BAUMGARTEN, 1993). Entretanto, o conhecimento sensível proposto por Baumgarten era considerado por ele como inferior ao conhecimento lógico-racional. Como aisthesis, a estética se aproxima dos estudos de percepção e de medialidade, que buscam figurar uma experiência de encontro, cuja descrição ou reelaboração conceitual mostra-se insuficiente. 
tentativa de interpretação esbarra sempre no insatisfatório que está além ou aquém do sentido, da ordem simbólica ou das estruturas de diferença: "Pós-hermenêutica é o nome que se dá para a explicação deste insatisfatório" (MERSCH, 2010a, p. 13).

A reivindicação por um campo pós-hermenêutico ganhou seus contornos principalmente a partir da proposta de um campo não hermenêutico, como figurada na obra do teórico e ensaísta alemão Hans Ulrich Gumbrecht ${ }^{11}$ (GUMBRECHT, 1998, 2004, 2006).

Já na década de oitenta, Gumbrecht havia proposto o conceito de materialidades da comunicação na tentativa de apreender aquilo que está fora do escopo hermenêutico: "Originalmente, materialidades da comunicação eram todos aqueles fenômenos e condições que contribuem para a produção de sentido, sem serem o sentido em si" (GUMBRECHT, 2004, p. 28). Para Gumbrecht, o campo não hermenêutico deveria investigar justamente essas "condições de possibilidade de emergência das estruturas de sentido" (GUMBRECHT, 1998, p. 147). O objetivo, portanto, seria o de identificar elementos constitutivos das formas de comunicação sem subjugá-los à significação ou à interpretação. Como ele mesmo apontou, o conceito de materialidades da comunicação "se volta a um discurso no qual o som como som, o grafema como grafema e os gestos corporais como gestos corporais possam ser tematizados sem que, como significantes, se percam com a identificação dos significados que eles designam" (GUMBRECHT, 1988, p. 915). A proposta de um campo não hermenêutico, portanto, não é a de significação e, sim, a de descrição destes fenômenos que participam da produção de sentido, mas não se manifestam no próprio sentido.

Para dar conta desta proposta, Gumbrecht se volta à presença das coisas do mundo, à aparição das coisas aos sentidos. Para ele, todo tipo de evento em que nossos corpos e as

11 Hans Ulrich Gumbrecht (* Würzburg, 1948) é professor de Literatura Comparada da Universidade de Stanford. Seu pensamento contra-hermenêutico tem suas raízes na chamada Estética da Recepção, proposta em meados da década de 1960 por Hans Robert Jauß - seu orientador de doutorado na Universidade de Constança (Konstanz). A estética da recepção (também conhecida como Escola de Konstanz) reuniu, além de Jauß, o latinista Manfred Fuhrmann, o anglicista Wolfgang Iser e o germanista Wolfgang Preisendanz. A partir destes teóricos, a experiência estética tornou-se uma ferramenta investigativa fundamental para o estudo da literatura: grosso modo, o objetivo era definir os efeitos e os significados de determinada obra para o leitor contemporâneo para tornar possível a reconstrução do processo histórico no qual o texto é recebido e interpretado. Reafirmando o triângulo autor-obra-leitor, a estética da recepção quis destacar o papel deste último na história literária - a obra só acontece a partir do leitor: os textos são processos de significação que só se "concretizam" ou se "atualizam" na prática de leitura (Cf. COSTA LIMA, 1979; ISER, 1996; JAUSS, 1979). A Estética da Recepção, portanto, propôs um modelo hermenêutico de investigação a partir da experiência estética. Gumbrecht, reencenando a contraposição entre mestre e aprendiz, contra-argumenta a Estética da Recepção ao apontar os limites da hermenêutica por meio de suas reflexões sobre a própria experiência estética, que instaura efeitos de presença e imediaticidade que estão além ou aquém de qualquer processo de significação. 
coisas se relacionam produz efeitos de presença e efeitos de sentido. Eles são duas medidas correlatas $^{12}$. O foco na presença seria uma forma de criticar o que, segundo ele, seria o causador do esquecimento do mundo: a metafísica, o cartesianismo e a hermenêutica (como parte de um mesmo campo semântico). Sua teoria ganha vigor em 2004, com a publicação do livro Productions of Presence: what meaning cannot convey [Produções de presença: o que o o significado não pode expressar $]^{13}$. Nesta obra, Gumbrecht dialoga com a filosofia do francês Jean-Luc Nancy ${ }^{14}$ e reafirma a presença como algo que surge apagando qualquer vestígio de representação. Para Nancy, a presença é aquilo que nasce e que não cessa de nascer e o nascimento figura aquilo que está no excesso de toda representação (NANCY, 1993, p. 2).

Por sua vez, a experiência estética assume no arcabouço teórico gumbrechtiano um papel fundamental por possuir a capacidade de acentuar os efeitos de presença em detrimento aos efeitos de sentido. Por meio de sua característica de excepcionalidade, ela seria capaz de recuperar o sentimento de ser tomado pelas coisas do mundo. Através do seu caráter repentino e provisório, a acentuação do efeito de presença seria capaz de anular o imperativo do sentido, da interpretação, ou seja, o conceito de presença agiria contra as demandas universalistas da hermenêutica.

É no campo da produção estética que Gumbrecht busca dar um passo além da elaboração teórica, particularmente nos livros In 1926: Living at the Edge of Time [Em 1926: vivendo no limite do tempo], publicado em 1997'15; e Nach 1945: Latenz als Ursprung der Gegenwart [Depois de 1945: latência como origem do presente], publicado em 2012. A partir de conceitos como atmosfera e latência, Gumbrecht trabalha na fronteira entre trabalho teórico-filosófico, literário e histórico, com o objetivo de re-apresentar - no sentido de fazer novamente presente - um determinado momento da história, de manifestar como seria ter vivido, por exemplo, no ano de 1926. Não são livros que interpretam uma determinada

12 Dieter Mersch (2010, p. 19) sugere que isto já havia sido apontado por Hegel, nas suas Lições sobre Estética [Vorlesungen über Ästhetik], quando a palavra alemã para sentido [Sinn] é concebida tanto como sentido (significado) quanto sentido (sensação). Tal fenômeno é observado sem grandes problemas de tradução no português, já que a palavra pode ser empregada desta mesma forma.

13 Sintomaticamente, na edição alemã o título da obra foi traduzido como Diesseits der Hermeneutik: Über die Produktion von Präsenz [Deste lado da hermenêutica: sobre a produção de presença]. Interessante notar que a preposição quando substantivada - "Diesseits" - significa "a vida terrena, a vida neste mundo". Cf. GUMBRECHT, H.U. Diesseits der Hermeneutik. Suhrkamp Verlag, 2004.

$14 \mathrm{Em}$ particular, no seu livro The birth to presence [O nascimento à presença], publicado originalmente em inglês pela Universidade de Stanford em 1993. A colaboração da obra do filósofo francês Jean-Luc Nancy para a composição desta tese é retomada na última parte deste trabalho.

15 Dois anos depois, a obra foi publicada em português. Cf. GUMBRECHT, H.U. Em 1926. Vivendo no Limite do Tempo. Rio de Janeiro: Editora Record, 1999. 
época, mas a reencenam. Produzem uma presença. ${ }^{16}$

Entretanto, o conceito de presença não deixa de ser problemático para a filosofia. É um termo que tem uma longa carreira na história da metafísica ocidental - a mesma que a não hermenêutica de Gumbrecht critica abertamente. É a "metafísica da presença" - a experiência imediata de um sentido originário: a presença de uma ausência, da origem que impõe um sentido, que determina a expressão e que se torna superior à própria corporalidade ou materialidade (significado sobre o significante), ou seja, a presença de um sentido para além da presentificação de uma coisa - que está na base da crítica do Desconstrutivismo do filósofo francês Jacques Derrida, particularmente em sua obra Gramatologia (DERRIDA, 2008), já que, para ele, a experiência de presença só pode ocorrer como um deslocamento, como um atraso, um retardado que, por sua vez, são os modos constitutivos da representação e da reflexividade.

Assim a teoria da presença de Gumbrecht não acerta alguns pontos com a história do pensamento filosófico, deixando de fora um debate mais detalhado com o método que ele critica: o hermenêutico - termo que assume, em sua obra, sentidos mais genéricos. Gumbrecht tem a importância inconteste de apontar, ainda nos anos oitenta, para um latente campo de pesquisa nas Humanidades, mas é com o filósofo alemão Dieter Mersch ${ }^{17}$ que essa outra possibilidade de pesquisa - para evidenciar aquilo que está além das estruturas de sentido - é decalcada com contornos mais demarcados. Além de assumir um debate filosófico capaz de contrastar a posição pós-hermenêutica com outras abordagens principalmente as de caráter semiótico, (pós-)estruturalista, hermenêutico e

16 A importância do pensamento de Hans Ulrich Gumbrecht para o estudo da comunicação ainda carece de um olhar mais demorado por parte dos teóricos da comunicação no país, ou seja, de uma investigação que não apenas se debruce sobre os aspectos teórico-conceitual e epistemológico - o olhar sobre as materialidade da comunicação -, mas também sobre as suas implicações metodológicas. Uma exceção é o trabalho desenvolvido pelo professor da Universidade Estadual do Rio de Janeiro (Uerj), Erick Felinto, que há mais de uma década aposta no estudo das materialidades como uma possibilidade de renovar os estudos teóricos da comunicação no Brasil (Cf. FELINTO, 2001, 2006). Do ponto de vista metodológico, as aproximações entre a abordagem gumbrechtiana e o método metapórico, proposto pelo teórico Ciro Marcondes Filho, ainda necessitam de uma consideração mais atenta. Sem se referir aos textos de Gumbrecht, o metáporo, contudo, é da mesma forma um método de pesquisa que se propõe a re-apresentar, a re-encenar, a manifestar um evento - no caso do teórico brasileiro, o acontecimento comunicacional - através do relato (Cf. o quinto tomo de MARCONDES FILHO, 2010a).

17 Desde 2004, o filósofo e matemático Dieter Mersch ( ${ }^{*}$ Köln, 1951) ocupa a cátedra de Teoria e Filosofia dos Media da Universidade de Potsdam, na Alemanha. Sua pós-hermenêutica tem origens na crítica à semiótica e à racionalidade, tema do seu doutorado realizado na Universidade Técnica de Darmstadt, em 1992. Oito anos depois, ele escreveu sua Habilitation (necessária na Alemanha para concessão do título de Professor) com o título Materialität, Präsenz, Ereignis: Untersuchungen zu den Grenzen des Symbolischen [Materialidade, presença, acontecimento apropriador: investigações sobre as fronteiras do simbólico]. Foi a partir da exposição dos limites da semiose e da busca por abordagens alternativas para aquilo que excede as teorias representacionais que a sua teoria negativa se constituiu. 
desconstrutivista -, Mersch refina a proposta pós-hermenêutica como um lugar privilegiado para se fazer uma filosofia dos media [Medienphilosophie].

A sua proposta de uma pós-hermenêutica é apresentada de forma mais contundente em seu livro homônimo, Posthermeneutik, publicado em 2010. Seu aparato conceitual, contudo, foi preparado durante mais de vinte anos de pesquisa em torno dos limites do simbólico, cujas definições centrais foram apresentadas principalmente nas obras Was sich zeigt: Materialität, Präsenz, Ereignis [O que se mostra: materialidade, presença, acontecimento] (MERSCH, 2002b); Ereignis und Aura: Untersuchungen zu einer Ästhetik des Performativen [Acontecimento e aura: investigações para uma estética do performativo] (MERSCH, 2002a). Como já se deixa antever pelos títulos dos seus livros, termos como materialidade, presença, acontecimento e performatividade são propostos na tentativa de se pensar o outro do hermenêutico, do semiótico e do estruturalista. Um outro que demanda outras categorias e formas descritivas. Não é uma tentativa de superar essas outras abordagens discursivas, de solapar o linguistic turn [virada linguística] do último século ou mesmo de invalidar seu apriorismo linguístico, mas uma tentativa de lidar com o resiliente, com aquilo que escapa a essas abordagens, daquilo que se mostra. A pós-hermenêutica ensaia a possibilidade de exibição deste mostrar-se como negatividade, como um excedente ou resto que não se deixa apreender pelas categorias fundamentadas no signo, na interpretação ou na estrutura. É um projeto contra qualquer totalização, contra aquilo que não permite o outro do sentido, da diferença ou da economia do simbólico. Uma abordagem do incompreensível e irrepresentável "que habita os paradigmas, discursos, figuras, modelos e visualizações como um parasita” (MERSCH, 2010a, p. 23).

O destrinchamento desta proposta não é objeto deste trabalho. Uma explicação mais detalhada extrapolaria o espaço desta introdução, que se propõe a apresentar o terreno, o lugar onde é cultivado o pensamento que movimenta esta tese. Entretanto, um olhar mais demorado sobre alguns aspectos do arcabouço teórico de Mersch se faz necessário. Tal incursão segue em dois momentos. Primeiramente, são apresentadas algumas distinções e aproximações entre a pós-hermenêutica e outras abordagens na história do pensamento do século XX. Num segundo momento, são discutidos de forma sumária e esquemática alguns dos conceitos utilizados pelo filósofo que desempenham um papel importante para a apresentação dos argumentos deste trabalho.

Uma questão ingênua, mas necessária: por que criticar a interpretação, logo ela que é considerada a raison d'être das chamadas ciências humanas? A questão é ingênua porque 
exige uma pragmatização, uma operacionalização e consequente eliminação de qualquer abordagem que não possui como fim a produção de sentido. Uma questão necessária, porque demanda uma discussão com a história da formação das ciências humanas - o que ajuda na acentuação das diferenças da perspectiva pós-hermenêutica. Em sua obra, Mersch realiza uma detalhada crítica aos principais modelos teóricos das ciências humanas principalmente os adotados pelos estudos dos media e pela filosofia da linguagem. É a partir da sua crítica principalmente aos modelos hermenêutico, semiótico, psicanalítico e estruturalista que o filósofo constitui seu aparato conceitual.

A hermenêutica é a teoria da compreensão. Seu nome deriva da mitologia grega, do deus mensageiro Hermes, que dentre as suas várias funções atribuídas está a capacidade de "traduzir" a língua incompreensível dos deuses para os homens, de interpretar o mistério e trazê-lo à compreensão, de iluminar o obscuro. Interpretação, tradução e compreensão são modos de revelação daquilo que está oculto. Tributária das interpretações dos textos bíblicos, toda hermenêutica está estritamente ligada à estrutura textual. Como Mersch (2005, p. 178) ressalta, o medium da hermenêutica é a linguagem e toda hermenêutica se orienta, consciente ou inconscientemente, à palavra. Ao contrário da semiótica, o seu objeto não é o signo em geral, mas o signo linguístico. Consequentemente, sob uma abordagem hermenêutica, qualquer outro objeto ou fenômeno que se busca compreender é necessariamente reduzido à um texto, a uma escrita, a um discurso.

Face ao avanço das ciências técnicas no século XIX, a hermenêutica surgiu como uma forma de assegurar a legitimidade das ciências humanas. Se as ciências da natureza criam objetos, formas de agir no mundo, as ciências do espírito interpretam, dão sentido a essas criações. Foi o filósofo alemão Friedrich Schleiermacher $\left({ }^{*} 1768\right.$ †1834) quem primeiro definiu o procedimento das ciências humanas como uma abordagem hermenêutica. Tal sugestão foi posteriormente aperfeiçoada por outro filósofo, Wilhelm Dilthey $\left({ }^{*} 1833 † 1911\right)$, quem elevou a hermenêutica à categoria científica e a transformou no próprio método das ciências humanas. Três são os princípios deste método: 1. só se pode compreender o que já se compreendeu; 2. toda compreensão busca compreender o autor mais do que ele mesmo se compreende; 3. a compreensão é inconclusiva, ela não tem limites, nem começo, nem fim. São três princípios inter-relacionados. Como Mersch observa, "o primeiro princípio parece iterativo porque ele se prova não como um paradoxo, como se ele fosse contraditório e, por isso, imprestável, mas sim porque ele eleva o ciclo como princípio da própria compreensão" (MERSCH, 2011, p. 65). 
Esse princípio de circularidade foi refinado pelo filosófica hermenêutica de Hans Georg Gadamer ( ${ }^{*} 1900$ †2002). Em sua principal obra, Wahrheit und Methode [Verdade e Método (GADAMER, 1997)], publicada originalmente em 1960, o filósofo afirma que toda compreensão necessita de uma pré-compreensão. O entendimento adequado não pode prescindir de preconcepções, já que uma de suas características é a expansão do seu próprio horizonte. Não existe entendimento sem pré-interpretações. Portanto, toda compreensão não possui uma origem, um início. A compreensão se realiza em círculos concêntricos: é a metáfora da água perturbada pelo arremesso de uma pedra que encarna a expansão dos horizontes da compreensão.

Tanto Gadamer quanto seu antigo orientador Martin Heidegger $\left({ }^{*} 1889\lceil 1976)^{18}\right.$ radicalizam a hermenêutica ao elevar a linguagem - particularmente a linguagem escrita como o princípio para o entendimento do mundo. É a partir desta mesma radicalização que surgem os limites da hermenêutica. Essas fronteiras estão precisamente na própria universalidade do linguístico. Quando ele é atacado ou posto em cheque, a hermenêutica entra em crise (MERSCH, 2007a, p. 349).

Tal crítica pode ser estendida à semiótica. O diferencial é que, ao invés de se propor uma interpretação de um incessante acontecimento discursivo textual, a semiótica se ocupa de um incessante acontecimento sígnico. Com o conceito de signo, a semiótica dá uma base material ao sentido. É o signo - que relaciona um objeto à sua significação - que está no foco das investigações. Para um dos fundadores da Semiótica, o pensador norte-americano Charles Sanders Peirce $\left({ }^{*} 1839+1914\right)^{19}$ não existe pensamento fora da semiose: "O único pensamento que possivelmente pode ser conhecido é o pensamento em signos. Entretanto, um pensamento que não pode ser conhecido não existe. Por isso, todo pensamento deve ser necessariamente em signos” (PEIRCE, 1965, p. 165[CP 5.251]) ${ }^{20}$. Tais pensamentos

18 As ideias de Martin Heidegger sobre a linguagem serão retomadas no terceiro capítulo deste trabalho. Mas para fins de contextualização, Heidegger deu um importante contribuição à filosofia da linguagem ao definir o ser a partir da linguagem, já que todo falar sobre ela é autorreferencial. Segundo o filósofo, é impossível tematizar a linguagem de outro lugar além da linguagem, já que a ferramenta necessária para a sua reflexão já seria linguagem. Por isso, somos/estamos na e pela linguagem. Todo discurso sobre a linguagem está "emaranhada num modo de dizer (...) que pretende justamente liberar-se da linguagem para representá-la como linguagem e assim exprimir o que assim se representa. Isso testemunha imediatamente que a própria linguagem já nos trançou num dizer” (HEIDEGGER, 2008, p. 192 e passim). Para a relação da filosofia heideggeriana com a teoria dos media, cf. ainda (MERSCH, 2013, pp. 210-211).

19 A semiótica de Peirce não constitui apenas uma epistemologia, mas uma metodologia, um modo de abordagem capaz de estruturar e esclarecer o mundo dos sentidos - mesmo que em detrimento de qualquer coisa que não pertença ou não caiba no conceito de signo.

$20 \mathrm{Tal}$ reflexão faz parte do texto Questions concerning certain faculties claimed for man [Questões concernentes a certas faculdades reivindicadas pelo homem], publicado em 1898 no Jornal of Speculative Philosophy (vol. 2, pp. 103-114). A referida citação faz parte da resposta à quinta questão, Whether we can 
totalizantes permeiam diversas abordagens dentro das chamadas ciências dos media e da comunicação, desde a sua instituição como campo acadêmico. Mesmo que por vezes não filiados diretamente a alguma dessas correntes, boa parte dos estudos comunicacionais possuem como seu principal elemento constitutivo o apriorismo sígnico ou linguístico. Seja na concepção de que todo fenômeno mediático é um texto esperando ser lido, seja na acepção de que todo suporte técnico e sua medialidade possam ser decupados em relações de signos, tais apriorismos agem diretamente na não problematização de conceitos-chave comunicação e medium - para a formação de uma teoria comunicacional. Alguns exemplos, de forma esquemática: a) para a hermenêutica, a linguagem é o medium do entendimento e a comunicação é o próprio processo de compreensão; b) para a semiótica, o signo é o medium do sentido e a comunicação é o processo de significação, a semiose; c) para a psicanálise, os símbolos são o medium do sentido, e a comunicação é seu processo de deciframento. $\mathrm{O}$ que se procura com esses métodos não é a medialidade do medium ou o processo de comunicação, mas a interpretação e o sentido (Cf. MERSCH, 2010a, p. 148 e ss.).

Se por um lado essas abordagens são bastante produtivas na criação de formas de entendimento e de discurso - portanto, fundamentais para a constituição do campo da comunicação - por outro lado, a totalização/redução de qualquer fenômeno em linguagem ou signo não alcança modalidades expressivas que não se deixam reduzir ou até mesmo que questionam o primado linguístico. Esse mal-estar teórico pode ser observado nos estudos comunicacionais da música instrumental, das artes de vanguarda, do cinema experimental, etc. particularmente quando a materialidade é posta em evidência em detrimento a qualquer sentido.

Os limites da abordagem hermenêutica nas ciências humanas foram testados durante todo o século XX, seja no campo das práticas, através da crise da representação nas artes e na literatura, seja no campo teórico, através dos inúmeros turns que sucederam o linguistic turn ${ }^{21}$, que havia substituído o a priori da consciência pelo a priori linguístico: sai de cena o primado do sujeito e da consciência e entra a investigação da medialidade das estruturas de consciência - formas nas quais o pensamento, a percepção e o conhecimento

think without signs [Se nós podemos pensar sem signos] (Cf. PEIRCE, 1965, pp. 150-151 CP 5.250 - 5.253).

$21 \mathrm{O}$ termo ficou conhecido após a publicação de uma antologia com título homônimo do filósofo pragmático americano Richard Rorty, em 1967, que pôs sob o mesmo guarda-chuva conceitual teorias de campos diversos, como a filosofia, a linguística e os estudos literários - principalmente os do início do século XX - que tinham como eixo central o estudo das estruturas da linguagem. 
se expressam. Em meados da década de setenta, o estruturalismo francês ${ }^{22}$ até se estabelece como uma alternativa, cujo centro de investigações não recai sobre o signo, mas sobre a estruturas de sentido. Entretanto, tal abordagem manteve, de forma semelhante, o significado e a produção de sentido como a categoria de análise sociocultural, seja com o foco no sentido simbólico, na natureza sígnica ou na sua estruturalidade como ordem simbólica: "a universalização do hermenêutico assim como do semiótico, do estruturalismo, do pós-estruturalismo e da teoria dos sistemas constituem apenas variantes de uma totalização idealista que, ao invés da racionalidade do conceito, aplicam a incontornabilidade do sentido, do signo, da linguagem, da estrutura, da diferença, etc." (MERSCH, 2010a, pp. 24-25). É só a partir do final dos anos oitenta que se pode falar sobre movimentos teóricos capazes de questionar a predominância do linguistic turn através de abordagens que buscam alternativas para o paradigma linguístico. Essa necessidade de se pensar o aquém ou o além da linguagem ganhou forma através dos vários turns que pulularam nas Humanidades: iconic ou pictorial turn, performativ turn, body turn, material turn, spatial turn, narrative turn, ludic turn, medial turn, para citar alguns. "Todos eles buscam tornar válido aquilo que escapa à fixação do sentido e à linguagem: o momento da prática, da materialidade, do espaço, do jogo, etc.” (MERSCH, 2011, p. 111).

Destes vários turns, o performativo desempenha um papel importante no esqueleto teórico de Mersch. Não apenas por já se tratar de uma virada prospectiva, com um programa de pesquisa, mas por ser um conceito que lida com a praxis, que busca descrever a dimensão das práticas que devem ser realizadas, instauradas, conduzidas, que são parte do real e que só se efetuam como tal. Grosso modo, o retalho conceitual do performativo foi costurado em três momentos principais: nos estudos etnográficos sobre os rituais realizados, entre outros, pelo antropólogo escocês Victor Turner; na filosofia da linguagem, mais precisamente com a teoria dos atos de fala, proposta pelo filósofo inglês John Langshaw Austin e desenvolvida por seu aluno, o filósofo norte-americano John Rogers Searle, a partir da filosofia de Ludwig Wittgenstein; e, por fim, no campo artístico com a arte da performance, a partir da década de 1960. Em comum, as chamadas teorias da performatividade empregam o performativo como uma categoria-chave para descrição de processos que não emergem necessariamente do simbólico. Os modos performativos, como a alusão ou o apelo no falar, por exemplo, são aquilo que desempenham sua função no

22 Deve-se ressaltar o caráter sumário deste momento do texto. Devido às necessidades esquemáticas para se posicionar o lugar da pós-hermenêutica no discurso contemporâneo, um estudo de caráter analítico e verticalizado sobre cada um desses movimentos é evidentemente sacrificado. 
recolhimento: o falar, "não ocorre nem a 'unidirecionalidade' do conceito, nem a formatação da razão, mas sim, ele se realiza em uma metafórica do mostrar" (MERSCH, 2010a, p. 11).

Com isso, retoma-se as duas dimensões da ideia básica da pós-hermenêutica: 1. toda relação refere-se sempre $a$ algo que já não é determinado através dela: "Assim, 'há' um 'outro da relação' que pode ser associado principalmente com a 'dádiva' da 'ex-sistência' [Ex-sistenz]" (ibid., p. 26); 2. a relação está fundamentada em algo que a carrega e a entrega sem que este esteja contido nela: "Nenhuma relação pode se relacionar com aquilo que a estabelece, como nenhuma função é capaz de figurar sua própria figura. (...) O que funda a relação permanece 'recolhido'. Ao mesmo tempo, 'há' antes a possibilidade de relação. O modo desta possibilidade é imanente à forma da relação" (ibid., pp. 26-27).

A ex-sistência, por sua vez, não descreve nenhuma propriedade, mas as condições básicas de qualquer propriedade, aquilo que tanto a possibilita quanto a transporta, imiscuindo-se em sua definição. Como o filósofo explica,

[a ex-sistência] antecede tanto os conceitos e seus determinantes, como os signos e os media. Isso não significa apenas que estes - como esquemas relacionais - devam se relacionar com algo anterior - isto seria de novo a repetição da pergunta da referência -; antes uma antecipação aos próprios literalmente se revela na medida em que é inerente, que é este ser próprio, ou seja, que também deve estar fundamentado em alguma coisa e deve se destacar de si. Consequentemente, não existe nenhum signo, nenhuma estrutura, nenhuma significação ou mediação, nem mesmo a instanciação de uma diferença ou de um rastro sem sua emergência a partir do 'há' como 'fundamento', portanto, sem a base de qualquer forma de 'ex-sistência', de maneira residual (ibid, p. 24).

O que dá a relação, não pode ser parte da relacionalidade. Ele permanece sempre estranho a ela. "Nenhum conceito, nenhum signo ou medium encerra, designa ou mediatiza sua própria 'ex-sistência'" (idem). Por isso, o conceito de materialidade é estritamente ligado à ex-sistência. A materialidade está "enraizada" nela, pois deve "haver" algo para que algo surja. A materialidade é aquilo que resiste, que atrapalha, que torna opaco: "Os resíduos do 'assemiótico' ou do 'amedial' constituem a materialidade das coisas, a corporalidade dos corpos, mas também os restos, os vestígios indeléveis de que nunca seremos senhores, a decadência, o envelhecimento ou a erosão temporal, que não podem ser apreendidos, conceituados ou tocados e que anunciam a finitude irrevogável do mundo" (ibid., p. 11). A pós-hermêutica se ocupa, portanto, do excesso, do suplemento, da mediatização e da significação. 
Essa insuficiência está registada no próprio conceito de presença. Mersch retoma o termo sugerido por Hans Ulrich Gumbrecht, só que o concebe como negatividade e defende-o sob uma perspectiva pós-Derrida, ou seja, uma presença "que se assenta sobre a insuficiência crônica ou aquele não abrir-se, que se revela como lugar paradoxal dentro da mediação ou da cadeia de significados, portanto, da estrutura e da escritura" (MERSCH, 2010a, pp. 21-22). A experiência de presença não pode ser conformada ou remoldada através de conceitos, muito menos pode ser excluída ou negada.

A negatividade é um conceito fundamental para a pós-hermenêutica de Dieter Mersch e desempenha um papel fundamental na argumentação da tese aqui proposta. Este termo é discutido na última parte deste trabalho. Mas assim como outros conceitos que são retomados em momentos diversos durante este texto, tais como ex-sistência, materialidade e presença, é necessário uma breve olhar sobre a negatividade.

O não é uma recusa de qualquer reivindicação construtivista de soberania, seja linguística ou estrutural, contra qualquer reivindicação totalizadora. A negatividade, portanto, é uma abordagem do precário, do provisório. É a impossibilidade de dispensa da presença, como algo que possa ser negado. A negatividade é uma dupla figuração: "trata-se de uma 'constelação quiasmática' que produz um cruzamento entre negação e afirmação e que se deixa apenas ser marcada indiretamente" (ibid., p. 26). É neste método indireto que a pós-hermenêutica mostra sua importância. É essa forma desviada, deslocada, crepuscular que embala a despalavra ex-comunicação. Como afirmado anteriormente, não se trata aqui de uma ontologia, de um "é", mas de uma insinuação, de uma alusão, de um caminho lateral que se esconde no pronome "que": aquilo que não se dá através de, mas com, na medida em que possibilita. É uma tentativa de ex-pôr a não conceitualidade e incontornabilidade da ex-comunicação. Este é o terceiro gesto deste trabalho: apresentar uma abordagem negativa e pós-hermenêutica da comunicação.

Como Mersch (ibid., p. 15) justifica, a aposta da pós-hermenêutica se constitui na afirmação de que esse jogo de transparência e opacidade não se distingue em esquemas de uma experiência "imediata" nem nos fantasmas de uma mudez mística, mas sim que ele é inerente desde o princípio às práticas de significação ou mediação como uma co-lateralidade, uma co-ocorrência que não se pode ignorar.

Esse olhar fronteiriço não é novo. O filósofo alemão Friedrich Nietzsche (2000) já havia denunciado desde o século XIX o caráter frágil e provisório das interpretações. As investigações fenomenológicas de Martin Heidegger (1985, 2003, 2008, 2009) já se 
movimentaram nas margens do pensamento. A filosofia ética de Emmanuel Levinas (1988, 1991, 2008) trouxe para o centro do pensamento aquilo que não pode ser apreendido conceitualmente: o outro. O conceito de différance de Jacques Derrida (1991, 2008, 2009) evidenciou o aspecto inapreensível do infinito jogo de diferenças dentro da linguagem. $\mathrm{O}$ pensamento heterológico de Georges Bataille (1985, 1987, 1989, 1992), o discurso noturno de Maurice Blanchot (1983, 1987, 1988, 2005, 2007), e a filosofia do fora de Jan-Luc Nancy (1991, 1993) fornecem os elementos para se pensar a comunicação e a obra para além das categorias hermenêuticas, semióticas ou estruturais.

Estes e outros autores aparecem no decorrer deste trabalho para subsidiar o argumento de que a comunicação, sob um ponto de vista pós-hermenêutico, é uma experiência existencial de pertubação de sentidos, cujo ruído - tão perseguido pelas chamadas teorias matemáticas da comunicação - constitui-se como um elemento chave para a figuração dos elementos que escapam às tradicionais abordagens da experiência comunicativa. A ex-comunicação é justamente uma tentativa de trazer para o palco aquilo que resiste a sua comunicação na experiência comunicativa.

Portanto, considerar a comunicação a partir da sua negatividade, do seu resto ou excesso não é algo novo na história deste conceito. Uma abordagem sobre as considerações deste termo - mesmo pelas disciplinas fundadoras do pensamento comunicacional no Brasil, como a sociologia, a psicologia, a psicanálise e as teorias informacionais - pode trazer alguns pontos de apoio para essa argumentação.

IV

\section{Por uma comunicação como diferença}

Se a palavra comunicação é utilizada para descrever fenômenos tão distintos, como transmissão, tradução, troca, comunhão, semiose, interpretação, consenso, etc. ainda seria válido perguntar o que haveria de comum entre as suas mais diversas conceituações? Ou formulado de outra maneira: existiria algum pressuposto, alguma condição básica, algum elemento que com-formasse toda e qualquer acepção de comunicação?

Se os conceitos de comunicação pudessem ser desmontados e comparados entre si, 
provavelmente o único elemento sem o qual não haveria o menor sentido em falar de um conceito de comunicação seria a diferença. Todo conceito de comunicação é constituído por uma diferença fundamental. Para a sociologia, a diferença entre o indivíduo e a sociedade; para a psicologia, entre o mundo e a consciência, entre a interioridade e a exterioridade; para as teorias informacionais, a diferença entre a fonte emissora e o destinatário. "A diferença constitui um - senão $o$ - pressuposto universal de comunicação" (KRÄMER, 2008, p. 16). Comunicar, portanto, é lidar com uma diferença. Imaginar um sistema fechado ou mesmo uma completude ou uma autossuficiência inata do ser humano anularia qualquer necessidade de comunicação. Este é, portanto, o quarto gesto deste trabalho: fundamentar uma crítica dos conceitos de comunicação a partir de uma reflexão sobre a origem do comunicar como diferença. Tal afirmativa pode soar como uma constatação simples ou mesmo apressada. Contudo, pretende-se mostrar aqui sua pertinência através de uma abordagem um pouco mais atenta a sua complexidade.

A filósofa alemã Sybille Krämer ${ }^{23}$ alinha as concepções de comunicação em dois grupos principais a partir das suas respectivas relações com a diferença: aqueles que aplicam um conceito técnico e aqueles que utilizam um conceito pessoal de comunicação. Os conceitos do primeiro grupo buscam criar uma ponte sobre a distância, mas que não é anulada; o conceito técnico de comunicação "estabiliza e fortalece o ser-distante [Entfernt-Sein] um do outro justamente através do e no transporte bem sucedido” (idem). Já o conceito pessoal busca superar e anular tanto a distância quanto a insuficiência mútua: "ele pressupõe uma diferença, mas não a confirma e nem a estabiliza, pois tende, na superação, a um idêntico, o qual é de fato compartilhado entre os comunicantes e que se torna algo 'comunitário'" (idem).

Para um desdobramento crítico deste agrupamento é necessário apresentar um breve mapa do conceito de comunicação e sua relação com a noção de diferença para que se ressalte, ao final deste tópico, a importância da negatividade para a elaboração conceitual do fenômeno comunicacional.

23 A filósofa Sybille Krämer (*1951) é professora de Filosofia Teórica na Universidade Livre de Berlim. Krämer está entre os autores mais influentes da Medienphilosophie alemã, principalmente por conta da sua reflexão sobre conceitos como língua, comunicação, medium e imagem a partir de um extenso debate com a filosofia da linguagem. Seus artigos tratam de temas como teorias da consciência, teorias dos media, teorias do performativo, filosofia da imagem, do diagramático e da escrita. Entre as suas principais obras, estão: Sprache, Sprechakt, Kommunikation. Sprachtheoretische Positionen im 20. Jahrhundert [Linguagem, ato de fala, comunicação: posições linguístico-filosóficas no século XX], publicada em 2001; e Medium, Bote, Übertragung. Kleine Metaphysik der Medialität [Medium, Mensagem, Tradução: pequena metafísica da medialidade], publicada em 2008. 


\section{Comunicação e interação \\ - ou o indivíduo e a sociedade}

Das já mencionadas dsciplinas que participaram da formação dos cursos de comunicação, o primeiro campo a incorporar a comunicação como um conceito-chave foi a emergente sociologia norte-americana do início do século vinte. Um marco foi a publicação, em 1909, do livro Social Organization: a study of the larger mind [Organização Social: um estudo sobre a mente expandida], do sociólogo norte-americano Charles Horton Cooley $\left({ }^{*} 1864 \dagger 1929\right)$.

O livro foi organizado em seis partes: Aspectos primordiais de organização; Comunicação; A mente democrática; Classes sociais; Instituições; Vontade pública. A partir dos títulos já se pode ver a importância dada ao conceito de comunicação. Para Cooley, a comunicação é aquilo que garante a relação entre a mente individual e a mente coletiva (organizações, instituições, opinião pública, classes sociais). Ela cria uma ponte sobre a diferença entre a mente individual e aquilo que só pode ser adquirido socialmente: "O que não vem por hereditariedade, vem por comunicação e por relações" (COOLEY, 1909, p. 9). A sociedade é concebida, portanto, como interação e influência mútua de indivíduos (por isso, vista como uma mente ampliada). O social é entendido como um organismo no qual a comunicação age como um tipo de ferramenta - uma invenção em constante progresso cujas melhorias atuam diretamente na humanidade, alterando a vida não apenas de cada indivíduo como também das instituições, que estão em constante relação entre si. Esta é a base da sua teoria: o indivíduo já é, mentalmente, um ser social, pois as representações mentais surgem das interações sociais e, por sua vez, a realidade social imediata reflete a mente do indivíduo. "A sociedade, então, em seu aspecto imediato, é uma relação entre ideias pessoais" (COOLEY, 1922, p. 119).

Assim, a conceituação de comunicação na sociologia surgiu, de um lado, agregada à ideia de interação e, de outro, associada ao desenvolvimento técnico dos meios de transporte e de informação - considerados como verdadeiras conquistas técnicas sobre o espaço e o tempo. Nas palavras de Cooley: "Por Comunicação entende-se aqui o mecanismo através do qual as relações humanas existem e se desenvolvem - todos os símbolos da mente, associados aos meios de expressá-los através do espaço e preservá-los através do tempo" (COOLEY, 1909, p. 61). 
Tal virada comunicacional logo nos primórdios da sociologia norte-americana foi consolidada com a Escola de Chicago ${ }^{24}$, particularmente com a psicologia social de Georg Herbert Mead ( $\left.{ }^{*} 1863 † 1931\right)$ - como apresentada em seu livro Mind, Self, and Society from the Standpoint of a Social Behaviorist [Mente, Self e Sociedade do ponto de vista e um behaviorista social], publicado postumamente em $1934^{25}$ - e com a publicação em 1935 do verbete "Comunicação" na Encyclopedia of The Social Sciences, escrito por Edward Sapir $\left({ }^{*} 1884 \dagger 1939\right)$.

Mead foi pioneiro a tratar a comunicação como um processo, no qual o indivíduo tanto afeta quanto é afetado não só por outro indivíduo, como também, consequentemente, pela sociedade. E é na tomada de consciência do self [si mesmo] e do other [outro] que se desenvolve a sociedade organizada. Daí a importância da comunicação. Nas palavras do próprio Mead: "O princípio que eu sugeri como base da organização social humana é o da comunicação envolvendo a participação no outro. Isto requer a aparição do outro no self, a identificação do outro com o self, o alcance da autoconsciência através do outro" (MEAD, 1934, p. 253).

Os limites desta identificação do eu com o outro são abordados na segunda parte deste trabalho ${ }^{26}$. Por enquanto, deve-se atentar aqui para as implicações da pregnante abordagem de Mead, cuja estrutura de causa e efeito da sua noção de comunicação (como processo de interação) conseguiu se transformar em um termo comum dos estudos sociológicos da comunicação focados nos efeitos dos meios de informação na sociedade. Como bem ressaltou o teórico da comunicação alemão Dirk Baecker em seu livro Kommunikation (2005, p. 60), ao conceber o conceito de comunicação como um processo, Mead evidenciou ao menos dois aspectos indissociáveis de um conceito sociológico de comunicação pois as relações sociais são, ao mesmo tempo, os pressupostos para a comunicação e o resultado dela.

24 Muito mais uma reunião de pesquisadores em um espaço compartilhado (a Universidade de Chicago, fundada fundada em 1895 com o financiamento do milionário John D. Rockefeller) do que uma linha de pensamento, a Escola de Chicago de Sociologia tem a interação social como a base de estudos comum entre seus pesquisadores (para citar alguns nomes: Albion Small, Robert E. Park, George Herbert Mead, Everett Hughes, Herbert Blumer, Howard Becker e Erving Goffman). O conceito de comunicação foi particularmente abordado por autores que atuavam na psicologia social. Para um relato sobre a formação da Escola de Chicago, cf. BECKER, 1996.

25 O livro é, na verdade, uma compilação das anotações dos seus alunos durante os seus cursos realizados entre 1901 e 1931 na Universidade de Chicago.

$26 \mathrm{O}$ caminho escolhido para o mapeamento das relações eu-outro - como apresentado na segunda parte desta pesquisa - não foi o da sociologia americana, mas o da fenomenologia. Tal escolha se deve não apenas ao debate filosófico com o qual essa tese de doutorado se propõe dialogar, como também por acreditar que as contribuições da fenomenologia apresentam uma caracterização do fenômeno comunicacional mais elaborada do que a apresentada pelos estudiosos da Escola de Chicago e seus sucessores. 
A troca, a atuação e reação, a cooperação, a capacidade de se colocar no lugar do outro e o desempenho de papéis sociais - numa palavra, a inter-relação - são definições agregadas ao conceito de comunicação a partir das obras de Georg Mead. Uma outra definição fundamental para o conceito sociológico de comunicação - o contexto - foi apresentado pelo antropólogo e linguista alemão naturalizado norte-americano Edward Sapir, também atuante na Escola de Chicago como professor de Antropologia entre 1925 e 1931. Para ele, "todo padrão cultural e todo simples gesto de comportamento social envolve comunicação, seja em um sentido explícito ou implícito" (SAPIR, 1935, p. 78).

Mesmo atento à importância da comunicação não verbal e ainda não formulada nas relações sociais - situada, particularmente, na atividade artística (ibid., p. 79) -, Sapir dedica-se ao estudo da linguagem, considerada como "um método não instintivo e puramente humano de comunicação de ideias, emoções, e desejos por meio de um sistema de símbolos produzidos voluntariamente" (SAPIR, 1921, p. 8). É a partir das suas pesquisas sobre a linguagem que ele se consagrou como um dos fundadores da linguística moderna norte-americana, sendo um dos primeiros a se dedicar ao estudo das relações entre linguagem e antropologia (no caso específico dos nativos americanos).

O efeito do pioneirismo comunicacional norte-americano e sua acentuação na interação social foi ampliada no pós-guerra principalmente a partir dos estudos de Herbert Blumer ( $\left.{ }^{*} 1900 † 1987\right)$ - que cunhou o termo “interacionalismo simbólico" em 1937 a partir dos estudos de $\mathrm{Mead}^{27}$, ressaltando, contudo, a importância do contexto (baseado no conceito de experiência do filósofo pragmatista John Dewey) como determinante da ação para relativizar o papel do indivíduo hipostasiado pelo seu mentor - e do sociólogo canadense Erving Goffman ( $\left.{ }^{*} 1922 \nmid 1982\right)$, cujo livro The Presentation of Self in Everyday Life [traduzido ao português como "A Representação do Eu na Vida Cotidiana"] publicado originalmente em 1956, tornou-se extremamente influente nos estudos voltados para os efeitos dos meios telemáticos e de informação no cotidiano ${ }^{28}$. Em sua obra, o conceito de

27 "Os interacionistas simbólicos veem a interação social essencialmente como um processo comunicativo no qual pessoas partilham experiências, mais do que um mero jogo de estímulo e resposta. Eles assumem que uma pessoa responde não ao que o outro indivíduo diz ou faz, mas ao sentido daquilo que ele diz ou faz. Consequentemente, este modo de ver pode ser considerado como a inserção de um meio-termo da interpretação no par estímulo-resposta, de tal forma que ele se torna estímulo-interpretação-resposta. O mais importante é ressaltar que os interacionistas simbólicos acreditam que a interação é mantida por símbolos ou sentidos" (BLUMER, 1937, p. 171).

28 A obra de Goffman trouxe ainda outros termos importantes que marcam até hoje as humanidades, como o refinamento e aplicação dos conceitos de papel social e de performance: "Uma 'performance' poderia ser definida como toda atividade de um dado participante em uma dada ocasião que sirva para influenciar de alguma maneira outros participantes. Tomando um participante particular e sua performance como um ponto básico de referência, nós poderíamos referir àqueles que contribuem na performance do outro como o público, 
comunicação é praticamente identificado ao conceito de interação, "grosso modo definida como a influência recíproca de indivíduos sobre as ações mútuas quando se está na presença física imediata um do outro" (GOFFMAN, 1956, p. 8).

Entretanto, a articulação desses autores e seus desdobramentos conceituais não são objetos desse trabalho. O objetivo deste item foi mostrar como a reflexão sobre a diferença entre indivíduo e sociedade e suas formas de relação pôs em cena o conceito de comunicação no seu trabalho interpretativo. Ainda mais relevante de se observar é o movimento executado pelo conceito de comunicação até ser substituído pelo termo interação. Logo, a origens teóricas da comunicação como processo, relação, ação e reação, formação do indivíduo e da sociedade, troca e interação podem ser localizadas na sociologia norte-americana do início do século passado e seus desdobramentos.

O conceito de interação trouxe mais precisão na descrição do fenômeno observado, já que se trata de um processo no qual dois agentes (indivíduos, instituições, organizações) se afetam mutuamente, inter-agem dentro de um determinado contexto. A interação ressalta o caráter intencional, objetivo e baseado numa estrutura de causa e efeito que serve bem a propostas de pesquisa sobre a relação entre empresas de comunicação ou mesmo suportes específicos e grupos sociais. Não é a toa que este conceito - mesmo que muitas vezes não explicitamente formulado - está por trás dos estudos de mediação sobre o papel da opinião pública, sobre as relações entre o social e os media (entendidos como jornalismo, publicidade e outras formas de transmissão massiva de informações ${ }^{29}$. A comunicação, portanto, se torna a interação social e o medium, sob uma acepção tecnológica, é o facilitador desta interação, um suporte que carrega símbolos entre duas instâncias separadas no espaço e no tempo.

A proposta deste trabalho é apresentar o negativo desta comunicação ativa. É uma tentativa de recuperação da diferença conceitual entre a comunicação e a interação. Como abordado na última parte desta tese de doutorado, o termo ex-comunicação ressalta uma experiência de passibilidade em detrimento à noção de sujeito contida no conceito de interação.

Mas ainda são necessárias algumas considerações sobre as abordagens do conceito de comunicação durante o século XX. Compreender a comunicação como interação é evidenciar o seu valor gregário de superação da distância, cujo resultado deve ser a 
influência - a transmissão - em forma de adaptação e consenso. Contudo, a psicologia social do início do século passado não se aprofundou na descrição do próprio processo comunicacional. Ele foi aplicado muito mais como uma categoria que permite superar a distância entre o indivíduo e a sociedade. A tentativa de descrição ou divisão deste processo em elementos discretos foi a tarefa da Teoria Matemática da Comunicação.

\section{Comunicação e informação \\ - ou o emissor e o receptor}

Não existe modelo teórico sobre o processo comunicacional mais difundido do que o da teoria matemática da comunicação. Seu conhecido esquema fundamental divide a comunicação em cinco elementos distintos: fonte de informação; transmissor; canal; receptor; e destinação. Mesmo ampliado ou contestado por sucessivas correntes teóricas, tal arcabouço permaneceu praticamente inalterado em sua estrutura básica. Nunca houve um modelo que permeasse áreas tão distintas, como a matemática, a engenharia, a antropologia, a biologia, a neurologia e a psicanálise. Mais uma vez, a diferença desempenha aqui um papel fundamental. A comunicação é concebida como um processo no qual uma informação deve ser transportada de um ponto a outro. Um estudo um pouco mais detalhado sobre esse sentido específico de comunicação pode fornecer as bases para uma crítica à visão técnico-instrumental agregada ao conceito de comunicação.

O marco da teoria matemática da comunicação foi a publicação de um artigo homônimo escrito pelo matemático e engenheiro elétrico norte-americano Claude Elwood Shannon ( $\left.{ }^{*} 1916 \nmid 2001\right)$, publicado no Bell System Technical Journal em sua edição de julho e outubro de $1948^{30}$. Em se setembro de 1949, o texto foi editado pela primeira vez em livro, com o mesmo título, The Mathematical Theory of Communication, que contou ainda com um texto do matemático também norte-americano Warren Weaver $\left({ }^{*} 1894 \nmid 1978\right)^{31}$ intitulado Recent Contributions to the Mathematical Theory of Communication [Recentes contribuições

30 Shannon era funcionário da Bell Telephone Laboratories. Seu artigo encontra-se disponível no próprio site da Bell System (http://cm.bell-labs.com/cm/ms/what/shannonday/shannon1948.pdf). Último acesso em 20/01/2014.

31 Weaver era membro da Fundação Rockefeller, na qual permaneceu durante 27 anos. Além das suas contribuições à teoria informacional, ele desenvolveu projetos de ciências naturais - a criação do termo "biologia molecular", por exemplo, é de sua autoria. 
para a teoria matemática da comunicação], cujo resumo havia sido publicado na revista Scientific American em julho de 1949. Deve-se observar neste tópico a relação entre esses dois textos, já que comumente o modelo matemático de comunicação é referenciado como o modelo "Shannon-Weaver".

O artigo de Shannon surgiu dos seus estudos sobre a transmissão de informações via telégrafo. Como engenheiro de uma companhia telefônica, seu objetivo era otimizar a transmissão de informações de um ponto a outro com a menor perda possível. Seu artigo é altamente técnico, cuja palavra comunicação é um mero sinônimo para transmissão. Nas palavras do próprio Shannon: "O problema fundamental da comunicação é o de reproduzir em um ponto ou exatamente ou aproximadamente uma mensagem selecionada em um outro ponto" (SHANNON \& WEAVER, 1949, p. 31). Ou seja, o que importa não é o sentido, a semântica da mensagem, mas a capacidade do sistema em operar qualquer informação selecionada dentro de um campo de possibilidades. E esse é um aspecto importante em sua teoria, mas nem sempre explorado pelos teóricos comunicacionais: a comunicação é uma escolha dentro de possibilidades (pré-programadas).

Já que a semântica não é objeto do seu modelo de comunicação, o conceito de informação não pode ser confundido com o de saber ou de conhecimento. Informação é algo que pode ser calculável. É a redução de uma mensagem aos seus menores elementos ${ }^{32}$. Informação é a possibilidade: a quantidade de informação é definida como algo que pode ser medido pelo logaritmo do número de escolhas disponíveis (Cf. SHANNON \& WEAVER, 1949, p. 9).

Se a comunicação é concebida como a transmissão de informações de um ponto a outro com o menor ruído possível, o medium é consequentemente definido como o canal de transmissão: "O canal é apenas o meio usado para transmitir o sinal de um transmissor a um receptor. Ele pode ser um par de fios, um cabo coaxial, uma banda de frequências de rádio, um feixe de luz etc." (ibid., p. 34).

Para ser transmitida por um canal, a informação precisa ser codificada. Aqui há a instauração de um segundo momento de diferença: não apenas entre a fonte emissora e receptora, mas entre a mensagem e sua tradução em um código pelo transmissor e sua decodificação pelo receptor.

O potencial desta teoria para o desenvolvimento de tecnologias computacionais é

32 Dígito binário [binary digit] ou simplesmente bit: a unidade mínima de informação, termo sugerido por John W. Turkey. 
notório. Mas é de se questionar como tal modelo matemático - baseado no cálculo, na decidibilidade, na tradução em algoritmos e com um sistema de regras tão fixo - conseguiu se expandir para as áreas distintas, como a biologia e as ciências humanas. Tal fato deve ser creditado em boa medida aos esforços de Warren Weaver.

Como bem observado por Dirk Baecker (2005, p. 63), "Waver pode ser definido como o tradutor da formulação teórica de Shannon para um público mais amplo". Não é à toa que seu artigo procede no livro o texto de Shannon. Ele acreditava que a teoria matemática da comunicação poderia ser expandida tanto para a problemática da comunicação humana, como para qualquer processo no qual um elemento qualquer seja simplesmente afetado por um outro. Em outras palavras, "a intenção de toda comunicação é influenciar a conduta do receptor" (SHANNON \& WEAVER, 1949, p. 5).

Em seu artigo, Shannon diz ter derivado sua concepção de comunicação do matemático norte-americano Norbert Wiener ${ }^{33}\left({ }^{*} 1894 † 1964\right)$. Este, por sua vez, tomou o termo emprestado do matemático austro-húngaro John von Neumann ( ${ }^{*} 1903$ †1957). Mas nenhum deles fez uma tentativa de discussão conceitual do termo. Foi Weaver quem buscou certa reelaboração da palavra para além do sentido de transmissão de informações. A comunicação foi definida em um sentido muito mais amplo, como todo procedimento no qual não apenas uma mente pode afetar outra mente (seja pelo discurso oral, pictórico, pelas artes em geral), mas como um mecanismo pode afetar um outro mecanismo. (ibid., p. $3) .^{34}$

A partir do modelo matemático de Shannon, Weaver propõe uma teoria geral da comunicação, já que ao reduzir qualquer sistema simbólico à informação, a amplitude e generalização da matemática permite tratar indistintamente imagem, som, texto, notas musicais ou qualquer forma de expressão (humana ou mecânica). Ou seja, é um modelo de comunicação totalizante que acredita na tradução da linguagem do mundo em linguagem da aritmética.

Em suas contribuições para a teoria matemática da comunicação, Weaver identificou três níveis de problemas comunicacionais: o técnico (o quão precisamente os símbolos de comunicação podem ser transmitidos), o semântico (o quão precisamente os símbolos transmitidos expressam o sentido desejado) e efetivo (o quão efetivamente o

33 Cf. Cybernetics, or control and communication in the animal and the machine, Wiley, 1948 [2. Edição, MIT Press 1961].

34 Neste ponto, Weaver cita curiosamente um exemplo bélico no qual um equipamento automático para rastrear uma aeronave e para calcular suas prováveis posições futuras afeta um outro mecanismo (um míssil guiado perseguindo esta aeronave). 
sentido recebido afeta a conduta de uma maneira desejada). O que se deixa entrever nessa categorização não é apenas o caráter intencional localizado no emissor da informação, mas também da sua causalidade. Mesmo com as posteriores reelaborações da Cibernética e sua introdução da circularidade da retroalimentação, o controle da fonte emissora nunca perdeu seu foco. Tal centralidade da comunicação no emissor, sua intencionalidade e o campo de possibilidades de uma determinada ação - também presentes nos primevos usos sociológicos do termo comunicação - são objetos de crítica deste trabalho durante os próximos capítulos. Mas os três problemas comunicacionais de Weaver ainda precisam de alguns comentários.

Mesmo considerando o plano semântico e efetivo da comunicação, o matemático norte-americano acredita que todos eles são suplantados pelo primeiro nível, já que o técnico é o que os possibilita. A partir daí, o modelo matemático pode ser aplicado para melhorar a comunicação em qualquer dimensão, já que em seu fundamento ela deve ser a mais efetiva possível, ou seja, com menos ruído. Por isso a redundância tem um papel essencial na redução da entropia ${ }^{35}$. Curiosamente, reduzir a entropia é reduzir a informação, já que esta está diretamente ligada à possibilidade, ou seja, à quantidade de escolhas. Quanto mais ruído, mais informação, mais incerteza indesejada. Com isso, a redundância é baseada no conceito de equivocação, que mede o grau de incerteza na mensagem quando o sinal já é conhecido: "Se não há ruído, então não haveria nenhuma incerteza no que concerne à mensagem quando o sinal é conhecido. Se na fonte de informação tem alguma incerteza residual depois que o sinal é conhecido, então isto deve ser incerteza indesejada provocada por ruído" (SHANNON \& WEAVER, 1949, p. 20).

Por esse motivo, a estatística tem lugar privilegiado neste pensamento. A teoria matemática da comunicação vê a linguagem como a totalidade de coisas que pode ser dita: "Linguagem deve ser projetada (ou desenvolvida) com uma visão para a totalidade das coisas que o homem poderia querer dizer; mas não sendo capaz de conseguir tudo, ela também deve fazer tão bem e tão frequentemente quanto possível. Isso quer dizer que ela deveria lidar com sua tarefa estatisticamente" (ibid., p. 27).

É por conta desses elementos (exclusão da semântica; seleção de informações a

35 A entropia - em notação matemática assinalada comumente com um eta $(\mathrm{H})$ maiúsculo, é a medida para a densidade média de informação de um processo de transmissão ou o conteúdo médio de informação por sinal de uma fonte. Analogamente à termodinâmica e à mecânica estatística - das quais o termo foi derivado como a perda de energia ou desordem em um sistema - a entropia ressalta que quanto maior o grau de incerteza, menor a eficácia da transmissão. Daí a necessidade de uma quantidade maior de informação (redundância) para redução da perda ou da desordem em um determinado sistema. 
partir de um campo de possibilidades; ruído como algo a ser eliminado; redução de qualquer expressão a uma codificação) que a teoria matemática da comunicação é, na verdade, uma teoria matemática da informação. A comunicação tratada por ela é um modelo de tradução e transmissão de informações em códigos que busca sistematizar e medir a eficácia do transporte, da decodificação e do recebimento de determinada informação pela fonte receptora. Ao considerar que a condição de possibilidade de comunicação está naquilo que se quer comunicar-se, a teoria matemática ignora a tradição existencial, filosófica e religiosa que a palavra comunicação carrega. Este é o tema do primeiro capítulo deste trabalho.

A importância da teoria da informação de Shannon e Weaver pode ser medida pelas suas reverberações. Não apenas na engenharia de telecomunicações e matemática, mas também na cibernética e seus desdobramentos: seja na biologia (Humberto Maturana e Francisco Varela), na teoria dos sistemas (Niklas Luhmann) ou na psicanálise (Gregory Bateson e Jürgen Ruesch) ${ }^{36}$.

Entretanto, foi somente a partir das questões sobre a origem da comunicação humana empreendidas por psicanalistas que a comunicação surgiu para além de suas relações causalísticas e instrumentais. Além disso, é na psicanálise que as relações entre a negatividade e o conceito de comunicação são postas em evidência através dos elementos pré-linguísticos da comunicação. Este é o último tópico antes deste trabalho redirecionar todos os seus esforços em torno das abordagens filosóficas do conceito de comunicação.

\section{Comunicação e negação}

\section{- ou a consciência e o mundo}

Ao contrário da psicologia social e da sociologia que buscaram uma depuração conceitual da palavra comunicação desde o início do século passado, até meados da década

\footnotetext{
36 Para Baecker, o livro "Comunicação: a matriz social da psiquiatria" [ Kommunikation: Die soziale Matrix der Psychiatrie], de Bateson e Ruesch, foi a primeira e a mais abrangente tentativa de formulação do conceito de comunicação como um termo fundamental para as pesquisas psicofisiológicas e sociais, pois é a diferença entre indivíduo e socialidade os constituem mutuamente. "Ruesch e Bateson definem como os elementos fundamentais da comunicação a percepção mútua, a recursividade e a metacomunicação, tanto o 'relato' (report) e 'comando' (command) como o duplo aspecto necessário de qualquer comunicação. A formulação da 'matriz social' já indica aquilo que a medida de análise desses elementos não é o indivíduo, nem mesmo uma pluralidade de indivíduos, mas a situação social” (BAECKER, 2005, p. 74).
} 
de cinquenta a psicanálise não havia produzido grandes escritos sobre o conceito. Não que a comunicação não fosse importante: ao contrário, o método psicanalítico é baseado naquilo que é comunicado (como linguagem). Mas poucos foram os textos sobre a comunicação verbal e raros foram os artigos sobre a comunicação não verbal. Ao menos essas são algumas das constatações apresentadas pelo psicanalista austríaco e naturalizado norte-americano René Arpad Spitz ( ${ }^{*} 1887$ †1974) no livro No and Yes: On the Genesis of Human Communication [Não e Sim: Sobre a Gênese da Comunicação Humana], publicado originalmente em 1957.

Nesta obra, Spitz investigou o surgimento da comunicação humana a partir da observação de recém-nascidos. Ele se debruçou sobre a comunicação pré-verbal dos bebês e sobre o processo de aquisição da comunicação verbal. Com base nos escritos de Freud, Spitz define a comunicação como qualquer mudança reconhecível - consciente ou inconsciente, direcionada ou não - de comportamento "através da qual uma pessoa (ou várias pessoas) influenciam intencionalmente ou não a percepção, os sentimentos, os afetos, os pensamentos ou as ações de uma outra" (SPITZ, 1992, p. 12).

Assim, René Spitz rompe com a intencionalidade intrínseca aos modelos de comunicação anteriores, já que observar a comunicação em recém-nascidos é atentar para uma comunicação que não tem por objetivo comunicar algo diretamente. É um processo de descarga que diz algo sobre o que se passa com a criança.

Como aponta o próprio Spitz, tal modelo de comunicação encontra suas próprias referências em escritos de Freud, mais precisamente no manuscrito de 1895 (publicado em 1950) Entwurf einer Psychologie [Esboço de uma Psicologia], no qual ele afirma que esses difusos movimentos de expressão interior do bebê para atuar no ambiente, na forma de choro, de gritos, de estrebuchamentos, assumem uma função importante de comunicação ${ }^{37}$ e que "o desamparo inicial do humano é a fonte original de todos os motivos morais" (FREUD, 1987, p. 325).

Como René Spitz desenvolve, esta "comunicação" é apenas um processo de descarga [Abfuhrvorgang] sob o ponto de vista subjetivo do recém-nascido. Mas esse processo de liberação, que pode ser observado como uma mera expressão do estado corporal interno da criança, é compreendido pela mãe como um apelo à sua assistência. Ela responde a esse apelo na medida em que ela ajuda dirimir essa tensão de descarga (por exemplo, 
amamentando). "Logo, através de uma ajuda externa, o processo de descarga não direcionado da criança atinge seu objetivo. Este círculo que se renova continuamente, portanto, constitui o início da comunicação [Kommunikation] e da relação de objeto [Objektbeziehung]" (SPITZ, 1992, pp. 13-14).

Depois de um processo não direcionado de exteriorização, a criança atinge um estágio em que consegue direcionar suas descargas, a partir do desenvolvimento da percepção e da memória. É na passagem do primeiro para o segundo estágio que o psicanalista austríaco identifica a origem de comunicação, ainda bem antes do desenvolvimento do entendimento verbal e que tem seu fundamento na aquisição do "não" pelo bebê. Com isso, René Spitz põe em evidência o poder do negativo na origem da comunicação humana.

A aquisição do "não" é o indicador para o alcance de um novo estágio de autonomia, para a percepção do "outro" e para a consciência do "si". Ele assinala o início de uma nova estruturação dos processos de pensamento para uma camada maior, mais complexa. Ele dá o impulso para um amplo desenvolvimento do eu, no qual o domínio do princípio de realidade torna-se cada vez mais acentuado sobre o princípio de prazer" (ibid., p. 111).

O não - seja como rejeição, choro, grito - assinala o processo de descarga direcionado. Ele marca o início da autopercepção e do reconhecimento do outro. É nesta fase, pouco depois do aparecimento do sorriso e da ansiedade dos oito meses [Achtmonatsangst ${ }^{38}$, que Spitz delimita a origem da comunicação humana.

O não é uma incompletude, uma insatisfação original. De acordo com as ponderações de Spitz, a satisfação imediata das necessidades atrapalha o desenvolvimento das funções de desvio inerentes à comunicação. Já que ela cria meios indiretos de ação, ela é necessária quando se faltam meios imediatos de suprir uma necessidade: "A comunicação é uma função de desvio e ocorre de acordo com o princípio de realidade, ou seja, adiando a satisfação da pulsão com o objetivo de uma obtenção cada vez melhor desta satisfação" (ibid., p. 123).

A comunicação instaura-se, portanto, como a diferença entre o eu o não eu. É na consciência de si e do outro e no reconhecimento da impossibilidade de autossatisfação que surge a necessidade de comunicar. Como aponta Spitz, a origem da comunicação é o não. Por sua vez, as as relações com os objetos são conquistadas a partir da aquisição da $38 \mathrm{~A}$ ansiedade dos oito meses descreve o momento a partir do qual a criança consegue fazer a distinção entre as pessoas que a são familiares e as pessoas estranhas. Para mais detalhes, cf. SPITZ, 1973, pp. 32-38. 
negação.

Nos primeiros meses de vida do recém-nascido, a comunicação e a ação são equivalentes. As atividades do bebê resumem-se a descargas de pulsão. Como visto anteriormente, do ponto de vista de um observador, essas atividades podem ser compreendidas como um comunicado do bebê. Do ponto de vista psicanalítico, há comunicação porque há entendimento [Verständigung]. A partir da repetida experiência de adiamento de satisfação da necessidade, a comunicação separa-se da ação. Esta recusa ou retardo transforma a ação - que até então era o único caminho para a descarga de pulsão em um meio de comunicação: "A partir daí acontece a comunicação através de comunicados direcionados; um pouco mais tarde, desenvolve-se a comunicação como substituto apropriado da ação nas relações sociais, quando a criança toma consciência que ela se comunicou com o 'outro'” (SPITZ, 1992, p. 124).

A partir do automatismo motor inato do comportamento de busca no recém-nascido, que ainda não possui consciência e para quem ainda não há o 'não', há um salto de desenvolvimento para o conceito de negação e para o seu uso na comunicação. Para René Spitz, o uso consciente do "não" semântico é o caminho para o tornar-se humano (Cf. SPITZ, 1992, p. 127). É na capacidade de dizer não e na sua relação com a satisfação que a comunicação assume seus contornos.

Em consonância com a psicanálise freudiana, no arcabouço teórico de Spitz a comunicação realiza-se como um processo hermenêutico. Seja intencional ou não, direcionada ou não, a comunicação efetiva-se como entendimento ou compreensão [Verständigung]. E cabe ao psicanalista a tarefa de tradução daquilo que está direta ou indiretamente comunicado: para além do que é expresso, há o sentido. Mesmo constituindo-se como um autor fundamental para a argumentação de uma teoria negativa da comunicação, a tese proposta neste trabalho busca uma alternativa para a reflexão comunicacional para além da interpretação, já que, como argumentado no tópico anterior, a a noção psicanalítica de comunicação como Verständigung ainda esta entranhada na tradição hermenêutica das Humanidades. Este é o ponto no qual as ideias de Spitz não são mais acompanhadas. Por outro lado, a localização do insatisfatório como a origem do comunicar será retomado particularmente no último capítulo deste trabalho. É a negatividade como o indomado, o inominável na comunicação que deve ser perseguido.

Ainda no campo psicanalítico, deve-se ressaltar o trabalho do médico e psicanalista inglês Donald Woods Winnicott ( ${ }^{*} 1896$ †1971), que já na década de sessenta ponderou 
sobre a importância do inefável para a comunicação humana. Em seu ensaio Communicating and not Communicating: leading to a study of certain opposites [Comunicar e não comunicar: conduzindo a um estudo de certos opostos] publicado em 1963, no qual estuda a constituição da comunicação humana na relação entre a mãe e o bebê, Winnicott concebe uma comunicação fundada não por meio da aquisição da linguagem, mas em uma interação pré-verbal pela mutualidade. Para ele, a comunicação surge de uma não comunicação, de uma interioridade cuja comunicação é impossível. É na relação entre a mãe e o bebê, na alternância dos estados de acalento e ausência durante o período transicional no qual a diferenciação entre interior e exterior começa a tomar forma na criança, que nasce o desejo de comunicar.

O brincar e o simbolizar precede o uso das palavras. Comunicar e não comunicar são entendidos como um dilema: há uma necessidade urgente de comunicar e uma necessidade ainda mais urgente de não ser descoberto. "O que é fundamental em Winnicott no que diz respeito à comunicação é que cada indivíduo constitui-se como isolado e, em consequência disso, o direito a não se comunicar” (ABRAM, 2000, p. 72). Nas palavras do próprio Winnicott, mesmo que "as pessoas sadias comuniquem-se e apreciem comunicar-se, um outro fato também é verdadeiro, o do que cada indivíduo é isolado, estando permanentemente sem comunicar-se, permanentemente desconhecido, de fato nunca descoberto" (WINNICOTT, 1990, p. 187).

Com isso, Winnicott não apenas faz uma crítica à psicanálise freudiana, que constitui uma ameaça à esta possibilidade de ser secretamente isolado, como também opõe-se à teoria da comunicação da Escola de Palo-Alto, cuja máxima desenvolvida por Paul Watzlawick versa justamente sobre a impossibilidade de não comunicar (Cf. WATZLAWICK, BEAVIN \& JACKSON, 2007, p. 50 e ss.). A teoria desenvolvida por Winnicott, ao contrário, fundamenta a comunicação a partir de uma interioridade incomunicável.

O incomunicável da comunicação: sua alusão e tentativa de teorização constitui o quinto gesto deste trabalho. Na comunicação existe algo de insatisfatório, de irrealizável, que escapa à discursividade. Algo que constitui o comunicar, mas que foge à tematização. A insuficiência, a incompletude, a irrealização solitária do ser humano são marcas, ranhuras, aberturas, inclinações do eu para o outro. A comunicação não nasce da falta, mas da incompletude radical. Esses temas são ponderados na segunda e, principalmente, na terceira parte desta tese de doutorado. 
Até este momento, foi-se afirmado que a ex-comunicação possui uma dinâmica outra do que o termo comunicação instrumentalizado pelas teorias informacionais, pela psicologia social e pela psicanálise. Como argumentado anteriormente, comunicação não é informação, transporte, transmissão ou decodificação. Ela não pode ser gradualmente reduzida por processos de traduções até sua total numerização e redução do seu campo de possibilidades para eliminação do ruído. O movimento executado por este trabalho quer presentificar o seu negativo: o ruído constitui a possibilidade de comunicação. Por sua vez, a ex-comunicação expõe uma comunicação que não pode ser medida pelos seus efeitos. Ela não parte de uma fonte emissora e reverbera em uma fonte receptora. Aqui age um outro negativo: comunicação é passibilidade. A ex-comunicação expõe, antes de tudo, a comunicação como abertura, como ser afetado por algo que excede. Por fim, a comunicação não é entendimento, interpretação, transmissão ou negociação de sentidos. A ex-comunicação deve evidenciar o caráter mágico da comunicação: sua imediaticidade. A ex-comunicação é a exposição da comunicação humana observada a partir de sua negatividade originária.

Tais considerações que recolocam o ser humano e sua existência no centro das reflexões sobre a comunicação demandam, naturalmente, uma reflexão ética. Este é o sexto gesto deste trabalho de doutorado: a partir da reelaboração teórica da ex-comunicação, a comunicação deve ser considerada como um fenômeno eminentemente ético, com implicações práticas. Isto significa considerar as dimensões éticas da diferença - até sua radicalidade na constituição do conceito de comunicação. Por meio de um estudo mais detalhado sobre as abordagens fenomenológicas da comunicação, este é o tema da segunda parte deste trabalho.

Antes de iniciarem-se as ponderações sobre as abordagens filosóficas e teórico-mediais do conceito de comunicação, faz-se necessário ainda um breve excurso sobre a relação entre os conceitos de comunicação, medium e comunidade e como eles são instrumentalizados neste trabalho. A pergunta a ser respondida é por quê o conceito de comunicação assume aqui o papel principal, em detrimento aos outros dois conceitos, que possuem uma fortuna teórico-filosófica tão ou mais abrangente do que o primeiro. 


\section{V}

\section{Comunicação | Medium | Comunidade}

A proposta deste trabalho é apresentar uma argumentação em favor de uma teoria negativa da comunicação. Isto significa observar os principais conceitos de uma teoria comunicacional - medium, comunicação e comunidade - sob uma abordagem negativa. Mas por quê precisamente esses três conceitos para a composição desta proposta?

Uma teoria da comunicação deve, evidentemente, dedicar-se a um fenômeno que seja caracterizado como comunicacional. Como apresentado durante essa introdução, este fenômeno assumiu formas variadas e múltiplos foram os modelos de descrição teórica. Em comum, todas essas teorias lidam com o par conceitual comunicação-medium para suas elaborações modelares. Exemplificando, tem-se para a psicologia social, a comunicação como um fenômeno de interação e o medium como o facilitador técnico da relação entre indivíduos e organizações; para as teorias informacionais, a comunicação é um fenômeno de transporte (de informações) e o medium é o canal no qual o comunicado é transportado de um ponto a outro; para a psicanálise a comunicação é um processo que se realiza na compreensão - deciframento e dotação de sentido - cujo medium são as descargas (interpretadas simbolicamente), os símbolos (a linguagem) e suas fraturas (por exemplo, atos falhos) - sejam esses estímulos direcionados ou não, intencionais ou não.

Portanto, se por um lado a comunicação é o trato com uma diferença fundamental, por outro lado é o medium que torna possível a sua ocorrência. Como escreveu Dieter Mersch (2006, p. 9), “existe medium porque existe alteridade”. O medium possibilita, assim, a percepção e o entendimento. Os media participam de quaisquer processos de comunicação, na medida em que o fenômeno comunicacional torna-se possível apenas pela diferença e pela medialidade. Pode-se até teorizar sobre a existência de uma comunicação i-mediata, ou seja, sem um meio aparente, mas não sem um medium. Essa diferenciação fundamental é abordada na última parte desta tese de doutorado.

Por sua vez, o conceito de comunidade foi deixado de lado pela maioria dos construtos teóricos observados até aqui. Com exceção da psicologia social e da sociologia, que ora adotaram o termo de forma genérica, como agrupamento humano em que seus membros compartilham normas, valores, língua, costumes, espaço etc., ora herdaram o termo do sociólogo alemão Ferdinand Tönnies ( ${ }^{*} 1855$ †1936), que em sua principal obra 
Gemeinschaft und Gesellschaft [Comunidade e Sociedade], publicada em 1887, opôs esses dois conceitos. O termo comunidade foi utilizado para grupos cuja coesão e comunhão estão baseadas na tradição, em relações de parentesco ou religiosas etc. Já o termo sociedade relaciona-se às complexas relações sociais e de trabalho dos centros urbanos.

Como é apresentado no capítulo conseguinte, a relação entre comunicação e comunidade não é apenas etimológica, mas os termos implicam-se mutuamente: não há comunicação sem comunidade, assim como não há comunidade sem comunicação. A partir de uma investigação das origens judaico-cristãs dos usos dessas palavras, pretende-se ressaltar a necessidade de trazer para o campo da comunicação as reflexões de autores que forçaram ao máximo o pensamento dos limites da comunidade, como Franz Rosenzweig, Martin Buber, Emmanuel Levinas, Maurice Blanchot e Jean-Luc Nancy.

Por sua vez, poder-se-ia deduzir um certo conceito de comunidade implícito nas teorias comunicacionais abordadas anteriormente: na hermenêutica, na semiótica, nas teorias informacionais e na psicanálise, para que sejam assegurados o entendimento, a semiose, a compreensão, a transmissão e o consenso é necessário um plano comum (uma língua, um código, uma linguagem, um contexto etc.). Ou seja, o papel do conceito de comunidade seria o de assegurar as condições para que, possibilitado por um medium, a comunicação ocorra. Vale ainda ressaltar que o conceito de comunidade segue a mesma lógica da diferença dos termos medium e comunicação. Comunidade implica uma diferença fundamental entre os que fazem parte dela e os que não fazem: ao mesmo tempo delimitação e limitação.

Este trabalho busca explorar ao máximo essa diferença inerente aos termos comunicação, comunidade e medium para abordar o negativo desses conceitos: ao mesmo tempo em que se distancia das abordagens comunicacionais apresentadas até o momento, esta tese de doutorado busca a valorização de um outro olhar - evidenciado por vários pensadores durante o século XX - para um mesmo fenômeno. Um rápido exemplo (portanto, genérico e superficial) sobre a experiência comunicacional na leitura de uma obra literária deve ajudar na visualização deste gesto.

De acordo com a teoria informacional, tem-se uma fonte emissora (o escritor), um transmissor (a escrita), um código (a palavra escrita), um canal (o livro), um decodificador (a leitura) e a fonte receptora (o leitor). Logo, o processo de comunicação será mais efetivo quando menos ruído houver entre a transmissão das informações selecionadas pelo emissor e o recebimento dessas informações pelo receptor. Comunicação e medium (neste caso, o 
suporte físico livro) podem ser avaliados pelo seu grau de eficiência de tradução de um ponto a outro. A comunidade poderia ser deduzida neste contexto como a existência de um código comum a ser codificado e decodificado, a língua escrita. Não é difícil de perceber os problemas deste modelo quando se trata da comunicação com uma obra, cujos efeitos não são tão claros como em uma escolha de uma informação dentro de um campo de possibilidades pré-programado.

Tomando o mesmo fenômeno, mas de acordo com as abordagens hermenêuticas (entre elas a psicanálise), temos um significado da obra (mesmo que múltiplo, aberto) a ser decifrado ou compreendido pelo leitor. Diferentemente da abordagem matemática, o leitor tem um papel tão - ou mais - relevante quanto o do escritor: é necessário um exercício de interpretação para extrair o sentido do texto. A comunicação ocorre na produção das camadas de sentido e interpretação. Ela é exegética. Por isso, a comunicação é fruto de um sujeito doador de sentidos e medium é a linguagem através do qual algo é compreendido.

Sob o ponto de vista psicossocial e sociológico, a comunicação toma forma com a relação autor-leitor a partir da interação com a obra. A comunicação assume papel de intermédio entre grupos sociais distintos que atuam entre si. A linguagem (escrita e leitura) é o meio técnico social para isso. O livro, a tecnologia. Por conta do ser caráter contextual, cresce a importância dos efeitos de uma obra, não apenas no indivíduo, mas na sociedade. Além disso, é através da comunicação que a comunidade é assegurada: é com a criação de algo comum, compartilhado via comunicação e da instauração do consenso que a comunidade (como grupo de semelhantes) pode emergir.

Para uma teoria negativa da comunicação, todas essas categorias são subvertidas. A comunicação não ocorre mais com o autor ou com sentido do livro, mas a obra mesma está em comunicação. É a contingência absoluta do encontro, quando a intencionalidade do autor e do leitor são subjugadas pela criação da unicidade da experiência. A soberania do eu é posta em suspensão: é um momento de escuta e de acolhimento (que não está livre do trauma). A comunicação é abertura e passividade: mas quando ela ocorre, não pode ser tematizada. Em comunicação, o livro e o leitor diluem-se em um momento trágico - porque ilusório e precário - de fusão. É quando se está com-penetrado na obra, tal como um sentir-com, quando ocorre a sensação de suspensão de si. O medium é o próprio modo de percepção: ele não é a linguagem, nem as letras e os espaços dispostos ordenadamente no livro, mas aquilo que faz com que esses e outros elementos sejam literatura. O medium possui materialidade, mas a esconde no momento em que atua. O medium torna algo 
presente, mas não se ex-põe. O que deixa rastros é a medialidade do medium. Assim como a comunicação que se nega à tematização no momento em que ocorre (apenas seus vestígios são passíveis de reflexão), a sua medialidade só pode ser tematizada quando há ruídos, ou seja, quando ele se mostra como obstáculo para a comunicação, quando o medium não cumpre sua função.

A medialidade do romance, por exemplo, fica evidente em livros como Malone meurt [Malone Morre], escrito em 1951 por Samuel Beckett, cuja narrativa se esvai assim como o corpo moribundo do personagem. Narrativa que se nega à apreensão direta de um sentido: "Parei de olhar para ele. Me acostumei com sua presença. Pensava nele, tentava compreendê-lo, não se pode fazer isso e olhar ao mesmo tempo" (BECKETT, 1986, p. 123). Ou ainda o seu livro conseguinte escrito em 1953, L'Innommable [O inominável] (BECKETT, 2009) - último da sua trilogia do pós-guerra, composta ainda por Molloy (BECKETT, 2008) que ao insistir na impossibilidade da narrativa, de permanecer sobre seus escombros, Beckett deixa transparecer alguns dos elementos que compõem a medialidade, que está além da escrita e da relação signo-significado, além ainda da intencionalidade de um autor: ainda resta algo. Este excesso sobre o significado é o que emerge por entre as palavras. É neste momento de intensa exposição ao estranho (uma comunhão negativa) com a obra que emerge uma comunidade precária - ela que ao contrário de ser garantida pela comunicação, garante a própria possibilidade de ilusão fusional (e por isso, trágica). Em comunidade há espaço para o inexprimível.

A ex-comunicação - para ressaltar-se aqui a diferença desta abordagem em relação às outras teorias da comunicação - é este momento em que se ex-põe algo para além do jogo de significados, em que se quebra o horizonte de expectativa (para usar a terminologia hermenêutica), em que se manifesta em uma atmosfera criada pelo encontro que suspende o estar-para-si-mesmo e inaugura um estar-para-e-com-o-outro. Na teoria negativa da comunicação, o medium torna-se transparente, a comunidade torna-se ex-positória, a comunicação torna-se transcendente.

Estas definições são desdobradas neste ensaio de uma teoria. Como já colocado no início deste capítulo, a comunicação ensaiada na tese de doutorado é, acima de tudo, uma experiência acontecimental, ou seja, uma experiência que transforma o 'eu' em 'mim', pois ele não é necessariamente causa ou efeito desta experiência, mas é exposto à ela, como uma ferida aberta. O medium é o modo de percepção que opera esta experiência: ele não é uma ponte entre o abismo que separa o mim do outro, pois ele acentua esse abismo, na medida 
em que ele se imaterializa no momento da experiência, como uma materialidade que se descorporifica. E quando essa experiência efetua-se, é porque se é exposto à coexistência finita de seres singulares, é porque se está em uma comunidade: mesmo que precária ou evanescente, ela incorpora a possibilidade da ocorrência deste fenômeno.

Tal construto é figurado durante este trabalho, cuja última parte apresenta os argumentos finais para defesa de sua pertinência. Devido à própria processualidade inerente ao conceito de comunicação, esses três termos são retrabalhados insistentemente: a cada emergência de um dos termos os outros dois são interrogados, mesmo quando não explicitamente nomeados. Esta pesquisa foi estruturada em torno da busca por uma constituição de um aparato conceitual que possa ser designado como comunicacional. Se esta reelaboração teórica e instrumentalização filosófica conseguem dar conta da tese proposta, isso é algo a ser avaliado ao final deste trabalho.

Este longo capítulo introdutório foi estruturado ao modo de uma via negationis. Por meio de sucessivas negações, esta primeira parte foi desenvolvida não apenas para delimitar o lugar de elaboração do pensamento que move esta proposta, como também para apontar suas diferenças em relação às abordagens ditas comunicacionais de outras áreas das ciências humanas. Além disso, esta introdução serviu para apresentar o aparato conceitual básico utilizado nesta tese de doutorado.

Este é o momento de retomar alguns pontos e apresentar a estruturação dos próximos capítulos. Como descrito anteriormente, este trabalho é composto por seis gestos e três conceitos-chave. Os gestos acompanham as três partes que constituem a tese proposta e operam como pontos de orientação para sua argumentação. São eles: 1. discussão sobre os movimentos do pensamento ocidental nos quais a comunicação foi tratada como categoria ou conceito; 2. valorização da dimensão existencial da comunicação; 3. apresentação de uma abordagem negativa e pós-hermenêutica da comunicação; 4. fundamentação de uma crítica aos conceitos de comunicação a partir de uma reflexão sobre a origem do comunicar como diferença; 5. exposição teórica do incomunicável da comunicação; 6. consideração do fenômeno comunicacional sob sua dimensão ética. Esses 
seis gestos devem fornecer argumentos para a reelaboração negativa dos conceitos de comunicação, medium e comunidade. O mapa conceitual abaixo apresenta o modo de articulação de todos esses pontos na elaboração desta tese de doutorado:

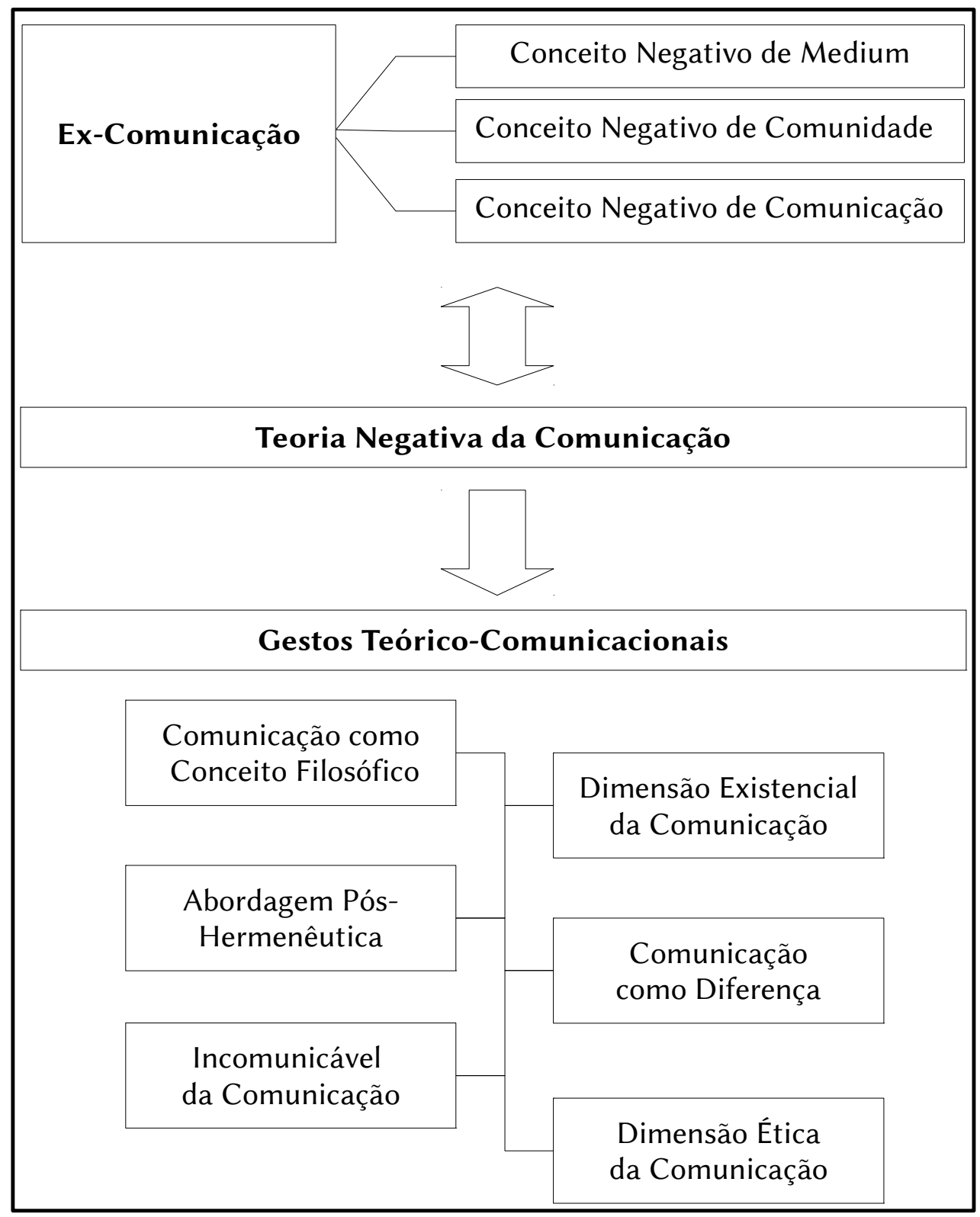

Fig. 1

Para o desenvolvimento desta proposta, este trabalho foi dividido em três partes. A primeira, intitulada Communicatio, disserta sobre as abordagens filosóficas do termo comunicação. Devem ser levados em consideração não apenas os usos e reflexões em torno da palavra comunicação, mas os contextos nos quais o conceito emergiu como um 
problema filosófico. Este capítulo é fundamental para a redefinição das dimensões humana, mística e existencial inerentes a esta palavra.

A segunda parte, intitulada $E x$-, estrutura-se como uma monografia em torno do conceito de alteridade e sua importância na constituição de uma teoria comunicacional. É uma apologia à integração dos estudos filosóficos do outro à teoria da comunicação. Tal capítulo justifica-se por possibilitar argumentos em favor de um conceito de comunicação baseado na receptividade, em detrimento ao caráter ativo dos recorrentes modelos teóricos comunicacionais.

Com o título Ex-communicatio, a última parte desta tese de doutorado apresenta a reelaboração negativa dos conceitos de medium, comunidade e comunicação. Após uma longa revisão e discussão teórica empreendida nos capítulos anteriores, este é o momento propositivo deste trabalho. O objetivo é ressaltar a pertinência conceitual de uma teoria negativa da comunicação e apontar para os desdobramentos de pesquisa implicados em tal teorização.

Deve-se ressaltar, por fim, que as obras de arte referenciadas aqui não são objetos de estudo ou interpretação. Elas possuem um importante papel de reverberação, no plano estético, de uma intuição teórica, cuja elaboração discursiva é insuficiente para sua exposição.

A tentativa de proposição teórica de uma ex-comunicação, ou seja, a tentativa de apresentar uma comunicação indireta cujos elementos com-formadores não tomam parte no comunicado, possui a mesma desvantagem que todo discurso sobre o silêncio carrega consigo: discorrer sobre ele é assassiná-lo. Mas ainda restam estratégias retóricas e estéticas, como a alusão, a criação de atmosferas e a figuração.

Propor uma tese de doutorado sobre um tema aparentemente tão fugidio é assumir o desafio e o risco implicados por uma reflexão no limiar da argumentação acadêmica. A possibilidade de apreensão da proposta pelo leitor é assombrada pelo fracasso iminente devido ao paradoxo de figurar-se na linguagem algo que, a princípio, não pode ser representado por ela. Sobre o êxito desta argumentação deve sempre pairar uma dúvida, como uma fermata reverberando em uma grande sala vazia. 


\section{CAPÍTULO I. COMMUNICATIO}

$\mathrm{Na}$ fonte dos teus olhos vivem os fios dos pescadores do lago da loucura.

$\mathrm{Na}$ fonte dos teus olhos o mar cumpre a sua promessa.

Aqui, coração que andou entre os homens, arranco do corpo as vestes e o brilho de uma jura:

Mais negro no negro, estou mais nu. Só quando sou falso sou fiel. Sou tu quando sou eu.

$\mathrm{Na}$ fonte dos teus olhos ando à deriva sonhando o rapto.

Um fio apanhou um fio: separamo-nos enlaçados.

$\mathrm{Na}$ fonte dos teus olhos um enforcado estrangula o baraço.

Elogio da distância, Paul Celan ${ }^{39}$

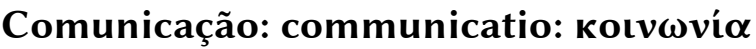

"Rigorosamente, esta palavra é insustentável" Jean-Luc Nancy

Comunicação. Palavra sedutora. Exaltada e desgastada nos mais diversos discursos contemporâneos, sejam eles científicos, tecnológicos, sociais, psicológicos, artísticos, filosóficos, cotidianos. Uma onipresença que se converte em ideologia, poética, utopia, distopia, marketing. A comunicação aparece como uma marca intrínseca ao mundo atual.

39 Im Quell deiner Augen/leben die Garne der Fischer der Irrsee./Im Quell deiner Augen/hält das Meer sein Versprechen.//Hier werf ich,/ein Herz, das geweilt unter Menschen,/die Kleider von mir und den Glanz eines/Schwures://Schwärzer im Schwarz, bin ich nackter./Abtrünnig erst bin ich treu./Ich bin du, wenn ich ich bin.//Im Quell deiner Augen/treib ich und träume von Raub.//Ein Garn fing ein Garn ein :/wir scheiden/umschlungen.//Im Quell deiner Augen/erwürgt ein Gehenkter den Strang.. (Paul Celan, Lob der Ferne. in "Papoila e Memória". Tradução de João Barrento e Y. K. Centeno). 
Uma característica mágica que se adere a qualquer conceito ou objeto para emprestar-lhes ares de modernidade.

Mas ao contrário do que parece, a palavra comunicação é muito antiga. E tanto sua longa tradição no pensamento ocidental, quanto seu vasto campo semântico desencorajam qualquer tentativa de determinação conceitual por meio da etimologia. Contudo, uma empreitada etimológica pode ser válida devido ao seu aspecto inspirador, capaz de revelar associações, campos semânticos e empregos perdidos ao longo da história e que podem fornecer um outro cenário necessário para uma revisão conceitual.

A palavra comunicação, que teve sua primeira aparição em português registrada no século XV (comunjcaçã), tem sua origem na palavra latina communio, a mesma da palavra comunhão, grafada no século XIII como comoyon (Cf. CUNHA, 1982). Esta relação fica ainda mais clara na língua alemã, na qual o verbo kommunizieren não se traduz apenas como comunicar, mas também pode ser entendido como ir à comunhão cristã, como comungar - guardando de certa forma ainda a mesma origem das palavras Kommunion e Kommunikant (aquele que comunga pela primeira vez). Communio também está na origem da communitas, que seria traduzida ao português como comunidade. A profunda relação entre as palavras comunhão, comunidade e comunicação atinge diretamente a problemática deste trabalho e será retomada mais adiante. Por ora, deve-se permanecer nos empregos iniciais da palavra comunicação.

Em um dos primeiros dicionários da língua portuguesa moderna, o Vocabulario Portuguez, e Latino (1712-1728), organizado pelo francês Rafael Bluteau ${ }^{40}$, já continha a separação latina entre comunhão e comunicação - communio e communicatio. Como será

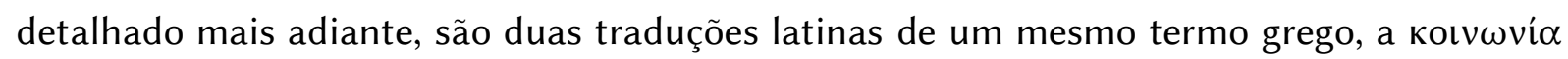
[koinonia]. Entre as definições apresentadas por Bluteau, no início da formação do português moderno, a comunhão era um vocabulário apenas do domínio religioso, enquanto a palavra comunicação (apresentada em duas grafias: communicaçam e communicaçaõ) - além do sentido sagrado - dividia-se em uma série de expressões

40 "A lexicografia moderna do português, que tem o seu início em 1789 com o Diccionario de António Morais Silva, é precedida por um conjunto de obras que constituem a transição entre a dicionarística latino-portuguesa e o primeiro dicionário monolingue. O Vocabulario Portuguez, e Latino de Rafael Bluteau (1638-1734), publicado entre 1712 e 1728, é o ponto de referência fundamental para compreender um processo de renovação da descrição da língua, da tipologia dos dicionários e das funções que os leitores atribuíam a estes instrumentos metalinguísticos" (SILVESTRE, 2008, p. 7). O dicionário de Bluteau (cujo título completo é Vocabulario Portuguez e Latino, Aulico, Anatomico, Architectonico, Bellico, Botanico, Brasilico, Comico, Critico, Dogmatico, etc. autorizado com exemplos dos melhores escriptores portuguezes e latinos, e oferecido a el-rey de Portugal D. João V.) pode ser consultado online na página do Instituto de Estudos Brasileiros da Universidade de São Paulo (http://www.ieb.usp.br). 
mundanas (BLUTEAU, 1716, p. 406). A palavra também foi listada como uma tradução da palavra latina commerč̆um, mais comumente traduzida como trânsito, transporte, comércio ou relações de troca. Já o verbo comunicar, com a antiga grafia communicár, foi tratado tanto como uma tradução direta do verbo latino communicare - ou seja, como "communicár alguma cousa a alguem, dandolhe parte dela" (sic) (ibid., p. 407), - quanto do verbo participare e ainda colocada no mesmo campo semântico das palavras contagione (contaminação) e confilia (conselho). Além disso, comunicar já possuía o sentido de ligação de duas coisas materiais com a ajuda de algum meio (o exemplo dado por Bluteau é uma ponte).

Com isso, pode-se perceber, já em uma das primeiras aparições dicionarísticas da palavra comunicação, a amplitude de traduções de termos latinos que se fragmentaram nos mais variados usos deste termo. Quase um século após a publicação do dicionário de Bluteau, a comunicação ainda retinha seu duplo caráter mundano e sagrado. No Diccionario da lingua portugueza, de Antonio Moraes Silva, cuja segunda edição foi publicada em 1813, esta palavra manteve o sentido do ato de fazer-se algo comum a muitos, e o verbo comunicar foi caracterizado como o ato de participar dos ofícios divinos. Mas nesta obra surge algo novo, o sentido da comunicação como expressão: "a comunicação dos conceitos por palavras, acenos" (1813, p. 423).

Ainda digno de nota são as definições da palavra como "convivência", "trato" e "incorporação", apresentada em um dos primeiros dicionários dedicados ao português do Brasil, o Diccionario da lingua brasileira, escrito por Luiz Maria da Silva Pinto e publicado em 1832, em Ouro Preto (Cf. PINTO, 1832). Nesta mesma obra, o verbo comunicar apareceu como sinônimo de ter uma conversação com alguém. É interessante perceber como a maioria desses sentidos permaneceram até hoje e, mais ainda, como os diferentes significados da palavra comunicação - e do verbo comunicar - foram derivados de diferentes termos latinos.

Se a noção de comunicação na aurora do português moderno já possuía uma jornada cheia de vicissitudes derivadas de uma série de transformações de palavras latinas, mais complexa ainda é apreensão da sua longa carreira na Antiguidade Clássica e no desenvolvimento do Cristianismo. Uma história do conceito de comunicação ainda urge ser escrita. Mesmo o termo não tendo surgido dentro do pensamento judaico-cristão, a formação dada por ele emprestou sentidos que a palavra carrega até os dias atuais. Por isso, as maiores referências históricas nesta área encontram-se na teologia (Cf. MÖRES, 2006; 
SEESEMANN, 1933). Consequentemente, o tema tem ganhado bastante relevância nos estudos teológicos, principalmente após o Concílio Vaticano II, de 1961, no qual o próprio sentido da palavra comunicação foi posto em pauta pela Igreja Católica.

Como a elaboração de tal estudo histórico-etimológico escapa ao objetivo deste trabalho, deve-se agora tecer apenas algumas considerações referentes às antigas origens conceito de comunicação com o intuito de ressaltar uma ambivalência conceitual que perdura até hoje no sentido desta palavra, mas que vem sendo teoricamente suprimida desde as primeiras teorias da comunicação do início do século passado.

Como discorrido anteriormente, a palavra comunicação é uma tradução direta da palavra latina communicatio, que por sua vez é o substantivo para a forma verbal communicare e para o adjetivo communis. Mas a origem desses termos latinos vem das palavras gregas $\alpha v \alpha \kappa o \iota v \omega \sigma \varepsilon \iota \varsigma$ [anakoinoseis] e $\kappa o \iota v \omega v i ́ \alpha$ [koinonia]. Communis

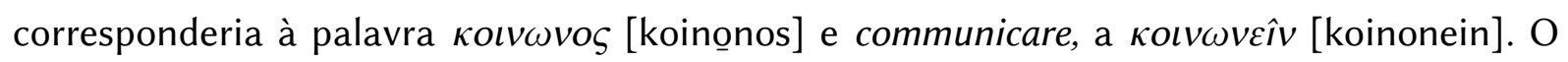
prefixo grego кoıv- possui o mesmo sentido do com- latino. Outra palavra grega traduzida ao latim como communicatio foi a $\mu \dot{\varepsilon} \theta \varepsilon \xi \iota \varsigma$ [méthexis] (Cf. MÖRES, 2006, p. 157 e ss.). O mais

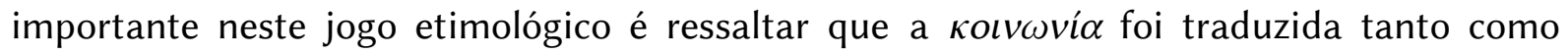
communicatio, quanto como communio.

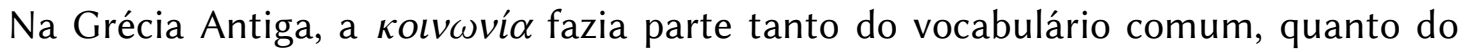
discurso sagrado e mitológico. Como ressaltou Seesemann (1933, pp. 3-23), a palavra

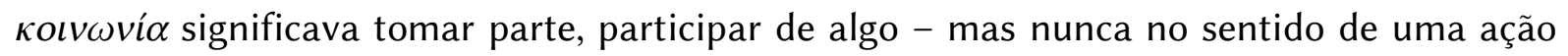
futura, ainda não realizada. O seu uso dativo - comunicar com alguém ou algo - já denotava a constituição de uma comunidade ou sociedade. O termo também foi largamente empregado pela filosofia grega, mesmo que não fosse tematizado como um conceito. Nas

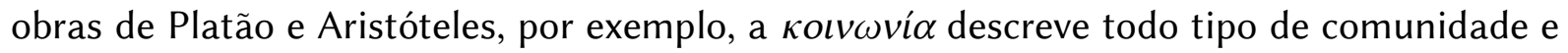
união sustentada por interesses comuns (MÖRES, 2006, p. 163).

Mas mesmo não sendo uma criação judaico-cristã, foi só a partir do Novo

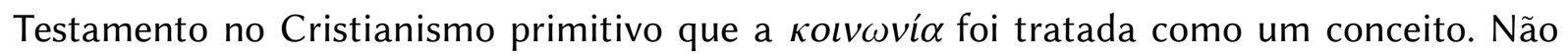
por acaso, foi Paulo de Tarso quem definiu, através de suas epístolas, o sentido ocidental-cristão do termo. Nas versões latinas dos seus escritos bíblicos, a palavra

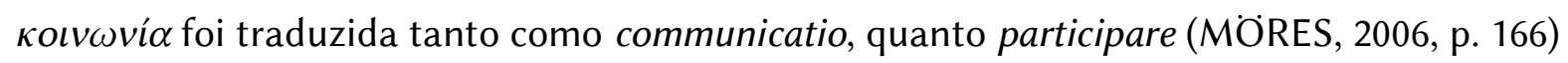

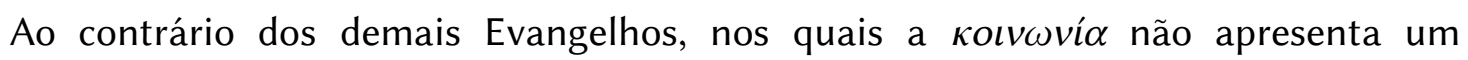
sentido unitário, os escritos de Paulo dedicam-se intensamente à palavra como um conceito

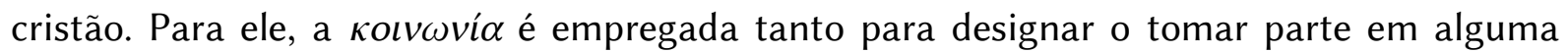


coisa, como aquilo que constitui a comunidade: isto significa que a comunidade é

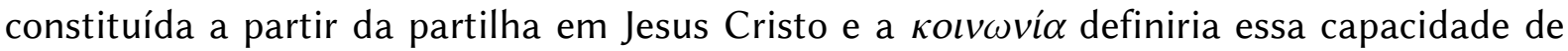
comunicação, como um tipo de comunicalidade. "Somos irmãos, koinonai, mas em Cristo, quer dizer, em uma alteridade que nos subtrai nossa subjetividade, nossa propriedade subjetiva, para cravá-la ao ponto de 'sujeito vazio' do que viemos e para o qual somos chamados" (ESPOSITO, 2003, pp. 36-37).

Dois pontos nesta definição paulina de $\kappa o \iota v \omega v i ́ \alpha$ são fundamentais. Primeiramente, a comunicação em Cristo não é algo que depende do crente, mas da graça de Deus. "Ou seja, um dado a priori que não pode ser dado pelo ser humano" (MÖRES, 2006, p. 171). A

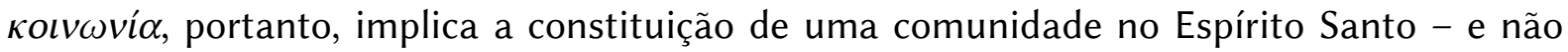
entre os homens. É a participação em um já-dado divino que constitui a comunidade. Como Sessemann (1933, p.86) explica, o sentido de comunhão não é o que funda a comunidade, mas ao contrário, é a participação numa comunidade que possibilita a comunhão.

Deve-se reter essa característica para entender aquilo que Möres chama de

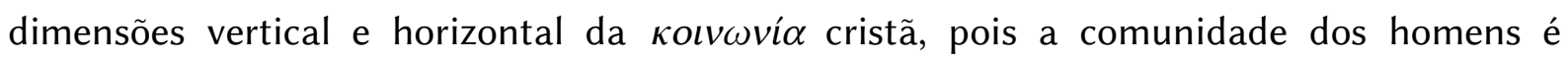
definida apenas através da comunicação com Cristo. Portanto, estão assegurados dois sentidos no conceito de $\kappa o l v \omega v i ́ \alpha$ : um interpessoal e outro sacramental. Assim, a primeira tentativa de definição programática do conceito de comunicação no Cristianismo primevo reteve tanto o aspecto mundano quanto sagrado da palavra grega $\kappa o \iota v \omega v i ́ \alpha$.

Mesmo com sua dupla tradução latina - que no português atual constituem as palavras comunicação e comunhão - a tensão entre essas duas dimensões (imanente e

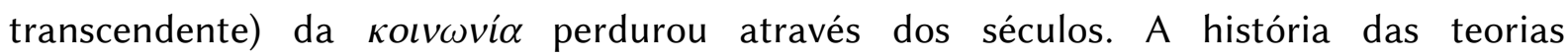
(linguísticas, semióticas, sociais e matemáticas) da comunicação poderia ser contada como a história da supressão desta dimensão mística do conceito de comunicação. Por outro lado, a operacionalização ou redução aos aspectos práticos produzem a ilusão de transparência e ausência de conflito inerentes a essa palavra. Tais aspectos não deixaram de ser percebidos pela filosofia ocidental. Mesmo face às precariedades provocada pela multiplicidade de sentidos, o termo foi utilizado de forma efetiva - embora na maioria das vezes não diretamente conceitualizado. A recuperação desta dimensão místico-existencial - e não apenas comercial, processual ou veicular - do conceito de comunicação é uma tarefa que esta tese doutorado se propõe a realizar. 


\section{II}

\section{Comunicação como conceito filosófico}

Durante o último século, o conceito de comunicação - bem como todos os seus compostos derivados, como sociedade da comunicação, ciências da comunicação, competências da comunicação etc. - adquiriu uma aparente ineficácia teórica (RITTER \& GRÜNDER, 1976, p. 893). Tal aparente abandono de sua conceptualização pode ser explicado, por um lado, pelo avanço no cotidiano das tecnologias de transmissão de informações (rotuladas sumariamente de comunicacionais) e, por outro, pelo enraizamento da discussão da linguagem e do signo pelo chamado linguistic turn na filosofia. No nível linguístico-filosófico, pode-se afirmar que o conceito de comunicação foi herdeiro tanto do modelo matemático de informação (SHANNON \& WEAVER, 1949) quanto do modelo sociopsicológico de interação (COOLEY, 1909; GOFFMAN, 1956; SAPIR, 1935). A comunicação ficou à margem dos debates, considerada apenas como um efeito do (ou o próprio) uso da linguagem. O conceito de comunicação sofreu - mais uma vez, aparentemente - o desdém da filosofia do último século, manifestado na sua recusa à necessidade - ou afirmação da nulidade - do apuro conceitual do termo.

A ideia de comunicação ficou associada à relação intersubjetiva, sendo por esse motivo ou operacionalizada pelo estruturalismo como sinônimo de relação, ou rechaçada pelo pós-estruturalismo por supostamente reafirmar um sujeito autocentrado. Como exemplo, pode-se apontar aqui a abordagem dos filósofos franceses Gilles Deleuze e Félix Gattari (1992, p. 14 e ss. e passim), que em seu livro $O$ que é a filosofia? classificam a comunicação como um dos três tipos de universais (que não criam conceitos, que não explicam nada, mas devem ser explicados), ao lado da contemplação e da reflexão, que corresponderiam às três eras de uma filosofia (a ser) superada: à eidética (contemplação), à crítica (reflexão) e à fenomenologia (comunicação), "que não se separam da história de uma grande ilusão" (DELEUZE \& GUATTARI, 1992, p. 64). Por trás da palavra comunicação utilizada por esses filósofos encontram-se claramente duas correntes de pensamento que, mesmo se apropriando deste conceito, não o definem expressamente: a racionalidade comunicativa de Habermas e a fenomenologia husserliana. De um lado, a comunicação surge como sinônimo de consenso (instaurado no espaço público), nos moldes preparados por Jürgen Habermas (1995), em cuja obra mais conhecida (a extensa Teoria da Ação 
Comunicativa) a palavra comunicação emerge como uma adjetivação: não há uma discussão conceitual mais ampla do termo, derivado diretamente da sociologia e da psicologia social. Nas palavras de Deleuze e Guattari: “(...) a filosofia não encontra nenhum refúgio último na comunicação, que não trabalha em potência a não ser de opiniões, para criar o 'consenso' e não o conceito" (ibid., p. 14). Por outro lado, a comunicação surge como sinônimo de relação intersubjetiva: por isso ponto de partida para a crítica ao sujeito (transcendental) da comunicação. Vale lembrar que na conhecida quinta meditação das Meditações Cartesianas (HUSSERL, 1987), na qual o filósofo argumenta sobre a intersubjetividade, o termo Kommunikation só aparece uma vez, no $\S 58^{41}$.

Em um texto anterior - Postulados de Linguística (1995, p. 11 e ss.), publicado originalmente em 1980 - os filósofos apontam para a necessidade de separação entre a linguagem e a comunicação: “A linguagem não é informativa nem comunicativa, não é comunicação de informação, mas - o que é bastante diferente - transmissão de palavras de ordem" (ibid., p.15). A discussão sobre a teoria linguística dos dois autores e do seu conceito de palavra de ordem não é objeto desta tese de doutorado. Cabe ressaltar que para eles a linguagem não pode ser informativa nem comunicativa, pois ela não seria intersubjetiva, nem significante, mas agenciamentos de "enunciados-atos".

Entretanto, tal redução do conceito de comunicação às suas dimensões consensuais,

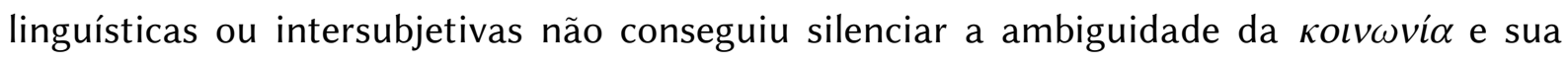
impossibilidade de imanentização radical. As dimensões sagrada, ética e estética da comunicação demandavam uma violência contra o senso comum, contra a sua redução à linguagem e contra o seu uso publicitário. E isso havia sido percebido pela própria filosofia francesa contemporânea. A título de ilustração, pode-se elencar os textos Assinatura Acontecimento Contexto, de Jaques Derrida (1991, p. 341 e ss.), publicado em 1971; e Algo assim como: comunicação... sem comunicação, de Jean-François Lyotard (1991, p. 108 e ss.), publicado originalmente em 1985.

Conhecedor da obra de Georges Bataille - um dos pensadores do século XX que mais avançaram na caracterização do conceito de comunicação a partir da sua dimensão mística e existencial e que será objeto de estudo do último capítulo deste trabalho - Derrida já havia apontado para a necessidade de reconsideração conceitual do termo. Uma palavra que não pode ser negligenciada, porque ela "abre um campo semântico que precisamente

41 A importância da fenomenologia para uma teoria negativa da comunicação é abordada no segundo capítulo deste trabalho. 
não se limita à semântica, à semiótica, ainda menos à linguística. Pertence ao campo semântico da palavra comunicação o designar de movimentos não-semânticos" (DERRIDA, 1991, p. 349).

Em suas considerações, Derrida acompanha o caminho aberto pela teoria performativa de Austin (1975), que desvinculou a comunicação dos estudos do signo e da linguagem por não mais designá-la como o processo de transporte de um sentido. Nas palavras de Derrida, o "performativo é uma 'comunicação' que não se limita essencialmente a transportar um conteúdo semântico já construído e vigiado por um objeto de verdade (de desvelamento do que é no seu ser ou de adequação entre um enunciado judicativo e a própria coisa)" (DERRIDA, 1991, p. 363). Entretanto, para o filósofo que conseguiu registrar o aspecto acontecimental da linguagem através do seu conceito de différance, o conceito de performativo de Austin insistiria na intencionalidade do enunciado - o que, para Derrida, seria incompatível com o conceito de comunicação. A enunciado performativo demandaria a intencionalidade consciente do sujeito no ato ilocutório. "Por isso, a comunicação performativa torna-se comunicação de um sentido intencional, mesmo se este sentido não possui referente na forma de uma coisa ou de um estado de coisas anterior ou exterior" (ibid., p. 364).

Derrida insiste na questão da incomunicabilidade do conceito de comunicação, aproximando-o aos seus conceitos de escrita - que não cede a uma hermenêutica - e disseminação. Logo, pode-se deduzir uma íntima relação entre o conceito de comunicação e a différance. Entretanto, este momento da pesquisa quer mais apresentar um mapeamento da tematização do conceito de comunicação pela filosofia, do que a elaboração de um exercício exegético sobre o conceito de comunicação na obra deste filósofo francês.

O ensaio de Derrida pode ser lido como uma abertura para revisão conceitual da comunicação a partir de uma leitura crítica do performativo. Ele não desenvolve uma proposta de um outro conceito de comunicação, mas aponta caminhos ao modo de uma negação: "enquanto escrita, a comunicação, se nos mantivermos fiéis a esta palavra, não constitui o meio de transporte do sentido, a troca de intenções e querer-dizer, o discurso e a 'comunicação das consciências'"' (ibid., p. 371).

A necessidade de se pensar o reverso da intencionalidade - a passividade - na experiência comunicativa também é uma marca do texto Algo assim como: comunicação... sem comunicação, do filósofo Jean-François Lyotard. O ponto de partida para a sua reflexão é a analítica do sublime de Kant, mais precisamente o conhecido parágrafo 40 da Crítica da 
Faculdade do Juízo, intitulado "Do gosto como um tipo de sensus comunis" (KANT, 1991, pp. 213-218), no qual o filósofo alemão afirma que o gosto é a faculdade de julgamento a priori daquilo que atinge os sentidos e que procede de uma representação universalmente comunicável sem a mediação de conceitos.

Uma comunicação não conceitual ou imediata é incompatível com uma noção de comunicação como transmissão e controle de informações. Ao observar os discursos e produções artísticos que exaltam a interação, Lyotard questiona o lugar da passibilidade da comunicação com a obra de arte (LYOTARD, 1991, p. 110 e ss.). Essa dimensão anterior à qualquer controle e intencionalidade é o que caracteriza a abertura necessária para a experiência comunicacional. É a dimensão ético-estética do conceito: um espinho cravado em sua própria pele.

Texto fundamental para as teorias da comunicação contemporâneas, este ensaio de Lyotard executa um duplo gesto: de um lado, ele aponta para aquilo que se retrai nas abordagens processuais da comunicação, como a presença de uma ausência; e, por outro lado, ele recupera com Kant essa dimensão ignorada: o aspecto sacramental do conceito de comunicação e da experiência comunicacional podem encontrar abrigo na estética, a partir da concepção de uma comunicação sem a mediação de conceitos.

O retorno a Kant também revelou que o desdém conceitual da filosofia para a palavra comunicação era apenas uma ilusão. Além da $\kappa o \iota v \omega v i ́ \alpha$ e da communicatio, tematizadas pela filosofia clássica e pela escolástica, uma outra palavra alemã para comunicação, a Mitteilung ${ }^{42}$, foi largamente utilizada pela filosofia dos séculos XVIII, XIX e XX (RITTER \& GRÜNDER, 1976). A Crítica do Juízo de Kant parece ser o primeiro momento no qual a comunicação (como Mitteilung) assumiu um papel relevante na filosofia moderna ocidental. Logo o conceito foi integrado à nascente filosofia da linguagem alemã, com Herder (1986) e Humboldt (2003).

Contudo, o conceito de comunicação só adquiriu o status de categoria filosófica com a filosofia da existência e, posteriormente, com o desenvolvimento da fenomenologia por Edmund Husserl e seus desdobramentos como, por exemplo, a Begegnungsphilosophie [filosofia do encontro] de Martin Buber, a ética da alteridade de Emmanuel Levinas e a

42 A palavra alemã Mitteilung e o verbo relacionado mitteilen são traduções germânicas das palavras latinas communicatio e communicare. Por extensão, tanto o adjetivo mitteilbar como kommunizierbar podem ser traduzidos como "comunicável". Entretanto, o emprego da palavra Mitteilung foi mais frequente nos séculos anteriores ao XX. Atualmente, a palavra Mitteilung é mais utilizada como "comunicado" (oficial, jurídico etc.), "recado" ou "mensagem"; da mesma forma, o verbo mitteilen significa "comunicar", utilizado tanto no sentido de transmitir um comunicado, de enviar um recado etc., quanto o de comunicar-se. 
fenomenologia da responsividade de Bernhard Waldenfels.

Do lado da filosofia existencial podem ser elencados tanto o filósofo dinamarquês Søren Kierkegaard e sua comunicação indireta, quanto o filósofo alemão Karl Jaspers, o pioneiro em tratar a comunicação (desta vez como Kommunikation) como um conceito fundamental para a filosofia. Nos próximos tópicos são realizados dois pequenos resumos sobre a importância destes dois filósofos para a subversão do conceito de comunicação como transmissão de uma mensagem e de um sentido. Devido às transformações da comunicação empreendida pela fenomenologia e a sua elaboração da categoria filosófica do outro, a sua importância para a reflexão do conceito de comunicação é o objeto de estudo da segunda parte deste trabalho.

\section{Søren Kierkegaard e a comunicação indireta}

O filósofo dinamarquês Søren Kierkegaard $\left({ }^{*} 1813\right.$ †1855) é conhecido por tratar de temas que até então não haviam sido tocados - ou abordados apenas marginalmente pela filosofia, como por exemplo a ironia, a angústia e o desespero. Considerado o precursor do existencialismo, Kierkegaard toma a existência do ser humano singular como seu principal objeto. O humano só pode ter existência como sendo si mesmo - um indivíduo que é livre ao fazer suas próprias escolhas entre as várias possibilidades da existência. Mas discorrer sobre o indivíduo não significa ignorar o voltar-se para o outro, não significa ignorar a comunicação. Ao contrário, é a partir do indivíduo que Kierkegaard esboça um conceito ético-existencial de comunicação. Não é por acaso que alguns estudos contemporâneos reafirmam a necessidade de realocar a obra de Kierkegaard dentro das teorias comunicacionais (Cf. BODE, 2009; CATTEPOEL, 1992).

O objetivo deste tópico não é discorrer sobre a filosofia de Kierkegaard (seus principais conceitos e desdobramentos $)^{43}$, mas esboçar um rascunho daquilo que poderia ser identificado como sua teoria da comunicação, com o intuito de traçar alguns pontos de contato com a teoria negativa proposta neste trabalho. Antes de tudo, assume-se que a obra de Kierkegaard tem um potencial canônico para uma teoria negativa da comunicação, mas que, devido ao aspecto panorâmico deste trabalho, um estudo monográfico sobre 
Kierkegaard e a comunicação permanece como um desdobramento urgente da proposta de uma teoria negativa da comunicação.

Como escrito anteriormente, para o filósofo dinamarquês cada ser humano é um ser singular. Por sua vez, desafio da comunicação é o de fazer com que um outro ser humano atente para o fato de que ele só pode encontrar-se em uma existência verdadeira se ele se reconhecer como ser singular. O "si mesmo" - e por extensão, o ser humano - é uma síntese: "O si mesmo é uma relação que se relaciona consigo mesma. (...) O ser humano é uma síntese de infinitude e finitude, de temporal e eterno, de liberdade e necessidade, em suma, uma síntese. Uma síntese é uma relação entre dois" (KIERKEGAARD, 1997a, p. 13). E mais adiante, Kierkegaard complemente: "Uma tal relação, que se relaciona consigo mesma - um si mesmo - tem que ser colocada ou por si própria ou por um outro" (idem).

A existência assume o sentido de criação e de escolha. Cada indivíduo deve produzir sua própria verdade, experienciar sua própria existência. Justamente para evitar a armadilha solipsista que ameaça qualquer filosofia subjetiva, Kierkegaard lidou insistentemente com a problemática da comunicação, mais precisamente da comunicabilidade de uma verdade subjetiva e que não pode ser diretamente comunicável. Mesmo sem abordar o conceito de comunicação de forma sistemática ou programática, ou ainda sem produzir qualquer texto exclusivamente dedicado ao tema, uma teoria comunicacional pode ser derivada da sua obra.

Tal teoria pode ser apreendida não apenas pela dimensão conceitual, mas pela sua dimensão metodológica. Kierkegaard não apenas escreveu indiretamente por pseudônimos, mas sua própria escrita - no limiar da literatura, da filosofia e da teologia - é inclinada ao ao outro: ele produz um tratamento socrático do leitor. Isso quer dizer que, inspirado pela maiêutica de Sócrates, Kierkegaard busca realizar com o leitor - com o indivíduo - um movimento em que o próprio leitor encontre sua verdade, sua essência, sua existência em sua liberdade. Esse acolhimento ou provocação ética instaura aquilo que ele chamou de segredo da comunicação, cuja função é constituir a liberdade do outro e exatamente por esse motivo é que não pode ser comunicada diretamente.

Esse conceito de comunicação indireta, como explica Johannes Bode ${ }^{44}$, pode ser apreendido como uma obrigação ética de abertura ao outro: “A comunicação, que se trata

44 Como Bode ressalta, Kierkegaard não chegou a conceituar de forma clara, sistemática ou programática a "comunicação indireta", mesmo que tenha utilizado a expressão. Mesmo assim o termo ganhou força a partir de vários comentadores contemporâneos da obra do filósofo, seja interpretado como um método, seja como uma teoria em si. Cf. DISCHNER, 1997; GREVE, 1999; LÜBKE, 1990; NIENTIED, 2003; PURKARTHOFER, 2005; WESCHE, 2003. 
inteiramente do cuidado existencial do outro, deveria ser precedida em todo caso de uma escolha (não arbitrária) com a qual o indivíduo também carrega a responsabilidade e é consciente" (BODE, 2009, p. 41). Por isso, a função da comunicação é a de exibir a existência ao indivíduo, mas não a de fazer com que o outro exista e aceite sua liberdade, pois cada um deve realizá-lo por si próprio.

Tal movimento teórico-epistemológico fica evidente no livro Ou-ou: Um Fragmento de Vida (KIERKEGAARD, 1980), publicado em $1843^{45}$ sob o pseudônimo de Victor Eremita que assina como se fosse o editor do livro ${ }^{46}$. Considerado a primeira grande obra de Kierkegaard, Ou-ou foi constituído por textos e cartas identificadas como de uma pessoa A e uma pessoa B e através dos seus escritos são figuradas duas formas de existência delineadas pelo filósofo: a estética e a ética. O ser humano ético vivem na e com a comunidade - por isso, com responsabilidade diante dela. Por outro lado, o ser humano estético vive apenas para si. "Enquanto o esteta atenta, acima de qualquer outra coisa, para a maneira como ele faz (ou seja, se tem valor estético), o ser humano ético trata daquilo do que ele faz (ou seja, se é defensável eticamente)" (BODE, 2009, p. 38). Isso não quer dizer que o ser humano ético seja melhor ou tenha mais razão que o estético. A questão é justamente apresentar duas dimensões que não necessariamente se anulam e cuja reflexão e tomada de partido deve ser realizada pelo leitor da obra.

O comunicável que depende da linguagem permanece como determinação ética. A música, por sua vez, representa o grau mais elevado da estética. A problema da comunicação estaria em achar um ponto de equilíbrio, pois a forma de existência estética tende para o demoníaco.

O demoníaco é aquilo que fragmenta o diálogo, que não cria possibilidades para a realização existencial do outro em sua liberdade, é um desvio. A figura dos demônios na filosofia de Kierkegaard foi sistematicamente abordada por Jan Cattepoel. Em seu livro O demoníaco e a sociedade: Søren Kierkegaard como crítico social e teórico da comunicação ele defende a ideia de que o próprio filósofo dinamarquês já se considerava um teórico comunicacional, não apenas por se voltar para a possibilidade de comunicação de uma verdade subjetiva, mas como crítico da imprensa de suja época: “A crítica social de Kierkegaard é uma crítica da comunicação humana. De acordo com a concepção de

45 No mesmo ano, foram publicados mais dois livros sob pseudônimos diferentes: Repetição (KIERKEGAARD, 2007) por Constantin Constantius e Temor e Tremor por Johannes de Silentio.

46 Um ano após a publicação de $\mathrm{Ou}$-ou, o tema da comunicação - mais precisamente em que medida a verdade pode ser ensinada e aprendida (ou seja, a relação comunicativa entre mestre e aprendiz) - retorna em Migalhas filosóficas ou um bocadinho de filosofia, sob o pseudônimo de Johannes Climacus. 
Kierkegaard, a possibilidade da mentira também é dada com a linguagem, através da linguagem o ser humano engana a si mesmo" (CATTEPOEL, 1992, p. 285).

A liberdade, a intimidade e o bem ético são ameaçados pelo demoníaco: ele é a angústia diante da própria liberdade existencial. O conceito de demoníaco foi desenvolvido no livro $O$ conceito de angústia, publicado originalmente em 1844 sob o pseudônimo Vigilius Haufniensis. Para uma teoria da comunicação, o demoníaco também poderia ser compreendido "como um tipo de fechamento comunicativo" (BODE, 2009, p. 49).

A angústia revela ainda a dimensão existencial da comunicação, pois ela denuncia os próprios limites do pensamento, da capacidade de discernimento. A comunicação sofre com as disposições físicas e existenciais do ser humano: "A angústia não apenas dissocia o pensar, mas o singulariza. Logo, a generalização do significado linguístico é meramente a forma oca de comunicação, a qual o indivíduo deve pressupor para poder transmitir de maneira indireta um comunicado que é limitado por fim apenas ao seu horizonte" (GAMM, 2000, p. 98).

A comunicação direta de ilusões conduzem à angústia existencial. Elas atrapalham o desenvolvimento da indivíduo, que deve ser responsável nas suas escolhas diante da sua liberdade. A comunicação indireta é uma forma de abertura capaz de romper com a servidão, o fechamento do indivíduo. "A comunicação indireta deve até mesmo ser aplicada lá onde o outro se encontra, mas não por simpatia, mas sim para movimentar o outro em sua diferença para a realização da sua existência, para uma tomada de posição, para uma escolha a partir de sua liberdade" (BODE, 2009, pp. 158-159). Nas palavras de Kierkegaard: “A liberdade é permanentemente comunicante (mesmo quando se leva em consideração o sentido religioso da palavra [comunicar = receber a comunhão], não importa), a servidão será sempre mais fechada e não quer a comunicação" (KIERKEGAARD, 1984, p. 113).

Como explica Purkarthofer (2005, p. 64 e ss.), Kierkegaard concebeu em 1847 uma série de palestras sobre o tema da comunicação que - mesmo inconclusas - foram reunidas na obra $A$ dialética da comunicação ética e ético-religiosa (KIERKEGAARD, 1997b). Neste trabalho ele esboça um modelo próprio de comunicação, no qual ele diferencia 1. um objeto de comunicação; 2. um comunicante (emissor); 3. o receptor; 4. a comunicação como processo. Além disso, para determinadas comunicações, deve-se considerar 5. a situação; e 6. a atmosfera adequada. Quando a comunicação tem um objeto definido, ela é apreendida como a comunicação de um saber, quando não, ela é designada como a comunicação de uma capacidade, de um poder. Esta divisão corresponde à contraposição entre ciência e 
arte, na qual são contadas, para a arte, todas as formas de práticas. Por esse motivo a arte pertence também à ética. Por sua vez, "a comunicação [Mitteilung] que não pode ser suficientemente descrita sem uma reflexão sobre o emissor, o receptor, o processo, a situação e a atmosfera da comunicação [Kommunikation] não possuem consequentemente nenhum conteúdo claramente definido (objeto)" (PURKARTHOFER, 2005, p. 65) (ibid., p.65).

Quando tanto o emissor quanto o receptor são importantes, pode-se falar em uma capacidade estética. Quando o receptor é definitivo, fala-se em uma capacidade ética. No modo ético não há um emissor - no melhor dos casos um maiêutico (no sentido orig inal da palavra: aquele quem ajuda no parto). Logo, a partir deste modelo, tem-se que a comunicação de um saber e de uma capacidade correspondem à comunicação direta e indireta. A comunicação indireta está relacionada à problemática da forma e do conteúdo, que numa relação ética eles devem coincidir. Muito antes da teoria do double bind desenvolvida por Gregory Bateson na década de 50, Kierkegaard já atentava para que uma ordem direta e paradoxal como "Seja espontâneo!", por exemplo, não é comunicação alguma. Em seu conceito de comunicação encontram-se não apenas os domínios ético e estético, como a dimensão semântica e performativa - praxiológica - da comunicação.

Por fim, é necessário ressaltar um importante aspecto implicado no conceito de comunicação de Kierkegaard que é objeto desta tese de doutorado e que será retomado na terceira parte deste trabalho: a negatividade. O filósofo não foi apenas um dos primeiros a refletir sobre a comunicação como um conceito filosófico, como também a perceber sua inerente negatividade. A negatividade é fundamentada na própria existência caracterizada pela síntese entre finitude e infinitude. Na comunicação, ela pode ser percebida sua dupla reflexividade, sugerida por sua divisão entre forma e conteúdo: "Quando o pensamento encontrou sua expressão verbal correta, o que é alcançado através da primeira reflexão, então ocorre uma segunda reflexão que atinge a própria relação da comunicação ao que é comunicado e que reproduz a própria relação do que é existencialmente comunicado à ideia" (KIERKEGAARD, 1994, pp. 68-69). Isso pode ser verificado, por exemplo, na ironia, que é produzida pela tensão inscrita daquilo que se diz e do que se quer dizer. "A negatividade da comunicação é pensada na artimanha da dupla reflexão e, por esse motivo, esta comunicação - que em comparação com qualquer outra comunicação não parece ser alguma - é exatamente comunicação" (ibid., p. 68). A negatividade da comunicação é o que provoca o não fechamento do emissor: quando o que se quer comunicar está centrado no si mesmo, não há negatividade e, consequentemente, 
não há comunicação. É justamente a negatividade que fundamenta a comunicação indireta. Esta sustenta a responsabilidade diante do outro. Um cuidado necessário de aprendizado, de auxílio para que a liberdade de escolha e as possibilidades de existência do outro sejam garantidas.

O conceito de comunicação de Kierkegaard dá suporte a uma subjetividade não isolada, um indivíduo vive sua existência ao não apenas afirmar, mas também a de acolher a existência do outro. Ele busca não apenas equilibrar os aspectos éticos e estéticos, mas também a positividade e a negatividade da relação comunicativa. O deslocamento do olhar filosófico para a comunicação realizado por Kierkegaard e a necessidade de sua reflexão quando se coloca em evidência a existência humana produziu vários frutos no pensamento ocidental. Para citar alguns nomes (Cf. RITTER \& GRÜNDER, 1976, pp. 894-895), Hermann Cohen $\left({ }^{*} 1842\right.$ †1918) e seu conceito de correlação; Ludwig Feuebach ( ${ }^{*} 1804$ †1872), Ferdinand Ebner ( ${ }^{*} 1882$ †1931), Franz Rosenzweig ( $\left.{ }^{*} 1886 \uparrow 1929\right)$ e Martin Buber $\left({ }^{*} 1878\right.$ $\left\lceil\right.$ †1965) e a filosofia dialógica do eu-tu; Max Scheler $\left({ }^{*} 1874\right.$ †1928) e seus conceitos de simpatia e pessoa; Martin Heidegger $\left({ }^{*} 1889\right.$ †1976) e o conceito de Mitsein; Gabriel Marcel ( ${ }^{*} 1889$ †1973) e seus conceitos de participação, comunhão e presença; Jean-Paul Sartre ( ${ }^{*} 1905$ †1980) e o pour-autrui; e o filósofo suíço Heinrich Barth ( ${ }^{*} 1890 † 1965$ ) e seu conceito de coexistência. Mas foi apenas com o filósofo alemão Karl Jaspers $\left({ }^{*} 1883\right.$ †1969) que a comunicação ganhou status de categoria filosófica.

\section{Karl Jaspers e a comunicação existencial}

Se para Kierkegaard a comunicação, acima de tudo, tem uma função ética, para Karl Jaspers ela assume uma função ontológica e existencial: a comunicação não apenas cria condições para que o outro construa sua verdade e sua existência a partir de sua liberdade, mas a verdade só pode existir da comunicação entre dois seres humanos: "O que não se realiza em comunicação, ainda não é; o que por fim não se fundamenta nela, está sem fundamento suficiente. A verdade começa a dois” (JASPERS, 1989, p. 95).

Aluno de Edmund Husserl e amigo de Martin Heidegger (antes da curta aproximação deste com a ideologia nazista), Jaspers pensa a filosofia sob a perspectiva da 
comunicação. Se se pudesse afirmar a pertinência de uma filosofia da comunicação, suas bases certamente seriam encontradas em suas obras ${ }^{47}$.

Se Heidegger escreveu sobre a história da filosofia como esquecimento do ser, Jaspers aponta um outro esquecimento: o da própria filosofia - e sua consequente relação com a existência. Por sua vez, a existência só encontra sua justificativa na comunicação: "Existência é somente na comunicação de existências. O ser-si-mesmo, como ser-para-si que se isola, não é mais ele próprio. Só se vem para si quando, na comunicação com outro si-mesmo, este vem para si. (...) Porque nenhuma verdade que se isola é ainda verdade" (JASPERS, 1984, p. 120).

Assim, Jaspers faz da comunicação uma categorial essencial para a reflexão filosófica sobre a existência. A sua radicalidade no tratamento da comunicação - e Jaspers usa a palavra Kommunikation, em detrimento à Mitteilung - desloca-a para o fundamento da filosofia:

\begin{abstract}
A origem da filosofia pode até estar no deslumbramento em si, na dúvida e na experiência de situações-limite, mas, incluindo todos estes, a origem está em última instância na vontade por comunicação verdadeira [eigentlichen Kommunikation]. Isto se mostra, desde o princípio, no fato de que toda filosofia urge por comunicação [Mitteilung], por expressar-se, por querer ser ouvida, de que sua essência é a própria comunicabilidade [Mitteilbarkeit] e esta é indissociável da veracidade. O objetivo da filosofia só é alcançado na comunicação, no qual o sentido de todos os fins é, por fim, constituído: a percepção do ser, a iluminação do amor, a conclusão da paz [Ruhe] (JASPERS, 1989, p. 22).
\end{abstract}

Para Jaspers a existência só pode ser compreendida a partir da comunicação entre seres humanos: "eu sou apenas em comunicação com o outro" (JASPERS, 1973, p. 50). Por sua vez, ele diferencia entre dois tipos de comunicação: a comunicação factual do ser-aí [Daseinkommunikation] e a comunicação existencial [existentielle Kommunikation]. A primeira é facilmente identificável nas relações cotidianas de negociação, troca, interação. A segunda, anterior à primeira e fundamental, não existe empiricamente, mas é através dela em conjunto com o outro que o ser é conhecido e articulado. Se a comunicação do ser-aí pode ser estudada pela sociologia e psicologia, a comunicação existencial deve ser iluminada pela filosofia.

O conceito de existência de Karl Jaspers não pode ser confundido com o conceito de

47 Infelizmente, sua principal obra sob o título Philosophie - publicada originalmente em 1932 e dividida em três tomos: I. Philosophische Weltorientierung [Orientação filosófica do mundo]; II. Existenzerhellung [Iluminação da existência]; III. Metaphysik [Metafísica] - ainda não possui tradução para o português. 
ser, nem com o de ser-aí [Dasein]. Toda existência é sempre um poder-ser: há sempre a escolha, a liberdade se ser ou não. Assim, o humano seria o próprio ser-aí na existência possível. Consciência, liberdade e transcendência constituem, portanto, a existência que só se realiza na comunicação, já que o ser é sempre ser-com-o-outro.

A comunicação existencial não pode ser prescrita nem reencenada, pois é sempre única. Ela não é uma relação psicológica ou social, mas o encontro de duas existências, cuja situação de resposta a uma outra existência instaura o processo de existir, já que o "mim mesmo" é sempre insuficiente.

Para que a existência se revele na comunicação é necessário abertura. Esta por sua vez recai na solidão e na consciência. O princípio de solidão não implica o isolamento, mas sim, uma valorização do silêncio e de acolhimento do outro. A solidão é a consciência da disposição de uma possível existência, que somente se torna em comunicação. É tarefa da consciência ser o mediador entre estar para si e para o outro, fazendo nascer a disposição à comunicação.

A comunicação existencial não pode ter medidas definidas e diretas. Toda necessidade de prova permanece secundária: todos os elementos são o medium da comunicação e não as suas condições. O que é direto é sempre o medium que torna algo experienciável ou que pode ser experimentado. Na proposta de Jaspers pode-se então perceber os ecos do filósofo dinamarquês Søren Kierkegaard e seu conceito de comunicação indireta, já que para o alemão, falar em uma comunicação indireta significa dizer que todo comunicado que está lá e que pode ser dito permanece como o desimportante, mas ao mesmo tempo ele é o portador indireto do essencial.

Se ao tomar o conceito de comunicação como um fenômeno básico e situação-limite, Jaspers foi pioneiro ao introduzi-lo como categoria no discurso filosófico, por outro lado ele ainda permaneceu vinculado a categorias como sujeito e relação intersubjetiva, herdados da fenomenologia do seu mentor Edmund Husserl. Como explica o teórico alemão Erich Hörl (2005, pp. 209-210), a obra de Jaspers pode ser apreendida como a "última consequência de uma reformulação da ontologia sobre o solo de um pensamento do ser [Seinsdenken] no conceito de comunicação, o ser [Sein] pensado apenas como 'ser em relação', para além da 'ilusão ser [Wesen] isolado". Tal reformulação apresenta os limiares da reflexão sobre uma relação inter-subjetiva. Uma crítica desta relação e uma tentativa de se pensar o conceito de comunicação para além das categorias sujeito-objeto foram realizadas pela obra do filósofo francês Georges Bataille, que será retomado na última parte desta tese 
de doutorado.

Antes, faz-se necessário um pequeno estudo sobre a constituição da reflexão teórica sobre o outro e o papel da fenomenologia na formação de uma teoria da comunicação que se propõe a ressaltar os aspectos ético-existenciais da experiência comunicacional.

Infelizmente, na tentativa de se apresentar um corpo coerente de teorias que sustentem a proposta de uma teoria negativa da comunicação, o espaço para uma verticalização da filosofia de Karl Jaspers torna-se limitado. Um estudo monográfico sobre a importância da sua obra para as teorias da comunicação também é um desdobramento necessário dentro do proposto quadro teórico de uma teoria negativa comunicacional. 


\section{CAPÍTULO II. EX-}

PARA AMBAS AS MÃOS, ali onde as estrelas me cresciam, distante de todos os céus, perto de todos os céus:

Como

se vela ali! Como o mundo se abre para nós, no meio através de nós!

Tu estás, onde

teu olho está, tu estás acima, estás abaixo, eu descubro a saída.

Oh, este errante vazio hospitaleiro Meio. Separados, eu caio em ti, cais

em mim, um sobre o outro desabamos, nós vemos através:

ex- $\mid$ eis $\left.\right|^{49}$

(prefixo latino ex-, ação de tirar, saída, acabamento, ação de levar, privação ou negação, reforço)

1. Indica fora de, derivação, saída, separação, afastamento, apartamento em palavras de várias categorias morfológicas (ex.: exterritorialidade).

2. Quando unido por hífen a um substantivo, indica que o nome indicado deixou de ser aquilo que era (ex.: ex-mulher) ou de exercer o cargo ou função que tinha (ex.: ex-presidente).

48 ZU BEIDEN HÄNDEN, da / wo die Sterne mir wuchsen, fern / allen Himmeln, nah / allen Himmeln: / Wie / wacht es/ sich da! Wie / tut sich die Welt uns auf, mitten / durch uns! // Du bist, / wo dein Aug ist, du bist / oben, bist / unten, ich / finde hinaus. // O diese wandernde leere / gastliche Mitte. Getrennt, / fall ich dir zu, fällst / du mir zu, einander / entfallen, sehn wir / hindurch: // Das / Selbe / hat uns / verloren, das / Selbe / hat uns / vergessen, das / Selbe / hat uns - - (In: CÉLAN, 2003, p. 20).

49 "Ex-", in: Dicionário Priberam da Língua Portuguesa, 2008-2013, http://www.priberam.pt/dlpo/ex[consultado em 03/11/2013]. 


\section{Da semelhança, da complementaridade, da diferença}

Alteridade: característica de ser outro, do que é outro que não eu. Separados, eu caio em ti, cais em mim. Do latim alter, altera, alterum: o outro, o segundo. Tu estás onde teu olho está. Condição de possibilidade e impossibilidade de comunicação. Errante, vazio, hospitaleiro Meio. Entre Eu e Tu, proximidade e distância, ausência e presença: o medium. $O$ mundo se abre para nós, no meio. Aquilo que se opõe à identidade. O Mesmo nos perdeu, o Mesmo nos esqueceu, o Mesmo nos--

Situada no campo semântico da diferença, do estranhamento, da distinção, do diverso, a alteridade se coloca como o contraponto àquilo que permanece, que identifica, que absolutiza - é a quebra da totalidade. Sob o ponto de vista da lógica, a alteridade já implica uma negatividade, uma relação assimétrica e intransitiva: negação direta do mesmo. O "aquilo que é outro", portanto, se coloca como uma das noções fundamentais do pensamento ocidental, cuja mera precisão é impraticável ${ }^{50}$.

A noção de alteridade emerge da relação entre interioridade e exterioridade. Ela se refere - de forma genérica e a partir de uma oposição sumária entre o eu e o não eu - a tudo aquilo que vem de encontro a mim: "O sujeito, o meu próprio pensamento. O objeto, um golpe vindo de fora. O objeto é o outro: uma sensação, uma tração, uma fricção, uma dor" (LALANDE, 1999, p. 47). À primeira vista, tal conceito parece reinstituir a dualidade sujeito-objeto que boa parte do pensamento ocidental - de Nietzsche ao pós-estruturalismo francês ${ }^{51}$ - questionou. Mas como deve ser verificado no decorrer deste capítulo, o conceito de alteridade se estabeleceu como uma crítica à ênfase na autoconsciência absoluta e no seu suposto universalismo. Ou seja, ele serve de instrumento para algumas correntes do pensamento contemporâneo que buscam colocar o outro como o elemento constitutivo das relações eu-mundo, sejam elas de bases fenomenológicas, estruturalistas ou hermenêuticas,

50 "O idêntico não se define pela negação da diferença assim como a diferença não se define pela negação do idêntico; há aí dois conceitos que se implicam e que são a definição fundamental do pensamento. Contudo, deve-se notar que o idêntico é privilegiado em relação à diferença: a diferença pura é impensável (...). Mesmo assim, o privilégio da identidade não parece menos realíssimo: consiste em que a diferença é sempre imposta ao espírito como um problema a resolver, enquanto a identidade, pelo contrário, lhe dá satisfação, e resolve o problema. O movimento da inteligência faz-se do outro para o mesmo; e, por conseguinte, pode-se dizer que este último, indicando o sentido do esforço intelectual, exprime mais essencialmente a natureza do espírito" (LALANDE, 1999, p. 504-505)

51 Cf. PETERS, Michael. Pós-estruturalismo e filosofia da diferença. Belo Horizonte: Autêntica, 2000. 
cuja importância é posta em evidência a partir do combate ao eu monádico pela sua construção discursiva e pela localização histórico-cultural do sujeito.

Entretanto, o questionamento da relação sujeito-objeto como redução do segundo pelas categorias primeiro - o que eliminaria seu caráter de outro, portanto, a alteridade não deve ser confundido com a supressão dos polos eu-tu, figuração do encontro entre dois elementos irredutíveis, cujo espaço relacional surge como o próprio lugar da comunicação. Por isso, é necessário reivindicar a elaboração de uma interioridade como contraponto à consciência do sujeito cartesiano, pronta para constituir o mundo a partir de suas categorias.

Enxergar o lugar do outro: não pelos seus próprios olhos - impossibilidade fenomenológica - mas ao assumir sua importância na constituição do que chamamos de $\operatorname{mim}^{52}$. Tal noção de interioridade será delineada no subcapítulo dedicado ao filósofo franco-lituano Emmanuel Levinas, cujo pensamento conseguiu delimitar o lugar da alteridade no pensamento contemporâneo a partir de um intenso diálogo com a filosofia de Hegel, Husserl e Heidegger, afinando o debate sobre a relação eu-tu com a experiência de estranhamento, ou seja, aquilo que supera minha conceituação, meu entendimento ou minha capacidade de descrição. Com Levinas, portanto, o significado da expressão "alteridade" é deslizado para um outro inexorável. Distante de todos os céus, perto de todos os céus.

Mas a relação eu-outro apreendida sob a marca da alteridade nem sempre é assumida em termos de uma diferença radical. Como será apontado nos próximos tópicos, as correntes que reivindicam o termo como instrumental teórico são no mais das vezes incompatíveis. Através de uma pesquisa sob as lentes da filosofia do século passado pretende-se fundamentar o estudo da alteridade como o locus propício para se pensar uma comunicação negativa, apreendida como desejo de transcendência, ou seja, como um desejo de sair de si, de romper com o isolamento do eu por meio da abertura ao outro, de se lançar ao abismo entre o eu e o tu.

Da simples constatação da minha relação com o espaço e o tempo - do ato de dizer "aqui" e "lá" - brota a possibilidade do encontro com o outro que me mobiliza e me transforma: a experiência com a alteridade. Todo encontro também é confronto: a tensão e a incerteza irritam os horizontes, criam rachaduras no que já está estabelecido. É um

52 O pronome "mim" implica receptividade - "algo acontece a mim" - e participação num contexto maior que relativiza a figura de um "eu" centralizador de toda a experiência. 
defrontar-se singular com aquilo que não sou eu: um objeto, uma paisagem, outrem. É justamente esse último - a relação com um outro alguém - que se lança como um desafio para as teorias comunicacionais: este outro que me interpela e que faz de mim seu outro espelho distorcido e estilhaçado em todas as suas formas presenciais, telemáticas, artísticas: rastros de outra existência, destacada de mim, que me interpela, que sempre vai me questionar.

A elaboração do pensamento sobre a relação de estranheza com este outro - que também é fonte de intencionalidade e de sentido - é atribuída à Fenomenologia de Husserl (2001). Em suas Meditações Cartesianas ele afirma que, no nível do transcendental, “a explicação do outro não pode ser feita nos mesmos termos que a explicação da coisa e, no entanto, na medida em que o outro é para mim, ele é também por mim” (LYOTARD, 1967, p. 36). Husserl parte da noção de semelhança - do reconhecimento de outra consciência semelhante à minha - para a apreensão do outro. Daí a importância do seu conceito de empatia [Einfühlung], pois a experiência do outro só se dá através de uma experiência minha, de uma mediação.

Mas se o intuito for empreender uma genealogia da alteridade, não se pode evitar uma breve incursão no pensamento grego clássico. Portanto, pode-se dizer que algumas das primeiras ponderações escritas sobre a relação eu-outrem são encontradas no livro Ética $a$ Nicômaco, de Aristóteles (2006), especificamente nos livros VIII e IX, nos quais o filósofo discorre sobre as formas de amizade. A importância do pensamento aristotélico para o estudo da alteridade será objeto do próximo tópico. Entretanto, é interessante notar neste momento que, logo no início dos seus argumentos, Aristóteles aponta para uma espécie de taxonomia da relação eu-outro, agrupadas em torno dos nomes de Empédocles, Eurípedes e Heráclito e que, de certa forma, ainda podem ser utilizadas para delimitar a variedade de perspectivas para as discussões em torno do par eu-tu.

Com Empédocles, a $\varphi \imath \lambda i ́ \alpha$ [amizade] se caracterizaria pela busca de semelhantes: a relação com o outro é pautada pela comunhão entre iguais. Com Eurípides, Aristóteles (2006, p. 181 [1115b1-1514] ${ }^{53}$ ) ressalta a complementaridade: ao destacar a frase "quando a terra está seca, tem desejos de uma tempestade de chuva e quando o venerável céu está cheio de chuvas, tem desejos de se abater sobre a terra" o filósofo aponta para a base do discurso da relação eu-tu como fusão. Por fim, com Heráclito é ressaltada a relação pautada

53 A partir de agora, todas as referências ao livro Ética a Nicômaco, de Aristóteles, serão feitas respeitando a paginação da edição da Academia de Berlim de 1831, cuja numeração foi realizada pelo filólogo clássico alemão Immanuel Bekker, sendo utilizada pela maioria das traduções desta obra. 
na diferença, como mostram os três aforismos destacados pelo próprio Aristóteles: "O que se opõe, faz convergir", "A mais bela harmonia nasce das divergências"; "tudo nasce da contenda". Semelhança, complementaridade e diferença. Pontos de partida para a reflexão sobre a problemática do estar-junto.

Entendimento, fusão ou negação de qualquer denominador comum. No primeiro, a possibilidade de apreensão do outro depende de um plano comum, uma língua capaz de assegurar o consenso. No segundo, a diluição do eu-tu implica a constituição de uma comunhão estésica, uma fusão que formaria uma comunidade estética ou a que, em sua radicalidade, culminaria na eliminação da alteridade. No último, fulgura a diferença radical, na qual não o outro não pode ser assimilado pelo mesmo, entre eu e tu não há pontes, apenas abismos cuja precariedade das nossas formas de medialidade os torna cada vez mais evidentes. O outro só pode ser tematizado a partir dos seus vestígios.

A necessidade de caminhar entre veredas aparentemente irreconciliáveis pode ser uma tentativa de um outro caminho, capaz de dialogar com o par alteridade-outridade. Sumariamente entendidos como sinônimos ${ }^{54}$, pretende-se aqui delimitar uma diferença entre os termos ${ }^{55}$ para que eles possam representar na esfera deste trabalho duas posturas teóricas cuja relação é, no mais das vezes, problemática.

Logo, a outridade figura aqui como a possibilidade de um diálogo pleno: a realidade do outro pode ser traduzida e comunicada. Ela pressupõe a existência de um plano comum pelo entendimento e sustenta, portanto, a interpretação, o compartilhamento, a apreensão plural, a problematização contextual, a clínica. A outridade é o ponto de partida para a comunicação, a semiótica, a antropologia, a sociologia, os estudos culturais e a psicologia que se ocupam da hermenêutica do outro. E este outro não encarna apenas o encontro com um objeto, uma paisagem ou um outro alguém, mas abrange sobretudo o Outro, escrito com inicial maiúscula para representar a cultura e a língua, as realidades sócio-estruturais que nos habitam e nos confrontam.

Por sua vez, a alteridade figura a possibilidade de encontro com o inefável: a realidade do outro é irredutível e incomunicável - as palavras faltam ou porque ainda não existem ou porque não podem ser pronunciadas sem correr o risco de assassinar o que é outro. A alteridade situa-se, portanto, como o ponto de partida para a comunicação, a antropologia, a estética e a fenomenologia que buscam apresentar esse encontro com o 54 Também existentes em outras línguas, como no inglês [alterity-otherness] e no alemão [Alterität-Andersheit].

55 Cf. SIMÃO, 2010. 
outro de forma que seu próprio caráter insondável seja posto em evidência, sem reduzi-lo às categorias do mesmo. Por isso, ficam desarticuladas quaisquer possibilidades para um entendimento mútuo e abrangente. A relação eu-outro só pode ser aproximada, figurada, ficando excluídos quaisquer clínica e argumentos propositivos. A alteridade é uma experiência com o estranho: não é o encontro de um objeto que é estranho, mas com algo experienciado como estranho (WALDENFELS, 1997). Ou seja, o outro não é um mero objeto passível de compreensão ou redução às categorias do mesmo, mas uma experiência de estranhamento, de desalojamento, de intensidade, a partir de um encontro com algo "que não sou eu" e que me (des)mobiliza.

É exatamente a partir da caracterização da alteridade e da outridade como experiência que se pretende lançar uma ponte entre os termos: "Toda experiência tem suas condições de possibilidade e a experiência do estranho também está ligada a essas condições" (WEIDTMANN, 2011, p. 259). Dito com outras palavras, as formas de alteridade e outridade permanecem interligadas, pois as primeiras só podem irromper a partir de experiências prévias e já assimiladas pela segunda. Uma experiência intensa com o estranho não pode prescindir de um campo comum produzido a partir de outras experiências.

Por isso, o que se propõe com esse breve estudo sobre a alteridade é a investigação de um caminho "entre". Deve-se, de um lado, evitar a queda no apriorismo comunicacional, para o qual a comunicação humana é confundida com entendimento e transmissão, tomada como eficaz pela mera utilização da linguagem e dos media. Por outro lado, não se pode cair no solipsismo da falta de relação, apreensão e assimilação do outro, sem deixar de considerar o valor cognitivo da experiência de impossibilidade e estranhamento - pois ela mesma é uma experiência doadora de sentidos e que possibilitam o ruído necessário para o surgimento da diferença.

Portanto, a proposta elaborada neste trabalho reafirma o abismo entre o eu e o tu, mas ao mesmo tempo busca refletir sobre as possibilidades de sua superação ou supressão - factíveis, improváveis ou ilusórias. 
II

\section{A relação eu-mundo na filosofia clássica}

No pensamento grego da Antiguidade, ainda não há uma discussão clara sobre a relação eu-outro. Mas assim como toda empreitada teórico-conceitual do Ocidente, é na tradição grega que podem ser observados os primeiros olhares para a experiência de alteridade, encarnada nas formas de relação entre o mundo e as pessoas.

Este capítulo esboça um breve comentário sobre a ética aristotélica e sua contribuição para os estudos da alteridade, por ser considerada a primeira análise da relação eu-outra pessoa, na qual o outro é concebido a partir de um eu, pois deve sempre espelhar o seu melhor. "É somente quando Aristóteles toma o fenômeno da amizade como paradigma para as compreensões humanas, que se instaura um olhar especificamente dirigido à relação eu-outro na filosofia grega" (SIMÃO, 2010, p. 36) ${ }^{56}$. A relação entre duas pessoas sob o conceito de amizade foi caracterizada pelo pensador grego principalmente nos livros VII e IX da sua Ética a Nicômaco (2006) e este livro é o ponto de partida para o tópico seguinte.

\section{Aristóteles: amizade como semelhança e reciprocidade}

A análise ética possui um importante papel na obra de Aristóteles ( ${ }^{*} 384$ a.C. †322 a.C.). A ética (do grego ńӨoc [êthos],, que significa caráter, mas que em cuja origem guarda o sentido de "local familiar") se apresenta não apenas como uma conduta, como uma forma de relação com o mundo que, por ser uma prática, já fundamenta nossa existência - "Nós existimos na e através da atividade de uma operação específica” (ARISTOTELES, 2006, 1168a6) -, mas sobretudo como a própria condição para o homem se cumprir plenamente como ser humano. ${ }^{57}$ Para a filosofia aristotélica, o cumprimento de si é a felicidade. Logo, ela é a meta de toda relação entre dois seres humanos, cuja relação de amizade seria um meio de alcançá-la.

56 Para um estudo das relações eu-mundo do pensamento grego, cf. VOLKE, 1961.

57 Cf. CAIEIRO, Antônio de Castro. Apresentação ao Ética a Nicômaco (ARISTÓTELES, 2006, p.13-14). 
Mesmo apontando outros modelos de reflexão sobre a relação com o mundo e com as pessoas, vistos anteriormente sob os nomes de Empédocles, Eurípides e Heráclito, Aristóteles funda sua abordagem na relação de excelência ${ }^{58}$ a partir da simetria e harmonia entre os pares. Pode-se inferir a suposição de um self ou um eu autocentrado, cujas boas qualidades são espelhadas no amigo. Para o filósofo, a amizade existiria apenas entre homens de bem pelo simples fato de serem bons em si próprios. Os sentimentos de amizade e as características pelas quais as formas de amizade são definidas, portanto, resultariam dos comportamentos e das relações que o homem tem consigo próprio. "É a partir do amor a si próprio que todas as disposições de afeição e amor se estendem depois também aos outros"(1168b5).

A amizade é categorizada na ética aristotélica com base na utilidade e no prazer. Os que têm a amizade com base na utilidade gostam uns dos outros pelo bem que os outros Ihe fazem; os que têm uma amizade com base no prazer, gostam uns dos outros pelo próprio prazer que lhes dá, ou seja, não se gosta do outro por aquilo que ele é, mas por ser vantajoso ou ser agradável. Contudo, para o próprio Aristóteles, esses são os laços de amizade que mais facilmente se rompem, principalmente quando o outro se torna diferente ao longo do tempo ${ }^{59}$. São amizades baseadas no interesse ou na necessidade. "Toda amizade tem em vista um bem ou um prazer - um bem e um prazer que podem ser absolutos ou existir apenas através da vivência da amizade e é conformada por uma determinada semelhança"(1156b1/20). A amizade verdadeira e mais excelente se verifica apenas entre os melhores: cada qual recebe de retorno o mesmo que dá ou de modo semelhante.

Por isso, é importante lembrar que Aristóteles recupera em sua ética a acepção estrita da $\varphi \iota \lambda i ́ \alpha$, o que implica a reciprocidade de sentimento. "Apenas uma benevolência que admita reciprocidade de sentimento é amizade"(1148b1/34). Por isso não pode haver tal relação com seres inanimados e inferiores - o que caracteriza, por sua vez, a afeição. A reciprocidade como condição reforça o argumento de que a amizade pode apenas se manifestar entre seres do mesmo gênero. "Para que duas pessoas sejam amigas é necessário que se queiram bem uma à outra e se desejem mutuamente tudo de bom, mas de uma forma tal que isso não lhes passe despercebido" (1156a1).

A felicidade só pode ser alcançada com a harmonia da amizade excelente. Concórdia

58 Grosso modo, o conceito de excelência em Aristóteles faz referência ao aprimoramento das virtudes morais e intelectuais. Daí o discernimento ser destacado como uma faculdade de excelência moral, o que torna possível a conduta ética.

59 Já que a amizade é apreendida como uma prática, a mera distância não romperia seus laços, mas poderia ocasionar seu esquecimento. 
e a amizade, portanto, tornam-se praticamente sinônimos, pois a amizade com base na excelência é a única que pode existir sem conflitos, diferente na baseada na utilidade ou no prazer. De certa forma, já se encontra na ética aristotélica uma crítica a instrumentalização do outro, explícita na afirmação de que "todos os homens, ou a maior parte deles, desejam o que é nobre, mas escolhem o que é vantajoso. Nobre é fazer o bem sem esperar receber nada em troca; simplesmente vantajoso, contudo, é ser beneficiado" (1162b35). Concórdia, reciprocidade, igualdade, são princípios reguladores da relação de amizade e que, à primeira vista, caracterizam a relação eu-outro como uma relação eu-outro eu (alter ego), pois ela constitui um encontro especular entre um eu e um outro que reafirma a excelência deste eu:

Ao amarem o amigo, amam o seu próprio bem, porque quando uma pessoa de bem se faz amigo de outrem, torna-se num bem para seu amigo. As pessoas de bem amam o seu próprio bem e, assim, restituem, em conformidade, em parte igual o bem que querem e o prazer que dão. É, por isso, que também se diz que amizade é igualdade, sobretudo aquela que existe entre homens de bem (1157b5/3).

Por esse motivo, na relação eu-tu como figurada pela relação aristotélica de amizade, não há espaço para a transformação do mesmo pelo outro. Não há relação de conflito, de choque, de desmobilização, de assimetria. O próprio Aristóteles pressupõe algumas formas de amizade em que podem admitir diferenças entre os envolvidos: "entre alguém mais velho por alguém mais novo (por exemplo, a relação entre pais e filhos); entre o homem e a mulher; e em geral da parte de alguém com poder relativamente a quem lhe está subordinado" (1158b11). Mas eles se sustentam apenas se houver alguma forma de compensação da parte considerada inferior: "A parte melhor, superior em utilidade ou a respeito do que quer que seja, deve receber mais amizade do que a que oferece. Quando a afeição que nasce é oferecida ao outro de acordo com o valor merecido, só nessa altura se gera, de algum modo, uma igualdade, coisa que parece ser, então, próprio da amizade" (1158b11/25). Seguindo a sua pragmática, pode-se deduzir que quando a diferença se acentua, cessa a amizade. Assim, os que dão sua amizade de acordo com o valor e a dignidade de cada um são amigos mais duradouros. Deste modo, os que são iguais entre si serão mais amigos, porque procuram restabelecer a igualdade.

A relação é especular: a igualdade e semelhança são tomados como sinônimos da amizade porque através dos amigos conseguimos ver refletida a excelência que existe em 
nós. Todos têm amor próprio enquanto estão satisfeitos consigo e se acham excelentes.

É pois porque no excelente estão presentes cada uma das características essenciais na relação consigo próprio e porque o seu comportamento relativamente ao seu amigo é o mesmo que relativamente a si próprio (pois o amigo, na verdade, é um outro si próprio) que também a amizade parece consistir em alguma destas formas de comportamento e os amigos são aqueles que a detêm. (...) A amizade na sua forma extrema se assemelha ao amor-próprio (1166a31).

Mas não foi apenas na relação com uma outra pessoa que a noção aristotélica de amizade foi aplicada. O próprio filósofo expandiu seu debate para as relações sociais: "Na verdade, parece ser a amizade que mantém unidas as comunidades dentro dos Estados" (1155a1/20). Isto porque a amizade sustenta a necessidade de uma base mínima para o entendimento mútuo. É a partir da relação nuclear entre dois seres humanos - da relação eu-tu, caso se possa inferi-la - que parte suas considerações éticas sobre a formação de uma comunidade ao mesmo tempo em que evidencia a duplicidade desta relação: "o ponto a que chega a comunidade é o ponto até onde vai a amizade: e assim também o direito. E o provérbio 'bens de amigos, bens comuns' está correto. Porque a amizade radica na comunidade" (1159b30). E mais adiante, Aristóteles sentencia: "Todas as comunidades parecer ser assim partes da comunidade de Estado. E as espécies de amizade resultam das formas de comunidades correspondentes" (1160a28).

A concórdia só ocorre quando cada parte quer a mesma coisa para a outra parte. Daí a importância da amizade na constituição das relações humanas, porque há mais bens comuns a serem partilhados entre aqueles que se consideram iguais. Por isso que, para o filósofo grego, "as espécies de amizade conformam a natureza do respeito pelos direitos dos outros" (1161a20).

Logo, além de ser caracterizada pela semelhança e pela analogia, a amizade também se apresenta como uma relação de complementaridade: “(...) um amigo que é um outro si, fornece-lhe aquilo que ele é incapaz de arranjar apenas só por si” (1169b7). Para Aristóteles, a existência é mais feliz quando uma atividade é exercida com a ajuda dos outros e também dirigida para os outros. Por esta razão, não se pode cair na inferência de se considerar a amizade aristotélica como uma defesa de certo solipsismo ou como uma concepção isolacionista do homem (PRICE, 1989, p. 114).

Mesmo assim, não se pode esperar um instrumentário já bem acabado sobre a relação eu-outro, pois, além de não conseguir escapar ao cânone grego da lei da não 
contradição (SIMÃO, 2010, p.34), o próprio debate em torno do conceito de sujeito e sua relação com o mundo demoraria mais de dois milênios para entrar na pauta da Filosofia, com o cogito cartesiano.

Mas foi apenas com a Fenomenologia do filósofo alemão Edmund Husserl que a relação com o que não sou eu tornou-se mais evidente, a partir de seu questionamento fundamental sobre de que de forma eu sei - ou de que forma eu posso realmente saber que outros seres humanos (os outros) que eu encontro também são, como eu, seres conscientes e percipientes.

\section{III}

\section{Husserl e os primórdios da experiência de alteridade}

O filósofo tcheco-alemão Edmund Husserl ( ${ }^{*} 1859$ †1938) foi sem a menor dúvida um dos mais influentes pensadores do último século. Conhecido como o fundador da Fenomenologia, Husserl buscou reelaborar a filosofia como uma ciência capaz de propor um método rigoroso de descrição do mundo. Para que o foco deste trabalho não seja diluído em uma discussão sobre a vasta e complexa obra de Husserl, o objetivo deste tópico deve ser bem claro: apontar o momento em que o outro surge como uma questão para fenomenologia husserliana ${ }^{60}$.

Como base deste curto estudo foi escolhido o livro Meditações Cartesianas: Introdução à Fenomenologia (1987), cuja versão alemã foi publicada apenas postumamente em 1950. Husserl quis que esse livro servisse de introdução à sua fenomenologia ${ }^{61}$ e devido a várias alterações ele nunca chegou a ser publicado em vida. Originalmente, Husserl havia utilizado as Meditações como o material de uma série de conferências proferidas na Universidade de Sorbonne em 1929, cuja versão francesa - traduzida por Emmanuel Levinas e Gabrielle Peiffer - foi publicada em 1931.

A referência às meditações de René Descartes está diretamente relacionada à ideia de uma tentativa para se fundamentar uma ciência universal. Em sua busca por uma

60 Para uma visão mais geral da obra de Husserl, cf. PRECHTL, 1998.

61 Não por acaso este livro compõe o primeiro tomo da coletânea que reúne a gigantesca obra de Husserl em mais 41 volumes sob o título de Husserliana (a reunião das suas obras completas ainda não está concluída e a publicação de novos volumes vem sendo realizada desde a década de setenta). 
evidência - de uma verdade incontestável - para a fundamentação de uma filosofia rigorosa, Husserl analisa o cogito ergo sum cartesiano. Para o filósofo da modernidade, não se pode questionar o pensar porque o ato de fazê-lo, já é, ele mesmo, um pensar - logo, uma verdade incontestável. Husserl vai mais além: ele escreve que a dúvida precede o próprio pensar.

Através do seu método chamado de redução transcendental-fenomenológica - ou epoché - Husserl coloca o mundo "entre parênteses", ou seja, ele busca com isso eliminar qualquer preconcepção para colocar em dúvida qualquer acepção sobre o mundo e as coisas com o objetivo de ir em busca de suas formas de aparição, às coisas como tais. Tal exercício o conduz para a evidência do ego transcendental ${ }^{62}$, "o fundamento sobre o qual todo o conhecimento objetivo acontece" (HUSSERL, 1987, p. 28). Isso significa que tudo - o mundo, as coisas, as pessoas - são dadas como fenômeno à consciência: "Objetos são para nós, e são para nós o que são, somente como objetos de uma real e possível consciência" (ibid., p. 66). Essa consciência é, acima de tudo, intencional, ou seja, toda consciência é consciência de algo: ela é com-posta pelo objeto da intencionalidade.

A afirmação sobre a evidência da aparição das coisas somente como um fenômeno a uma consciência pode dar margem a acusações de uma teoria solipsista, fechada no sujeito consciente. Husserl estava ciente disso, ao ponto de ressaltar que tal aparente solipsismo transcendental é apenas um estágio filosófico necessário para "poder instaurar a problemática da intersubjetividade transcendental como um estágio sólido, mais alto, de uma maneira correta" (ibid., p. 32).

Quando o objeto da intencionalidade da consciência é um outro ego, o eu também se torna objeto de intencionalidade e sentido. Tal relação é de um outro tipo, que Husserl denominou de Fremderfahrung [experiência do estranho - do outro/de alteridade]. Esse foi o tópico do último capítulo das Meditações e que teve um grande impacto na recepção francesa de sua obra, cuja problemática do reconhecimento do outro disseminou-se nos textos daqueles classificados como os mais importantes filósofos do século XX, como Jean-Paul Sartre, Maurice Merleau-Ponty, Emmanuel Levinas, Jacques Derrida, Jean-François Lyotard e Jean-Luc Nancy.

$\mathrm{Na}$ conhecida quinta meditação cartesiana, Husserl discorre sobre uma teoria transcendental da Fremderfahrung. Em linhas bem gerais, o segundo ego não está apenas lá

62 Transcendental porque para conhecer o mundo ele não pode ter a mesma constituição que ele, ou seja, deve permanecer a uma outra categoria. 
como um já-dado, mas constitui-se como um alter ego. O "outro" ao mesmo tempo é objeto da minha intencionalidade e me faz objeto da sua intencionalidade. Como Husserl explica no §44 das suas Meditações (HUSSERL, 1987, pp. 96-97), o alter ego é um reflexo de mim mesmo, sem ser realmente reflexo e análogo a mim sem ser de fato análogo num sentido comum. O problema da empatia se instaura no momento em que um outro ego está lá para a minha consciência. Eu percebo o outro como objeto do mundo e como sujeito deste mundo, que percebe este mundo que eu também percebo, que me percebe como objeto e como sujeito deste mundo. Fenomenologicamente, só poderia perceber o mundo junto com o outro, mesmo assumindo a impossibilidade de ter a experiência de sua percepção de mim e do mundo.

Entretanto, a existência de uma teoria da intersubjetividade husserliana ainda é controversa. A acusação mais comum é a tônica solipsista da sua teoria - mesmo que ainda nas Meditações Cartesianas Husserl reafirmasse que solipsismo transcendental seria apenas um instrumento metodológico para se alcançar o conceito de intersubjetividade transcendental. Entretanto, como todos os escritos husserlianos sobre a intersubjetividade foram publicados postumamente (na reunião das obras do filósofo, conhecida como Husserliana, tratam do tema os tomos I [Cartesianische Meditationen], XIII, XIV, XV [Zur Phänomenologie der Intersubjektivität]), a tentativa de uma constituição teórica sobre a questão do outro em Husserl coube aos seus comentadores. A filósofa argentina Julia Iribarne (1994) escreveu um dos livros mais importantes sobre a questão intersubjetiva em Husserl, publicados em duas partes: La Intersubjetividad en Edmund Husserl, Bosquejo de una teoría, Vol. I (1987) e Vol. II (1988).

\section{Excurso: A Fenomenologia da Comunicação}

O termo fenomenologia da comunicação foi empregado em 1977 na publicação do quarto número da revista alemã Phänomenologische Forschungen, uma das mais importantes publicações internacionais de estudos fenomenológicos, cujo dossiê temático foi intitulado "Homem, Mundo, Compreensão: Perspectivas de uma Fenomenologia da Comunicação" [Mensch, Welt, Veständigung: Perspektiven einer Phänomenologie der 
Kommunikation] (ROMBACH, SEEBOHM \& SOKOLOWSKI, 1977). Organizado pelo filósofo Ernst Wolfgang Orth, então professor da Universidade de Trier, a intenção do dossiê foi a de abrir um espaço para a crítica fenomenológica à visão instrumental dos conceitos de informação e comunicação. A proposta de uma "fenomenologia da comunicação" buscava denunciar a insuficiência das teorias informacionais e comunicacionais dominantes (principalmente oriundas da matemática e da cibernética), acusadas de reduzirem a comunicação à linguagem, ao signo e ao código, como uma forma pronta para a simbolização de qualquer conteúdo, e que não dariam conta da situação da chamada cultura comunicacional, tensionada de um lado pela perfeição técnica e pela massificação dos meios de comunicação e informação e, de outro lado, pela crescente desorientação e perda de sentido. Além de Wolfgang Orth, o dossiê contou com textos dos filósofos Heinrich Rombach, Thomas M. Seebohm e Robert Sokolowski.

Em sentido estrito, pode-se afirmar que a abordagem da comunicação como um problema da fenomenologia já havia sido proposta pelo seu próprio fundador, o filósofo Edmund Husserl, na quinta meditação da sua obra Meditações Cartesianas (1929) intitulada "Desvelamento da esfera de ser transcendental como intersubjetividade monadológica" - , tanto ao definir o conceito de intersubjetividade transcendental, quanto ao fundamentar a experiência de alteridade [Fremderfahrung], na qual o outro (alter ego) também é fonte de intencionalidade e sentido.

Numa concepção mais abrangente, o termo fenomenologia da comunicação delineia todas as abordagens apoiadas nas teorias e métodos fenomenológicos de fenômenos considerados geralmente como comunicacionais e/ou mediáticos, tais como o cinema, a televisão, o rádio, a imprensa, a internet etc.

Como proposto pelo fenomenólogo Heinrich Rombach, ter a comunicação como problema central para a fenomenologia - como fenômeno-base da existência humana, ou seja, como estrutura geral do sistema de orientação das relações humanas - significa que ela deve ser estudada nas fronteiras de sua aparição com o objetivo de descrever as suas estruturas fundamentais. Este seria, portanto, o objetivo de uma fenomenologia da comunicação: a análise e a representação das camadas e instâncias mais fundamentais do fenômeno comunicativo.

A multiplicidade de etapas e superfícies é a própria condição de possibilidade da comunicação. O jogo infinito das relações deve ser considerado em relação a estrutura subjetiva transcendental, como proposta por Husserl, e sua descrição deve estar em 
correlação à redução eidética. Já o conceito de intersubjetividade transcendental deve assegurar a universalidade do fenômeno comunicativo, já que, segundo o argumento de Rombach, todo eu é ao mesmo tempo um nós, bem como todo nós também é vivido como um eu.

\section{IV}

\section{Da fenomenologia à xenologia}

O objetivo deste tópico é o de apresentar alguns desdobramentos da fenomenologia husserliana no decorrer do século passado que se desenvolveu em uma verdaderia filosofia ou teoria do outro, em uma xenologia (xenos, do grego: outro). Dentre vários filósofos que tematizaram a experiência de alteridade como um dos fundamentos da filosofia deve-se neste momento do trabalho ressaltar a obra do filósofo franco-lituano Emmanuel Levinas (1988, 1991, 1996, 2008) e, mais recentemente, do filósofo alemão Bernhard Waldenfels (1998; 1990, 1994, 1997, 1998, 2008, 2010).

A escolha desses dois autores justifica-se por conta da preparação de certo vocabulário conceitual para a última parte deste trabalho que, através da proposição de uma teoria negativa da comunicação, busca colocar os estudos comunicacionais como um dos campos mais profícuos para o estudo da alteridade.

\section{Emmanuel Levinas e a alteridade radical}

Foi o filósofo lituano naturalizado francês Emmanuel Levinas $\left({ }^{*} 1906\right.$ †1995) quem mais se aprofundou na reflexão filosófica da relação "Eu-Tu", encarnada na figura do rosto - condição fundamental para a comunicação. Com Levinas, pode-se apreender uma comunicação como proximidade ética, um encontro com um outro que não é pode ser concebido como uma fusão, mas antes como uma relação que não supõe nem a anulação da alteridade do outro, nem a supressão do eu no outro (LEVINAS, 2008). Para que a comunicação possa ocorrer, é necessário um acolhimento da irredutibilidade deste outro 
que interpela o eu - de forma concreta, como um corpo que surge diante do mim - e que se nega a qualquer evasão.

Emmanuel Levinas reclama por uma ética como a filosofia primeira - em detrimento da ontologia. Tal é o ponto de partida para a sua principal obra, Totalidade e Infinito, publicada originalmente em 1961. Para ele, a ontologia - base de toda filosofia ocidental que busca a verdade no desvelamento e na interpretação do Ser - significa a "redução do Outro ao Mesmo, pela intervenção de um termo médio e neutro que assegura a inteligência do ser" (LEVINAS, 2008, p. 30). O mesmo é a figura da totalidade, do Uno, do solipsismo, do fechamento em si. Uma filosofia que toma a ontologia como ponto de partida, seria uma filosofia de dominação e do poder. Conhecer ontologicamente - e, poder-se-ia acrescentar, hermeneuticamente - seria, portanto, a eliminação da alteridade. Por isso, para Levinas, um pensamento universal, que eliminasse a diferença fundamental e radical do outro, dispensaria a comunicação. A alteridade proposta na obra de Emmanuel Levinas inaugura uma ética intersubjetiva que fundamenta a própria constituição da interioridade. $\mathrm{O}$ eu não se sustenta sozinho. Só a partir do encontro com o completamente outro é que ocorre a formação da subjetividade.

Para a superação da totalidade, da ideia de redução do outro no mesmo, é introduzida a noção de infinito. Pensar o infinito é pensar o que não se pode pensar. É aquilo que excede o eu, que o transforma em um mim, que o destrona como o senhor da experiência. A experiência de alteridade instaura uma relação transcendente, cujo desejo pelo infinito é metafísico. É bom notar que Levinas não utiliza o adjetivo metafísico para designar algo que remete a um plano superior ou ainda a algo cujo significado estivesse para além da aparição. A metafísica é uma relação entre termos irredutíveis, cujo movimento é transcendência e transcendente. A transcendência indica a separação desses termos, que permanecem isolados e sem nenhuma totalidade que os englobe. Ela rivaliza com a objetividade. É a exterioridade absoluta, cujo movimento dá-se em direção ao exterior.

O conceito de outro remete a algo que está além do mesmo, ou seja, da totalidade do meu ser - é aquilo que me escapa: o outro é pura exterioridade. A relação entre o eu e o outro é uma relação de desencaixe, não é uma relação de falta. É a impossibilidade de apreensão e representação. A radicalização dessa relação, o absolutamente outro, é o outrem, cujo rosto me abre a possibilidade de infinito. Outrem é aquilo que me ultrapassa absolutamente, que não faz número comigo: “A coletividade em que eu digo 'tu' ou 'nós' 
não é um plural de 'eu'. Eu, tu, não são indivíduos de um conceito comum. Nem a posse, nem a unidade do número, nem a unidade do conceito me ligam a outrem" (LEVINAS, 2008, p.25). O eu é e permanece separado desse outrem. O outrem é aquilo que não sou eu e sua presença se impõe ao mim e ultrapassa-o infinitamente. É aquilo sobre o qual o eu não pode mais poder.

A distância entre eu e outrem é caracterizada por Levinas como a presença do infinito, uma forma de aparição que precede qualquer significação. O face a face é o acesso ao homem em sua estranheza. Outrem interpela, ele fala, ele fala ao mim. Em uma situação em que a diferença e o estranhamento entre dois universos - duas pessoas - não existisse, a linguagem não seria mais necessária: "Há linguagem, porque não existe nada de 'comum' entre aqueles que se exprimem, separação que é suposta - não superada, mas confirmada em toda palavra verdadeira" (ibid., p. 103). A linguagem revela a dimensão assimétrica da comunicação, logo ela é uma relação transcendente, uma relação de exterioridade. "A palavra afirma o abismo existente entre 'eu' e 'outrem' e ela ultrapassa o intransponível, mas sem aboli-lo nem diminuí-lo" (ibid., p.114). Um espaço que impede a reciprocidade e produz uma diferença absoluta de níveis entre os termos em comunicação. Todo discurso verdadeiro não é uma conversa entre iguais. Por isso, o acolhimento do completamente outro assume a forma de ensinamento: não é mais uma relação Eu-Tu, mas Eu-Vós. "A exterioridade coincide, portanto, com um domínio. A minha liberdade é assim posta em causa por um Mestre que a pode bloquear. A partir daí, a verdade, exercício soberano da liberdade, torna-se possível” (ibid., p. 92).

Por sua vez, seu conceito de rosto (visage) ressalta o caráter imediato da experiência de alteridade. Ao mesmo tempo uma presença viva, uma expressão e algo concreto, o rosto também é uma manifestação, uma revelação, uma epifania. Acima de tudo, o rosto é uma relação ética que põe a liberdade do eu em questão.

É a partir da independência entre os interlocutores que Levinas funda sua comunicação no diálogo, cuja irreversibilidade entre Mim e o Outro supõe, contudo, uma abertura a partir da proximidade, ou em outras palavras, da responsabilidade diante do outro. Uma relação de "substituição" que põe em relação elementos irredutíveis. "O diálogo, assim, para ele, é algo que transcende a distância sem suprimi-la, sem recuperá-la como o olhar que busca a englobar, a compreender. Eu e Tu não podem ser objetivamente capturados, não há 'e' possível entre eles, não formam um conjunto” (MARCONDES FILHO, 2007, p. 66). 
O diálogo como abertura indica, antes de tudo, que a comunicação não implica nenhuma transmissão de conhecimento, nem mesmo apreensão de um sentido. "É acima de tudo um comunicar a comunicação, um sinal para dar sinais, e não a transmissão de algo a uma abertura" (LEVINAS, 1991, p. 119). É na experiência da comunicação em que o mesmo acolhe o rosto do outro. Para o filósofo este encontro com o rosto do completamente outro seria a própria fonte da significação. Portanto, a comunicação para Levinas, seja como substituição, acolhimento, solicitação, proximidade, abertura ou ensinamento, funda-se a partir do outro numa situação de encontro - de face a face. O outro está no começo da experiência. Entretanto, o eu só pode acolher a alteridade radical a partir da sua própria interioridade constituída (um mim): "é a partir de mim e não por comparação do eu com o Outro que eu lá chego" (LEVINAS, 2008, p.112).

Com a filosofia de Levinas, pode-se refletir sobre a comunicação como uma experiência de alteridade. Tal experiência dá-se ao mesmo tempo em uma dimensão ética e uma dimensão estética. "Seu fundamento forma a experiência estética no sentido de contemplação de um rosto, que como tal realizado e aceitado, contém ao mesmo tempo uma dimensão ética" (MERSCH, 2007b, p. 50).

Há portanto a reversão da intencionalidade husserliana. A passividade inaugura uma dimensão que não tolera qualquer definição ou identificação. O "como" ou o "o que" que transformam uma experiência em narrativa é substituída por um "que", do qual se instaura a inefabilidade: a experiência de alteridade radical é uma experiência que ocorre de forma mística, extática ou epifânica. A passividade revela a impossibilidade de dissolução da diferença que fundamenta a comunicação.

Mas o que significa encontrar-se com o outro em uma experiência de alteridade como passividade radical? Como abordar uma experiência que reclama pela preservação do seu mistério? Como pensar a relação de alteridade para além do impasse da inefabilidade instaurado por Levinas?

A fenomenologia da responsividade de Bernhard Waldenfels apresenta um dos mais consistentes estudos sobre as categorias do outro [Anders] e do estranho/estrangeiro [Fremde] na filosofia contemporânea. Infelizmente ainda pouco conhecido no Brasil, a obra de Waldenfels não apenas fundamenta epistemologicamente essas categorias através de um mapeamento desses termos na história do pensamento ocidental, como desenvolve uma teoria original capaz de apresentar uma fenomenologia da experiência de alteridade. 


\section{Bernhard Waldenfels e a fenomenologia da estranheza}

O filósofo alemão Bernhard Waldenfels (*1934), professor emérito da Ruhr-Universität Bochum, tomou como objeto de suas pesquisas a experiência de estranheza [Fremderfahrung], proposta por Husserl no seu livro Meditações Cartesianas. Diferentemente de Levinas, a problemática que surge na obra de Waldenfels não é a do outro [Anders], mas a do estranho [Fremde $]^{63}$. O par próprio-estranho não é idêntico ao par mesmo-outro. A estranheza ainda possui pontos de referência, como por exemplo de uma língua estrangeira, de uma outra cultura, de uma outra pessoa. Já a categoria do outro descreve a distinção e a falta completa de algo comum, como a distinção entre madeira e metal, por exemplo. Nas palavras de Waldenfels, "a estranheza pressupõe o domínio do próprio e o ser-próprio de um si mesmo (ipse, self); e este si mesmo não pode ser confundido com um mesmo (idem, same) que, por sua vez, é distinguido a partir de um terceiro" (WALDENFELS, 2006, p. 21).

A categoria do estranho é tratado pelo filósofo como um fenômeno-limite por excelência, porque ele não apenas desestabiliza qualquer ordem, como provoca a criação de novas estruturas. Por sua vez, todo processo de ordenação delimita novas fronteiras. Logo, tudo que está para além delas, é estranho a elas. O conceito de ordem está por trás de categorias como o si mesmo, o sujeito e o próprio. O que escapa a essas categorias é justamente o estranho, o alheio. O ser humano é um ser-limiar, por agir no espaço entre a criação de ordens e as suas desestabilizações.

A experiência de estranhamento, portanto, pressupõe certa normalidade das coisas. Ela é justamente o que está fora da ordem - o extra-ordinário - que ultrapassa o campo de possibilidades desta ordem. Por isso, o estranho pode ser descrito como a própria im-possibilidade - não no sentido ontológico ou epistêmico, mas de um não-poder vivido. Já o processo de agregar essa experiência à ordem que a sofre - ou seja, via denominação, classificação, localização, explicação etc. - é chamado de normalização (Cf. WALDENFELS, 2008). Esse processo, entretanto, não alcança o próprio estranhamento, mas apenas os seus efeitos. "Para qualquer ordem o estranho permanece sempre como um corpo estranho" (WALDENFELS, 2006, p. 33).

$63 \mathrm{O}$ campo semântico do adjetivo alemão fremd é muito maior do que o produzido pelas palavras estranho e estrangeiro em português, sendo por vezes traduzido como outro, alheio, desconhecido, forasteiro etc. 
A fenomenologia husserliana, através dos conceitos de horizonte de sentido e experiência, buscou descrever os limites da significação, mas sem anulá-la. Waldenfels, por sua vez, delineia uma outra fenomenologia, não mais baseada no sentido. Ele descreve a superação fenomenológica da esfera de um sentido intencional ou constituído por regras, que se realiza na resposta a uma demanda estrangeira - estranha - que não tem nem sequer um sentido, nem segue uma regra.

A experiência de estranhamento é descrita por Waldenfels como um hiperfenômeno (WALDENFELS, 2012). Isso significa dizer que ele apresenta um movimento negativo, ou seja, ele só se mostra na medida em que se recolhe. O estranho, por estar aquém do sentido e da regra, é ainda um fenômeno originário [Urphänomen], comparável a experiência de contraste. Como ressalta o próprio filósofo alemão (WALDENFELS, 1997, p. 90), Husserl já havia caracterizado o estranho como uma "acessibilidade comprovável do inacessível original". Afirmar a radicalidade do estranho significa dizer que ele não pode ser conduzido para o próprio nem pode ser suspenso em uma generalização.

Essa experiência de estranhamento tem basicamente duas dimensões: a do arrebatamento [Pathos] e da resposta [Response]. O arrebatamento descreve a forma da experiência de estranhamento, pois nossa atenção - em detrimento à intencionalidade - é assaltada. Ele é a marca da incontrolabilidade do tempo-espaço da experiência. Algo simplesmente nos toma, nos acontece: "Arrebatamento não significa que exista alguma coisa que aja sobre nós, muito menos significa que algo é compreendido ou significado como algo. Ele significa ao mesmo tempo menos e mais do que isso, ele se nega à alternativa de causalidade e intencionalidade em todas as suas formas tradicionais" (WALDENFELS, 2006, p. 43). O arrebatamento não depende de um "o quê" anterior nem mesmo um "para quê" posterior. No arrebatamento o sujeito não é mais sujeito, mas está sujeito (a) - para manter o sentido empregado por Levinas. O arrebatamento não é algo que seja passível de significação, compreensão, julgamento, rejeição ou aceitação. Mas ele "figura um tempo-espaço do qual nós fazemos tudo isso no momento em que respondemos a isso. Tudo aquilo pelo qual sou acometido e ao qual eu respondo não tem, como tal, qualquer sentido e não é regido por qualquer regra" (ibid., p. 50).

$\mathrm{O}$ arrebatamento é uma precedência que exige a posterioridade da resposta. $\mathrm{O}$ arrebatado "por algo" corresponde a uma resposta "a algo" - mesmo que na experiência de estranhamento esses dois elementos se negam a qualquer definição satisfatória. $\mathrm{O}$ arrebatamento e a resposta não são dois acontecimentos sucessivos - nem sequer dois 
acontecimentos. Eles descrevem uma única experiência de deslocamento de tempo. Essa experiência é antes de tudo ética, porque caracteriza não só uma recepção, como uma reação.

Entretanto, mesmo não pertencendo ao domínio do sentido nem sendo sujeitada a qualquer regra, a resposta possui uma lógica própria, que é diferente da lógica do entendimento (hermenêutica), da lógica da ação comunicativa (Habermas) e da lógica do ato intencional (Husserl). Waldenfels distingue quatro elementos que caracterizam a responsividade (a segunda dimensão, junto com o arrebatamento, da experiência de estranhamento): 1. a singularidade (de acontecimentos, que possibilitam outras formas de ver, de pensar e de agir); 2. a inevitabilidade, pois não se pode não responder (o não responder já é uma resposta $)^{64}$; 3. a temporalidade deslocada, definida como diastase: "O atraso genuíno da resposta enterra o primado de um presente originário. (...) A resposta acontece aqui e agora, contudo ela começa em outro lugar.(...) Resposta significa prescindir de uma primeira - e consequentemente também de uma última - palavra” (WALDENFELS, 2006, p. 65); 4. a assimetria, já que, assim como em Levinas, a experiência de estranhamento não fundamenta o diálogo, mas é um arrebatamento, um momento de passividade.

A resposta pode ser repetitiva/reprodutiva ou criativa/produtiva, entretanto, aquilo que a provoca ou a que $(\mathrm{m})$ ela se destina, permanece uma incógnita. A única certeza é a que que não se pode deixar de responder. Para que o tema da relação eu-outro abordada no início desta segunda parte da tese de doutorado seja retomado, a própria presença do outro obriga a uma reação. Há um imperativo, uma necessidade de uma resposta, um apelo para uma tomada de posição: "algo como no momento de uma quietude insuportável ou a pressão opressiva de um silêncio, bem como através do encanto que alguém emana apenas através da sua simples presença ao entrar em um espaço ou afastar-se" (MERSCH, 2007b, p. $54)$.

Como o filósofo Dieter Mersch defende, a própria responsividade inaugura a comunicação (MERSCH, 2010a, p. 255). A resposta é anterior a própria intencionalidade e dotação de sentido. Toda intenção de expressão, de indicação ou de insinuação está ligado a um pré-dado e já são respostas a uma exterioridade. "O significado é menos uma função da fala ou da intencionalidade ou da performance de ações, muito menos a estrutura da linguagem enraíza-se em uma relação ontológica com o mundo; antes o sentido acontece de

64 Essa dupla negação indica o procedimento indireto que marca essa experiência. Tal negatividade contida na experiência de estranheza (que pode ser estendida para a experiência comunicacional) é abordada na última parte deste trabalho. 
um espaço-entre de um responder que sempre já contém a resposta de uma resposta" (MERSCH, 2007b, p. 54).

Antes do eu, ex-siste o outro. Antes do emissor e da mensagem, está a resposta: a uma reivindicação, a uma demanda, a um desejo, a uma ausência, ao vazio. O outro é sempre pre-suposto. A resposta não é uma relação direcionada a ele, nem mesmo uma tentativa de sua apreensão, mas um movimento "que começa no outro, que o recebe, o acolhe para aceitar desta maneira seu 'dom', sua específica e insubstituível maneira de dar por isso que, ao contrário, precede o outro e se (ou seja, o si mesmo) permite ex-traviar sua própria identidade ou soberania" (ibid., p. 52).

O outro pré-cede o si mesmo. O si mesmo cede ao outro. Tal afirmação demanda a descrição de uma outra lógica comunicacional, cujo motor é a sua própria negatividade. Após a recuperação da dimensão existencial do conceito de comunicação (I. Communicatio) e da recolocação da problemática da experiência comunicacional dentro dos estudos de alteridade (II. EX-), tem-se constituído um cenário provisório para a proposta de uma teoria negativa da comunicação (III. Excommunicatio), cuja defesa é realizada a partir da exibição das estruturas de negatividade implicadas nos conceitos de medium, comunidade e comunicação. 


\section{CAPÍTULO III. EXCOMMUNICATIO}

Hoje eu atingi o reino das imagens, o reino da despalavra. Daqui vem que todas as coisas podem ter qualidades humanas. Daqui vem que todas as coisas podem ter qualidades de pássaros. Daqui vem que todas as pedras podem ter qualidades de sapos. Daqui vem que todos os poetas podem ter qualidades de árvores.

Daqui vem que os poetas podem arborizar os pássaros.

Daqui vem que todos os poetas podem humanizar as águas. Daqui vem que os poetas devem aumentar o mundo com suas metáforas. Que os poetas podem ser pré-coisas, pré-vermes, podem ser pré-musgos.

Daqui vem que os poetas podem compreender o mundo sem conceitos. Que os poetas podem refazer o mundo por imagens, por eflúvios, por afeto.

Manoel de Barros

A ex-comunicação poderia ser descrita como essa experiência de ser tomado pelo reino da despalavra. A tentativa deste último momento do trabalho é a de argumentar e defender teoricamente a pertinência deste conceito - já implicado na poesia de Manoel de Barros - para os estudos comunicacionais. É um assassínio da abertura do poema, para tornar produtivo no domínio teórico-conceitual algo que é essencialmente inoperante. A ex-comunicação é apenas algo que se mostra, mas não se deixa dissecar em elementos discretos. Ela só pode ser presentificada negativamente.

Para alcançar essa proposta, esta terceira parte do trabalho foi dividida em quatro capítulos: um sobre o conceito de negatividade e o método negativo e mais outros três sobre a revisão negativa dos conceitos de medium, comunidade e comunicação. Com isso espera-se apresentar as linhas gerais de uma teoria negativa da comunicação.

\section{I}

\section{Via negationis}

Mais que uma qualidade definida por uma adjetivação relacionada a algo ruim, o termo negativo empregado nesta proposta teórica sugere uma postura metodológica em consonância a certo movimento do pensamento ocidental que se ocupa com a abordagem de categorias precárias de indeterminação. Logo, para tornar essa opção conceitual mais 
clara, este tópico detêm-se à pegunta: mas, afinal, o que se quer dizer com os termos negativo, negação e negatividade?

Antes de mais nada, o negativo adjetiva formas de experiências cotidianas. Portanto, possui tanto um sentido factual (fragilidade, violência, repressão, finitude, vulnerabilidade, falibilidade, imperfeição, necessidade, ameaça, mortalidade, carência etc.) quanto de julgamento prático do que é negativo (culpa moral, limites de ação, conflitos de interesse etc.) que são experenciados e reconhecidos coletivamente como negativos ${ }^{65}$. Tomados como conceitos, o negativo, a negação e a negatividade assumem diferentes acepções a partir dos mais variados campos do saber em que exercem um papel fundamental, como, por exemplo, na lógica, na sintaxe, na ontologia, na ética e na estética ${ }^{66}$.

De maneira geral, negativo é o contrário do positivo e do afirmativo. Na gramática, a negação é vista como um constituinte facultativo, ou seja, como um possível complemento em uma oração base que se distribui por vários grupos de palavras, sejam pronomes, numerais, artigos indefinidos ou advérbios. Na lógica, a negação assume pelo menos quatro formas básicas: a) como ato de julgamento negativo, ou seja, como negação de uma afirmação, sentença ou declaração; b) como negação lógica (o contraditório) ela forma uma declaração $(p)$ com a ajuda do prefixo não, ou seja, o não $p(\neg p)$; c) como cópula negativa, cuja palavra não é usada para negar uma palavra conceito $(\mathrm{P})$ que, expressa na forma de sentença, temos: $x$ não é $P\left(x \varepsilon^{\prime} P\right)$; d) como conceito negativo, isto é, como conceitos em que aparecem na forma não-P, por exemplo, não-verde (BONSIEPEN, 1984, pp. 666-667). Deve-se ressaltar que este último sentido lógico é uma das camadas semânticas que o prefixo ex assume na teria proposta neste trabalho, no momento em que ele nega os correntes conceitos de comunicação e ressalta a importância de refletir sobre uma não comunicação.

Como ressalta Rentsch (2000, p. 9), em sua dimensão ontológica os fenômenos de negatividade surgem como rejeição, nulidade (o nada) e morte. Como meio ontológico de conhecimento, o negativo e a negação são tratados pelo pensamento ocidental desde os

65 Para a abordagem desses aspectos sob o ponto de vista de uma filosofia social e antropológica, cf. RENTSCH, 2000.

66 Para um abrangente resumo teórico-filosófico dos termos, cf. RITTER\&GRÜNDER, 1984, pp. 666-692. Sobre as relações entre teologia e negatividade, cf. THEUNISSEN, 1991. Para uma abordagem dos aspectos epistemológicos, antropológicos e filosóficos do conceito de negatividade, cf. RENTSCH, 2000; WEINRICH, 1975. Para as suas implicações estéticas, cf. BOHRER, 2002. Para a relação entre linguagem e negatividade, a partir das obras de Hegel e Heidegger, cf. AGAMBEN, 2006 . Para a discussão do conceito de negatividade em Hegel, cf. HEGEL, 2012a, 2012b; HEIDEGGER, 2009; NANCY, 2002; OTTMANN, 1981; SAFATLE, 2008. Para os desdobramentos dos conceitos na filosofia contemporânea, cf. HETZEL, 2009. 
primórdios da filosofia, presente, por exemplo, na obra de Parmênides de Eleia (*entre 520-515 a.C. †entre 460-455 a.C.) e a sua instauração da metafísica a partir da sua distinção entre o ser e o não ser ${ }^{67}$. Ou ainda com o sofista Górgias de Leontinos ( ${ }^{*}$ entre 490-485 a.C † entre 396-380 a.C.), que em sua obra principal, Sobre o não-ser ou sobre a natureza, já havia conduzido a negatividade ao seu limite ao afirmar que nada existe, pois nada pode ser de fato conhecido ${ }^{68}$. Essa oposição entre Parmênides e Górgias perdurou na longa querela entre filósofos e sofistas: enquanto esses últimos acentuaram que toda plena identidade do ser positivo é impedido por um tornar-se negativo, os filósofos por sua vez buscaram despontencializar o negativo, situando-o como mera troca de sinal. "Em certa medida, a filosofia ocidental se constitui como projeto de um recalque do negativo - no qual o negativo ganha acima de tudo o seu contorno conceitual e acompanha a filosofia através da história como um espinho cravado na própria pele" (HETZEL, 2009, p. 7). O não ser como a impossibilidade de pensamento se opõe à identificação entre o ser e o conhecimento, a qual - passando por Platão e Aristóteles até a filosofia medieval ${ }^{69}$ - era a grande bandeira da filosofia que se colocava à serviço de uma verdade metafísica e eterna. Somente com o início da filosofia moderna, particularmente com o pensamento de Hegel e Schelling, que o negativo assume um papel fundamental na filosofia.

\section{A dialética negativa do reconhecimento}

Foi apenas com o filósofo alemão Georg Wilhelm Friedrich Hegel $\left({ }^{*} 1770\right.$ †1831) que a negatividade surgiu como conceito filosófico ${ }^{70}$. Os conceitos de negação e negatividade

67 Parmênides contrapôs um ser idêntico, eterno e imutável a um não ser - aos modos de uma ordem ameaçada pelo caos iminente. "O não ser é o modelo perfeito daquilo que ameaça a identidade, a perfeição e a eternidade: a mudança, a diferença, a pluralidade, a contingência, a falta, a opinião e a prática” (HETZEL, 2009, p. 8). Por isso, o negativo foi combatido pelos filósofos da Grécia antiga e lançado ao mundo das meras aparências.

68 Ao contrário de Parmênides, que acreditava no conhecimento do ser único e imutável, Górgias dizia que "não há nada", portanto, nada de absoluto. Essa era sua primeira tese - a ontológica. A segunda, gnosiológica, afirmava a impossibilidade de conhecimento, mesmo se algo existisse. A última tese é a da impossibilidade de comunicação do ser - o que existiria seria apenas uma forma retórica flutuante e empírica, não fundamentada em verdades absolutas. Cf. GÓRGIAS, 1993. Assim, Górgias já havia refletido, na aurora do pensamento ocidental, sobre a impossibilidade de pensar a perfeição sem a falta, a eternidade sem o tempo, a identidade sem a diferença e o mesmo sem o outro.

69 Para um consistente estudo sobre o conceito de negativo na Antiguidade Clássica e na Escolástica, cf. HÜBENER, 1977.

70 Vale ressaltar que o objetivo deste tópico não é dissertar sobre a extensa e hermética obra hegeliana, mas 
aparecem em incontáveis momentos da sua vasta obra e fazem parte da sua terminologia filosófica desde os seus escritos de Jena (1801-1806). Em seu primeiro grande trabalho, a Fenomenologia do Espírito (1807) - livro que quer fundamentar "a ciência da experiência da consciência" (GAMM, 2012, p. 124), no qual são empreendidas análises individuais dentro de uma fundamentação sistemática da filosofia especulativa e da lógica - a consciência é confrontada com diversas formas de negatividade: "absoluta, natural, geral, existente [daseinende], simples, refletida em si, real, pura, que se move, não realizada, negatividade em si, negatividade do conceito, negatividade em geral” (BONSIEPEN, 1984, p. 679). Também em seu grande trabalho posterior, a Lógica da Ciência (1812-1816) surgem termos como negatividade concreta, absoluta, negação da negação, negatividade abstrata e negatividade em geral (ibid.).

De modo geral, o conceito de negatividade em seu sistema filosófico assinala o movimento de formação da consciência-de-si ou autoconsciência [Selbstbewusstsein]. A negatividade é uma relação negativa instaurada entre o si mesmo e o outro: "Dialeticamente, a filosofia hegeliana tenta explicitar todas as formas positivas do ser e da consciência sobre uma 'mediação do seu tornar-se outro consigo mesmo', um movimento (...) que Hegel caracteriza como 'pura simples negatividade' (HETZEL, 2009, p. 10). Como foi discutido no capítulo anterior, o desafio do reconhecimento do outro como outro em seu recolhimento absoluto foi um dos grandes debates filosóficos do último século. Mas foi somente com Hegel, com sua reflexão sobre a negatividade como processo de constituição da subjetividade ${ }^{71}$, que a consciência foi concebida a partir de uma autoconsciência que se dissocia de um outro e que é dividida em si mesma. "Diferentemente da tradição filosófica, que compreende a consciência primariamente teórica no sentido de uma subjetividade autoconsciente, a ideia de uma gênese do si mesmo - que é social e baseada na teoria do reconhecimento - é constitutiva para a dialética" (GAMM, 2012, p. 127). O mais importante

apresentar alguns aspectos da operacionalização do conceito de negatividade em seu pensamento. Para uma discussão introdutória sobre a obra de Hegel, bem como sua posição no chamado Idealismo Alemão cf. GAMM, 2012. Outro ponto importante deste capítulo é o de recuperar a relevância deste filósofo para o pensamento comunicacional atual que, devido à forte influência da filosofia contemporânea francesa, particularmente de Deleuze via leituras de Kojève (SAFATLE, 2008, p. 113), desconsidera apressadamente a sua obra sob a acusação de ser um sistema totalizante - nas famosas palavras de Hegel na introdução da Fenomenologia do Espírito: "A verdade é o todo" (HEGEL, 2012b, p. 14). Cabe ainda ressaltar que o pensamento hegeliano - como diálogo e crítica - está fortemente presente tanto em Levinas (como discutido na segunda parte deste trabalho), quanto em Georges Bataille que, como se verá adiante, foi quem mais consequentemente teorizou a comunicação sob o ponto de vista da negatividade.

71 Como observa Bohrer (2002, p. 162), Hegel define já no prefácio da Fenomenologia do Espírito a subjetividade como negatividade, ou seja, sob em determinação relacional e não em uma identificação substancial. 
nesse momento da pesquisa é ressaltar que, para Hegel, "o que incita o processo dialético é um bloqueio da experiência ou a relutância do si mesmo em abrir-se diante o outro, não importa em qual forma o outro se mostra: seja como mero objeto ou como alter ego, seja como natureza ou sociedade" (GAMM, 2012, p. 135).

É na separação que se dá a experiência da autoconsciência. Por sua vez, a consciência-de-si é concebida como a consciência de separação. Como explica Nancy (2002, p. 4), "é porque o mundo se sujeita como um mundo de separação que sua experiência assume a forma do 'si'. Esta forma é aquela de uma relação e um movimento. 'Si' quer dizer 'relacionando-se a si mesmo': é uma relação cujos termos não são dados". Mas ainda é necessário ilustrar melhor este movimento do si ao outro e do retorno a si como negatividade na obra hegeliana que caracteriza a dialética do reconhecimento. Em outras palavras, pode-se dizer que a consciência-de-si exprime o desdobrar do si mesmo até a outridade - o ser-outro [Anderssein] - e o redobrar da consciência para si que, como síntese, consegue tornar-se outro em si mesmo.

Com efeito, a primeira figura da consciência-de-si não é a identidade vazia do Eu penso ou a "imóvel tautologia" do Eu=Eu que, de Descartes a Fichte, a filosofia moderna colocara no centro do novo universo copernicano da razão. $\mathrm{Na}$ verdade, a consciência-de-si é reflexão a partir do ser do mundo sensível e do mundo da percepção e é, essencialmente, um retorno a partir do ser-outro. Esse ser-outro (o mundo sensível) é conservado no movimento dialético constitutivo da consciência-de-si como uma segunda diferença que se insere na primeira diferença com a qual a consciência-de-si se distingue de si mesma na identidade reflexiva do Eu. Assim, o mundo sensível se desdobra no espaço dessa identidade mas não mais como o objeto que faz face à consciência, e sim como o ser que, para a consciência-de-si, é marcado com o "caráter do negativo" e cujo em-si deve ser suprimido para que se constitua a identidade concreta da consciência consigo mesma (VAZ, 1981, p. 15).

O desejo é o motor deste movimento da consciência que tem como resultado a formação da consciência-de-si. O desejo, como negatividade, é uma falta. Entretanto, como argumenta Safatle (2008, p. 110 ss.), Hegel não trata da falta como mera privação ou carência; nem mesmo de um modo de ser da consciência, inaugurado pelo pensamento platônico, no qual a falta marca algo que simultaneamente está em mim, mas que não possuo, ou seja, a falta como transcendência do ser. O desejo é manifestação da infinitude. "Esta infinitude pode ser ruim, se a satisfação do desejo for vista como consumo reiterado de objetos que produzem um gozo que é apenas submissão narcísica (...) do outro ao Eu. 
Mas ela será infinitude verdadeira quando se confrontar com objetos liberados de determinações finitas" (SAFATLE, 2008, p. 114) ${ }^{72}$.

Por sua vez, a satisfação do desejo busca reduzir o outro à mera categoria de repositório do desejo do Eu. Mas quando duas consciências encontram-se nesta relação, há um conflito por reconhecimento. "Aqui a consciência faz verdadeiramente a sua experiência como consciência-de-si porque o objeto que é mediador para o seu reconhecer-se a si mesma não é o objeto indiferente do mundo mas é ela mesma no seu ser-outro: é outra consciência-de-si” (VAZ, 1981, p. 23). Hegel ilustrou esta tensão constitutiva da autoconsciência com a famosa dialética do senhor e do servo ${ }^{73}$, exposta detalhadamente na quarta parte da sua Fenomenologia do Espírito, intitulada Independência e dependência da consciência-de-si; dominação e servidão (HEGEL, 2012b, p. 104 ss.).

Como explica Henrique de Lima Vaz (1981), a dialética do senhor e do servo pode ser compreendida como uma parábola. De um lado, ela ilustra a unilateralidade do reconhecimento, na qual o senhor recusa apreender o servo como outra consciência-de-si, mas por outro lado, a parábola mostra como o servo consegue, através da superação do desejo - superação da satisfação imediata - pelo trabalho, tornar-se senhor do senhor, já que este encontra-se alienado da ação direta sobre o mundo que está, agora, mediada pelo servo: ou seja, "a consciência servil passa a ser a verdade da consciência independente" (VAZ, 1981, p. 21). Esse tipo de movimento não pode ser tomado como relação concreta, entre duas pessoas, mas como alegoria da luta pelo reconhecimento recíproco, cujo resultado vai em direção a um indefinível e que caracterizaria a intersubjetividade como cisão.

O ponto central aqui não é discorrer sobre essa relação dialética, que adquiriu diversas interpretações - passando por Karl Marx e toda tradição marxista do último século, até a psicanálise e a filosofia social. O que interessa aqui, deve-se insistir, é o papel da negatividade nesta relação intersubjetiva definida por Hegel. Por esse motivo, deve-se atentar ainda para alguns momentos da dialética do reconhecimento. Num primeiro estágio, há uma mera projeção da autoconsciência no outro: "Cada termo é um simples ser-para-si na sua imediatidade singular e, portanto, cada um aparece para o outro como um objeto ou o que está simplesmente diante - marcado com o caráter do negativo: o

72 A concepção hegeliana de falta como a manifestação da infinitude será retomada ainda neste capítulo para a caracterização de um conceito negativo de comunicação.

73 Para uma discussão mais detalhada desta questão, traduzida no Brasil frequentemente como a Dialética do Senhor e do Escravo, cf. VAZ, 1981. Para uma abordagem do papel do desejo na dialética do reconhecimento hegeliana, cf. SAFATLE, 2008. 
outro não se prova ainda como essencial para que cada um se constitua como efetiva e concreta consciência-de-si" (VAZ, 1981, p. 20). Aqui há apenas distância e diferença absoluta na desigualdade entre as consciências. Num segundo momento, ocorre a negação da outra consciência, uma supressão que guarda no si-mesmo o que é suprimido. Ou seja, a partir de uma dupla negação ocorre uma positivação que constitui a autoconsciência. É a relação para si a partir da negação do ser-outro: "em Hegel, a ontogênese do sujeito é o reconhecimento de uma anterioridade ontológica do conflito que se manifesta nesta ligação necessária entre subjetividade e negatividade" (SAFATLE, 2008, p. 105). Portanto, a negação da negação marca um movimento dialético e também o retorno deste movimento, caracterizado por uma suspensão ou sublimação [Aufheben $]^{74}$.

O pioneirismo de Hegel está em postular a reflexão sobre um negativo que por si próprio repousa sobre si mesmo positivamente, "de uma negação que converge em si mesma - mesmo que num primeiro momento apenas na forma de um movimento do nada para o nada produzido fora e dentro de si mesmo - que está na base da lógica da essência” (HÜBENER, 1977, p. 480). Assim, o poder da negatividade assume a forma de uma inquietude que ao ser tranquilizada (apreendida, absorvida pelo si mesmo - que se transforma), gera novas inquietações. Como conceito lógico-formal, o conceito de negatividade hegeliano tem duas dimensões fundamentais: "de um lado ele caracteriza o movimento de reflexão do sujeito até o seu próprio outro. Por outro lado, ele caracteriza o déficit recorrente na estrutura dos conceitos do ser [Seins-Begriffen], como consciência [Bewusstsein] e autoconsciência [Selbstbewusstsein]" (BOHRER, 2002, p. 163). Tal movimento lógico busca apreender (agregar ao si-mesmo) até mesmo aquilo que se encontra fora da lógica - marcas da dimensão da totalidade do projeto hegeliano.

Entretanto, vários filósofos e teóricos retomaram o pensamento negativo de Hegel na tentativa de exibir fenômenos para além da racionalidade, que escapam à discursividade ou mesmo à impossibilidade de apreensão deste outro - como na obra de Emmanuel Levinas, discutida no capítulo anterior. Mas as sementes para transformar a negatividade

$74 \mathrm{O}$ verbo alemão substantivado Aufheben ou o seu substantivo Aufhebung possui vários sentidos na língua alemã - muitas vezes contraditórios - como suspender, guardar, levantar, anular, sublimar. A palavra é muito cara ao pensamento de Hegel, que explorou os seus significados para a constituição da sua dialética: "O que se suspende não se transforma no nada. O nada é o imediato; algo em suspensão é, ao contrário, um mediato, é o não ente, mas como resultado que é proveniente do ser; o suspendido tem, portanto, ainda em si a determinação daquele que ele se origina. A suspensão tem na linguagem um duplo sentido que tanto significa reter, conservar, quanto, ao mesmo tempo, interromper, dar um fim. O próprio conservar já encerra o negativo em si ao retirar algo da sua imediaticidade e, com isso, de um ser aberto a efeitos externos. Logo, o que está suspenso [das Aufgehobene] é simultaneamente algo conservado [ein Aufbewahrtes] que apenas perdeu sua imediaticidade, mas que, por isso, não está destruído" (HEGEL, 2012b, p. 78). 
em um supraconceito capaz de articular vários modos do negativo ${ }^{75}$ já haviam sido lançadas pelo jovem Hegel quando, nos seus textos produzidos durante as disciplinas ministradas entre os anos de 1805 e 1806 em Jena sobre Filosofia Natural e Filosofia do Espírito, ele escreveu poeticamente sobre a noite como uma certeza imediata que nos abala. Nas palavras do filósofo:

O ser humano é esta noite, este nada vazio que contém tudo na simplicidade dela - uma abundância de representações, de imagens infinitamente variadas e que nenhuma lhe ocorre de maneira exata -, ou não estão como que presentes. [...] Nós encaramos esta noite quando olhamos o ser humano nos olhos - Noite adentro, que se torna terrível, aqui somos tomados pela noite do mundo (HEGEL, 1987, p. 172).

Esta noite representa ainda uma crítica do jovem Hegel ao pensamento esclarecido. Crítica que substitui a concepção de um encontro de todos os seres humanos em uma razão global e condicionante por uma ausência de qualquer pressuposição, ou seja, pela negatividade. "Todas as pessoas juntas são, a partir deste cenário, apenas a ausência de comunalidades, a 'noite', que se abre para mim no olhar do outro. Não é a reconciliação forçada que está no centro da ética esboçada [em Hegel], mas uma notável divisão positiva” (HETZEL, 2009, p. 9). A um movimento reconciliador na própria divisão. O reconhecimento do outro a partir da rejeição de suas propriedades e da aceitação do seu profundo recolhimento é devedor do pensamento hegeliano.

Essa negatividade conduz à negatividade mais radical - a não experiência, ou seja, a morte - que mais tarde vai remodelar o pensamento filosófico com a filosofia da existência (como visto no primeiro capítulo deste trabalho). Mas, como veremos mais adiante, é com o escritor e filósofo francês Georges Bataille que a negatividade radical vai assumir um papel definitivo para o conceito de comunicação.

O objetivo deste tópico foi o de abordar um aspecto do pensamento hegeliano - o seu conceito de negatividade - para apresentar a lógica intrínseca ao modelo teórico defendido neste trabalho que sustenta um olhar negativo sobre os conceitos de medium, comunidade e comunicação. O negativo é concebido, portanto, como uma ferramenta teórica capaz de ex-pôr aquilo que escapa à ontologia da comunicação: a definição do fenômeno comunicacional. Uma discussão mais demorada sobre os modos e categorias do negativo deve fornecer o aparato necessário para a caracterização do movimento executado 
pelo conceito de ex-comunicação.

\section{A inquietude do sentido}

A partir de reflexões sobre o negativo na obra hegeliana, o filósofo Jean-Luc-Nancy afirma que o "infinito trabalho da negatividade é a inquietude do sentido" (NANCY, 2002, p. 5). Em outras palavras, a negatividade é um processo infinito que desestabiliza toda e qualquer determinação (finita). O negativo possui a capacidade de expor as rachaduras de toda pressuposição, de qualquer já-dado. Com isso, Nancy reinterpreta o papel do absoluto na dialética hegeliana, assumindo-o como o único pressuposto possível: o absoluto é ser, é o estar aí, aqui e agora, é a concretude das coisas. É o todo que carrega a ruína da imobilidade. "Tal é a primeira e fundamental significação da negatividade absoluta: o negativo é o prefixo do in-finito, como a afirmação de que toda finitude (e cada ser é finito) é, em si, um excesso de sua determinação. Está em infinita relação” (ibid., p. 12).

O negativo é tratado neste trabalho de doutoramento como a lógica entranhada em categorias ou modos que ressaltam a indefinição, a impossibilidade de conceituação de um fenômeno. Tal lógica é expressa por um recolhimento - ou um bloqueio - do que é tratado como objeto e que escapa à estabilidade garantida pelo conceito. A epígrafe deste trabalho, o poema As três palavras mais estranhas, da polonesa Wisława Szymborska, expressa bem a tensão entre o nomear e a imediata ruína do que se pretende nomear implicada neste gesto. A presença de uma ausência é uma das marcas do negativo. É o que se recolhe no mostrar ou, quiasmaticamente, mostra-se no recolher.

Mas isso não significa uma total despotencialização investigativa. Dizer que algo não possui uma definição direta não implica que não possa ser estudado. O que está aquém ou além do discurso demanda um olhar indireto para sua exposição. Isso foi abordado logo na introdução deste trabalho, no tópico sobre a abordagem pós-hermenêutica. Os procedimentos para exibição das engrenagens negativas encontram seu lugar, por exemplo, na alusão, na tradução, na presentificação, na figuração, na reverberação, na criação de atmosferas. Assim como o escudo de Perseu, no seu encontro com a aterrorizante e encantadora Medusa. Apenas reflexos desfigurados, rastros, vestígios e sombras são passíveis de observação, sem que o fenômeno em curso corra o risco de ser petrificado. No 
espaço desta tese de doutoramento, esses elementos são corporificados com as noções de medialidade do medium, comunalidade da comunidade e comunicalidade da comunicação.

Deve-se neste momento insistir na abordagem desta lógica negativa da indefinição ${ }^{76}$, inerente a terminologias como ambivalência, sobredeterminação, imprevisibilidade, indisponibilidade, inefabilidade e contingência. Essas e outras palavras remetem a uma forma imediata de percepção, a uma evidência ${ }^{77}$, a uma revelação - uma forma de conhecimento sem a mediação lógico-proposicional do conceito e que, portanto, deságua em uma estética. Entretanto, há sempre o risco de que tal terminologia derivada das artes e das religiões reverbere apenas no vazio de um jogo de metáforas estéreis. Metodologicamente esses termos podem tornar-se produtivos quando conseguem exibir essa forma aparentemente imediata em suas fissuras. Epistemologicamente podem descrever fenômenos que escapam obstinadamente às abordagens das teorias da linguagem, como a voz, os gestos, as imagens, a escrituralidade da escrita ou mesmo a materialidade do signo $^{78}$.

A problematização destes fenômenos e dos limites de sua conceituação é colocada, principalmente, através de obras artísticas que atuam nos limites de suas aparições. Por este motivo o campo estético é tão importante para este tipo de pesquisa: a inquietude do sentido, os limites da materialidade e o limiar da experiência permitem de forma mais enfática a exibição da lógica da negatividade implicada no pensamento de uma ex-comunicação.

\section{Entre a palavra e o silêncio}

No âmbito deste trabalho, o conceito de negatividade é empregado para explicitar a impossibilidade de tematização de uma experiência comunicacional no momento em que ela ocorre. Quando um processo é caracterizado como comunicacional, significa que ele já

76 O filósofo alemão Gerhard Gamm, professor da Universidade Técnica de Darmstadt, é autor de consequentes estudos sobre a semântica e a lógica da indefinição na filosofia ocidental. Para ele, o devir indeterminável e reflexível de toda definição do saber e do agir é atualmente a principal dimensão da relação-de-si e da relação com o mundo. Cf. GAMM, 1994, 2000.

77 Aqui pensada não no sentido religioso, mas no sentido fenomenológico. Cf. HUSSERL, 1987, pp. 13, 15, 33, 59 et passim.

78 Para uma abordagem medial-filosófica desses e outros fenômenos, cf. KRÄMER, 2004; MERSCH, 2002; SCHWARTE, 2011. 
deixou de sê-lo. Não apenas no sentido de uma interrupção, mas também na forma de sua reflexividade. Seja qual for o resultado desta experiência - consenso, conflito, imobilidade, êxtase, aprendizagem etc. -, quando uma comunicação se realiza, já deixou de existir. O desafio, portanto, é o de conseguir exibir o potencial reflexivo do ato comunicacional no momento da sua experiência. Mas o que significa fazer uma experiência? Seria possível discorrer sobre a especificidade de uma experiência comunicacional? O objetivo deste tópico não é o de discorrer sobre as vicissitudes da aplicação deste rico conceito ${ }^{79}$, mas o de ensaiar algumas considerações sobre a sua importância para a proposta de uma teoria negativa da comunicação.

O que caracteriza uma experiência é sempre uma transformação. E por esse motivo, toda experiência implica uma negatividade fundamental: a mudança implica um conflito ou, para usar uma terminologia hermenêutica, uma superação do horizonte de expectativa (Cf. GADAMER, 1997). O movimento de retenção/suspensão do outro no si-mesmo ou o negativo e a negação da negação, explicitada pela dialética hegeliana, exibem esse momento de constante transformação em nossa relação com o mundo. A experiência marca uma situação-limite na qual, após a sua ocorrência, nada pode ser refeito ou restituído ao seu estado original: "Uma experiência, não importa como seja definida, não pode simplesmente duplicar a realidade interior prévia de quem a realiza, deixando-o exatamente como ele ou ela era anteriormente: algo deve ser alterado, algo novo deve acontecer" (JAY, 2005, p. 7)

Refletir sobre uma experiência é refletir sobre a processualidade, pois fazer uma experiência é estar no andar, estar a caminho, alcançar alguma coisa: "Fazer uma experiência com algo, seja com uma coisa, com um ser humano, com um deus, significa que este algo nos atropela, nos vem ao encontro, chega até nós, nos avassala e transforma" (HEIDEGGER, 2008, p. 121). Ou seja, ela evidencia a incapacidade do mesmo de operacionalizar o outro, que o interpela e supera-o. Se a reflexão recai sobre esse aspecto relacional, tem-se que toda experiência é provocada pelo outro, portanto, toda experiência é uma experiência de alteridade. Caso os estudos da alteridade sejam tomados como o lugar para uma teoria negativa da comunicação, tem-se que toda experiência é comunicacional no momento em que a comunicação é concebida como um momento singular, cujo encontro com a alteridade amplia e questiona horizontes, provoca interpretações,

79 Para um debate conceitual aprofundado sobre o termo experiência na história da filosofia ocidental, cf. JAY, 2005. 
reverberações e transformações posteriores, mas que no seu durante nada pode ser, de fato, agarrado $^{80}$.

A partir dos estudos do filósofo norte-americano Martin Jay (2005), a articulação da experiência possibilita a observação do fenômeno da comunicação em sua complexidade: não só os caracteres linguísticos, como também os elementos extralinguísticos são postos em evidência. Por outro lado, a experiência retém tanto a dimensão imediata e arrebatadora do momento comunicacional, como ainda possibilita a sua tradução (visual, gestual, escrita, sonora etc.), ou seja, ela já carrega a própria possibilidade do compartilhamento desta tradução. Nela encontram-se, portanto, os elementos que fundamentam a proposta teoria negativa da comunicação que serão discutidos nos próximos tópicos: a ex-comunicação e seus derivantes conceitos negativos de medium, comunidade e comunicação.

O conceito de experiência está situado no ponto de cruzamento entre objetividade e subjetividade, entre o inefável e o exprimível, entre a unicidade da vivencia individual e a recorrência da vivência coletiva: "Ao mesmo tempo é um conceito linguístico coletivo, um significante que apreende uma classe de significados heterogêneos localizados em um campo de forças diacrônico, e um lembrete que tais conceitos sempre deixam um resíduo que escapa ao seu domínio homogeneizante" (JAY, 2005, p. 6).

Se todas essas características estruturam a experiência como comunicacional, quais as diferenças ou peculiaridades que poderiam salientar o atributo "ex-comunicacional", o qual esta tese de doutorado propõe defender? Em outras palavras, em que medida poder-se-ia caracterizar uma experiência como ex-comunicacional?

Este desvio é o gesto fundamental ensaiado neste trabalho: a passagem de uma visão voltada à comunicação para um olhar - lateral - sobre a ex-comunicação. Acima foi argumentado que toda experiência surge do encontro com aquilo que não sou eu, portanto, com a outridade. O seu caráter comunicacional aponta para dois momentos distintos mas indissociáveis: a transformação e sua tradução. Por sua vez, o caráter ex-comunicacional de uma experiência caracteriza a indefinição da transformação, um estranhamento insolúvel

$80 \mathrm{Um}$ dos pioneiros a tratar a comunicação como transformação no Brasil foi o teórico paulista Ciro Marcondes Filho que empreendeu uma revisão do conceito de comunicação para compor sua Nova Teoria (Cf. MARCONDES FILHO, 2002, 2010, 2010, 2011). Em seu projeto de uma filosofia da comunicação, a Razão Durante, o autor apresenta dois argumentos que se alinham a uma proposta de uma comunicação estética: primeiro, a estética estaria na base de qualquer processo comunicativo; e segundo, o processo comunicativo não seria exatamente o sentido, mas a inefável fonte de todo o sentido. Em sua proposta, Marcondes Filho articula Deleuze e Heidegger para situar a comunicação no eixo do Acontecimento: a comunicação como faísca para que se crie o sentido, a interpretação. Por isso, ele concebe a comunicação como um ato de violência, pois ela nos forçaria a pensar. 
que conduz a um mutismo, ao recolhimento, à escuta. Como o negativo da comunicação predicativa e transitiva, a ex-comunicação é comunicação como passibilidade. Uma indefinição entre a reflexividade intransitiva absoluta - expressa no "comunico-me." - ou a inominável voz passiva de um "sou comunicado". Esse movimento opaco é característico das experiências estética, mística, religiosa, erótica. Em comum, elas dependem de uma abertura, de uma entrega, da escuta. A passibilidade evidencia o silêncio como a fonte e o destino da comunicação: "O silêncio é um ponto nulo duplo da linguagem, de onde todo falar provém e no qual todo falar deságua” (KAMPER \& WULF, 1992, p. 1).

O silêncio não é apenas o resultado de uma experiência ex-comunicacional, mas a sua condição: seja no silêncio meditativo dos templos, no silêncio ofegante dos amantes, no silêncio contemplativo nos museus, teatros, cinemas. A música guarda a própria metáfora que expõe a dimensão ex-comunicacional proposta: sua irrecuperabilidade no tempo, sua recusa à localização espacial, a forma como reverbera em todo corpo e a sua demanda pela escuta. "O silêncio forma o horizonte diante o qual todo dizer se realiza. Ele penetra e delimita o processo. A melodia do dizer se constitui de palavras e pausas. Nas pausas entre as palavras e frases, nas quais o pensamento se forma, ele tem seu lugar e seu tempo" (WULF, 1992, p. 7). A comunicação que este trabalho tenta expôr retém a tragédia da própria palavra silêncio: sua expressão implica sua morte. A morte, a propósito, é o mais profundo silêncio, a não experiência, onde o sentido cessa.

Dizer que a comunicação é uma experiência é negar sua substancialidade (mas não sua materialidade). Ao ser ponderada como uma experiência negativa, ela é tomada como um sair de si pelo encontro com o outro e um voltar a si transformador, sob a lógica da negatividade. É uma experiência de evidência e de esquecimento. É afirmar que apenas sua "comunicabilidade" se mostra, ou seja, suas condições de possibilidade: contextos, linguagens, estruturas, elementos etc. É afirmar que quando ela ocorre, o medium que realiza a experiência não está lá - não pode ser tematizado, sob o risco de ser eliminado. Para que a comunicação ocorra, é necessário que ela seja silenciada. Isso quer dizer que ela assinala uma distância - a separação existencial entre dois seres - mas em cuja experiência de limiar essa diferença torna-se esquecida (mas não superável), pois sua tematização colocaria em cheque a própria concretização da experiência.

A abordagem dos elementos que constituem essa experiência silenciadora - e que apenas se mostram - é o tema dos capítulos subsequentes: o medium, a comunidade e a comunicação. Retendo a lógica da negatividade apresentada nesta primeira parte, busca-se 
então a composição das linhas gerais de uma teoria negativa dos media.

\section{II}

\section{A negatividade do medium}

Mesmo de origem latina, a palavra medium nunca foi incorporada ao vocabulário da língua portuguesa. Originalmente, o termo for traduzido do latim como meyo (meio). Com a emergência das tecnologias massivas de transmissão de informações, a palavra medium (e seu plural media) foi empregada pelos países de língua inglesa. Consequentemente o Brasil adotou, como uma redução da expressão anglo-saxã mass media, a palavra mídia. Ciro Marcondes Filho, um dos críticos desta terminologia para os estudos comunicacionais, escreveu: "a forma brasileira mídia (...) é uma construção linguística espúria, obtida a partir da pronúncia norte-americana do termo media e não se justifica essa incorporação ilegítima e empobrecedora, já que o termo medium é latino, e nos dotada fora linguisticamente mais correta do termo media" (MARCONDES FILHO, 2009, p. 249).

Por outro lado, longe de cair em um debate terminológico, a proliferação do termo mídia no vocabulário cotidiano oferece uma vantagem no momento em que este trabalho utiliza o termo medium ${ }^{81}$. Não apenas por conta do estranhamento provocado, mas porque ele aponta essencialmente para uma outra coisa, mais próxima de uma teoria da recepção ou de uma estética. O conceito de medium não caracteriza um mercado empresarial, uma técnica, um aparato, o conjunto das formas de transmissão de informações e conhecimento, mas, sim, um modo, uma função ou uma estrutura que torna possível a aparição de algo e que, paradoxalmente, esconde suas formas no momento desta aparição.

O termo latino medium se refere àquilo que está no meio ou o que media entre outros, como, por exemplo, na matemática, na qual os termos médios de qualquer série proporcional são os que estão entre os extremos. Tal sentido - daquilo que está entre - está naturalmente contido na palavra meio - e isso desde os primeiros dicionários da língua português, como pode ser verificado no Vocabulario Portuguez, e Latino (1712-1728), de Rafael Bluteau. Entretanto, como o próprio verbete deste antigo léxico expressa, o termo

81 Consequentemente, utiliza-se durante todo o texto o adjetivo "medial” e sua derivada substantivação, já que o adjetivo "mediático" refere-se expressamente à palavra "mídia". 
primevo meyo já era uma tradução de distintos termos latinos, como via, ratio, modo, semi e inter (deduz-se que os três primeiros sentidos estão retidos na corrente expressão "meios de comunicação"). Como tradução direta do termo medium, Bluteau define o meyo como aquilo que está entre suas extremidades e, dentre outros exemplos, cita uma máxima de Cícero: "Entre guerra, \& paz não há meyo [sic]. Inter bellum, \& pacem medium nihil est" (BLUTEAU, 1716, p. 474).

Curiosamente, a palavra medium só aparece em algum dicionário contemporâneo português em sua forma acentuada médium, que denota uma pessoa que em determinados rituais religiosos serve como intermediária entre os espíritos e os viventes. Tal fato não deixa de ser interessante porque o termo médium guarda extremas semelhanças com o significado do conceito de medium observado a partir da sua negatividade. No médium pode ser observado a aporia ou o paradoxo do medial: o médium ausenta-se no momento mediúnico para presentificar uma outra entidade - o seu corpo está ali, mas o médium não pode mais estar presente, ele está impossibilitado de se co-mediar. Ele sacrifica suas formas de aparição no momento em que deixa algo aparecer. Ela já é um outro - mas suas características inter-ferem e tomam parte no próprio processo mediúnico. Este paradoxo medial, ou seja, a impossibilidade de uma mediação co-mediar suas materialidades e estruturas, é o eixo central de uma teoria negativa dos media, cujas linhas gerais foram delineadas pelo filósofo alemão Dieter Mersch.

Ao contrário do português, a palavra medium possui uma longa história em outras línguas. Como conceito filosófico ${ }^{82}$, pode-se encontrar um debate em torno de sua conceituação desde os escritos estéticos de Aristóteles (De Anima) e seu conceito de media diaphana em contraponto ao conceito de metaxy ${ }^{83}$. Introduzido como estrangeirismo em meados do século XVII na língua alemã, o termo foi largamente explorado pela filosofia de Kant, passando pelo Idealismo Alemão com Fichte, Schelling e Hegel, pela nascente filosofia da linguagem com Humboldt e Herder, até os escritos do início do século XX com Walter Benjamin e Theodor Adorno. As teorias dos media da Alemanha expressam, cada qual a seu modo, as diferenças que a própria língua alemã possibilita entre as palavras Medium, Mitte (meio) e Mittel (aquilo que media).

O desdobramento consequente deste capítulo deve, portanto, salientar a diferenciação conceitual entre medium e meio para, em seguida, apresentar a proposta de 82 Para um consistente estudo sobre a história do conceito de medium no pensamento ocidental, cf. HOFFMANN, 2002.

83 Esta questão será retomada adiante, no tópico "O medium negativo”, na página123. 
uma teoria negativa dos media. A especificidade do conceito de medium foi objeto de diferentes perspectivas filosóficas contemporâneas ${ }^{84}$, como por exemplo a fenomenologia (MATZKER, 1993; WIESING, 2005), a pragmática (SANDBOTHE, 2001; VOGEL, 2001), a filosofia da linguagem (KRÄMER, 2008) e os estudos da performatividade (KRÄMER, 2004; MERSCH, 2002; SCHWARTE, 2011). Como este trabalho busca sobretudo dialogar com o contexto brasileiro das teorias da comunicação, no próximo tópico será executado um movimento duplo: ao mesmo tempo em que se busca a especificidade do conceito de medium, deve-se questionar a ausência de um debate em torno de uma teoria dos media no Brasil. Tal proposta é conduzida a partir de um estudo sobre a obra de Walter Benjamin, cuja divisão conceitual entre medium e meio foi proposta em seu ensaio Sobre a linguagem em geral e sobre a linguagem humana, escrito em 1916.

Argumenta-se, por sua vez, que tal apuro terminológico pode fundamentar um conceito de medium para uma teoria negativa da comunicação contrária à arbitrariedade do signo linguístico. Por outro lado, por meio de uma revisão das versões brasileiras de alguns dos mais influentes textos de Benjamin, busca-se recolocar a questão do medium nos estudos nacionais de comunicação, silenciada nas traduções e debates brasileiros da obra benjaminiana.

\section{O medium silenciado}

No deserto canônico das teorias da comunicação no Brasil ${ }^{85}$, a obra do escritor alemão Walter Benjamin (1892-1940) surge como um dos poucos oásis, cuja nascente ainda está longe de se esgotar. Incessantemente referenciados, seus textos parecem resistir à força diluidora da discussão apressada e da ânsia pela legitimação acadêmica via citações fora de contexto. Leituras quase obrigatórias nos cursos de graduação em Comunicação Social, ao menos três dos seus ensaios entrariam em qualquer compêndio de uma teoria contemporânea da comunicação: Pequena história da fotografia (1931), O autor como

84 Para um consistente panorama dos debates teóricos contemporâneos em torno do conceito de medium, cf. MÜNKER \& ROESLER, 2008.

85 Cf. o artigo de Muniz Sodré (2012) que considera a Comunicação no Brasil como um campo em apuros; cf. a obra recente de Ciro Marcondes Filho e a sua provocativa afirmação de que nunca se pesquisou o que é a comunicação no Brasil (2010a, 2010b); Cf. ainda José Luiz Braga (2010) e seu argumento sobre a necessidade de se lançar perguntas de pesquisa, metodologias específicas da Comunicação para os fenômenos observados. 
produtor (1934) e A obra de arte na era de sua reprodutibilidade técnica (1936) ${ }^{86}$. São textos que há muito fundamentam o argumento de que o cinema e a fotografia - e por extensão qualquer outro "meio de comunicação", numa espécie de antecipação a Marshall McLuhan (1964) - alterariam os modos de percepção humana. Logo, a obra de Benjamin se tornou um dos pilares dos estudos orientados para as os efeitos dos meios de comunicação. Essas pesquisas não hesitaram em assumir as tecnologias tratadas por Benjamin - a fotografia e o cinema - como media.

Entretanto, é de se estranhar que os conceitos de medium e de comunicação na obra de Benjamin raramente são postos em questão pelo chamado campo comunicacional, que o mantém como autor-chave. Em seus principais textos, o próprio Walter Benjamin criticou abertamente esta concepção instrumental que identifica os termos meio, material, mídia, canal, suporte. O estranhamento deste silêncio teórico extingue-se quando se é confrontado com as traduções brasileiras: como será discutido mais adiante, elas não chamam a atenção para essa diferenciação na obra benjaminiana, mesmo porque o "medium" não é uma questão para os campos teóricos que produziram essas traduções - sobretudo as Ciências Sociais, a Filosofia e a Crítica Literária. Este é um problema que deve ser assumido pelos teóricos da Comunicação. O que se pretende agora é ensaiar algumas perguntas teórico-comunicacionais à obra benjaminiana para resgatar a sua depuração conceitual de termos essenciais para o campo, como "comunicação" e "medium".

\section{Medium $\neq$ meio}

Tal diferenciação aparece pela primeira vez e de forma bastante clara no ensaio Sobre a linguagem em geral e sobre a linguagem humana ${ }^{87}$, escrito em 1916 - bem anterior aos textos mais conhecidos do autor - e que pode ser lido como um tratado sobre a magia da linguagem. Bastante hermético, com várias referências ao Velho Testamento e enevoado pelo tom místico-revelador, o próprio Benjamin escreveu este texto com a intenção de compor um conjunto de referencial teórico, confiado-o inicialmente só a poucos amigos. Entretanto, como apontou um dos mais importantes estudiosos sobre a teoria da linguagem de Walter Benjamin, o filósofo Winfried Menninghaus, em seu livro A Teoria da Magia da

86 Traduzidos para o português por Sérgio Paulo Rouanet e publicados na coletânea de ensaios Magia e Técnica, Arte e Política: ensaios sobre literatura e história da cultura. Cf: BENJAMIN, 1987.

87 No original, Über Sprache überhaupt und über die Sprache des Menschen. Cf. BENJAMIN, 2010. 
Linguagem de Walter Benjamin ${ }^{88}$, este ensaio é um, senão $o$, fulcro de toda obra benjaminiana (MENNINGHAUS, 1995, p.49), pois apresenta todos os teoremas e terminologias essenciais da sua teoria da linguagem que, por sua vez, fundamentam uma teoria não instrumental e não semiológica da comunicação ${ }^{89}$.

Numa só lufada, a ousadia teórica de Benjamim: "O que a linguagem comunica? Ela comunica seu ser espiritual correspondente. É fundamental saber que que este ser espiritual se comunica na linguagem e não através da linguagem. Também não há um falante da linguagem, se se quer dizer com isso que ele se comunica através da linguagem" (BENJAMIN, 2010, p.31-32). Mais adiante, ele arremata: "Cada linguagem se comunica em si própria, ela é, em sentido mais puro, o 'medium' da comunicação. O medial é a imediaticidade de toda comunicação espiritual, este é o problema fundamental da teoria linguística, e se quisermos chamar esta imediaticidade de mágica, então o problema original da linguagem é a sua magia” (ibid, p.32).

O desafio agora será desdobrar esse origami conceitual, de tal forma que ele possa ser redobrado sem se rasgar. Logo no início do seu ensaio, Benjamin assume que a linguagem ${ }^{90}$ está em todas as coisas - e não apenas no humano - e que ela é um princípio voltado à comunicação. Princípio este que também foi denominado de comunicabilidade [Mittelbarkeit] (KRÄMER, 2008, p.43). Por sua vez, cada linguagem, como um medium, possui seu ser espiritual que não é comunicado através da linguagem, mas dentro dela e, por isso, não toma parte da expressão. Contudo, todas essas afirmações ainda permanecem obscuras. Se a linguagem é definida em relação a noções como ser espiritual, medium, comunicabilidade, imediaticidade, magia e expressão, estes termos devem ser, portanto, esclarecidos.

Como o filósofo escreveu, o ser espiritual é este "se" do comunicar-se. "Ou seja, o que se comunica na linguagem não é a própria linguagem, mas algo que se diferencia dela" (BENJAMIN, 2010, p.31). Isso quer dizer que o ser espiritual da linguagem não toma parte

88 Em alemão, Walter Benjamins Theorie der Sprachmagie, publicado originalmente em 1980.

89 As reflexões desenvolvidas neste tópico se concentram no conceito de medium presente no ensaio "Sobre a linguagem em geral e sobre a linguagem humana" com o intuito de ressaltar a sua importância para os recentes debates teóricos da comunicação. Para uma profunda análise da constituição da filosofia da linguagem de Walter Benjamin - não apenas a partir dos seus antecedentes em Johann Georg Hamann e na obra de Wilhelm von Humbold, como também sob o ponto de vista dos seus desdobramentos para a Filosofia da Linguagem - conferir a obra Walter Beniamins Theorie der Sprachmagie, de Winfried Menninghaus (1998) e, mais recentemente, o livro Es spricht der Mensch: Walter Benjamins Suche nach der Lingua adamica, de Anja Hallacker (2004).

90 Na língua alemã, o substantivo Sprache denota tanto língua como linguagem. Este tipo de "indistinção" está presente no ensaio de Walter Benjamin que elenca, por exemplo, tanto a linguagem da técnica, da arte, da justiça, quanto a própria língua alemã como tipos de linguagem que possuem seu próprio ser espiritual. 
no comunicado. Ele se dá na linguagem, e não através dela. Aqui está a diferença fundamental entre medium [Medium] e meio [Mittel] na teoria benjaminina. A consideração da linguagem como um meio de comunicação constitui aquilo que Benjamin criticou como a "concepção burguesa da linguagem: o meio da comunicação é a palavra, seu objeto a coisa, seu remetente um ser-humano" (ibid., p.34). Em outras palavras, um homem comunica algo a outro homem no momento em que ele nomeia este "algo" através da palavra. A sua crítica assinala, assim, a divisão entre ser espiritual e ser linguístico: "a diferenciação do ser espiritual do ser da linguagem, no qual aquele se comunica, é a diferenciação fundamental da investigação teórico-linguística” (ibid., p.31). O ser linguístico - cuja categorização recai no signo - é apenas um elemento da linguagem. Benjamin busca ressaltar um outro aspecto não observado pelas teorias linguísticas da sua época, pois, para ele, a linguagem é um medium no qual se comunica seu ser espiritual. Como explica Menninghaus, para Benjamin a comunicação não significa "a troca de conteúdos predicativos fixos, mas um processo não-predicativo de representação e compreensão, para o qual a 'primária' semântica das palavras e frases é apenas um - embora indispensável fundo" (MENNINGHAUS, 1995, p.16). E qual a relação destas duas dimensões para o pensador alemão? Como o próprio Benjamin escreveu, "o ser espiritual é idêntico ao linguístico somente no comunicável. O que é comunicável em um ser espiritual é o seu ser linguístico. A linguagem comunica, portanto, o ser linguístico particular das coisas, mas seu ser espiritual [é comunicado] somente se ele se assentar de forma imediata no linguístico" (BENJAMIN, 2010, p.32).

E aí está a magia da linguagem. É na recusa do medium como meio (i-mediato) ${ }^{91}$ que Benjamin instaura o conceito de medium como algo que torna possível que algo se comunique. Ele não é um veículo, um canal. Como explica a filósofa alemã Sybille Krämer, "os media instituem o potencial de se comunicar, mas eles não são nenhum meio de comunicação" (KRÄMER, 2008, p.48). E mais adiante, ela complementa de maneira esclarecedora: "O medial é a capacidade de se expressar a si próprio - ou seja, sem a intervenção de um meio externo” (idem). A magia é essa imediaticidade do medium.

"O que a linguagem comunica? Ela comunica a si mesma" (BENJAMIN, 2010, p.32). Com isso, o pensador alemão amplia o entendimento da linguagem/língua para além da sua concepção instrumental ou semiológica, pois para ele a linguagem é "a expressão imediata

91 Em alemão, o adjetivo unmittelbar ressalta bem a separação benjaminiana entre medium e meio, pois a palavra negada com o prefixo un- é justamente o meio [Mittel] e, não, o medium. 
daquilo que se comunica nela” (BENJAMIN, 2010, p. 31). Como explica Krämer, comunicar-se e mostrar-se ganham dimensões semelhantes. "As pessoas e as coisas podem expressar algo no momento em que elas manifestam algo de si. Ou seja, o homem não comunica, mas a linguagem sim” (KRÄMER, 2008, p.46). Ou seja, o comunicável é imediato na própria linguagem. "O que se expressa na linguagem não é um comunicado, mas a própria comunicabilidade" (ibid., p.47).

Tal afirmação pode ser verificada no insólito exemplo dado por Benjamin sobre a linguagem da lâmpada: a lâmpada não seria comunicada pela linguagem da lâmpada, porque o ser espiritual da lâmpada não seria ela própria. A linguagem da lâmpada, por sua vez, comunica "a linguagem-lâmpada, a lâmpada na comunicação, a lâmpada na expressão. Porque, na linguagem, isso se comporta da seguinte forma: o ser linguístico das coisas é a sua linguagem" (BENJAMIN, 2010, p.32).

Neste momento, é introduzida uma nova diferenciação: entre a linguagem das coisas em geral e a linguagem humana. O homem comunica seu ser espiritual quando ele nomeia, pois "o ser linguístico do homem é que ele nomeia coisas" (ibid., p.33). Mais uma vez, Krämer desdobra bem esta passagem: "Se a lâmpada se expressa e se mostra no momento em que ela ilumina, então o homem se expressa e se mostra quando ele nomeia" (KRÄMER, 2008, p.46).

O nome é tomado como a linguagem da linguagem humana. E como o próprio Benjamin (2010, p.35) ressalta, o genitivo aqui não indica a função de meio, mas de medium, pois o homem comunica o ser espiritual na medida em que ele nomeia as coisas. Ou seja, aqui paira a critica à relação arbitrária entre as palavras e as coisas. "Isso não significa uma mimética entre a linguagem e as coisas, mas se constitui na experiência de um terceiro: em uma relação de expressão" (MENNINGHAUS, 1995, p.20). Logo, a palavra deve comunicar algo além dela mesma, pois "comunicar através da linguagem torna a linguagem um sistema arbitrário de signos verbais, que é aplicado como instrumento de comunicação. Onde nesses sentidos arbitrários se é comunicado através da linguagem, há o falante. Contudo, o 'ser-falante' para Benjamin já não é nenhum fato linguístico-filosófico instrutivo" (KRÄMER, 2008, p.45).

Mas antes que sejam lançadas acusações metafísicas a essa teoria da comunicação que agora começa a mostrar seus contornos, cabe ressaltar que, para Benjamin, existência e linguagem como duas faces da mesma moeda. Daí a importância das suas observações sobre a "revelação" - conceito retirado diretamente do contexto teológico - e sua forte 
vinculação à imanência em detrimento à transcendência das coisas. O conceito de revelação, portanto, "é antes compreendido como o reflexo sempre desajustado da experiência que manifesta imediatamente (magicamente) no formulado uma força não formulada, no pronunciável um não dito e como declaração predicativa frequentemente um 'indizível'” (MENNINGHAUS, 1995, p.21). Ou seja, a revelação na linguagem acontece na própria linguagem. Mas ela não é comunicada pelos conteúdos verbais. "O mostrar-se de algo inefável é uma qualidade da expressão de todo falar" (ibid., p.22). Neste momento, além da crítica à instrumentalidade da linguagem, Benjamin condena paradoxalmente a tese de uma significado para além da linguagem.

Ademais, a imediaticidade linguística é concebida de maneira dupla: de um lado, extensivamente, entre a linguagem e as coisas; e, por outro, intensivamente, entre o princípio do movimento da linguagem em si e o ser de um falante ou de uma obra. "A conexão destes dois elementos de não-instrumentalidade linguística conduz Benjamin subsequentemente ao conceito de uma 'magia própria imanente' dos 'elementos linguísticos concretos'”(MENNINGHAUS, 1995, p.40). Há uma correspondência das esferas do comunicante (nomeante) e do comunicado (nomes) na comunicação. Como escreve o próprio Benjamin: "Através da palavra a humanidade se liga à linguagem das coisas. A palavra humana é o nome das coisas. Com isso não se pode assumir a noção da perspectiva burguesa da linguagem, na qual as palavras se relacionam ocasionalmente com as coisas e que são signos estabelecidos das coisas (ou do seu reconhecimento) através de uma convenção qualquer. A linguagem nunca dá meros signos” (BENJAMIN, 2010, p.41).

Se a magia é a imediaticidade da comunicação do ser espiritual, sua emergência é provocada pela denominação das coisas: pela tradução da linguagem das coisas - uma linguagem silente - na linguagem humana. Mas é bom frisar que a "tradução da linguagem das coisas na dos homens não é a tradução do mudo para o sonoro, ela é a tradução do inominado ao nominado" (ibid., p.42). Com o conceito de tradução, Benjamin proporciona a visualização do medium em movimento, pois a "força mágica da língua pode ser reconstituída como sua capacidade de tradução" (KRÄMER 2008, p.49). É a partir desta lente, proposta por Krämer (idem), que se apreende aqui a longa incursão de Benjamin nas passagens bíblicas do Gênesis e da Queda do Homem, pois a larga utilização de obras religiosas para a composição da sua teoria dos media não deve ser vista como teológica. Vale ressaltar que a análise dos textos bíblicos foram fundamentais para as teorias linguísticas do período barroco e romântico alemão, das quais Benjamin foi tributário (Cf. 
MENNINGHAUS, 1995, p. 43). O próprio autor se antecipou a essa possível crítica, ao afirmar que a Bíblia e a filosofia da religião foram tomadas como reflexões sobre a natureza da linguagem: "É um movimento de reapropriação e ressignificação, como feito em obras de artes e outros textos teóricos. Não como fonte de verdade revelada" (BENJAMIN, 2010, p.38).

A partir do mito da Criação, Benjamin observa que a natureza nasce da palavra e o homem, da terra. Logo, o dom da palavra foi dado àquele não nascido da palavra. Seguindo a interpretação de Benjamin, para Deus a língua era o medium da criação. Para o homem, mero instrumento, um meio do seu conhecimento. O nascimento da palavra humana surge no momento de sua queda, de sua expulsão do paraíso. A Queda do Homem é o nascimento da palavra humana, na qual o nome não vive mais imaculado: "a própria magia imanente sai para expressar como que de fora, para se tornar mágica. A palavra deve comunicar algo (para além de si mesma). Esta é a verdadeira Queda do espírito linguístico” (ibid. p.44). Como explica Krämer (2008, p.52), "Deus cria, na medida em que nomeia; isto é uma forma indisfarçada, 'pura' da magia linguística, na qual a linguagem é agida imediatamente porque produtora de realidades. A fatalidade do homem se constitui em ter perdido esta forma de poder linguístico e, com isso, sua criatividade linguística (somente ainda) pode ser praticada como tradução". Mais adiante, a filósofa dos media arremata: "Quando Deus fala, ele cria; quando o homem fala, ele traduz" (ibid., p.53).

A tradução, portanto, é a encarnação do conceito de medium. Assim, o medium da formação linguística é concebido como um emaranhado singular entre recepção e criação: "A tradução é a conversão de uma linguagem em outra através de um continuum de metamorfoses. São continua de metamorfoses, e não zonas de semelhanças e equivalências, que atravessam a tradução" (BENJAMIN, 2010, p.42). Por isso, o medium não transmite, ele traduz ao manifestar. Com a incursão bíblica, Benjamin busca mostrar que a linguagem humana é um híbrido entre medium e instrumento: "a um só tempo, o medium é a linguagem humana do criar e do receber, da imediaticidade e da mediaticidade, da expressão e do signo, da magia e da técnica” (KRÄMER, 2010, p. 53).

Se até este momento a pregnância ou mesmo a aplicação desta teoria dos media baseada no olhar sobre o medium em detrimento aos "conteúdos verbais" permanece obscura, o próprio Benjamin - como aponta o filósofo Winfried Menninghaus (1995) fornece exemplos mais concretos que permeiam toda sua obra: suas considerações sobre o tom, o estilo e a forma linguística. Antes mesmo do surgimento da teoria da conotação, o 
tom apareceu na obra benjaminiana como algo que não se realiza por meio dos conteúdos verbais, mas imediatamente na própria linguagem (MENNINGHAUS, 1995, p.13). Por sua vez, ao contrário dos conteúdos verbais, o estilo "não é nem um formalismo que possa ser subtraído, nem um mero filtro de representação, mas, sim, ele deixa perceptível, acima de tudo, o conteúdo espiritual da época, desenvolvendo em si mesmo, portanto, uma qualidade doadora de sentido" (ibid., p.13-14). O estilo, portanto, não é um fenômeno psico-individual de um autor, mas a expressão e o elemento instaurador de uma comunicação da produção artística e da experiência histórica. Já a forma linguística, aparece no seu estudo da tragédia: uma alegoria que significa alegria (conteúdo verbal) ao mesmo tempo expressa em si o trágico (ibid., p.14).

Contudo, o espaço deste texto não permite um desenvolvimento maior destas questões. E por conta do longo desdobramento conceitual empreendido no tópico anterior, faz-se necessário uma breve revisão para que os vincos fiquem bem marcados. Logo, seguindo o argumento de Menninghaus (1995), tem-se como pressupostos básicos da teoria dos media de Walter Benjamin: 1. Cada pessoa, acontecimento ou coisa possui um "ser espiritual"; 2. cada "ser espiritual" se comunica como fisionomia imediata na "expressão"; 3. qualquer expressão pode ser concebida como um tipo de linguagem sem que, com isso, a palavra linguagem se evapore numa metáfora. 4. A linguagem no sentido de expressão não é separável do seu próprio ser espiritual.

A linguagem, portanto, comunica seu ser espiritual correspondente, que se comunica na própria linguagem e não por meio/através dela. A linguagem como algo que comunica a si em si mesma pode ainda ser interpretada como a própria forma linguística como um próprio conteúdo em si, antes mesmo da famosa formulação medium is message de McLuhan. Contudo, tal acepção já tem seu centro na filosofia de Wilhelm von Humbolt (MENNINGHAUS, 1995, p.11) - ainda pouco discutida pelas teorias da comunicação.

A partir da relação materialista entre a linguagem e as coisas proposta por Benjamin, pode-se deduzir que o ser espiritual é imanente: estou lançado no mundo das coisas que falam a/em mim. Algo acontece a mim: transcendência só pode vir a partir da materialidade do mundo. A teoria benjaminiana assume ao mesmo tempo a impossibilidade da existência de um fora da linguagem e uma comunhão entre todas as coisas.

O imediato - a magia - é a chave para a diferenciação do conceito de medium do conceito de meio, ou seja, do sentido instrumental da linguagem como uma relação instrumental de um significante com um significado - este repousando como a carga 
(conteúdo verbal) daquele. Logo, um medium "é o elemento de uma representação, sem contudo ser o meio dela" (MENNINGHAUS, 1995, p.17). O medium, portanto, é um conceito que não pode ser apreendido pelas relações instrumentais meios-fins da racionalidade técnica. Por sua vez, a representação e a percepção mágicas são identificadas na área mais comum e geral da experiência, ou seja, "na linguagem em geral", na fronteira entre a sensação e sentido: "O correlato direto deste modo formal de existência da magia da linguagem como de uma - transitório entre sensualidade e sentido - aparição, de um surgimento, é um momento de infinitude tanto 'objetiva' quanto voltada à teoria da recepção" (ibid., p.18).

Mas o que aqui se defende como o ponto de virada engrenado pela teoria benjaminia para a teoria dos media é a clara separação entre meio e medium. Tal formulação fornece uma base para a constituição de uma teoria não instrumental dos media e inaugura o desenvolvimento de um olhar medial sobre o fenômeno da comunicação. Benjamin deu largos passos na experiência da linguagem para rastrear os momentos de intensidade de representação linguística e de percepção. Se a teoria comunicacional no Brasil, fortemente influenciada pelo pensamento do autor, ainda não discute largamente a sua problematização dos conceitos de medium, de medialidade e de comunicação, a suspeita é de que nos textos mais conhecidos do autor estes termos não exercem grande função. Um olhar direcionado desautoriza esta suposição. Se o termo medium aparece nestes textos, é de se supor que ele guarda alguma relação com o ensaio de 1916. O problema se dá justamente quando as traduções substituem este termo sem ao menos atentarem para suas sutilezas conceituais. Quando o medium não traduz, a mudez permanece.

\section{Uma questão de tradução}

Como afirmado anteriormente, sustenta-se aqui que as traduções não chamaram a atenção para essa diferenciação na obra benjaminiana. Mas não se trata, de forma alguma, de questionar a qualidade dessas traduções. Ao contrário: elas também são responsáveis pela instauração das chamadas teorias da comunicação. O ponto é que elas serviram a outros campos: principalmente às Ciências Sociais e - por que não? - a própria Comunicação Social, cuja formação, como já sinalizada no nome composto, é tributária das 
primeiras. Daí a dificuldade de serem lançadas perguntas teórico-comunicacionais, o que fez com que a depuração conceitual em torno de termos-chave, como comunicação e medium, fosse esquecida.

Portanto, o foco agora se direciona para a aparição do termo medium nos dois textos mais conhecidos do autor: Pequena história da fotografia (1931) e A obra de arte na era de sua reprodutibilidade técnica (1936). No primeiro, palavra surge apenas uma vez. No segundo, duas. Em ambos os casos o termo "medium" esta estritamente ligado à discussão do conceito de aura - um do mais importantes em ambos os textos. Benjamin raramente usou a palavra "medium" em outros ensaios tão extensivamente quando no Sobre a linguagem em geral e sobre a linguagem humana (Cf. MERSCH, 2006, p. 64).

No ensaio Pequena história da fotografia, a palavra medium surge no momento do seu comentário sobre a foto de Kafka quando criança: "Dies Bild in seiner uferlosen Trauer ist ein Pedant der frühen Photographie, auf welcher die Menschen noch nicht abgesprengt und gottverloren in die Welt sahen wie hier der Knabe. Es war eine Aura um sie, ein Medium, das ihrem Blick, indem er es durchdringt, die Fülle und die Sicherheit gibt" (BENJAMIN, 1992, p.54-55). Que na versão traduzida por Sérgio Paulo Rouanet, ficou assim: "Em sua tristeza, esse retrato contrasta com as primeiras fotografias, em que os homens ainda não lançavam no mundo, como o jovem Kafka, um olhar desolado e perdido. Havia uma aura em torno deles, um meio que atravessado por seu olhar lhes dava uma sensação de plenitude e segurança” (BENJAMIN, 1987,p.98).

A palavra medium foi, portanto, traduzida por meio, perdendo a força do conceito na obra de Benjamin. Vale ressaltar que o seu texto seminal sobre a linguagem não só deu base para para todo o desenvolvimento da crítica à racionalidade técnica, quanto o próprio conceito de aura foi derivado da magia como o imediato do medium. A aura é, no caso acima, o próprio medium. Ela é a contrapartida do instrumento. "Aura constitui a medida, o critério e, ao mesmo tempo, o conceito que contrapõe a esfera da reprodutibilidade técnica" (MERSCH, 2006, p.69).

Isso fica mais evidente no ensaio $A$ obra de arte na era de sua reprodutibilidade técnica. A sua primeira edição já foi publicada como uma tradução em francês por Pierre Klossowski na Zeitschrift für Sozialforschung, em maio de 1936. Essa versão foi criticada pelo próprio Benjamin, numa carta a Horkheimer em 27 de fevereiro daquele ano: "Os primeiros capítulos, que Klossowiski tinha traduzido sem me consultar, contêm uma série de incompreensões e deturpações" (BENJAMIN, 2007, p.61). 
A primeira tradução brasileira deste ensaio, por Carlos Nelson Coutinho, foi publicada na Revista Civilização Brasileira em 1968 (Rio de Janeiro, ano IV, n. ${ }^{\circ}$ 19/20, maio/agosto) e teve como base a terceira edição alemã revisada por Benjamin e publicada por Theodor Adorno em 1955 na coletânea Schriften. Em 1969, José Lino Grünewald publica uma tradução no livro $A$ Idéia do Cinema, organizado e traduzido por ele, a partir da primeira versão do ensaio e que, mais tarde, foi editada na Coleção Os Pensadores, da Abril Cultural. Já outra tradução bem conhecida, a de Sérgio Paulo Rouanet, publicada em 1985 na coletânea de ensaios Magia, Técnica, Arte e Politica, tem como base a segunda versão expandida por Benjamin entre dezembro de 1935 e janeiro de 1936.

As duas ocasiões em que o termo "medium" foi utilizado em A obra de arte na era de sua reprodutibilidade técnica encontram-se justamente no início da terceira parte do ensaio, pouco antes da sua clássica definição de aura ser exposta (com grifos nossos): “Die Art und Weise, in die menschliche Sinneswahrnehmung sich organisiert - das Medium, in dem sie erfolgt - ist nicht durch natürlich sondern auch geschichtlich bedingt" (BENJAMIN, 1992, p.14). E pouco depois: "Für die Gegenwart liegen die Bedingungen einer entsprechenden Einsicht günstiger. Und wenn Veränderungen im Medium der Wahrnehmung, deren Zeitgenossen wir sind, sich als Verfall der Aura begreifen lassen, so kann man dessen gesellschaftliche Bedingungen aufzeigen" (ibid., p.15). No primeiro trecho, tanto na tradução de Grünewald quanto de Rouanet, "medium" foi novamente traduzido por "meio". Na última parte, na tradução de Sérgio Paulo Rouanet (BENJAMIN, 1987, p.170) desta última parte, lê-se: "Em nossos dias, as perspectivas de empreender com êxito semelhante pesquisa são mais favoráveis, e, se fosse possível compreender as transformações contemporâneas da faculdade perceptiva segundo a ótica do declínio da aura, as causas sociais dessas transformações se tornariam inteligíveis". Aqui o medium da percepção foi vertido para faculdade perceptiva. Já na versão de Grünewald, a expressão foi traduzida como "o meio onde opera a recepção".

O que se perde nesse momento são as inferências a partir da mística da linguagem sobre o conceito de aura. A forma com que a percepção sensível humana se organiza é associada ao medium. Portanto, ela não é instrumental ou condicionada pelo suporte. Sob esta perspectiva, o ensaio $A$ Obra de Arte... pode ser entendido como uma história não apenas do técnico, mas da medialidade. Como ressalta Mersch (2006, p. 69), "a figura do corte, da montagem são as condições mediais que irrompem nas formas de percepção, que provocam cesuras e deslocamentos" (MERSCH, 2006, p. 69). A medialidade que afeta os 
modos de experiência foi incrivelmente descrita por Benjamin. Se o medium da linguagem incorpora os caráteres inefáveis da própria linguagem, o medium da percepção do tempo em que relata benjamim, portanto, é evidenciado pela queda da aura - mas o que é a aura senão o elemento inefável da percepção da obra de arte? Logo, o artigo é uma descrição de uma nova medialidade - a partir do cinema - e sua relação com a experiência perceptiva. Por contraste, a palavra alemã para "meio", Mittel, está continuamente associada a meio de produção, ao meio como suporte, como instrumento. Por exemplo, no trecho: "O Dadaísmo buscou produzir os efeitos, que hoje o público procura no filme, com os meios/através [Mitteln] da pintura (ou da literatura)" (BENJAMIN, 1992, p.37). Mas as diferenciações entre medium e meio e a relação entre os conceito de aura e medialidade no $A$ obra de arte... não podem ser expostas apressadamente: ainda é um campo a ser explorado e que extrapola o escopo deste trabalho.

\section{Teoria Negativa dos Media}

Como destrinchado no tópico anterior, Walter Benjamin fundamenta o conceito de medium como uma tradução que interfere tanto no traduzido quanto no que é traduzido e que, ao mesmo tempo, não é nem o conteúdo da tradução, nem pode ser exposto por ela. Por sua vez, como um continuum de metamorfoses, toda tradução implica uma cadeia de diferenciações que se desenvolve infinitamente, sem encontrar qualquer origem, paragem ou chegada. Consequentemente, tal movimento pode ser exposto por uma negatividade constitutiva que atribui ao medium a característica de esconder sua própria medialidade, ou seja, suas estruturas no momento em que representam, traduzem ou mediam.

Essa característica foi consistentemente explorada pelo filósofo Dieter Mersch em sua abordagem negativa do conceito de medium. Para ele, a estrutura do medial não pode ser co-mediatizada, ela se mostra apenas. "Portanto, todo esforço de uma teoria negativa dos media se baseia em arriscar o impossível para de alguma forma extrair tal mostrar-se das próprias mediatizações e tornar o medial visível nele mesmo como medial" (MERSCH, 2013, p. 210). Assim, de acordo com sua definição, o medium sacrifica sua aparição na medida em que fazer algo aparecer: "Sua presença tem o formato de uma ausência" (ibid., 
p.208). De forma programática, tal teoria desdobra-se em uma filosofia negativa dos media e transforma-se no eixo central de uma ciência da cultura a partir dos fenômenos mediais. De acordo com sua proposta, os media não são um objeto adequado de pesquisa (Cf. MERSCH, 2010b), mas, sim, as suas materialidades, ou dispositivos ou performances que acompanham os processos mediais, que fazem parte deles, mas sem serem comunicados.

Contudo, diferentemente de Benjamin - cujas bases do seu pensamento encontram-se tanto na teologia judaica quanto na filosofia de Johann Georg Hamann e Wilhelm von Humbold -, Mersch fundamenta suas reflexões essencialmente a partir filosofia da linguagem de Ludwig Wittgenstein, Martin Heidegger e Jacques Derrida para constituição do seu conceito de medium. Por outro lado, a sua teoria negativa é em uma encruzilhada entre a filosofia dos media, a estética (como estudos dos modos de percepção, exibidos pela dinâmica negativa da experiência e do acontecimento) e uma filosofia da arte (já que os próprios objetos artísticos são lugares privilegiados para exposição do medial, ao desentranharem os limites da medialidade)

O desenvolvimento desta encruzilhada teórica é o objeto dos próximos tópicos. A partir do desdobramento desta proposta de uma teoria negativa dos media, busca-se exibir a pertinência de estudos que levem em consideração o aspecto negativo dos fenômenos mediais.

\section{O medium negativo}

A teoria negativa dos media proposta por Dieter Mersch pode ser considerada como uma crítica - ou uma saída - ao apriorismo medial que inundou às ciências humanas nas últimas décadas. Entender o medium como um a priori significa dizer que não existe um fora do medium, já que toda forma de conhecimento e reconhecimento seriam mediadas (por signos). Ou seja, a partir desta visão se instaurou um topos comum nas humanidades que reverbera a certeza de que o real é um efeito dos media, de que os media constroem realidades, produzem conhecimento, representam pensamentos, guardam memórias, possibilitam a ação e a comunicação, em suma, uma atitude teórica que reverbera a máxima de que os media são as condições de possibilidade de toda experiência: "O que se pode compreender, é mediatizado. O ser do ente se revela necessariamente como um ser mediatizado" (MERSCH, 2004, p. 75)..$^{92}$ 
Assim, tal visão - que estrutura a nossa relação com o mundo como uma relação mediada - incorre em uma espécie de idealismo medial ${ }^{93}$, em uma totalização que fica paralisada diante da questão de como o medium poderia ser reconhecido, já que tudo seria seu produto: como a medialidade poderia ser percebida, localizada ou compreendida? Como experenciar algo medial dentro do próprio medial? Estas são algumas das perguntas que movem a teoria negativa dos media.

Mersch reconhece que o pensamento e a produção de sentidos não podem existir sem os media, mas - e esse é o ponto crucial de sua argumentação - isso não quer dizer que os media são os produtores destes sentidos. Os media tornam algo audível, visualizável, sensível, eles organizam, retêm, transportam, transformam, mas não criam significados: eles os pressupõem. "Não existe nenhum simbólico, nenhuma percepção livre dos media - mas nenhum medium é jamais o doador do seu acontecimento" (ibid., p. 77).

Além deste aspecto imaterial ou operacional, o filósofo ressalta a inseparabilidade da dimensão material do medium, já que eles também são, sempre, alguma coisa, sejam arquivos, imagens, aparatos técnicos etc. ${ }^{94}$. Por isso, mesmo que transparente, a medialidade não brota metafisicamente das funções do medium. A transparência da medialidade $^{95}$ é inspirada na concepção de medium da estética aristotélica exposta no livro Sobre a Alma [De Anima], mais precisamente na sétima parte do segundo livro, intitulada $A$ sensibilidade: A visão e o seu objeto (ARISTÓTELES, 2010, p. 80 ss.). Para o filósofo grego, o diáfano ${ }^{96}$ é aquilo que possibilita a percepção. O transparente atua como o contraponto do $\mu \varepsilon \tau \alpha \xi_{0}$ (metaxy), ou seja, daquele vazio que está no meio (entre) o órgão sensorial e o objeto. Nas palavras de Aristóteles:

Não se pronuncia corretamente Demócrito, ao considerar que, se o que está no meio estivesse vazio, se veria claramente até uma formiga no céu. Ora isso é impossível. O ver acontece, de facto, quando o órgão sensorial sofre alguma afecção - e é impossível, evidentemente, que tal afecção seja produzida por ação da cor vista. Resta, nesse caso, que a afecção seja produzida pelo intermediário, pelo que tem de existir necessariamente um

obra da filósofa Sybille Krämer (Cf. 1998, 2003).

93 A mera intermedialidade, ou seja, a tradução de um medium em outro, não possibilitaria de forma imediata a apreensão das estruturas mediais do medium traduzido.

$94 \mathrm{~A}$ questão da materialidade do signo vai ser explorada extensivamente por Mersch em sua obra Was sich zeigt: Materialität, Präsez, Ereignis, particularmente na segunda parte, intitulada Os signos e seu outro [Die Zeichen und ihr Anderes]: Cf. MERSCH, 2002, pp. 131-355.

95 Outro filósofo que explora a característica da transparência do medial, mas sob uma perspectiva fenomenológica, é o professor da Universidade de Jena, Lambert Wiesing, cf. WIESING, 2005.

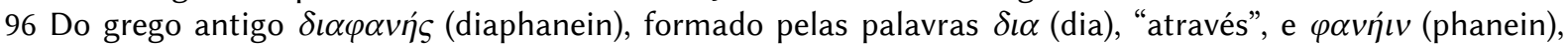
"parecer". A palavra medieval latina transparente-guarda este mesmo sentido. 
intermediário. Assim, se de facto estivesse vazio o espaço entre eles, não se veria claramente - ou melhor, nada se veria, de todo (ARISTÓTELES, 2010, p. 82).

Para Dieter Mersch, o diáfano pode fornecer um outro modelo para compreensão do medial, considerado portanto como algo - material - que possibilita o aparecer. Não é o material que é transparente, mas o próprio aparecer como trans-parente, na medida em que algo através disso se faz visível. Como o filósofo alemão desenvolve no ensaio Meta/Dia: Zwei unterschiedliche Zugänge zum Medialen [Meta/Dia: Dois acessos distintos ao medial] (MERSCH, 2010b), o diáfano surge como o lugar próprio da visualização: algo que mostra, mas que ao mesmo tempo se recolhe.

O deslocamento do "meta" para o "dia", ou do espaço-através para o diáfano, direciona a pesquisa para a necessidade de uma compreensão performativa do medial, que implica uma passagem do debate em torno da transcendentalidade do medial e do problema da constituição das condições de possibilidade para a questão das práticas criadoras e seus acontecimentos. Tal movimento impossibilita não apenas a discussão de uma teleologia do medial, como também de uma ontologia da mediação: "O que o medial é, não pode ser dito - não há qualquer ontologia da mediação, já que ela se nega de forma crônica à sua definição, mas provavelmente se consegue uma reconstrução parcial dos seus 'movimentos'" (MERSCH, 2004, p. 82).

Para explicitar essa impossibilidade de definição do medium e responder ao problema da tematização do medial no próprio medial, Mersch recorreu à filosofia da linguagem de Ludwig Wittgenstein, Martin Heidegger e Jacques Derrida ${ }^{97}$. A relação do pensamento destes filósofos para a constituição de uma teoria negativa dos media é o objeto do próximo tópico.

\section{Um paradoxo aparente}

O ensaio Sobre verdade e mentira no sentido extramoral [Über Wahrheit und Lüge im außermoralischen Sinne] escrito em 1873 (mas só publicado postumamente) pelo filósofo alemão Friedrich Nietzsche $\left({ }^{*} 1844\right.$ †1900) é um texto fundamental não apenas por ajudar a compreender o perspectivismo filosófico nietzscheano, mas particularmente por apresentar

97 O próximo tópico apresenta apenas um resumo e algumas reflexões do autor deste trabalho de doutoramento sobre esses filósofos. Para o destrinchamento destes autores sob o olhar de uma teoria negativa dos media, cf. MERSCH, 2002. 
de forma consistente a problemática que irá dominar não apenas a filosofia da linguagem do século XX como praticamente todas as ciências humanas: a nossa relação com o mundo é, acima de tudo, mediada pelo discurso.

Para o filósofo, a verdade (filosófica) é construída com base na linguagem, que em si mesma já é uma metaforização do mundo e nunca a coisa em si. Por isso, nunca se poderia falar da verdade das coisas a partir da linguagem. Por ser arbitrária, a linguagem se afastaria de qualquer pretensão de ser "A Verdade". Em outras palavras, a percepção do mundo está imersa em uma convenção. Para se tornar senhor do mundo, o homem necessita da ordem linguística. Por esse motivo, as ciências só se sustentam dentro de uma visão humanista: fora do homem, não existiria verdade alguma. Do ponto de vista do seu perspectivismo, a verdade só pode existir como relação que oscila no tempo e no espaço e nunca como verdade em si.

De acordo com Nietzsche, a figura que melhor representa a linguagem é a metáfora. Todo homem, portanto, seria um artista, pois necessita da criação de metáforas para compor sua relação com o mundo. Em seu ensaio, a linguagem é denunciada como uma prisão, cujo esquecimento da metáfora original seria o único motivo que ainda nos empurraria em direção à verdade. Pela linguagem, o homem se afasta dos objetos. Por esse motivo, a relação estética com o mundo seria a única possível: "Entre duas esferas absolutamente diferentes, como o sujeito e o objeto, não há nenhuma causalidade, nenhuma exatidão, nenhuma expressão, mas, no máximo, um comportamento estético, quero dizer, uma transmissão alusiva, uma tradução gaguejante em uma língua completamente estrangeira" (NIETZSCHE, 2000, pp. 19-20).

Mas um problema então permanece como um espinho encravado na pele da filosofia da linguagem ou, mutatis mutandis, de uma filosofia dos media: como então tematizar a linguagem quando todo falar sobre ela já é, ele próprio, linguagem?

O filósofo austríaco Ludwig Wittgenstein ( ${ }^{*} 1889$ †1951) em sua primeira grande obra, o Tractatus Logico-Philosophicus, publicada em 1922 e que constitui ao mesmo tempo uma teoria lógica e um método filosófico, extrai o cerne desta questão ao delimitar que onde cessa o dizer, entra a dimensão do mostrar. Acima de tudo, o dizer e o mostrar são dois regimes intraduzíveis. A forma lógica da imagem e da linguagem sempre buscam se exibir de forma diferente, como expresso em duas passagens: "Sua forma de afiguração, contudo, a figuração não pode afigurar; apenas a exibe" (WITTGENSTEIN, 1968, 2.172); e “A proposição não pode representar a forma lógica, esta espelha-se naquela. Não é possível 
representar o que se espelha na linguagem. O que se exprime na linguagem não podemos expressar por meio dela. A proposição mostra a forma lógica da realidade. Ela a exibe" (ibid., 4.121).

A partir dessas categorias, Mersch agrupa os media em modos discursivos (a palavra e os números) e os estésicos (o som e a imagem) que se desdobram como dimensões irredutíveis, ou seja, que não podem ser convertidas entre $\mathrm{si}^{98}$, mesmo que exista a possibilidade de transcrição em outro suporte. Por exemplo, no caso da música, que pode ser escrita como partitura musical, permanece sempre a diferença entre a percepção e a aparição, de um lado, e a textualidade e o discurso de outro. Um dos trabalhos de uma teoria dos media seria o de delimitar a incompatibilidade entre os media, na contramão da dinâmica de totalização presente em boa parte do discurso teórico em prol de uma intermedialização numérica absoluta. A diferença entre a aisthesis e o discursivo assinala a pluralidade dos media de acordo com o dizer e o mostrar nos moldes de Wittgenstein: "O que pode ser mostrado, não pode ser dito" (WITTGENSTEIN, 1995, p. 34 [4.1212]). Esses dois aspectos estão presentes em todos os formatos mediais, mas um deles rege o medium. "Media discursivos mostram - onde eles mostram - no modo do dizer, enquanto media estésicos - onde eles dizem - falam no modo do mostrar” (MERSCH, 2004, p. 85).

Mesmo diferentes, as dimensões do dizer e do mostrar são colaterais, ou seja, uma não existe sem a outra. "Poder-se-ia dizer com isso: a linguagem é sempre mais do que ela diz. Mostrando, ela abriga um excesso que, dizendo, não se deixa nunca apreender" (MERSCH, 2002, p. 244). A partir do pensamento de Wittgenstein, o que se expõe é a característica da linguagem como acontecimento que se mostra ao falar. Não por acaso sua filosofia fundamenta a teoria performativa dos atos de fala (AUSTIN, 1975).

Essa relação entre o mostrar e o dizer constitui uma estrutura quiasmática na qual permite a co-existência de dois contrários no processo de medialidade, a saber, a simultaneidade da distância e da proximidade, da ausência e da presença. Esse caráter de acontecimentalidade atingiria toda forma de comunicação ${ }^{99}$. Por exemplo, a percepção de uma imagem, na qual o processo de medialidade acontece a partir de uma dupla diferença: “Primeiro, por uma impossibilidade de mediatização do ponto sedutor do olhar e, segundo,

98 Para um aprofundamento desses quatro modelos mediais básicos (palavra, número, som e imagem) na obra de Dieter Mersch, cf. MERSCH, 2003.

99 Tal posição não é muito distinta da exposta pela Nova Teoria da Comunicação, elaborada pelo teórico brasileiro Ciro Marcondes Filho. A partir do conceito deleuziano de Acontecimento, Marcondes Filho considera o acontecimento comunicacional como um momento extremo de abertura a uma alteridade que nos força a pensar e nos transforma profundamente. Cf. MARCONDES FILHO, 2010a. 
pela impossibilidade de encenação da consumação comunicativa que pode acontecer por si só” (MERSCH, 2004, p. 87).

Como Mersch resume, a partir da filosofia primeira de Wittgenstein os aspectos mediais da linguagem podem ser exibidos pela lógica negativa do recolhimento: "Sobre' a linguagem não se pode falar, no melhor dos casos pode-se falar apenas 'dela': a linguagem se nega tanto à sua reflexão quanto a sua totalização. O linguístico [Sprachlichkeit] da linguagem permanece, com isso um mistério permanente" (MERSCH, 2002, p. 253).

Como pensar esse mistério da linguagem foi o objeto das investigações linguísticas do filósofo alemão Martin Heidegger ( ${ }^{*} 1889$ †1976), exibidas em ensaios escritos entre 1950 e 1959 e reunidos no livro Unterwegs zur Sprache [À caminho da linguagem]. Heidegger escreve sobre a necessidade de arruar um caminho pela linguagem até a linguagem, ou melhor, para trazer a linguagem para a linguagem e exibir sua essência (seu movimento) acontecimental, como expressa na sua fórmula: "Trazer a linguagem como linguagem para a linguagem" (HEIDEGGER, 1985, p. 242 et passim). Como o ser humano habita a linguagem, todo falar sobre a linguagem já está enredado em um dizer (ibid., p. 161). Portanto, é necessário se ter uma experiência com a linguagem para exibir, de forma indireta, sua medialidade. Como descrito anteriormente, o significado heideggeriano de experiência carrega o verbo alemão widerfahren, de difícil tradução ao português, já que ele guarda um sentido passivo de "ser atingido por algo que acontece", por algo que não se tem qualquer controle.

Como, então, a linguagem se revelaria como linguagem? "A linguagem fala [Die Sprache spricht]. O ser humano fala, na medida em que ele corresponde à linguagem" (ibid., p. 33). Isso significa que a essência da linguagem é a linguagem da essência, já que não falamos a linguagem como também falamos dela. "Toda fala que se encontra 'a caminho' da linguagem já 'marcou' esta última na própria fala, ou seja, também a modificou. Por isso, a filosofia da linguagem não consegue encontrar a linguagem - tampouco uma filosofia dos media os próprios media -, mas tão somente 'sulcamentos' ou rastros de tal modificação"(MERSCH, 2013, p. 211). Para caminhar à linguagem é necessário uma escuta: escutar o falar linguagem. Percebê-la em movimento a partir dos seus rastros, seus sulcos [Furchen], onde manifesta-se sua "rasgadura" [Aufriss] $]^{100}$ : "a linguagem fala no momento

100 Apesar do uso comum da palavra alemã Aufriss como "planta”, "contorno", "delineação”, optamos pelo termo utilizado na tradução de Márcia Sá Cavalcante Schuback do livro A caminho da linguagem, com a finalidade de uma coerência terminológica. Além de rasgadura, o conceito foi traduzido por ela em outras passagens do livro como debuxo, sulco e fenda. 
em que ela diz, ou seja, mostra" (HEIDEGGER, 1985, p. 255). Para Heidegger, esse momento em que a linguagem se mostra pode ser revelado no recolhimento à linguagem (em contraponto ao isolamento) e, particularmente, na poesia. No momento em que acontece, a linguagem concede, em sua essência, a morada aos mortais. "O movimento [Be-wägung] traz a linguagem (o ser da linguagem) como linguagem (a saga) para a linguagem (para a palavra falada)"(ibid., p. 262). A saga é justamente o caráter acontecimental da linguagem, que se mostra. Como ressalta Dieter Mersch, tanto Heidegger quanto Wittgenstein usam a mesma palavra para apresentar a linguagem para além de uma ferramenta simbólica, a saber, o "mostrante" [Zeige]: "O 'mostrante' é aquilo que no processo do falar, isto é, na performatividade da fala, consegue apenas mostrar-se ou revelar-se. E o que se manifesta ou se mostra não pode ser pronunciado. Ele se nega a uma possibilidade de definição adequada" (MERSCH, 2013, p. 212).

A abordagem da negatividade medial na linguagem também pode ser encontrada ressalvando-se as diferenças nas formações filosóficas desses pensadores - na obra do filósofo francês Jaques Derrida. Para ele, o signo é aquilo que representa o presente na ausência: "Quando não podemos tomar ou mostrar a coisa, digamos o presente, o ente-presente, quando o presente não se apresenta, então significamos, servimo-nos do subterfúgio de um signo. Significamos. O signo seria então a presença diferida" (DERRIDA, 1991, p. 41). Em sua conhecida conferência "La Différance", pronunciada na Sociedade Francesa de Filosofia em 1968, Derrida mergulhou até as margens do signo para tentar figurar algo que não pode ser expresso por nenhum conceito, nenhuma palavra, nenhuma expressão, que nenhuma língua poderia exprimir: a própria estruturalidade do signo. Aqui pode-se perceber o mesmo problema enfrentado por Wittgenstein e Heidegger: como conceituar algo no qual a própria conceituação eliminaria o que se pretende conceituar? Como (a)presentar o que não pode ser presente ou substancializado no verbo ser? Como escrever sobre o inominável, sobre o inexprimível?

Não é através de um conceito, de uma metáfora ou de uma figuração que Derrida busca manifestar a medialidade do signo linguístico, mas através de um jogo de provisoriedades, expresso pela troca do e por um a na palavra francesa différence, que significa "diferença". Tal alteração de vogais só é percebida na escrita, já que a pronúncia das palavras é a mesma. A différance é a própria condição de possibilidade do próprio sistema sígnico - e, por extensão, do pensamento - e por isso não pode ser descrita pela linguagem. É ela quem produz a linguagem através de espaçamentos, diferença entre as 
palavras, silêncios que mal cabem no próprio conceito de signo. A différence apresenta a recursividade e a iterabilidade da linguagem, bem como a falta de sua origem, na qual os conteúdos dos signos são apenas mais signos. Ao mesmo tempo, a différence acentua os deslocamentos e alterações que ocorrem através da presentificação, da performatividade da linguagem. A différance é rastro, traço [trace, Spur]:

\begin{abstract}
Uma vez que o rastro não é uma presença, mas o simulacro de uma presença que se desloca, se transfere, se reenvia, ele não tem propriamente lugar, o apagamento pertence a sua estrutura. Não apenas o apagamento que sempre deve poder surpreendê-la, sem o qual ela não seria rastro, mas indestrutível e monumental substância, mas o apagamento que desde o início o constitui como rastro, que o instala na mudança de lugar e o faz desaparecer na sua aparição, sair de si na sua posição. O apagamento do rastro precoce (die Frühe Spur) da diferença é portanto "o mesmo" que o seu sulcamento no texto metafísico. Este deve ter guardado a marca daquilo que perdeu ou reservou; pôs de lado. O paradoxo de uma tal estrutura é, na linguagem da metafísica, esta inversão do conceito metafísico que produz o efeito seguinte: o presente torna-se signo do signo, rastro do rastro. Ele não é mais aquilo para que em última instância reenvia todo reenvio. Torna-se uma função numa estrutura de reenvio generalizado. É rastro e rastro do apagamento do rastro (DERRIDA, 1991, p. 58).
\end{abstract}

O traço possibilita uma escrita sobre a escrita e dentro da escrita. Às origens do pensamento da différance são reveladas pelo próprio Derrida (ibid., p. 49 e ss.), que a encontra já nos textos de Nietzsche (força), de Freud (inconsciente), de Levinas (alteridade radical) e, principalmente, Heidegger. Os limites da metafísica, do pensamento, da linguagem, do eu, da consciência, ou sumariamente, de tudo aquilo que havia sido descrito por meio de suas estruturas - cujo limiares ou mesmo superação não se colocavam como uma possibilidade - foram a tônica do pensamento pós-guerra, retomando aquilo que Heidegger havia apontado com a sua diferença ontológica (a diferença entre ser e ente). $\mathrm{O}$ que Derrida escreve como sendo o movimento indefinido da estruturalidade da estrutura, ou seja, os rastros, pode ser entendido como alteridade: "Eles determinam que o acontecimento [Ereignis] do sentido surge [ent-springt] como acontecimento [Geschehen] do entre ou do meio de sua 'diferença absoluta"' (MERSCH, 2004, p. 89).

Ao tentar expressar o inexprimível como a estruturalidade da estrutura, Derrida apresenta resultados semelhantes ao de Heidegger. A instauração de um novo vocabulário e do trabalho nas margens do medium são necessários para exibir o medium que se nega a qualquer definição. O medium emerge como aquilo que com-forma, mas que sacrifica suas 
formas. Para Dieter Mersch, a medialidade se mostra "como aquela indefinibilidade da qual apenas novos esboços podem ser feitos e cujos riscos e rasgaduras provêm principalmente de performatividades e interrupções transversais, que chegam indiretamente e se agarram às estruturas, criando rachaduras e contradições, para combater o paradoxo do medial" (MERSCH, 2013, p. 212).

É a partir da possibilidade de manifestação da estruturalidade da linguagem com Wittgenstein, Heidegger e Derrida que se delineia uma teoria negativa dos media, cujo objetivo é revelar os traços do medial que obstinadamente desaparecem na aparição, que se sacrificam na perfeição técnica, mas que permanecem como a presença de uma ausência.

\section{A indefinibilidade medial}

A partir do que foi discutido, pode-se visualizar os três bloqueios mediais denunciados por Mersch em sua teoria negativa: ao bloqueios da materialidade (indisponibilidade de apreensão de todos os aspectos do medium), das diferenças (inescrutabilidade entre a palavra, a imagem, o som e o algarismo) e da autorrealização do medial (seu caráter acontecimental). "Essas três barreiras correspondem às três impossibilidades primordiais de representação: recolhimento da medialidade do medium, limites de possibilidade de conversão mútua e impossibilidade de definição do lugar de onde a mediatização ocorre" (MERSCH, 2004, p. 90).

Dizer que o medium não encontra uma representação adequada é retomar ao conceito de medium i-mediato colocado por Walter Benjamin e exposto no início deste capítulo. O conceito de medium recusa-se a qualquer explicação teórica estrita. Ele encerra qualquer possibilidade de explicação discursiva. Daí o caráter indireto de sua natureza. Ele se manifesta apenas na sua performance, ou seja, no momento de sua execução.

A materialidade do medium é a fronteira na qual se estruturam as condições mediais. Todo medium dispõe de algo finito, concreto, que limita sua execução. É justamente pela materialidade - a ex-sistência do medium - que ele deixa seus rastros. É no momento de sua deterioração, que a medialidade se torna aparente: "Não é um outro medium que o torna visível, mas ele próprio se faz visível, mostra-se, onde ele se despedaça. Seu mostrar está conectado à sua negatividade" (MERSCH, 2004, p. 83).

É na palavra rasurada, no disco arranhado, na tela travada, nos retardamentos, no 
filme mofado, no ruído, na pertubação da atenção, na cor desbotada, no bug, no pixel estourado, no controle emperrado etc. que a perfectio medial entra em crise. A efetivação de um medium está diretamente relacionada à criação da ilusão de uma amedialidade. Quanto mais os media e suas medialidades passam despercebidos, mais efetivos eles são. A teleologia da técnica é a manutenção do mistério medial, ou seja, em garantir sua impenetrabilidade que sustenta o ilusionismo do a priori medial. Por este motivo, os efeitos sempre foram os elementos mais ponderados do processo de medialidade, já que aquilo que está "no meio" tende a ser ignorado. $\mathrm{Na}$ imaterialização de sua materialidade o medium cumpre sua função. Mas até em processos de medialidade bem sucedidos existem elementos que logram ilusão de amedialidade: "Nenhuma percepção sucumbe totalmente ao medium no qual ela contempla, como nenhuma memória segue ao seu registro e nenhum pensamento corresponde inteiramente à escrita na qual ele se articula; sempre há 'inconvenientes' e com isso também indisponibilidades, que correm por assim dizer 'como rastros' sem deixar vestígios e frustram obstinadamente a realização do medial” (ibid., p. 83).

Algo sempre excede as estruturas de medialidade. E é esse próprio excesso que permite a reflexão do medial. Uma teoria dos media que atenta para o aspecto negativo do medial deve permanecer persistentemente nesta fronteira do recolhimento estrutural do medium. Por atuar nos limites das materialidades e das funcionalidades do medial, a arte emerge como um lugar privilegiado para apreensão do medium como medium ${ }^{101}$.

Por isso, a percepção, a linguagem ou qualquer forma de expressão não se resumem às suas medialidades. Existe algo se sempre escapa à qualquer tentativa de totalização. Daí a necessidade de várias abordagens sobre um mesmo fenômeno. Uma teoria negativa não anula qualquer outra teoria que se debruça sobre as condições ou os efeitos mediais. Elas atuam como um suplemento inesgotável, mas sempre incompleto.

$101 \mathrm{E}$ isso é basicamente o que Dieter Mersch busca em seus trabalhos estéticos ao se deparar com um dos grandes problemas da Estética, o essencialismo, que se debruça sobre questões como a especificidade do medium da imagem, da poesia etc. Cf. MERSCH, 2002. 
III

\section{A negatividade da comunidade}

O novelo teórico a ser desenredado neste capítulo constitui a seguinte tese: $\mathrm{A}$ (ex-)comunicação não com-põe uma relação intersubjetiva, mas uma comunidade (negativa). Como será detalhado mais adiante, recolocar o conceito de comunicação sob um olhar negativo - uma ex-comunicação - anularia o pensamento de uma comunidade formada pela relação entre indivíduos que possuem algo em comum. A comunidade não é uma promessa de imortalidade dos sujeitos, mas a ex-posição da sua finitude. Ela excede a capacidade do sujeito de voltar-se a si mesmo.

Mas por que a aposta em um conceito de comunidade? Assim como a palavra comunicação, este termo foi envolto com incontáveis camadas semânticas durante o último século: do comunismo marxista e sua noção de comunidade constituída por indivíduos produtores (o fundamento do ser humano é a produção através do trabalho e, portanto, os indivíduos constituem uma coletividade via trabalho); passando pelo par opositor sociedade-comunidade, que se reflete em outros tantos pares como cidade-campo, estruturas complexas-estruturas simples, individualismo-coletivismo; até à perigosa nostalgia ilusora de uma comunidade ancestral ligada ao sangue e à terra - presente no pensamento fascista. Apreender de forma abrangente as vicissitudes do conceito de comunidade é uma tarefa que excede os limites deste trabalho. O que importa nesta etapa da pesquisa é reverberar a familiaridade etimológica deste termo com o conceito de (ex-)comunicação para resgatar um conceito de comunidade como a figuração de um outro tipo de relação, uma alternativa face à estrutura intersubjetiva que configura certo pensar comunicacional discutido em diversos momentos deste ensaio.

Essa outra abordagem da comunidade é fruto do pensamento pós-guerra da segunda metade do século passado. O escritor e filósofo francês Georges Bataille ( ${ }^{*} 1897$ †1962), com seu diálogo intenso com as obras de Hegel e Nietzsche, inaugurou uma outra forma de expor a comunidade a partir do seu limite, para além da noção de identificação. Como escreveu outro filósofo francês Jean-Luc Nancy (*1940), Bataille foi "quem primeiro, ou mais agudamente, sofreu a experiência moderna de comunidade não como um trabalho a ser produzido ou como uma comunhão perdida, mas antes como um espaço em si e o espaçamento da experiência do aberto, do fora-de-si” (NANCY, 1991, p. 19). 
Entretanto, o conceito de comunidade em Bataille deixa-se apenas deduzir a partir da sua reelaboração do conceito de comunicação, espalhado em suas principais obras, como A Experiência Interior (1943), Sobre Nietzsche (1945) e O Erotismo (1957). Coube ao escritor e teórico Maurice Blanchot $\left({ }^{*} 1907\right.$ †2003) e, principalmente, ao próprio Jean-Luc-Nancy, a garimpagem e lapidação deste conceito que instaurou um debate revigorado sobre o ser-(em-)comum a partir de um diálogo entre Bataille e Heidegger - via Nancy, principalmente em suas obras $A$ comunidade inoperante (1983), Ser singular plural (1996) e $A$ comunidade afrontada (2001) - e Bataille e Levinas - via Blanchot, principalmente em suas obras A conversa infinita (1969) e A comunidade inconfessável (1983). Mais tarde, o filósofo italiano Roberto Esposito (1950) retoma este tema com sua sistematização e o confrontamento histórico das acepções de comunidade em Hobbes, Rousseau, Kant, Heidegger e Bataille, em seu livro Communitas: origem e destino da comunidade (1998).

Portanto, o objetivo deste capítulo é empreender uma breve incursão neste diálogo iniciado por Georges Bataille, desenvolvido por Jean-Luc Nancy, correspondido por Maurice Blanchot e retomado por Roberto Esposito, para aproximá-lo de um conceito negativo de comunicação. Com isso, busca-se apresentar uma abordagem negativa do conceito de comunidade, capaz de figurar não uma comunicação como comunhão, mas como ex-posição, como abertura àquilo que instaura a coexistência e o sentido.

\section{Im-munis / com-munis}

O ponto de partida para o conceito de comunidade inspirado na obra de Georges Bataille é a exposição à morte do outro. Entretanto, a força desta afirmação recai menos na "morte do outro", do que na palavra "exposição". Prova disso é que o fundador do absolutismo esclarecido, Thomas Hobbes ( ${ }^{*} 1588$ †1679), já havia observado o papel da morte na comunidade - mais precisamente da capacidade de matar e de ser morto. O medo do outro - que morre e também mata - torna-se uma categoria estrutural do indivíduo. Para Hobbes, caberia ao estado a garantia de isolamento do indivíduo - portanto, de eliminação da comunidade - para a inibição deste medo ${ }^{102}$. Os indivíduos de uma sociedade estão imunizados em relação ao outro. É exatamente como uma crítica à noção de indivíduo 
e de sujeito que o conceito de comunidade se renova.

A relação entre comunidade e imunização - ou entre communitas e immunitas - é o fulcro da reflexão política do filósofo napolitano Roberto Esposito. Para virar do avesso uma pesada camada semântica secular em torno do conceito de comunidade, o filósofo italiano empreende um exercício etimológico capaz de revigorar este termo a partir da oposição entre o comum e o próprio.

O comum está evidentemente entranhado na palavra comunidade. Por definição dicionarística, ele é oposto ao que é próprio, ao que é privado; e a comunidade, por sua vez, seria a própria qualificação deste comum. Contudo, as acepções corriqueiras do conceito de comunidade tratam-na em uma relação especular, na qual os sujeitos estão agregados via semelhança (alter ego ao invés de alteridade), mesmo quando a comunidade é a transformação desses sujeitos em algo maior. "O que em verdade liga todas essas concepções é o pressuposto não refletido de que a comunidade é uma 'propriedade' dos sujeitos que une: um atributo, uma determinação, um predicado que os qualifica como pertencentes ao mesmo conjunto" (ESPOSITO, 2003, p. 22).

De acordo com essa concepção mais corrente, a comunidade seria uma partilha, um pôr-algo-em-comum, mas sempre de algo que já pertence a um nós em detrimento a um eles. Por isso, a pertença é estrutural: seja como identidade territorial, étnica ou religiosa. Assim, os membros destas comunidades, na mesma medida em que só têm em comum os que lhes é próprio, "são proprietários do que lhes é comum" (ibid., p. 25). Entretanto, tal definição fere o sentido do comum impresso na palavra comunidade. Então, como conceber uma comunidade para além da posse ou da pertença? Como recuperar a insuficiência do sujeito diante da comunidade? Como apreender a insuficiência do próprio conceito de comunidade?

Para responder essas indagações, Esposito inicialmente pondera sobre a origem latina da comunidade na palavra communitas. Ela é composta basicamente por dois termos: cum (com) e munus (um fardo, uma dívida, uma tarefa). Dentre as várias acepções do termo munus, Esposito ressalta o sentido de dever alguma coisa - de dívida, como algo a que se está obrigado (um onus) a retribuir. Como explica o filósofo, o munus "é o dom que se dá porque se deve dar e não se pode não dar (...) É a obrigação que se contraiu com o outro e que requer uma adequada desobrigação” (ibid., p. 28). Tal doação obrigada implica, portanto, uma perda, uma concessão - e não um compartilhamento de algo próprio. É dar algo que não pode conservar para si, mesmo na mutualidade da doação. Por esse motivo, a 
communitas caracteriza "o conjunto de pessoas que estão unidas não por uma 'propriedade', mas justamente por um dever ou uma dívida" (ESPOSITO, 2003, p. 29). A relação é promovida por uma insuficiência, por uma negatividade original - diferentemente de quem está eximido desda dúvida, quem está imune.

A immunitas é justamente a negação do munus. É a ausência da insuficiência, da necessidade de doação: "A communitas está ligada ao sacrifício da compensatio, enquanto que a immunitas implica o benefício da dispensatio" (ibid., p. 30). A reunião de in-divíduos (ou seja, que não permitem mais uma divisão ou uma perda do si mesmo) não caracteriza uma comunidade. $\mathrm{Na}$ imunização não há mais dívida. "O imune não é simplesmente distinto do comum; é seu contrário, que o esvazia até a extinção completa não apenas dos seus efeitos, mas do seu próprio pressuposto" (ibid., pp. 39-40). As supostas comunidades por semelhança, portanto, perduram sob um contrato imunizante.

Assim, o com de communitas não marca uma pertença, nem mesmo uma posse, mas um dom a ser dado, um penhor, uma dívida. Estar em comunidade é estar em insuficiência: eu te devo algo, mas você não me deve nada. Mas que dívida é essa a que se reclama? É o vazio, o nada, exposto pela morte. Esse nada não significa um niilismo, mas uma impossibilidade. A insuficiência não é uma falta, não é algo não que pode ser preenchido, abrandado. A comunidade se cumpre naquilo que a limita: na exposição da morte do outro que expõe a impossibilidade de comunhão. Tal exposição a uma dependência de entrega, expropria o sujeito de sua subjetividade. A comunidade se instaura no conflito, no desafio, na diferença: uma exterioridade que produz um não pertencer-se comum. O comum não é, portanto, caracterizado pelo próprio, mas pelo outro - pelo impróprio:

\footnotetext{
Uma despropriação que investe e descentra o sujeito proprietário e o força a sair de si mesmo. A alterar-se. Na comunidade, os sujeitos não acham um princípio de identificação, nem tampouco um recinto asséptico em cujo interior se estabeleça uma comunicação transparente ou pelo menos o conteúdo a ser comunicado (ibid., p. 31).
}

A comunidade não é uma promessa de imortalidade do sujeito a partir de sua existência coletiva. Nem mesmo fusão libertária e comunal. Em comunidade o sujeito é posto em questão: é uma categoria que não resiste à exposição da comunidade. Além disso, a comunidade não constitui nenhuma forma restrita ou paralela de uma sociedade, já que sua diferença fundamental ao social estaria no fato de que ela é a inoperância: ela não cria nenhuma obra, nem tem qualquer produção de valor como meta. A comunidade negativa - 
para utilizar as palavras de Blanchot lendo Bataille - é "a comunidade daqueles sem comunidade" (BLANCHOT, 1988, p. 25). Finitude do abandono, a comunidade não é proteção ou redenção, mas ex-posição.

Mais uma vez, acumulam-se termos aparentemente enigmáticos para a descrição de algo bem concreto - experienciável - mas que escapa à representação. O objetivo dos próximos tópicos é, portanto, realizar uma aproximação gradual dessas adjetivações que caracterizam esse outro conceito de comunidade com o intuito de exibi-lo mais enfaticamente. Por fim, a comunidade é considerada sob o ponto de vista do seu vínculo com uma (ex)comunicação.

\section{A insuficiência comunitária}

Novamente, Georges Bataille: a comunidade como insuficiência é revelada diante da (não) experiência de morte: a exibição da inanidade do sentido da vida. Em sua conhecida síntese do movimento da existência humana, escrita na introdução d'O Erotismo, lê-se: "Somos seres descontínuos, indivíduos que morrem isoladamente numa aventura ininteligível, mas temos a nostalgia da continuidade perdida" (BATAILLE, 1987, p. 12). A descontinuidade caracteriza uma relação fundamentada no trabalho, na produção, na intencionalidade, na instrumentalização, na imunização que, por sua vez, constituem a relação intersubjetiva. É na revelação da continuidade pela comunidade - para Bataille, na relação erótica, amorosa ou estética - que a subjetividade é esmagada pela experiência do fora de mim mesmo. Como complementa Jean-Luc Nancy, em seu livro $A$ comunidade inoperante, na qual ele resgata a abordagem heterológica batailleana da comunidade, a revelação da minha experiência fora de mim mesmo "não significa minha existência reinvestida na ou pela comunidade, como se a comunidade fosse um outro sujeito que pudesse me negar, em um modo dialético ou comunal. Comunidade não nega a finitude que expõe. A comunidade mesmo, em suma, não é nada mais do que esta exposição" (NANCY, 1991, p. 26). A finitude, portanto, é o comunitário.

O princípio de insuficiência diante da mortalidade não significa que a associação de um ser a outro é uma busca por completude ou infinitude. Em comunidade, não há a 
constituição de uma totalidade entre os seres. Não há proteção, mas provisoriedades. Mesmo sozinho, não há isolamento. Como desenvolve o escritor Maurice Blanchot, na sua obra-resposta ao texto de Nancy, $A$ comunidade inconfessável, a "consciência de insuficiência surge do fato de que ela própria se questiona e cujas questões precisam do outro ou de um outro para serem efetivadas. Abandonado, um ser se encerra, adormece, acalma-se. Um ser ou é sozinho ou se reconhece sozinho somente quando ele não é" (BLANCHOT, 1988, p. 5).

Para não se entorpecer, o ser deve ser contestado. Não é o reconhecimento, mas o desafio da alteridade que instaura uma comunidade negativa. Nas palavras de Blanchot, para poder existir, o ser

vai em direção ao outro, que contesta e às vezes o nega, de modo a começar a ser apenas nesta privação que o faz consciente (aqui jaz a origem de sua consciência) da impossibilidade de ser a si mesmo, de subsistir como seu ipse ou, se você quiser, como si mesmo como um indivíduo isolado: deste modo ele irá talvez ex-sistir, experienciando a si mesmo como uma exterioridade sempre prioritária ou como uma existência constantemente estilhaçada, constituindo a si mesmo somente enquanto ele se decompõe constantemente, violentamente e em silêncio (ibid., p. 6).

De acordo com Georges Bataille, essa crise do ser é a própria experiência interior: “o ser tem a experiência interior do ser na crise que o põe à prova, é a atuação do ser numa passagem que vai da continuidade à descontinuidade, ou da descontinuidade à continuidade" (BATAILLE, 1992, p. 95). Permanecer na descontinuidade é permanecer no isolamento. É estar na ilusão de imunização à exterioridade, à ex-sistência. A experiência interior, portanto, é um movimento de contestação que não pode ser confundida com uma experiência subjetiva, pois o próprio isolamento do sujeito é arruinado pela comunidade instaurada pela relação com o outro: o completamente outro, a infinitude do rosto, a alteridade. Como desenvolve Blanchot: "mesmo se a comunidade exclui a imediaticidade que poderia afirmar a perda de todos no desaparecimento da comunhão, ela pressupõe ou impõe o conhecimento (a experiência, Erfahrung) daquilo que não pode ser conhecido; aquele 'além-de-nós-mesmos' (o fora) que é abismo e êxtase sem deixar de ser uma relação singular" (BLANCHOT, 1988, p. 17).

A experiência interior expõe um dos caracteres negativos da comunidade, pois ela, ao realizar-se, conserva em si a própria incompletude no momento da sua partilha. Como acrescenta Blanchot, neste seu partilhar, a experiência interior "expõe seus limites, expõe a 
si mesma dentro dos limites que se propõe a transgredir, como se expusesse, através desta transgressão, a ilusão ou afirmação de uma lei que escapa a qualquer um que pretendesse transgredi-la sozinho. Uma lei que pressupõe uma comunidade” (BLANCHOT, 1988, pp. 17-18).

No conceito batailleano de experiência interior podem ser ouvidos alguns ecos da constituição da consciência-de-si hegeliana ${ }^{103}$, pois nesta relação o sujeito nega o si-mesmo no seu tornar-se, ou seja, tal negação não permite um retorno a si. De acordo com as leituras hegelianas de Jean-Luc Nancy, o "si-mesmo é sem retorno para si; o si-mesmo não se torna o que ele já é: tornar-se é ser fora do si-mesmo - mas de tal forma que este fora, esta ex-posição, é o próprio ser do sujeito" (NANCY, 2002, p. 57). Com isso, reitera-se que a negatividade realiza-se apenas com e a partir de um outro. Ela é constitutiva de uma subjetividade (revisitada: apreendida como interioridade). Mais adiante, Nancy resume o papel da negatividade nesta relação entre a consciência-de-si e o outro:

O si-mesmo nega-se, ao invés de voltar-se para si, ele se arremessa ao outro e deseja-se como outro. Este é o motivo pelo qual o outro não é posterior. Se o outro, pelo simples fato de que eu o nomeio 'outro', parece pressupor o 'si' ou o 'mesmo' e ainda assim apenas para vir depois, este é o efeito de um pensamento ainda abstrato que não penetrou nem no si, nem no outro. O si ainda não começou: ele começa com o outro. Com o outro significa perto do outro, com o outro em seu lugar. Eu sou antes de tudo o hóspede deste outro: mundo, corpo, linguagem e meu 'par' [mon semblable]. Mas ser o-si-mesmo-com-o-outro só pode passar por uma unidade provisionalmente. Não mais do que o outro é um si-mesmo que poderia ter, tudo para seu si-mesmo, a subsistência que me faz falta forma este ser-com-o-outro uma subsistência maior, na qual o si como o outro encontrar-se-iam juntos, idênticos. $\mathrm{O}$ outro postulado como uma exterioridade consistente e dada é precisamente o que é negado no próprio momento da negação de si-mesmo (ibid., pp. 57-58).

De volta aos elementos que constituem uma comunidade, Nancy substitui o conceito de sujeito e indivíduo pelo conceito de singularidade ${ }^{104}$. No desaparecimento do indivíduo descontínuo surge um ser-em-comum finito e contínuo. Mas a singularidade não procede de nada. É um fundamento sem fundo, já que ela não pode ser produzida ou

103 Para um aprofundamento sobre as relações entre as obras de Bataille e Hegel, cf. DIDI-HUBERMAN, 2010, pp. 223-238.

104 Ante várias críticas - dentre elas a de Jacques Derrida - sobre a pertinência de um conceito de comunidade (já que o termo foi insistentemente retomado pelas teorias comunitaristas da década de noventa), Nancy o substituiu em seus estudos sobre o Mitsein (Ser-com) heideggeriano pelos temos ser-junto, ser-comum e por fim, ser-com (Cf. NANCY, 2000), sendo depois retomado como sinônimo em discussões posteriores como "com" (um "nós" fundamental) que sempre procede o "eu”. (NANCY, 2007, pp. 30-31 Cf.) 
derivada ou extraída ou operacionalizada: "Não há nada atrás da singularidade - mas há, fora e dentro dela, o espaço material $e$ imaterial que a distribui e a partilha como singularidade, distribui e partilha os confins da singularidade - o que significa dizer da alteridade - entre ela e ela mesma" (NANCY, 1991, p. 27). Por isso, não existe ser singular sem um outro ser singular. Contudo, mesmo em mútua relação, não existe qualquer comunhão entre esses seres singulares que os conduzam a uma totalidade superior. Se a comunidade não é o pressuposto e nem mesmo o resultado de uma comunhão entre os seres acometidos pela exterioridade, o que assumiria, portanto, o lugar desta comunhão? O negativo da comunhão: excommunicatio. Nancy, portanto, alcança imediatamente a problemática deste trabalho: "No lugar de tal comunhão, há comunicação. O que isso quer dizer é que, em termos muito precisos, a finitude em si não é nada; ela não é nem um fundo, nem uma essência, nem uma substância. Mas ela aparece, ela se presentifica, ela se expõe e assim ela existe como comunicação" (ibid., p. 28).

A existência só é exposta para a comunidade como comunicação, que emerge como o com-aparecer [com-paraît] da finitude. Esse conceito de comparição/com-aparição de Jean-Luc Nancy ressalta não apenas o caráter co-lateral da comunidade que surge apenas com o outro, mas também a sua dimensão performativa: ela apenas se mostra a partir de uma experiência comunicacional de alteridade. Por sua vez (para manter esse movimento de colateralidade), a comunicação se constitui neste partilhar e neste com-aparecimento da finitude: "ou seja, na deslocação e na interpelação que se revelam como constitutivas do ser-em-comum - precisamente enquanto ser-em-comum não é um ser comum” (ibid., p. 29).

Fundamento sem fundo, a comunidade pode ser figurada como o antesmente verbal do poema de Manuel de Barros: exposição a um outro areal, a uma outra singularidade que precede e com-forma uma comunicação - ou uma despalavra mesmo: uma excomunicação. Por isso, a comunicação - ou uma excomunicação - não constitui nenhum elo intersubjetivo. Para permanecer no pensamento de Nancy: o "com-aparecimento é uma ordem mais originária do que aquela do elo. (...) Ele consiste no aparecimento do entre como tal: você $e$ eu (entre nós) - uma fórmula na qual o $e$ não implica apenas justaposição, mas exposição" (idem).

O estar exposto - ou seja, a comunidade - é anterior à consciência-de-si. É um saber sem conhecimento. A comunicação é a exposição em si e somente nela os seres singulares se relacionam sem laço, sem comunhão, sem consensualidade, sem fusão, sem partilha de 
uma interioridade comum. "Comunicação é o fato constitutivo de uma exposição ao exterior que define singularidade. Em seu ser, como seu próprio ser, singularidade está exposta à exterioridade" (NANCY, 1991, p. 29).

Essa relação entre comunidade e comunicação será retomada no último capítulo deste trabalho. No momento, ainda se faz necessário desenvolver algumas implicações desta reformulação negativa do conceito de comunidade.

\section{Inoperante \& inconfessável}

Em seu sentido trivial, a comunidade representa a procura pela elevação da individualidade a algo maior que o sujeito, mas a uma coletividade que ao mesmo tempo empodere o indivíduo: desejo de onipresença pelo espelhamento do coletivo no individual e onipotência pelo espelhamento do individual no coletivo: desejo de soberania e intimidade através da reunião de um povo, de fiéis ou de um grupo que busca a manutenção de uma identidade. É justamente através da instauração da onipotência e da onipresença do próprio que a possibilidade de comunidade é dilacerada.

O com do comum, ao contrário, assinala a reciprocidade da divergência e da abertura. "No 'com' só pode haver forças que se confrontam entre si por conta da sua reciprocidade e suas presenças que divergem porque elas sempre devem tornar-se algo distinto do que as presenças (objetos dados, sujeitos reafirmados em suas certezas, mundo da inércia e da entropia)" (NANCY, 2007, p. 15).

Entretanto, esse confronto não produz nada, não é operacionalizável. A comunidade não é uma obra de uma ou outra singularidade. Ela não pode nem ao menos ser produzida - apenas experienciada. É um momento de suspensão na qual os seres singulares deixam de ser. Ela constitui a dimensão do sagrado, no sentido em que Bataille dá em sua obra, ou seja, como a dimensão oposta ao mundo do trabalho - social, econômico, institucional etc. - e que possui um fim em si mesma. A comunidade inoperante (Nancy) é inconfessável (Blanchot). Não porque não pode ser pronunciada, mas porque é negativa ao anunciar um segredo e, ao mesmo tempo, a impossibilidade de revelação deste segredo. A comunidade é a possibilidade de todo falar. É o estofo da (ex-)comunicação que não se deixa comunicar. 
Mas em comunicação a comunidade se ex-põe: "A 'comunidade' nos é dada, quer dizer, nos é dado um 'nós', antes mesmo que possamos articular um 'nós' ou mesmo justificá-lo" (NANCY, 2007, p. 38).

A comunidade é o território da estranheza, da nudez, da ferida aberta. Inquietude que se manifesta nas mais corriqueiras relações. Mas a estranha presença do outro não é aquilo que limita o "mim" - como poderia sugerir a concepção de Jean-Paul Sartre, na qual o olhar do outro põe em cheque minha liberdade -, mas ao contrário, em comunidade o "eu" experiencia a alteridade conjuntamente com a alteração do "mim" que ex-põe (que coloca para fora do) ao "mim" sua singularidade. Não há reconhecimento, nem mesmo redescoberta. Nem mesmo na morte do outro - aquilo não se pode vivenciar, por isso, uma não experiência - há reconhecimento: contudo, há a exposição de um limite irreversível.

A irreversibilidade das situações-limite pode ser traduzida como passividade. É um sofrimento, uma paixão, uma dilaceração, um êxtase, um abandonar-se, uma abertura à exterioridade. A comunidade partilha, mas esta é sempre uma partilha incompleta, pois o partilhado nem se esgota, nem se torna um pertence. A noite, o limite do saber, o nada da existência são revelados pela comunidade. Por sua vez, a passividade marca o caráter incontrolável e incontornável desta experiência de comunidade: "nós não podemos não com-aparecer" (NANCY, 1991, p. 35). No momento de sua manifestação, a comunidade transcende as formas de violência da subjetividade. Ela abre uma dimensão ética à qual não resta outra alternativa senão responder. Dádiva e anátema, a comunidade não é uma obra a ser realizada, mas uma tarefa sisífica de transformação das relações entre seres: "O que a comunidade transmite é a verdade do ser-em-comum" (ibid., p. 36).

Qual o que partilha a comunidade? A comunidade nunca para de se partilhar. $\mathrm{Na}$ exposição da finitude, a comunidade se realiza como um areal em que a comunicação acontece. Sob uma perspectiva de uma teoria negativa da comunicação, a comunidade é a ferida aberta pela experiência de alteridade na qual se manifesta a dimensão ética do ser-com (da impossibilidade de isolamento do ser). No lugar de uma comunhão intersubjetiva, uma comunicação comunitária.

Contudo, a comunidade não pode ser apreendida, ela se esfarela entre os dedos. Arenosa e provisória, ela instaura um território precário - mas indispensável - para a experiência comunicacional. Espaço-tempo com-posto pelas medialidades e pelo en-contro com a alteridade, a comunidade não pode durar. Ela permanece como a presença de sua ausência que con-forma o desejo de comunicar. A comunicação marca um trágico 
movimento da descontinuidade à continuidade e da continuidade à descontinuidade. Trágico porque não se pode viver em comunicação, mesmo que a própria ex-sistência seja comunicação. Nas palavras de Georges Bataille: “A existência é comunicação - e [...] toda representação da vida, do ser, e geralmente 'de qualquer coisa', deve ser revista a partir daí' (BATAILLE, 1992, p. 104).

\section{Comunidade dos sem comunidade}

A questão da instrumentalização deste outro conceito de comunidade para estudos particulares no campo comunicacional ainda permanece aberta e pouco explorada. Entretanto, alguns caminhos foram apresentados pelos próprios autores trabalhados neste capítulo, particularmente a partir de considerações sobre a escrita ${ }^{105}$. Algumas breves observações sobre este tema podem fornecer pistas para a compreensão da relação entre a comunidade e o medium na formação de uma teoria negativa da comunicação.

Para Maurice Blanchot (Cf. 1988, p. 24), a comunidade daqueles que não tem comunidade pode ser traduzida como o próprio trabalho literário: escrito de uma solidão anterior a qualquer isolamento, a obra se envolve intimamente com o desconhecido pois não se remete diretamente a alguém. Por sua vez, "a relação com o desconhecido, até na escrita, expõe-me à morte ou finitude, àquela morte que não possui nela o apaziguamento da morte" (ibid., p. 25). Essa relação entre o escritor, a escrita e o desconhecido é amplamente desenvolvida em seu livro O Espaço Literário (1955). Nele, o escritor francês acrescenta que "o escritor pertence a uma linguagem que ninguém fala, que não se dirige a ninguém, que não tem centro, que nada revela” (BLANCHOT, 1987, p. 17).

O que fundamenta a escrita é um não saber, um lançar-se ao risco. Essa doação a um desconhecido é uma das características da comunidade. Mas ela só se instaura -

105 Entretanto, faz-se necessário pontuar que a obra do filósofo Jacques Derrida pode ser apreendida acima de tudo com uma reflexão sobre (e a partir de) a escrita/escritura/escrituralidade, cf. DERRIDA, 1991, 2008, 2009. Para ele, "a escritura é o escoadouro como a descida do sentido para fora de si mesmo dentro de si mesmo: metáfora-para-outros-apontada-para-outros-aqui-e-agora, metáfora como a possibilidade de outros aqui-e-agora, metáfora como metafísica na qual o Ser deve se esconder se o outro está para aparecer. Escavação dentro do outro em direção ao outro na qual o mesmo procura seu veio e o ouro real do seu fenômeno"(DERRIDA, 2002, p. 35). Devido à seleção de um corpo de autores que tratasse diretamente com o conceito de comunidade, um estudo sobre a importância do pensamento de Derrida para a relação escritor-obra foi deixado de lado. 
precariamente - na experiência-limite da escrita e da leitura. Não apenas o encontro com uma obra que se mostra como estranhamento, mas a própria escrita - a própria criação e também um encontro - se descobre como estranhamento. O intenso movimento entre proximidade e distância, entre ausência e presença, entre o velar e o desvelar, entre o conhecer e o desconhecer que se desdobra durante a escrita e a leitura revela a finitude e o anátema da singularidade, ou de um sujeito plural, "condenando a nunca encontrar sua própria voz." (NANCY, 2007, p. 33).

A comunidade é esse espaço precário do encontro no qual o mim é acometido por uma exterioridade que o co-institui. Pode-se deduzir que esse encontro ético-estético que procede qualquer subjetividade isolada seja o mesmo que constitui a comunidade batailleana, ao falar de Nietzsche em sua obra $A$ Experiência Interior: "É de um sentimento de comunidade que me une a Nietzsche de onde nasce em mim o desejo de me comunicar, não de uma originalidade isolada" (BATAILLE, 1973, p. 37).

Qualquer comunicação, portanto, pressupõe uma comunidade. Esta última dispõe o movimento das relações e processos necessários para a comunicação. Nela habita a ética do outro. No isolamento do indivíduo, na imunização à radical diferença do outro, não há comunidade. No consenso, na partilha entre iguais, não há mais comunidade. Ela é o lugar do acometimento. A comunidade não é um espaço de diálogo, mas de co-respondência: é relação mútua do imperativo da resposta. Deve-se responder ao apelo que acomete o mim. É um espaço de escrita de uma carta sem conhecer o destinatário. Sem qualquer certeza de seu recebimento. Sem qualquer garantias de sua legibilidade.

Por isso ela é precária. É aquilo que subcutaneamente age entre amantes, numa jam sassion, na leitura de um livro, no momento de uma composição, na elaboração de uma obra, ao se assistir a um filme etc. Ou seja, a comunidade traduz todo o risco por trás de uma tentativa de comunicar e ser comunicado. Tentativa, pois nunca há garantias da sua efetivação. Contudo, a comunicação persiste sempre como a promessa da comunidade. Promessa infinita na finitude do ser. A experiência comunicacional instaurada pela comunidade é um oceano e um deserto, como bem caracterizou Bataille em sua linguagem poética: "Na experiência, não há mais existência limitada. Um homem não se distingue em nada dos outros: nele se perde o que em outros é torrencial. O preceito tão simples: 'seja esse oceano', ligado ao extremo, faz ao mesmo tempo do homem uma multidão, um deserto" (BATAILLE, 1992, p. 35).

A comunidade é uma categoria inoperante e provisória, mas capaz de descrever o 
areal em que a comunicação ocorre. Mais ainda, a comunidade assinala a uma exigência basilar para a experiência comunicacional: a consciência da separação entre os seres. "Essa consciência 'evidente' não pode então ocorrer em outro lugar que não seja a comunidade, ou melhor, ela só pode ocorrer como a comunicação da comunidade: tanto como o que comunica no interior da comunidade, como aquilo que a comunidade comunica"(NANCY, 1991, p. 19).

Assim, a comunidade - para usar um termo caro a Blanchot ao se referir ao êxtase (o que para esse trabalho é apenas um dos aspectos que com-formam a comunidade) - é o próprio fundamento sem fundo da comunicação. Apenas nos limites da relação intersubjetiva que a comunidade pode emergir. É a partir do estudo da comunidade que a dimensão ética de uma teoria negativa da comunicação ganha seus contornos com mais ênfase. Nas palavras do próprio Blanchot (1988, p. 43):

\begin{abstract}
Uma ética só é possível quando - com a ontologia (que sempre reduz o Outro ao Mesmo) sentada no banco detrás - uma relação anterior pode se afirmar, uma relação tal que o si mesmo não está satisfeito com o reconhecimento do outro, com o reconhecimento de si nele, mas sente que o outro sempre o coloca em questão ao ponto de ser capaz de respondê-lo somente através de uma responsabilidade que não pode limitar-se e que se excede sem exaurir-se. Uma responsabilidade ou obrigação em direção ao outro que não vem da lei, mas daquilo que esta última poderia derivar como aquilo que a faz irredutível a todas as formas de legalidade através das quais necessariamente se tenta regular, enquanto ao mesmo tempo ela pronuncia a exceção ou o extra-ordinário que não podem ser enunciados em qualquer linguagem já formulada.
\end{abstract}

Como uma possibilidade de apresentar uma comunicação para além - ou para aquém - da relação intersubjetiva, o estudo do conceito negativo de comunidade pode ser capaz de exibir as dimensões éticas (os paradoxos e dilemas estruturais do encontro com o outro) de uma teoria negativa da comunicação. Por sua vez, ao carregar consigo não apenas as materialidades do suporte, mas ao possibilitar a descrição de modos de percepção, o conceito negativo de medium exibe primordialmente os aspectos estéticos e formais imbricados na experiência comunicacional. Para finalizar este ensaio introdutório a uma teoria negativa da comunicação, ainda resta abordar a sua dimensão existencial, implicada em uma negativização do conceito de comunicação. A insistência na negatividade pode ser apreendida como o impaciente olhar de Orfeu, que perde Eurídice no momento em que se volta a ela por conta de um súbito desejo de sentir a presença de uma ausência (os passos 
dela já não eram ouvidos) e de fitar a impossibilidade, o coração da noite, a própria morte. A tragédia é o ponto de partida para a reflexão sobre o conceito de uma ex-comunicação.

\section{IV}

\section{A negatividade da comunicação}

Ponderar sobre a negatividade da comunicação é estar sempre a caminho do seu destino trágico. Por isso, o que se pretende manifestar neste trabalho através do conceito de ex-comunicação é a tragédia comunicacional. A tragédia é considerada aqui a partir de uma acepção mais geral, ou seja, como aquele iminente fracasso anunciado: não importa com quais estratagemas se busque evitá-lo, o desfecho será funesto. Mas tão importantes quanto a acontecimentalização catártica do desfecho trágico, são as transformações sucessivas liberadas pelos conflitos com entidades que estão infinitamente além de qualquer controle do personagem principal.

O fracasso é o vento que movimenta o insatisfatório - o pressuposto de toda (ex-)comunicação. Ele está na insuficiência do ser, no deterioramento das materialidades mediais, nos ruídos incidentais, nas gambiarras semânticas, nas restrições, nas contradições, nas ambivalências, nas evasões, na informação deficitária. A negatividade adere a qualquer prática relacional. Até porque toda entidade completa, que se basta em si mesma, prescinde da comunicação. Portanto, a negação é necessária ao movimento que caracteriza a (ex-)comunicação. Por sua vez, o fracasso é estrutural a esse conceito: "Porque a comunicação que sempre tem êxito, já deixou de ser comunicação" (RENTSCH, 2000, p. 14). A negatividade de um não poder, de uma impossibilidade, é o impulso comunicacional. "Ocorre uma decepção de uma expectativa, mas é justamente isso que mantêm a comunicação em movimento" (WELLERSHOFF, 1975, p. 467).

A impossibilidade como característica de uma ex-comunicação afasta a comunicação de qualquer familiaridade com conceito de informação. Como argumentado no início deste trabalho ${ }^{106}$, a informação é definida (tanto pelas teorias matemáticas e cibernéticas, quanto estruturalistas) como possibilidade, ou seja, ela é definida pelo número de escolhas disponíveis em um determinado sistema. A ex-comunicação está aquém de qualquer 
intencionalidade de uma escolha ou de uma determinação de um significado. Como ela não delimita uma zona de passagem ou de geração de um sentido - como tradutor, transportador ou signo - a ex-comunicação escapa a qualquer categoria de representação. Ela não está para alguma coisa, não presentifica nada (este é o papel do medium), nem possui qualquer finalidade (como a exposição da finitude pela comunidade). Ela é um movimento de abertura para o exterior e, ao mesmo tempo, uma abertura provocada pela exterioridade. É passividade, ferida aberta, acolhimento, escuta. É a manifestação da impossibilidade do sujeito, do indivíduo ou de qualquer categoria totalizante ou isolacionista. Ela marca o movimento da ex-sistência, ou melhor, da revelação da existência como aquilo que precede o sentido.

Como foi resumido na introdução deste trabalho, para certas teorias da comunicação - que sustentam o panegírico ao campo da Comunicação Social - a comunicação é um processo de troca, de tradução, de entendimento, de consenso ou de comunhão que instaura uma relação social intersubjetiva a partir dos meios técnicos de expressão. Para uma teoria negativa da comunicação, o medium com-forma uma comunidade que por sua vez constitui o solo para uma experiência de transformação e de finitude. A ex-comunicação é o movimento que (ir)realiza e é (ir)realizado por esta experiência. É abertura da qual emerge a possibilidade do ser-com e do estar-junto entre seres singulares; da qual perdura a promessa de transformação e superação de limites e fronteiras pelo encontro com o outro; e da qual se instaura o movimento de sair de si - de transcendência - e de retorno à interioridade.

O movimento acentuado pelo emprego de sua forma verbal é tomado por um deslocamento: ex-comunicar é um verbo intransitivo. Não há um predicado, muito menos uma comunhão. Excommunicatio: excomunhão e excomunicação. Essa relação torna-se ainda mais evidente quando se observa a tradução deste conceito latino para outras línguas: excommunication (tanto em inglês, quanto em francês), Exkommunikation (alemão), scomunicare (italiano). A excomunhão prevaleceu nas línguas portuguesa e espanhola (excomunión) ${ }^{107}$. Mais ainda, para além da intransitividade do verbo, o ex-comunicar só pode ser realizado em sua forma passiva. Quando se perde a intencionalidade e atividade características de um processo comunicativo por conta de um evento que inunda essas categorias, a ex-comunicação emerge como um deslocamento, pois no lugar desta 
comunicação uma vez soberana há certamente alguma coisa e não apenas um nada. Como o filósofo Jean-Luc Nancy ressalta, "nosso limite jaz em não ter de fato um nome para este 'alguma coisa' ou para este 'alguém'. (...) O que 'há' no lugar da comunicação não é nem o sujeito nem o ser comunal, mas comunidade e partilha” (NANCY, 1991, p. 25). O conceito de ex-comunicação é uma tentativa de exibição deste limite.

Até onde esta pesquisa conseguiu avançar na localização de empregos anteriores deste termo, a excomunhão [Exkommunikation] foi utilizada como conceito chave na obra do psicanalista e sociólogo alemão Alfred Lorenzer ( ${ }^{*} 1922 †$ 2002). No início da década de setenta, em sua obra Destruição da Linguagem e Reconstrução: Introdução a uma Metateoria da Psicanálise [Sprachzerstörung und Rekonstruktion: Vorarbeiten zu einer Metatheorie der Psychoanalyse], Lorenzer aplicou o conceito de excomunhão [Exkommunikation] para descrever a neurose como a destruição dos jogos de linguagem (no sentido delimitado por Wittgenstein). Dentro do contexto neuropsicológico, o mecanismo de defesa do recalque é apreendido como uma excomunhão da linguagem e da linguística (LORENZER, 1976, p. 25). Aquilo que é excomungado/excomunicado anularia as capacidades de reflexão e consciência, cabendo ao psicanalista a reconstrução dos jogos de linguagens fraturados por conta da "dessimbolização" patogênica. Para o psicanalista, aquilo que está excomungado do simbólico poderia ser lido cenicamente ${ }^{108}$.

Ainda mais próximo da forma retrabalhada por este trabalho foi o emprego do verbo “ex-comunicar” na obra A voz excomungada: Ensaios de memória [La voix excommuniée Essais de mémoire], escrita pelo filósofo e crítico de arte francês Louis Marin ( ${ }^{*} 1931$ †1992) e publicada originalmente em 1981. O contexto em que o termo surge é a problemática da autobiografia - da escrita de si mesmo - que necessita de uma distância e diferença, cuja voz do relato em primeira pessoa é uma voz impossível. Para Marin, a autobiografia é uma representação que o sujeito produz de si a partir de uma aparente transparência, mas que esconde uma enunciação opaca. A comunicação autobiográfica não é um movimento de exteriorização de uma interiorização, mas, ao contrário, é um movimento de interiorização acometido e atravessado pela exteriorização: o ex produz a autorreprodução de si e sua autorepresentacão: “(...) o relato autobiográfico apenas pode retornar através da auto-grafia sobre sua vida, para ex-comunicá-la [ex-communiquer] (...)" (MARIN, 2002, p. 201). Este verbo foi traduzido na versão alemã como ent-mitteilen [des-comunicar] - o prefixo ent é 
geralmente apreendido como o prefixo português des. O jogo prefixal jogado na obra de Marin é muito próximo da proposta desta tese de doutorado. Ele busca expor as tensões, aporias, paradoxos e intransparências das teorias dos signos e da representação. Entretanto, o desenvolvimento deste conceito em sua obra permaneceu em aberto ${ }^{109}$.

Como ponto em comum a essas primeiras propostas de conceituação de uma excomunhão/excomunicação está a reflexão da experiência comunicacional pela sua destruição e pela sua submissão a uma exterioridade que escapa a qualquer tentativa de apreensão. Diferentemente destes dois trabalhos citados, este capítulo quer ensaiar o desdobramento desta despalavra: a ex-comunicação. Os materiais para o arruamento deste conceito foram sendo recolhidos dos encontros com as teorias abordadas durante todo este trabalho. A ex-comunicação tenta corporificar uma inquietação ou mal-estar provocado pela presença da palavra comunicação - com suas promessas, ilusões e penetrabilidade no discurso teórico dos séculos XVIII, XIX e XX, cujas variações etimológicas e o potencial reflexivo chocavam-se com a sumária definição de comunicação como mero sinônimo de interação ou transporte. Tal inquietação ganhou forma com Kant e a comunicação [Mitteilung] sem a mediação de conceitos como a base da experiência estética; que avançou com Kierkegaard e a teorização da comunicação [Mitteilung] indireta; que encontrou seu lugar definitivo na história da filosofia com Jaspers e seu conceito de comunicação [Kommunikation] existencial; e que, por fim, assumiu uma posição contrária a dos meios de comunicação de massa a partir do pensamento pós-Segunda Grande Guerra e o questionamento da soberania do sujeito e da relação intersubjetiva, com Georges Bataille, Maurice Blanchot e Jean-Luc Nancy.

Se existe um autor que levou a experiência e o sentido existencial de comunicação aos seus limites, este foi o pensador francês Georges Bataille. Sua abordagem não convencional do conceito de comunicação fornece um aparato conceitual capaz de exibir sua a dimensão trágica. Como já foram discutidos alguns aspectos da sua teoria no capítulo anterior sobre a comunidade, no próximo tópico são exploradas suas reflexões sobre o conceito de comunicação. Por fim, são apresentadas algumas considerações sobre a pertinência de uma teoria negativa da comunicação.

109 O encontro com a obra de Louis Marin aconteceu apenas no final do desenvolvimento deste trabalho. Por esse motivo, a importância deste filósofo para o pensamento comunicacional permanece apenas como uma breve menção. 


\section{A tragédia comunicacional}

O escritor francês Georges Bataille foi quem mais detalhada e insistentemente escreveu sobre os aspectos místicos e negativos da experiência comunicacional. Particularmente imerso na atmosfera das duas Grandes Guerras, Bataille inscreveu definitivamente o conceito de comunicação no pensamento ocidental de tal forma que sua obra se comporta como uma verdadeira dobradiça teórica para esta palavra: síntese de um movimento iniciado com Hegel que já ensaiava o desejo de comunicar como a nova fundamentação do $\operatorname{ser}^{110}$ e, ao mesmo tempo, ponto de referência para qualquer reflexão posterior sobre a comunicação, o estar-junto e a comunidade ${ }^{111}$. Com sua obra, Georges Bataille inaugurou uma ontologia da comunicação como "uma ontologia do ser-deslocado - do ser fora [Draußen-Sein]” (HÖRL, 2005, p. 209).

O conceito de comunicação de Bataille carrega a tensão das semelhanças e diferenças originárias entre as palavras comunhão e comunicação. Para o escritor francês, a imagem de uma comunhão plena pode ser apreendida como uma fusão. A comunicação, por seu turno, é uma experiência ou sentimento de continuidade - o êxtase - capaz de desestabilizar o sujeito isolado, de superar o indivíduo, a partir da superação - ou fusão do par sujeito-objeto: "Não há mais sujeito-objeto, mas 'brecha escancarada' entre um e outro e, na brecha, o sujeito, o objeto são dissolvidos, há passagem, comunicação, mas não de um a outro: um e outro perderam a existência distinta" (BATAILLE, 1992, p. 66). Tal experiência de revelação da insuficiência subjetiva é a que mais se aproxima da não experiência da morte, já que ela se opõe contra a descontinuidade - ou autossuficiência do ser humano, relevando-a como uma grande mentira: "os seres descontínuos que são os homens se esforçam para continuar na descontinuidade. Mas a morte, pelo menos a contemplação da morte, entrega-os a experiência da continuidade" (BATAILLE, 1987, p. 78). O sentimento de continuidade - de êxtase - só pode acontecer em momentos específicos de comunicação. A superação do isolamento - o desejo de continuidade - é regulada, portanto, por uma "lei" de comunicação. Na obra batailleana, a comunicação é refletida em uma variedade de experiências derivadas ou exemplares (seja erótica, mística ou interior), que

110 Movimento que foi posteriormente retomado por Nietzsche, Feuerbach, Marx e Kierkegaard e, no século seguinte, por Heidegger e Jaspers. Cf. GAMM, 2000, p. 83 e ss.

111 Seja para o humanismo do outro homem de Levinas, para a experiência-limite de Blanchot ou para a comunidade inoperante de Nancy. 
carregam consigo uma experiência radical de aparente fusão.

Entretanto, não se deve esquecer do aspecto trágico desse conceito fusional de comunicação. A leitura que este trabalho propõe é a de que o conceito de comunicação como fusão ressalta uma dimensão trágica de impossibilidade. A comunicação é uma promessa de fusão precária que nos retira da descontinuidade por um curto momento para, logo em seguida, lançar-nos de volta à descontinuidade. A fusão seria apenas uma ilusão, mas ao mesmo tempo a exposição da comunicação: da possibilidade de sair de si e de ser atravessado pela exterioridade. Impossibilidade de ser o outro, mas exibição da transformação do mim pelo - e no - outro.

Para que esse posicionamento teórico seja exemplificado, deve se tomar a comunicação figurada como erotismo, como descrita no livro homônimo publicado em 1957. Como afirmado anteriormente, o erotismo é uma forma em que a experiência comunicacional se mostra, já que "toda a concretização erótica tem por princípio a destruição de uma estrutura do ser fechado" (BATAILLE, 1987, p. 17). Para o filósofo, o "sentido último do erotismo é a fusão" (ibid., p. 121). Tal desejo por fusão foi expresso em três dimensões da experiência erótica: no erotismo dos corpos, no erotismo dos corações e no erotismo sagrado. No primeiro, a superação da descontinuidade se dá através da pletora sexual que promove a continuidade dos corpos e a perdição dos seres no gozo - a "pequena morte". A atividade sexual é concebida como uma fissura, na qual "os dois seres estão ao mesmo tempo abertos à continuidade. Mas nada subsiste disso nas consciências vagas: depois da crise, a descontinuidade de cada um dos dois seres está intacta. Trata-se, ao mesmo tempo, da mais intensa e insignificante crise” (ibid., p.96). No segundo, a paixão "prolonga no campo da simpatia moral a fusão dos corpos entre si" (ibid., p.18). Mas esse prolongamento também implica uma tragédia: a procura de uma impossível continuidade duradoura. Por sua vez, a experiência mística do erotismo sagrado introduz a continuidade por outros meios que não o erotismo dos corpos e dos corações: uma possibilidade de continuidade com o mundo através das coisas, das paisagens, da poesia. Contudo a promessa de fusão plena é sempre ilusória. Por outro lado, mesmo precária, o desejo e a breve experiência fusional e o seu retorno trágico à descontinuidade expõe a comunicação como o movimento negativo de exibição dos limites da subjetividade a partir de uma exterioridade que supera infinitamente o eu: "Para além da sua imagem, de seu projeto, a fusão precária que reserva a sobrevivência do egoísmo individual pode, por seu lado, entrar na realidade" (ibid., p. 16). 
Deve-se ressaltar que esta interpretação da obra batailleana não é de forma alguma consensual. Alguns teóricos da comunicação assumem a fusão como o próprio telos de uma teoria da comunicação via obra de Georges Bataille e identificam aí seu principal problema $^{112}$. Este trabalho de doutorado, ao contrário, defende uma outra perspectiva. $\mathrm{O}$ conceito batailleano de fusão não constitui uma união ou eliminação do eu no outro e vice-versa, mas a exposição dessa impossibilidade: a tragédia comunicacional. Tal posicionamento é defendido por Maurice Blanchot e Jean-Luc Nancy, para quem “a fusão batailleana não produz uma união, não é uma fusão, é nada - mas esse nada em si é também, em sua 'consumação', uma comunhão" (NANCY, 2007, p. 37). O conceito de comunicação de Bataille ex-põe, portanto, um movimento de tensão existente entre communicatio e excommunicatio.

"A existência é comunicação..."

A manifestação da finitude e do desejo de abertura à exterioridade acentuam o forte caráter existencial de conceito batailleano de comunicação. Como o próprio Bataille escreveu em sua crítica à obra de Jean Genet - um dos ensaios que compõem o livro $A$ literatura e o mal, publicado originalmente em 1952 -

\begin{abstract}
A humanidade não é feita de seres isolados, mas de uma comunicação entre eles; nós nunca somos dados, mesmo que fosse a nós mesmos, senão numa rede de comunicação com os outros: nós nadamos na comunicação, estamos reduzidos a esta comunicação incessante de que, até no fundo da solidão, nós sentimos a ausência, como a sugestão de possibilidades múltiplas, como a espera de um momento em que ela se resolve num grito que outros ouvem. Porque a existência humana está em nós, nesses pontos em que periodicamente ela se prende, apenas na linguagem criada, no espasmo cruel, no louco riso em que o acordo nasce de uma consciência enfim partilhada pela impenetrabilidade de nós mesmos e do mundo (BATAILLE, 1989, p. 177).
\end{abstract}

A proximidade da dimensão existencial da comunicação de Georges Bataille com o conceito de comunicação existencial de Karl Jaspers não deve ser ignorada. Como defende o teórico alemão Erich Hörl (*1967), mesmo sem qualquer referência ou citação direta, Bataille conhecia o conceito de comunicação existencial de Karl Jaspers (Cf. HÖRL, 2005, p. 209). O filósofo franco-russo Alexandre Kojève $\left({ }^{*} 1902\right.$ †1968) teve seu doutoramento 
orientado por Jaspers em Freiburg (concluído em 1924) e Bataille esteve presente nos cursos dados por Kojève sobre a Fenomenologia do Espírito de Hegel, na École pratique des hautes études entre 1933 e 1939.

Como foi apresentado no primeiro capítulo deste trabalho, para Karl Jaspers o eu só pode ser apenas em comunicação com o outro. Mas se Jaspers ainda constitui seu conceito a partir das categorias de subjetividade e intersubjetividade da Fenomenologia de Edmund Husserl, Bataille persegue um objetivo mais radical: não é apenas o eu que existe em comunicação com o outro, mas a própria categoria de "eu" é posta em questão pela comunicação com o outro ${ }^{113}$.

É na recusa de um sujeito e de um objeto da experiência comunicacional que o conceito de comunicação elaborado por Bataille exibe sua negatividade fundamental. Nesta supressão do par sujeito-objeto podem ser encontradas reverberações do idealismo especulativo de Hegel, no qual o objeto da consciência de si é suprimido, seja como objeto ou como conceito ${ }^{114}$ : quando se nega o outro, nega a si mesmo, e nessa segunda negação se ultrapassa sem entretanto voltar ao estado da primeira negação. Como escreveu Bataille n'O Erotismo: "o que a experiencia mistica revela é a ausência de objeto" (BATAILLE, 1987, p. 17). E anteriormente, n'A Experiência Interior, ao discorrer sobre o extremo do possível uma experiência intensa de comunicação: "Quando o extremo está lá, os meios que servem para atingi-lo não estão mais lá" (BATAILLE, 1992, p. 56). Essa negatividade é acentuada pelo recolhimento da própria comunicação: "O que não pode aparecer é tanto o outro quanto a comunicação” (NANCY, 1991, p. 24).

Para Bataille, experienciar a morte do outro é sofrer a experiência de negação da duração individual. A finitude é essencial para a experiência comunicacional. A comunicação como exposição à morte revela o monstruoso, imperativo e vão dispêndio que é a vida em sua criação incessante para a morte: "A sexualidade e a morte são apenas os momentos intensos de uma festa que a natureza celebra com a multidão inesgotável dos seres, uma e outra tendo o sentido de desperdício ilimitado que a natureza executa contra o desejo de durar que é próprio de cada ser" (BATAILLE, 1987, p. 58). Portanto, a comunicação

113 As relações entre Japers e Bataille, bem como a importância da filosofia da existência para a reelaboração do conceito de comunicação para além de suas determinantes técnicas, é um desdobramento consequente de um projeto de pesquisa que busque aprofundar a presente proposta de uma teoria negativa da comunicação. 114 Por mais que Bataille, sob influência das interpretações de Kojève, tenha eleito o pensamento hegeliano como contraponto ao seu atentado contra a totalização da filosofia, não são poucos os pontos de interseção entre esses dois filósofos. Tal proximidade foi objeto de alguns estudos mais recentes, cf. p.ex. "Uma estética negativa", de Georges Didi-Huberman, In: DIDI-HUBERMAN, 2010, pp. 223-238; Cf. ainda "Razão e Eros: A ideia de G. Bataille de superação de limites”, de Gerhard Gamm, In: GAMM, 2000, pp. 83-102. 
implica uma inoperância, uma superação de qualquer tentativa utilitarista ou da sua constituição como uma obra social. E o erotismo, como uma forma negativa de comunicação, é "a experiência contraditória da proibição e da sua violação: suspende a primeira sem a afastar completamente e, por conseguinte, deixa de poder assumir o caráter de um regresso à natureza ou da reconstituição de uma totalidade positiva” (BATAILLE, 1987, p. 19).

Tal movimento negativo realizado pela comunicação, também denominado por Bataille de êxtase, é capaz de desmascarar o indivíduo como mera abstração. "O próprio êxtase é comunicação, a negação do ser isolado que, ao mesmo tempo em que desaparece naquela ruptura violenta, pretende exaltar-se ou 'enriquecer-se' com aquilo que quebra seu isolamento indo tão longe ao ponto de abrir-se para o ilimitado" (BLANCHOT, 1988, p. 18).

Essa abertura é o sair-de-si. É a possibilidade de recepção do intransmissível. No momento desta experiência de êxtase, não há mais porquês, sujeitos e predicados. "Seu aspecto decisivo é que aquele quem a experiencia não está mais lá quando a experiencia, logo, não está mais lá para experienciá-la" (ibid., p. 19). Tal movimento constitui uma ontologia do ser-em-comunicação. Um ser atravessado por uma exterioridade. Uma ex-comunicação com-posta pelos elementos trabalhados até aqui (comunidade e medium negativos) e que desloca a teoria da comunicação para o coração dos estudos de alteridade.

Comunicação e a alteridade - que é sua condição - podem ter apenas um papel e um status instrumental, mas não ontológico, em um pensamento que vê o sujeito como a identidade negativa mas especular do objeto, ou seja, como uma exterioridade sem alteridade. O sujeito não pode estar fora de si: isto é até mesmo o que por fim o define - que seu fora e todas as suas "alienações" ou "estraneidades" deveriam terminar sendo suprimidas por ele e negadas nele. Isto é completamente diferente com o ser da comunicação. O ser-comunicante (e não o sujeito-representante), ou se se quer correr o risco de dizê-lo, comunicação como o predicamento do ser, como "transcendental", é acima de tudo ser-fora-de-si (NANCY, 1991, p. 25).

A experiência-limite do ser-fora-de-si é a marca da exterioridade da qual depende a comunicação, da impossibilidade de constituição de uma intencionalidade do movimento comunicacional. Não há um eu e um não eu, um emissor e um receptor, mas uma abertura cuja angústia paira entre a tangibilidade e a inefabilidade. De acordo com a leitura desta experiência-limite por Maurice Blanchot (1988, p. 22), "às vezes - e ao mesmo tempo - a experiência ("ir até o limite") só pode ser como tal se ela permanece comunicável e ela só é 
comunicável porque, em sua essência, ela é uma abertura ao exterior e uma abertura a outros, um movimento que provoca uma dissimetria violenta entre mim mesmo e o outro: a fissura e a comunicação". São dois movimentos que se pressupõem e mutualmente se destroem.

O movimento comunicacional ex-põe a existência [Dasein] como ser-com [Mitsein]. Ele é anterior a qualquer dotação de sentido. A dimensão existencial da comunicação revelada ao ser-para-a-morte é anterior a qualquer sistema sígnico ou de iteração de significados - mesmo que a sua promessa seja mantida através dos sistemas de expressão sejam eles linguísticos, pictóricos, numéricos ou sonoros.

A promessa da comunicação é a abertura à exterioridade infinita do outro. É a possibilidade do impossível: é a quebra do isolamento, é o acolhimento da insuficiência do ser isolado, é a libertação momentânea dos domínios discursivos: uma promessa de apreensão do indizível. Como escreveu Bataille (1992, p. 22): "subsiste em nós uma parte muda, furtada, inapreensível. Na região das palavras, do discurso esta parte é ignorada. Por isso ela geralmente nos escapa. Se vivemos, sem contestar, sob a lei da linguagem, estes estados em nós estão como se não existissem".

A partir de Georges Bataille alcança-se a uma comunicação como contestação (co-testemunho). Uma ex-comunicação atesta o estado de passibilidade radical do ser humano a uma língua, a uma origem, a uma condição na qual se encontra arremessado. É desterro, desamparo, excomunhão: ex-comunicação. Por outro lado, ela contesta os limites desses próprios já-dados. Ela é movimento para fora. É um fazer da rua a sua morada. Ex-traneus: es-trangeiro: ex-comunicação. Tal movimento possui fortes implicações ético-estéticas. O próprio Bataille já havia percebido isso, ao escrever há mais de sessenta anos que "a existência é comunicação (...) e toda representação da vida, do ser, e geralmente 'de qualquer coisa', deve ser revista a partir daí’ (BATAILLE, 1992, p. 104)

\section{A experiência interior, ou uma ilusão necessária}

Em plena consolidação e predomínio do conceito matemático e cibernético de

115 Com Bataille, a comunicação ganha um lugar definitivo na ontologia fundamental, já que "a comunicação não é um fato que se acrescenta à existência (Dasein), mas a constitui” (BATAILLE, 1999, p. 42). Na versão original, Bataille não escreve "existence", mas "réalité humaine" que foi a tradução francesa corrente à época para o conceito de Dasein, de Martin Heidegger. A aproximação - as diferenças e semelhanças - entre esses dois autores - que foram contemporâneos e conhecedores de suas obras - extrapola a proposta deste trabalho. 
comunicação em meados do século passado, Georges Bataille recuperou o resíduo místico e existencial que a exigência dessas teorias por transparência e sistematização buscou suprimir. Essa dimensão inoperante e imediata da comunicação sempre acompanhou práticas mediais e comunicacionais ancestrais, seja na constituição oracular de uma comunicação direta com o transcendente, seja na constituição mediúnica de presentificação de outras temporalidades e espacialidades, ou ainda nos transes xamânicos e nos fenômenos de transubstanciações ritualísticas.

Para Erich Hörl, o pensamento de Georges Bataille marca o auge e o fim daquilo que ele chamou de pensamento primitivo da comunicação: "O último momento, talvez, no qual a comunicação pode ser remetida ao transcendental do existir, antes do conceito ter perdido o brilho de sua indefinição produtiva" (HÖRL, 2005, p. 208). O primitivo aí estaria relacionado à fantasmática do sagrado e do mistico da comunicação. A tese de Hörl, apresentada no seu livro Os canais sagrados: sobre a ilusão arcaica de comunicação [Die heiligen Kanäle: Über die archaische Illusion der Kommunikation], publicado a partir de seu trabalho de doutoramento defendido em 2002 na Humboldt-Universität em Berlim, sustenta que essa forma sagrada de comunicação perdeu sua plausibilidade com a primazia das teorias da informação e da cibernética.

Ao contrário do pressuposto de Hörl, este trabalho assume que a dimensão místico-existencial do conceito de comunicação não pode ser suprimida pela sua matematização e funcionalização. Ele resiste sempre como um recalcado no conceito. Desde os primeiros usos desta palavra - seja como relação, pertença, comunhão, transporte, tradução, mediação etc. e suas respectivas sistematizações com o objetivo de uma otimização (comunicação apreendida sobretudo como um processo) - os aspectos opacos que ameaçam a constituição do sentido estão sempre à espreita. O prefixo $e x$ - ressalta o ponto cego de qualquer teorização da comunicação. A retomada das características que se retraem ante qualquer tentativa de apreensão satisfatória é sempre um contraponto à crença cega no potencial transparente e consensual da comunicação. Os estudos em direção aos aspectos negativos da comunicação almejam desenvolver-se em uma crítica ao discurso (de um arraigado racionalismo técnico) que acredita que a mera interconexão técnica de pessoas já garantiria uma sociedade da comunicação. A numerização da comunicação com suas promessas de controle (seleção e intencionalidade) e segurança (via camadas de mediatização) dilacera os constituintes de uma experiência (ex)comunicacional de transformação e risco. A alteridade é despotencializada pelas promessas de gerenciamento, 
controle e disponibilidade proporcionada através da substituição do encontro pela onipresença nas redes telemáticas.

A disposição da comunicação como um sistema ou processo em direção à transparência deste fenômeno ignora seus aspectos noturnos. A figuração deste residual da comunicação pode ser encontrada no conceito de experiência interior, de Georges Bataille, desenvolvida no livro homônimo de 1943. Uma dimensão intocada pela constituição das ciências da comunicação e da informação - que ocorreu no mesmo período.

A experiencia interior não deve ser confundida com uma experiência subjetiva, mas como a revelação dos limites do sentido. Como uma experiencia mística ou uma experiencia de desnudamento do desconhecido, a experiência interior é a exibição dos limites da experiência discursiva e do conhecimento. Ela é a própria crise do ser - algo insuficientemente comunicável. Para Bataille, "a experiência não pode ser comunicada se os laços de silêncio, de desaparecimento, de distância, não mudam aqueles que ela coloca em jogo" (BATAILLE, 1992, p. 36). Após a experiência interior, o indivíduo é um outro. Ele é tomando por um estado de arrebatamento. Por isso, a experiência interior mostra os rastros do ser-em-comunicação: uma experiência provocada por um não saber, uma forma de uma presença que não mais se diferencia de uma ausência. "Na experiência o enunciado não é nada, senão um meio, e ainda, não somente um meio, mas um obstáculo; o que conta não é mais o enunciado do vento, mas o vento" (ibid., p. 21).

Este conceito acentua a inoperância da comunicação. Depois de Bataille, o conceito de comunicação não apenas se tornou a negação do domínio da ordem discursiva a partir da experiência do não saber, como também tornou-se um sinônimo para uma fundamental transformação daquele que a experiencia. A comunicação não aponta para algo a ser revelado, mas sua revelação é a sua própria existência: há comunicação (Cf. HÖRL, 2005, p. 213). Ainda na infância de uma pretensa sociedade da comunicação, Bataille ressaltava que o caminho para a comunicação não é a constituição de um espaço público consensual ou a disponibilidade de um mesmo conteúdo via radiodifusão, mas o desejo de se perder. Se o pensamento e as formas de expressão estão estritamente associados ao linguístico, pode-se deduzir que não há um fora da linguagem: não há uma experiência que não se remeta ao retardamento da lembrança que é concebida simbolicamente e que conforma a percepção. Mas a teoria negativa da comunicação de Georges Bataille apresenta as aporias desta dedução nas situações-limite da experiência interior, pois o outro, o estranho, o sem sentido, o corpo, o sexo, a morte etc., sempre escapam à categorização racional. Por outro 
lado, só existe sentido para um outro, ou seja, sempre na e pela comunicação o sentido é dispersamente constituído. A experiência interior, portanto, remete sempre a um outro - a um heterogênio - que escapa tanto ao discurso filosófico quanto cotidiano. Assim, "a própria razão excluí, oprime, ostraciza, difama alguma coisa a qual, ao mesmo tempo, deve ser levada em consideração enquanto a razão tiver interesse nas questões sobre a autoconstituição" (GAMM, 2000, p. 90).

A ex-comunicação é a exibição de um não saber, é aquilo que é excomungado da comunicação (como transmissão de um sentido). A exterioridade do outro, sua impossibilidade, é o que garante o movimento da comunicação. Refletir sobre uma subjetividade universal ou qualquer tipo de imanência radical ao mundo só é possível com a exclusão do outro. "Esta externidade (extemporalidade/exterritorialidade) do ser soberano remete ao ponto cego de uma vida na rede da mediação universal ou reflexividade. Mesmo quando a superação significa o impossível, da mesma forma é sabido que ele não é o nada, mas sim, aquilo que mantem o possível fluindo" (ibid., p. 101).

A ontologia comunicacional de Bataille do ser-fora-de-si constitui um dos pilares de uma teoria negativa da comunicação que propõe uma crítica da razão e da relação baseada na identidade lógica. Um movimento que ganhou seus contornos com a lógica hegeliana do reconhecimento e se desenvolveu com as abordagens fenomenológicas da relação eu-outro. Evocar uma ex-comunicação é uma tentativa de expor os limiares da comunicabilidade intersubjetiva, de apresentar um momento de movimento, de quebra da identificação e da representação implicadas na linguagem à qual o pensamento paga seus tributos: somos seres interpretantes apenas por meio de signos, vivemos expostos à uma realidade simbólica, a uma condição econômica, histórica, política etc., mas ainda persiste uma reflexividade própria de fenômenos que escapam às estruturas discursivas e que nos abandonam à experiência trágica da impossibilidade. Uma exposição a qual não temos qualquer domínio, a qual não permite qualquer totalização, à qual respondem a insuficiência e a necessidade trágica de abertura. 


\section{Por uma teoria negativa da comunicação}

Mesmo após várias tentativas de sistematização, matematização e cientificação, ainda persiste um aspecto inefável no conceito de comunicação, como algo reprimido que está na iminência de sua aparição e que frustra qualquer tentativa de apreensão esquemática. Espinho encravado na própria pele, ferida que não cicatriza. A proposta de uma teoria negativa da comunicação quer justamente expor essa dimensão informe do conceito de comunicação.

Por sua vez, como ensaiado até aqui, uma teoria negativa da comunicação é, ao mesmo tempo, uma colheita de teorias e filosofias comunicacionais que ainda não encontraram seu espaço na constituição de um campo acadêmico voltado à profissionalização de jornalistas, publicitários e assessores; e uma tentativa de renovação e atualização dessas teorias para a constituição de uma caixa de ressonância - de um outro plano conceitual - capaz de apresentar outros aspectos de um mesmo fenômeno: a experiência comunicacional.

Nunca se escreveu tanto sobre o conceito de comunicação quanto nos dois últimos séculos. Mas pouco dessa reflexão efetivamente foi transportada para as ementas das disciplinas de Teoria da Comunicação das universidades brasileiras, frequentemente tensionadas entre os estudos do funcionalismo americano, da Escola de Frankfurt, da semiótica e do estruturalismo francês. O que se ensaia neste trabalho são outras possibilidades de abordagens, cujas implicações ainda demandam desdobramentos.

Atualmente, refletir teoricamente sobre a comunicação significa confrontar-se com um desafio que não pode ser ignorado: sua onipresença e sua dispersão conceitual. Tamanho é o conglomerado heterogêneo de abordagens e teorias sob o guarda-chuva do campo da comunicação, que a própria tentativa de definição do termo é frequentemente abandonada sob a acusação de certo anacronismo contrário à tão difundida - mas pouco praticada - interdisciplinaridade. Tal argumento é o mesmo que fundamenta tanto a postura que defende a constituição de um campo de conhecimento a partir de uma prática profissional, quanto da divisão precária entre teoria e prática no saber comunicacional.

O que se abriga neste trabalho, ao contrário, é a necessidade constante de se refletir sobre o conceito de comunicação - seu lugar, seu movimento, suas relações. É um exercício contínuo contra a imposição mercadológica de um significado e contra a totalização do 
conceito de comunicação como relação, ao ponto em que qualquer interferência na ligação entre dois elementos distintos torne-se um "problema de comunicação" - com sua respectiva demanda por um discurso especialista de solução.

A proposta de uma ex-comunicação quer ressaltar a insuficiência inerente às teorizações do conceito de comunicação. Mais ainda: ela afirma que a definição dos fenômenos comunicacionais a partir dos aspectos técnicos pode obliterar suas dimensões existenciais, éticas e estéticas. Uma teoria negativa da comunicação não deve ser apenas descritiva, mas também propositiva. Assim, além dos seus aspectos ético-estéticos, ela deve ganhar uma dimensão política. Por exemplo, isso significa dizer que os discursos teóricos hypes que consideram cada novo gadget como a abertura de uma nova dimensão comunicacional contribuem para o enfraquecimento dos caracteres existenciais da comunicação. Pelo exagero comunicativo (interativo, intencional, controlável), a comunicação é perdida, seus aspectos de finitude, solidão e silêncio são ignorados. Ao invés de revelação de uma insuficiência fundamental, a comunicação torna-se uma estrutura imunizante de negação do outro, da impossibilidade e da ex-sistência.

A ex-comunicação, ao contrário, é a exposição dos limites da individualidade e o impulso existencial que dilacera o isolamento subjetivo. É uma atitude passiva ao outro e o imperativo de uma responsividade, de uma co-respondência imediata. Uma teoria negativa da comunicação exibe a inoperância da ex-comunicação que se opõe ao trabalho: ela é improdutiva. Por isso que as experiências estética, erótica e mística são momentos de intensa comunicação. Elas não podem ser operacionalizadas, não possuem qualquer utilidade que não seja a de sofrer a própria experiência de alteridade.

Como o próprio informe que é o pressuposto de qualquer necessidade de relação, a ex-comunicação assinala o desamparo constituinte da comunicação. Ela caracteriza a situação de estrangeiros e de desterrados a qual todos encontram-se arremessados. O abandono a uma língua que define a forma de pensar e a constituição do mundo; o abandono a um restrito campo de ação; o abandono a determinados meios de produção; o abandono a certos sistemas políticos e econômicos; o abandono ao limite do si mesmo. Por outro lado e ao mesmo tempo, a ex-comunicação assinala o movimento de resposta à esta penúria, à insuficiência - um movimento de negação deste outro que supera o mesmo, da negação do próprio si mesmo e da superação do estágio inicial: a transformação. A comunicação ocorre na diferença, não na igualdade ou disponibilidade e, muito menos, na indiferença. A ex-comunicação é um movimento de abertura e responsabilidade. 
Figurações ético-estéticas de uma teoria negativa da comunicação

Como já afirmado em outros momentos deste trabalho, refletir sobre a comunicação a partir da sua negatividade implica uma reconsideração das dimensões ética e estética para a composição do fenômeno comunicacional. Com o objetivo de desdobrar esse aspecto teórico, este breve tópico pretende apresentar algumas notas sobre a relação ético-estética enredada no conceito de ex-comunicação através da evocação daquilo que se poderia chamar de duas características ou figuras de uma teoria negativa da comunicação: a passividade e a correspondência.

A passividade deve ser concebida antes de tudo como uma atitude estética e como um modo de percepção. Diferentemente da intencionalidade, ela produz uma atenção desatenta ou um olhar absorto, capaz de descrever o momento de entrega, de abertura à comunicação, no qual a desarticulação de uma relação entre sujeitos - intersubjetiva - é proporcionada pela negação do isolamento, da suficiência. O próprio Bataille já havia apontado para a negatividade implicada na passividade, já que a atitude ativa de dissecação dos elementos de determinado acontecimento comunicacional assassina a própria experiência de comunicação:

Esses momentos de intensa comunicação que temos com o que nos circunda - que se trate de uma fileira de árvores ou de uma sala ensolarada - são em si mesmos inapreensíveis. Somente usufruímos deles na medida em que comunicamos, em que estamos perdidos, desatentos. Se deixamos de estar perdidos, se nossa atenção se concentra, deixamos igualmente de comunicar. Procuramos compreender, captar o prazer: ele nos escapa (Bataille, 1992, p.149).

A passividade é a caracterização de uma ex-comunicação descrita anteriormente como um profundo abandono. Um penhasco ao encontro das ondas. Um flutuar em mar aberto. Ela desloca inteiramente o foco dos estudos comunicacionais da relação emissor-receptor para uma experiência de comunicação.

Mas descrever a experiência comunicacional como um momento de passividade não sugere qualquer relação com o conceito de apatia. Contrária a qualquer abertura ou transformação pela alteridade, a apatia é a ausência de comunicação. É o embrutecimento cotidiano face à revelação da finitude da existência e da infinitude do outro. É imunização: 
eliminação daquele comum oposto a qualquer ideia de pertença e pertence ${ }^{116}$.

A passividade também não é sinônimo de empatia, pois não opera com estruturas de identificação e semelhança. A passividade é um acolhimento intranquilo daquele estranhamento que corrói internamente aquilo que é familiar ${ }^{117}$. Ela também é uma marca da inoperância da comunicação que se opõe ao momentos de produtividade, de utilitarismo e de objetificação. Por isso, a passividade é uma característica daquilo que Georges Bataille chamou de comunicação forte, que se realiza na aparição da existência: "A atividade habitual dos seres (...) os separa dos momentos privilegiados da comunicação forte, que baseiam as emoções da sensualidade e das festas, que fundam o drama, o amor, a separação e a morte. Estes momentos não são em si mesmos iguais entre si: frequentemente nós os buscamos por eles mesmos” (BATAILLE, 1989, pp. 179-180).

Por fim, a passividade não deve ser tomada como uma irresponsabilidade em uma experiência comunicacional. Permanecendo ainda no vocabulário batailleano, ela implica um momento de soberania, no qual a existência é revelada em/como comunicação. Como soberania, ela tece uma responsabilidade fundamental face ao outro diante do mim. A dimensão ética da passividade desdobra-se como necessidade de resposta à exterioridade, como uma correspondência.

O conceito de correspondência não deve ser compreendido como um sinônimo de simetria ou reciprocidade, mas como um apelo a uma resposta no momento da experiência comunicacional. É com-respondência. Uma correspondência sem remetente: o gesto ético de resposta/responsabilidade e doação à alteridade inapreensível ao $\operatorname{mim}$. A correspondência da ex-comunicação é uma carta em uma garrafa lançada ao mar. Mesmo a um destinatário desconhecido, a correspondência é imperativo, um impulso. É o lançar-se ao risco.

A correspondência mantém a ferida ainda aberta: uma necessidade de se criar relações que rompam com a apatia e que não se deixam reduzir a um discurso de igualdade de direitos, de consenso maioritário ou de uma burocracia reguladora. É a responsabilidade diante do outro que nunca poderá ser apreendido pelo mim mesmo. É um gesto de escuta.

116 Sob o ponto de vista de uma teoria negativa da comunicação, a apatia nos grandes centro urbanos brasileiros pode ser considerada um sintoma de uma atuante descomunicação, fruto estragado de um longo processo de isolamento do indivíduo em suas propriedades - e sua consequente indiferença ao outro - via consumo desenfreado como sinônimo de qualidade de vida: uma arquitetura descomunicante, uma mobilidade descomunicante, um espaço público descomunicante etc.

117 Não é por acaso que Freud abordou o termo Unheimliche - algo como o estranhamento naquilo que é próximo - em seu mais conhecido ensaio estético. Cf. FREUD, 2000. 
Em uma teoria negativa da comunicação, a correspondência ocupa o lugar deixado pelo diálogo. Nunca há articulações entre iguais, mas diferença infinita separadas no tempo e no espaço. A correspondência remete ainda à anterioridade da comunidade negativa: o antesmente verbal da comunicação é fundamentalmente ético.

Não há quaisquer garantias de que a experiência comunicacional aconteça, muito menos qualquer certeza de que se comunica algo a alguém. Entre o eu e o tu são necessárias elaborações de estruturas precárias, linguagens cuja eficácia é sempre contestada pela insuficiência da comunicação: cidades inteiras de areia sob a ameaça da próxima onda. Mas tão certa quanto a chegada da próxima vaga é a necessidade de um movimento de exteriorização daquele que sofre a experiência comunicacional, um imperativo para uma inclinação para o outro (seja ele um ser humano, uma obra de arte, uma paisagem, um animal etc.), uma necessidade de romper com a insuficiência. Mesmo diante da impossibilidade fenomenológica de enxergar pelos olhos do outro, a fala - a expressão - é o estar-a-caminho da experiência comunicacional: expressão é sempre desejo de transcendência.

Ao contrário de outras teorias comunicacionais, na qual a comunicação é entendida como um processo em que algo é enviado de um ponto a outro com o menor número de perda e sob supervisão do ponto emissor (já que o resultado do processo pode ser comparado com seu estado inicial), a teoria negativa da comunicação proposta por este trabalho de doutoramento salienta que a comunicação é algo que acontece ao $\mathrm{mim}$ e, por ser ao mesmo tempo uma necessidade de exteriorização, o conceito de comunicação negativa (ex-comunicação) implica todos os esforços de tradução desta experiência interior - entendida sob a teoria batailleana. Esse é o jogo encenado pelas palavras passividade e correspondência.

Essas duas figuras buscam descrever o modo como a experiência comunicacional é uma experiência ética que acontece aos modos de uma experiência estética. Com isso, esboçam-se as linhas gerais de uma teoria negativa da comunicação que articula uma ontologia (a do ser-em-comunicação), uma ética (dimensão primeira) e uma estética (modos de percepção) a uma filosofia da existência (revelada como um fenômeno comunicacional).

Tudo que foi escrito até aqui pode ser compreendido como uma introdução. Um mapa cuja função foi a de apresentar as articulações entre autores e conceitos que encontram-se em ressonância à proposta de uma ex-comunicação e que demandam consequentes desdobramentos e problematizações. 
Por fim, com o objetivo de ilustrar ou testar o alcance desta teoria proposta, são apresentados dois pequenos excursos: um ético-experimental e um último, imagético. $\mathrm{O}$ primeiro traz algumas considerações sobre o repetido potencial comunicacional das redes telemáticas. Já o segundo, faz referência a algumas obras da artista belga Berlinde de Bruyckere, julgadas capazes de traduzir visualmente a tese proposta.

Excurso I. Notas sobre uma não comunicação em espaços telemáticos

O objetivo agora é o de apresentar um breve estudo de caso sobre a relação eu-outro nos espaços mediados por computador. Pretende-se, com isso, apontar que o estudo da alteridade não pode ser facilmente traduzido para espaços controlados que busquem a criação "experiências seguras". Sugere-se que a relação eu-tu é deslocada para o espaço de jogo - por isso, necessita de outro instrumentário para observação dos processos de medialidade.

O espelho quebrado, ou o assassínio da alteridade

Como ser solitário sem estar isolado? Noites em companhia de íntimos estranhos, longas caminhadas entre chats e sites de relacionamentos. Garrafas lançadas ao mar. Mar de informações. De desejos. Mas as correntes trazem apenas mensagens desinteressantes. Ao menos, para mim. Sei que não estou só? Quem é esse outro que também escreve sem saber que estou aqui? Para quem escreve? Escrever apenas. Só mais um clique e a mensagem não me era endereçada. Corro os dedos entre os rostos disponíveis, de acordo com minha necessidade. Mera curiosidade, minha. Velhas comunidades abandonadas, encontros fugazes e aleatórios. Não há mais ágora agora. As decisões são tomadas em outro lugar. Várias garrafas boiando em volta de mim. Mas não posso desconectar: sentimento de pertença? Apenas a sensação de disponibilidade, de possibilidade, de não estar sozinho? A certeza de uma presença. Mas a presença de uma ausência: a do outro.

Fé cega nos potenciais comunicativos das redes eletrônicas: todos escrevem, falam de si, mandam mensagens e selecionam. A possibilidade de se desestabilizar a partir do 
encontro com o outro diminui. Sou eu quem seleciono o que me agrada: isolamento. A tragédia da impossibilidade de comunicar se anuncia a cada impossibilidade de desconexão, a cada esvanecimento da alteridade a partir de um clique. Os avatares transformam-se em meras projeções do Mesmo. O outro com quem "teclo" é o espelho de "mim". É uma possibilidade de tempo morto, de sexo, de possibilidades. Processo de progressiva incomunicabilidade cujo paroxismo pode ser observado no site de encontros aleatórios Chatroulette.

Apesar de recente (o Chatroulette foi programado no final de 2009 por Andrey Ternovskiy, um moscovita de dezessete anos), o website ganhou enorme visibilidade internacional após matérias publicadas em grandes empresas de informação, como o New York Times ${ }^{118}$ e a $\mathrm{ABC}^{119}$. A página utiliza a webcam do computador para iniciar um videochat e conectar aleatoriamente os usuários. Qualquer participante pode iniciar um outro sorteio a partir de um clique. A qualquer hora do dia, milhares de pessoas estão conectadas ao site. Existem ainda as opções de se criar salas específicas de bate-papo (Channelroulette) e sortear parceiros situados apenas localizados no país do qual se conecta (Localroulette). Ternovskiy relata que criou o site por considerar o Skype (um programa que permite ligações como as de telefone, mas com o uso de webcams) entediante. Em entrevista para a revista alemã Der Spiegel ${ }^{120}$, Ternovskiy considera o site como a rua de uma grande cidade, onde todos os tipos de rostos desconhecidos são vistos: "Alguns desses rostos te chamam a atenção, alguns te desagradam. Chatroulette é uma rua que você caminha e pode conversar com quem você gostar. O programa faz a internet ser mais parecida com a vida real”, afirmou à revista alemã.

Uma tentativa de recuperar a mística do encontro, da flanêrie baudelairiana? Tentativa frustrada que reverbera a impossibilidade de recuperar a alteridade nos espaços mediados eletronicamente: seria como andar na rua e eliminar qualquer pessoa que me interpele e me incomode com seu caráter de inapreensível. Apenas um clique (um tiro?). Relação asséptica que elimina o estranhamento, o silêncio, a contemplação, o encantamento. Verdadeiro assassínio do outro. Após os momentos iniciais de curiosidade, a pessoa do "outro lado" é um mero avatar - estou seguro em meu quarto: posso aqui realizar

118 "The Surreal World of Chatroulette", publicado em 21 de fevereiro de 2010 e disponível em: http://www.nytimes.com/2010/02/21/weekinreview/21bilton.html.

119 "Chatroulette: Talking to Strangers Is Cheap and Often Racy", publicado em 13 de fevereiro de 2010 e disponível em http://abcnews.go.com/Technology/chatroulette-talking-strangers-internet/story?id=9822879

120 Entrevista conduzida por Yevgeny Kondakov e Benjamin Bidder para a revista alemã Der Spiegel, publicada eletronicamente em 03/05/2010. Cf. www.spiegel.de/international/zeitgeist/0,1518,681817,00.html. 
meus desejos mais perversos. Tudo se transforma em um freak show global. A cada dez pessoas, oito estão se masturbando.

Para ilustrar, passamos a um relato da jornalista alemã Nicole Franziska Kögler publicado no site do jornal Die Zeit ${ }^{121}$. Ela conta suas experiências após passar um dia conectada ao Chatroulette e revela a fragilidade das relações produzidas neste ambiente:

Antônio teve tempo para mim. Na minha frente estava sentado um homem forte e simpático. Ele me contou que esteve no exército americano e que hoje comprou um creme anti-rugas. Nós brincamos, eu disse que ainda não precisava disso. "U look maaaad young" e "Very pretty nonetheless", Antônio escreveu, um galanteador. Ele tinha cabelos escuros e uma barba de três semanas, ombros largos. Não era o meu tipo, mas também não deixava de ser atraente. Foi bem engraçado quando ele, um completo estranho, de súbito me perguntou se eu gostava de animais. Depois de aproximadamente dezessete órgãos sexuais e oito pedidos para que eu me despisse, eu esperava tudo, menos o que ele fez: ele puxou um gato pro monitor e se abraçou com ele. Então ele me agradeceu por ter tido tempo para ele e se despediu. Eu nunca mais o verei novamente.

Mal-estar devido a impossibilidade de estabelecer uma relação. Antônio é uma caricatura. Um diálogo frágil, um avatar facilmente eliminável. "É meu duplo, espécie de outro eu, do lado de lá da tela, que ouve meus diálogos interiores e aceita-os ou critica-os. Extensão de mim e de meu solipsismo, que anula a alteridade e vê o mundo como caixa de ressonância de minhas próprias impressões" (MARCONDES FILHO, 2009, p. 6). É interessante notar ainda o desapontamento de Franziska Kögler sobre a possibilidade de manter um contato com outras pessoas:

\begin{abstract}
Meu último smalltalk sobre pênis eu tive com um estudante de medicina de Honduras. Ele estava estudando para uma prova e confessou que gostaria de morar na Islândia, embora no momento ele estivesse apaixonado. Mulheres e amor mudariam o mundo. Nossa conversa escorregou para o filosófico. Contudo, nós voltamos mais uma vez sobre os pênis, cinquenta e um vistos nas últimas seis horas e dezessete pessoas pediram para eu me despir: "That sucks, this would be a great place to meet different people", ele escreveu. Sim, talvez pudesse ser um lugar legal para encontrar pessoas. Eu tentei, mas para mim este não é um. Desisto.
\end{abstract}

Um outro exemplo sobre as tentativas frustradas no Chatroulette é um documentário

121 "Fast neunzig Prozent Männer und haufenweise Perverse sollen sich bei Chatroulette rumtreiben. Gibt es dort auch Schönes?" [Quase noventa porcento de homens e um montão de pervertidos circulam pelo Chatroulette. Também existe beleza ali?], publicado em 27 de abril de 2010. Disponível em: http://www.zeit.de/digital/internet/2010-04/chatroulette 
homônimo realizado pelo videasta nova-iorquino Casey Neistat ${ }^{122}$. Após noventa pessoas (sendo que $71 \%$ eram homens, $15 \%$ mulheres e $14 \%$ "pervertidos"), apenas $5 \%$ delas se dispuseram a conversar com o videasta. Pelos restantes 95\%, Neistat foi sumariamente nexted, ou seja, quando um estranho aleatório clica no botão 'next' (próximo) imediatamente após ver a aparência da outra pessoa: rejeição aniquiladora, cuja decisão não demorava mais do que três segundos.

Ausência de qualquer presença de um outro? Se o rosto não está lá, o que surge em seu lugar? É possível ainda falar de alteridade nesses ambientes? É claro que o contato via messengers ou e-mails com outras pessoas das quais já se conhece pessoalmente é bem diferente do tipo de relação que está sendo relatada aqui. Estímulos, mensagens, exposições continuadas: não ser solitário em seu próprio isolamento: resta apenas uma promessa indefinida de comunicação, mas a relação comunicacional não está mais fundada na presença do outro. Ela está em outro lugar?

A suposta comunicabilidade nas redes eletrônicas é suportada por uma experiência segura: não há um olhar sobre mim que me põe em xeque, pronto a perceber qualquer reação do meu corpo. É dado um tempo para recriar essa frase que se impõe diante de mim - e se há o olhar da câmera a incomodar-me, basta um clique. A semelhança a um espaço de jogo não deve ser ignorada. A exigência é seguir as regras para manter graus elevados de envolvimento e entretenimento, preservando certo cotidiano deixado em suspenso. Posso ferir esse avatar diante de mim com palavras, gestos. Afinal, é imenso o meu grau de controle sobre sua interferência no meu monitor. E essa figura luminosa que me interpela apenas faz parte do jogo.

\section{Jogo como emulação da alteridade?}

A premissa deste trabalho é a de que o conceito de comunicação acentua uma ética instaurada nos modos de uma experiência estética. Tal modelo teórico, ao ser confrontado com a onipresente promessa de uma comunicação eternamente disponível via tecnologias informacionais, vai em busca das experiências de alteridade implicadas nesses fenômenos. Entretanto, o que aparentemente se mostra no lugar de uma ex-comunicação são as estruturas que equivalem a comunicação ao jogo ${ }^{123}$. Isso significa que a comunicação é 
considerada não apenas dentro de espaços rigidamente regulamentados, como ainda aos modos de uma experiência segura e controlável. Este é um dos paradoxos de uma sociedade da comunicação: se por um lado cada vez mais são erigidas camadas de mediatizações tecnológicas para a produção de experiências “comunicacionais” seguras ${ }^{124}$, por outro lado, a alteridade é sacrificada tanto por meio da ausência da experiência de estranhamento radical, quanto da possibilidade de simples "eliminação" do outro através de um mero clique $^{125}$.

Como foi discutido anteriormente, o ponto de partida da ex-comunicação é um arrebatamento de si através da ex-posição a uma passibilidade radical. E quais seriam as relações entre o entre o conceito de jogo e o conceito de alteridade? O primeiro subjugaria o segundo na experiência comunicativa? Esta relação traz consequências ético-estéticas relevantes para o pensar comunicacional, já que o potencial lúdico dos media superou nas últimas duas décadas as fronteiras dos videogames e jogos de computador. O lúdico perpassa atualmente todo lidar com as interfaces das tecnologias digitais. O jogo não mais ocorre em um espaço-tempo definido separado do cotidiano, como nas clássicas teorias culturais do jogo (CAILLOIS, 2001; HUIZINGA, 2000), mas expande suas estruturas nas mais diversas dimensões da existência humana.

Sob o olhar de uma teoria negativa da comunicação, um estudo desta problemática pode ser promissor, já que uma abordagem dos aspectos performativos do jogo, sob um primeiro olhar, parece mais próximo das modalidades lúdicas da comunicação (particularmente nos videogames) do que uma abordagem dos aspectos narrativos. $\mathrm{O}$ aprofundamento das relações entre jogo e alteridade demandaria um outro projeto de pesquisa.

O que se busca neste momento é apenas ressaltar a possibilidade de um outro olhar que não considere a comunicação nos espaços eletrônicos para além - ou aquém - da interação. Evocar uma ferramenta como o Chatroulette não deixa de ser uma caricatura. É um modelo de sociabilidade via computador que provavelmente terá uma vida curta. Mas é através do exagero de uma caricatura que alguns traços talvez não tão visíveis em outras variações das chamadas "mídias sociais" podem ser observados.

O desafio da comunicação nos espaços eletrônicos seria o de criar uma fala plural.

Cf. BATESON, 1972, p. 184 e seguintes.

124 Faz-se aqui referência às formas de interação ser humano-computador como, por exemplo, através de jogos eletrônicos e das chamadas "mídias sociais".

125 A experiência de alteridade é marcada pela sua imprevisibilidade, sua incontrolabilidade e sua resistência a qualquer redução conceitual. Cf. p.ex. LEVINAS, 2008; MAYER, 2012; MERSCH, 2002, 2010. 
Transformar-se num espaço entre, num medium cuja medialidade se desdobra numa diferença radical que questiona, movimenta. Assim como um rosto, um objeto de arte, uma paisagem, um olhar, um suspiro, uma vida, ainda existem possibilidades dentro das redes telemáticas de arrebatamento pelo exterior, pelo sentimento de estarmos para e com o outro. Ainda é necessário desconstruir a imagem de uma sociedade da comunicação como o fruto da mera introdução de equipamentos telemáticos no cotidiano. Ainda é necessário abandonar a ditadura da interatividade, pois talvez a racionalidade técnica nunca se fez tão presente. Talvez desencantamentos sejam necessários. Ou uma comunicação como impossibilidade. 


\section{Excurso II. Ex-comunicação}

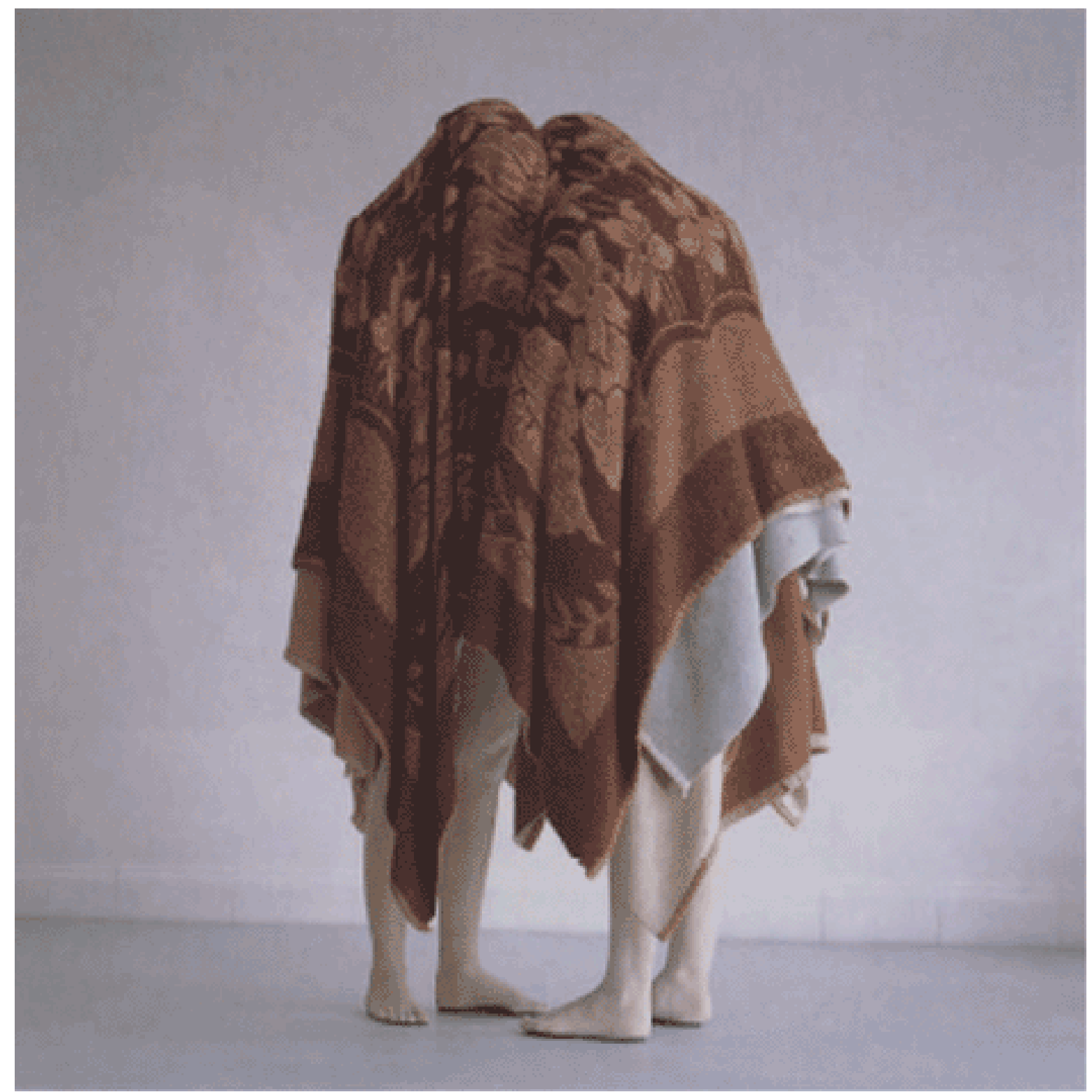

Fig. 1: Berlinde de Bruyckere, Spreken, 1999

Lençóis, cera, poliéster, madeira; 180 x 160 × $100 \mathrm{~cm}$

(c) Coleção MuHKA, Antuérpia, Bélgica 


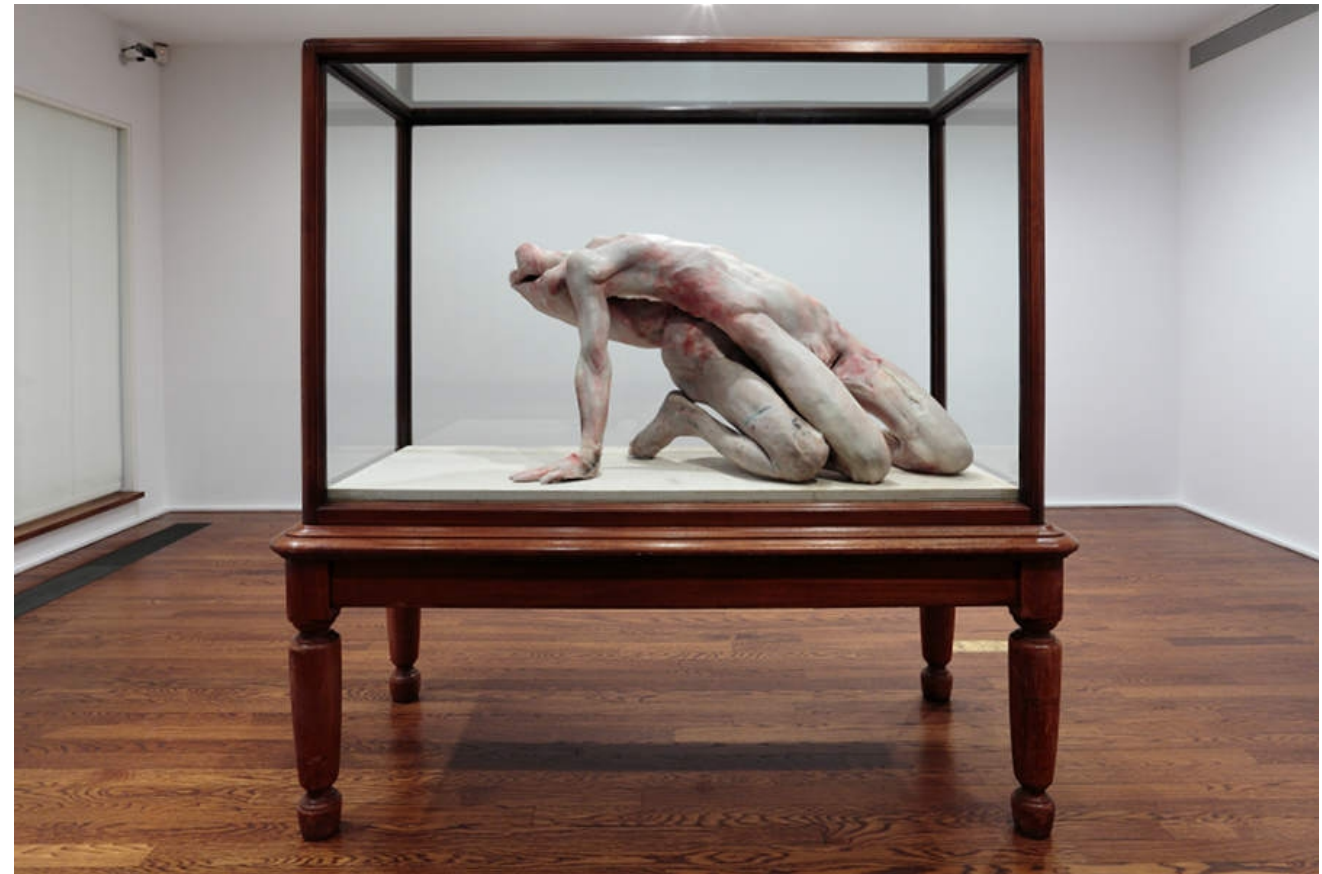

Fig. 2: Berlinde de Bruyckere, Into One-Another III To P.P.P., 2010

Cera, epóxi, ferro, madeira, vidro

(c) Foto: Thomas Müller, cortesia da galeria Hauser \& Wirth

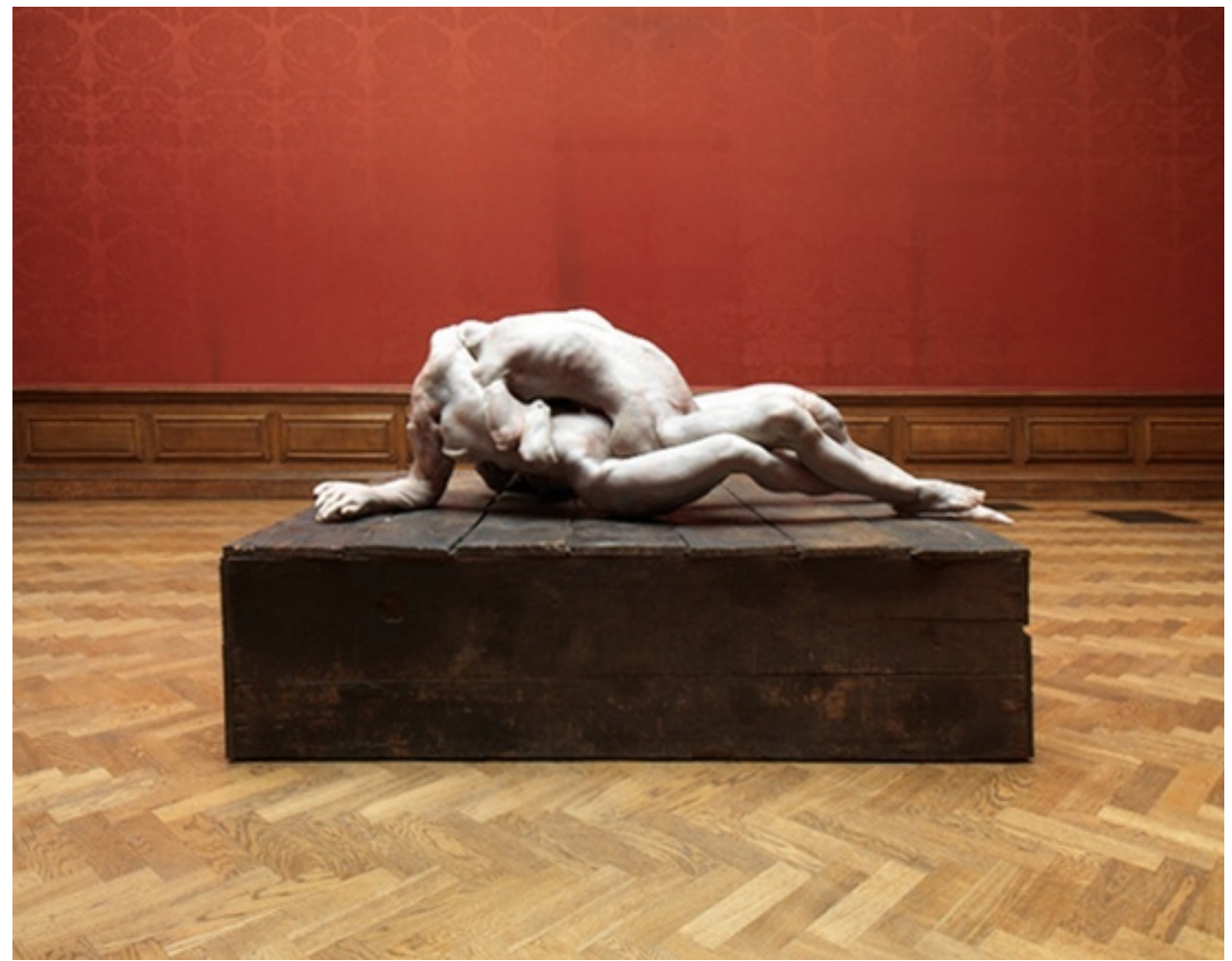

Fig. 3: Berlinde De Bruyckere, We are all Flesh, 2009

Madeira, cera, poliéster, aço $105 \times 110$ × $203 \mathrm{~cm} / 41$ 3/8 x 43 1/4 x 79 7/8

in: Installation view, 'Berlinde De Bruyckere, Luca Giordano. WE ARE ALL

FLESH', Hauser \& Wirth London, Old Bond Street, 2009

(c) Photo: Mike Bruce 


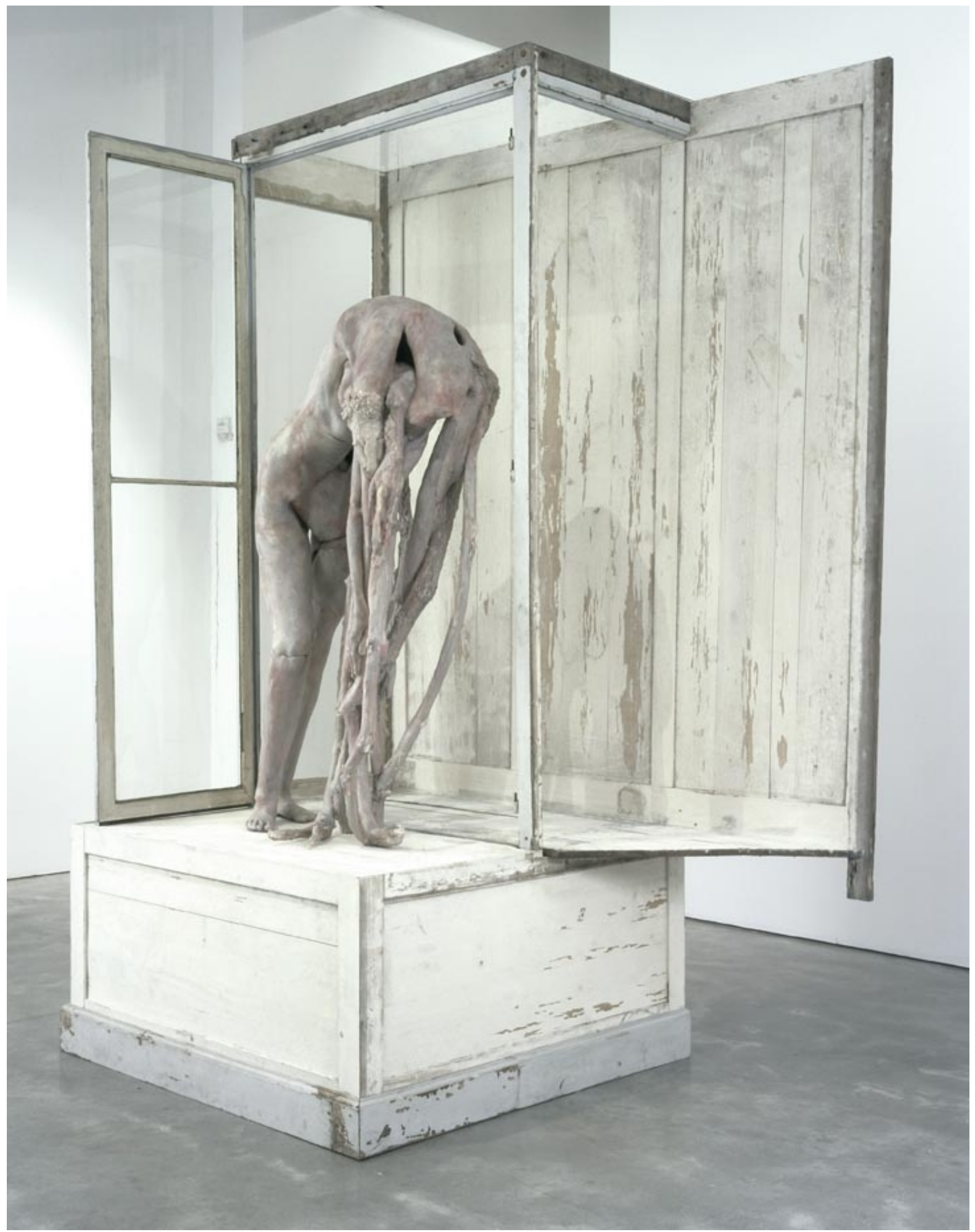

Fig. 4: Berlinde De Bruyckere, Marthe, 2008

Cera, epóxi, metal, madeira e vidro; $280 \times 172.5$ x $119.5 \mathrm{~cm}$

(c) Galeria Saatchi 


\section{CONSIDERAÇÕES FINAIS}

"Mas como é que não compreendi que aquilo que não alcanço em mim... já são os outros? Os outros, que são o nosso mais profundo mergulho! Nós que vos somos como vós mesmos não vos sois."

Trecho do livro A maçã no escuro, de Clarice Lispector

Este trabalho foi escrito na tentativa de traduzir a experiência de um pensamento provocado por sucessivos encontros e confrontos não apenas teóricos, mas também estéticos e existenciais ocorridos durante estes últimos anos. Experienciar alguma coisa é caminhar ao seu encontro. Dar forma a uma experiência através de um relato não deixa de resgatar o sentido etimológico da palavra método, do grego metha (movimento de um lugar para outro) e odos (caminho) - a meta deste trabalho escrito é expor seu próprio caminhar. Quanto mais vivos permanecem seus vestígios, menos fracassada é a sua metodologia. Face aos aspectos moventes e conflituosos de uma pesquisa, sua sedimentação na forma de uma tese de doutorado é marcada por ausências, superficialidades ou intuições que ainda carecem de uma maior fundamentação teórica. Algumas últimas ponderações podem ajudar não apenas a se fazer um balanço dessa errância teórica, como também a apertar os olhos na tentativa de entrever os seus desdobramentos.

O desenvolvimento desta tese de doutorado - uma teoria negativa da comunicação - foi antes de tudo uma tentativa de sistematização e argumentação teórica de uma incipiente abordagem para um outro conceito de comunicação que já estava latente na minha dissertação de mestrado intitulada Comunicar, verbo intransitivo: ensaio para uma comunicação estética. Tal intuição conceitual recebeu neste trabalho de doutoramento a (ainda precária) denominação de ex-comunicação, com o objetivo de ressaltar os aspectos existenciais entranhados no conceito de comunicação - bem como suas consequentes relações ontológicas, éticas e estéticas - que não se deixam exibir pelas (ou que não é o foco teórico das) abordagens semióticas, linguísticas, interacionais, psicológicas, sistêmicas, matemáticas e cibernéticas da comunicação.

Por esse motivo, o ambiente incubador deste projeto foi decisivo para a sua composição argumentativa. Durante os dois primeiros anos da pesquisa na Universidade de 
São Paulo, a Nova Teoria da Comunicação do teórico Ciro Marcondes Filho foi fundamental para a abertura da possibilidade de contínua reelaboração do conceito comunicacional e da necessidade do estudo dos seus aspectos existenciais. Durante os dois últimos anos de trabalho, na Universidade de Potsdam, a filosofia negativa dos media do filósofo Dieter Mersch foi essencial para a fundamentação de uma teoria negativa da comunicação dentro de uma perspectiva pós-hermenêutica.

O deslocamento entre essas duas abordagens distintas, mas que todavia partilham de um ponto de partida comum - a alteridade -, contribuiu para a tentativa de articulação dos conceitos de comunicação, de medium e de comunidade na constituição de uma teoria que fosse capaz de descrever fenômenos que participam da experiência comunicacional, mas que se recolhem no momento de sua ocorrência - ausentam-se no momento em que presentificam.

Sob um olhar crítico, o que este trabalho buscou apresentar foi uma introdução a uma teoria negativa comunicacional - um esboço cuja tentativa foi a de expor um campo de relações entre conceitos, autores, obras e sistemas teóricos capazes de compor uma teoria negativa da comunicação, cujos contornos já podem ser discernidos. Recapitulando, a proposta de uma teoria negativa da comunicação quer sugerir, ao mesmo tempo, um estudo da comunicação como locus privilegiado para os estudos de alteridade; um conceito de comunicação compreendido em sua dimensão existencial; uma ontologia a partir da análise do ser-com ou do ser-em-comunicação; uma estética a partir dos modos de percepção descritas pela teoria negativa dos media; uma ética descortinada pela abordagem negativa da comunidade do ser-com sem qualquer comunalidade.

Esses cinco aspectos, que foram elencados no decorrer deste trabalho, extrapolam os quatro anos de pesquisa concedidos para elaboração de uma tese de doutorado. Cada uma dessas dimensões reclamam para si um trabalho monográfico. Com tantas complexificações imbricadas na proposta de uma teoria negativa da comunicação, esta tese de doutorado consequentemente transforma-se em uma agenda de pesquisa, em um projeto a ser desenvolvido durante vários anos. Não apenas por conta do desdobramento das suas premissas teóricas, mas ainda pela necessidade de explanação de alguns aspectos da sua constituição que neste trabalho foram resumidamente abordados. A título de ilustração, esses elementos podem ser agrupados em:

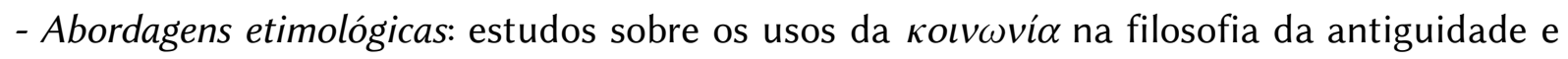


da commūnicātio na retórica da teologia antiga; abordagem das relações entre ex-comunicação e excomunhão; as diferenças e aproximações dos usos das palavras Mitteilung e Kommunikation no idealismo alemão e na fenomenologia. Cf. MÖRES, 2006; RITTER, 1976 e SEESEMANN, 1933.

- Abordagens filosóficas: estudos monográficos sobre a relação entre a negatividade e o conceito de comunicação [Mittteilung] na Crítica do Juízo de Kant; sobre o conceito de comunicação [Mitteilungsbegriff] na nascente filosofia da linguagem de Herder e Humboldt; sobre o conceito de comunicação [Mittteilung] como máscara na obra de Nietzsche: sobre a comunicação [Mittteilung] na filosofia existencial de Kierkegaard; sobre a comunicação [Kommunikation] como conceito filosófico na filosofia da existência de Karl Jaspers. Cf. BODE, 2009; CATTEPOEL, 1992; HERDER, 1986; HUMBOLDT, 2003; JASPERS, 1973; KANT, 2009; NIETZSCHE, 2000; PIEPER, 2000; SCHÜSSLE, 1995.

- Abordagens linguísticas: estudos comparativos entre as abordagens linguísticas e performativas; leituras críticas das obras de Saussure e Chomsky (a autonomia da linguagem), Austin e Searle (atos de fala e a comunicação como ação) e Habermas (comunicação como interação consensual); estudo comparativo entre as filosofias da linguagem de Wittgenstein, Heidegger e Derrida. Cf. AUSTIN, 1975; DERRIDA, 1991, 2008, 2009; HABERMAS, 1995; HEIDEGGER, 2003, 2008; KRÄMER, 2001; SAUSSURE, 2008 e WITTGENSTEIN, 1995.

- Abordagens pós-hermenêuticas / estudos de alteridade: realização de uma arqueologia do conceito de alteridade e da sua relação com os conceitos de comunicação no decorrer da história do pensamento; estudo sobre a importância da obra de Bernahrd Waldenfels para a atualização do debate em torno da alteridade como comunicação e responsividade; estudo sobre a obra da filósofa Sybille Krämer (a iconicidade notacional [Schriftbildlichkeit]); estudos sobre as recentes contribuições dos estudos dos media alemães que tratam dos aspectos performativos da linguagem [Sprachperformanz] e da imagem [Bildperformanz], particularmente as que ressaltam as características de passibilidade e performatividade da experiência comunicacional. Cf. BUSCH, 2012; FISCHER-LICHTE \& WULF, 2011; KRÄMER, CANCIK-KIRSCHBAUM \& TOTZKE, 2012; KRÄMER, 2001, 2011; MAYER, 2012; MERSCH, 2002; SCHWARTE, 2011; STOELLGER, 2010.

Esses são alguns temas que não foram suficientemente explorados ou que surgiram apenas perifericamente neste trabalho. As investigações destes tópicos devem contribuir 
para a defesa da pertinência de uma ex-comunicação. Por outro lado, a proposta de uma teoria negativa da comunicação provoca outras questões que não foram mencionadas por este texto e que ainda precisam ser investigadas. Por exemplo, é necessário testar a abrangência e a relevância do conceito de ex-comunicação para a manifestação dos aspectos performativos e responsivos da comunicação. Os estudos comunicacionais no Brasil estão situados em uma encruzilhada entre as ciências humanas e as ciências aplicadas. Por isso, a aplicação e a provação metodológica deste conceito face aos fenômenos contemporâneos de mediação ${ }^{126}$ sugerem-se como um desdobramento coerente para esta pesquisa. Outro problema que não deve ser ignorado são as implicações sociopolíticas desta teoria: até que ponto ela é capaz de produzir estudos propositivos e produtivos para o fazer no campo comunicacional? Além disso, o debate sobre um método próprio de uma teoria da comunicação é um tema candente e que merece um debate mais amplo pelas teorias comunicacionais praticadas nacionalmente ${ }^{127}$.

Deve-se ressaltar ainda que escrever sobre uma teoria negativa da comunicação, muito mais do que fundamentar um sistema teórico, é compor uma caixa de ressonância, um agrupamento de conceitos, autores e obras que se articulem entre si com o objetivo de expor os caracteres negativos do fenômeno comunicacional. Por isso, a proposta de uma teoria negativa da comunicação não deixa de ser problemática, já que os trabalhos que a fundamentam possuem no mais das vezes bases divergentes. Propor uma teoria negativa da comunicação é antes de tudo a tentativa de mostrar um areal no qual habitam vários trabalhos, cuja premissa é a impossibilidade de uma imanência radical do conceito de comunicação.

Por isso, a tese proposta aqui reitera a necessidade de uma teoria - e não de uma filosofia - da comunicação. Em uma teoria, a filosofia é instrumentalizada para a visualização de um fenômeno através de um conceito. A problemática de uma teoria da comunicação não deve ser a formação de um sistema filosófico a partir da experiência comunicacional - como o fez Karl Jaspers ou Georges Bataille - mas, antes de tudo, a caracterização de um ou mais termos - no caso específico deste texto, a comunicação, o medium e a comunidade. Portanto, a filosofia possui neste trabalho uma função semelhante a de filtros fotográficos: ela auxilia para ressaltar determinados fenômenos

126 Por exemplo, cf. algumas questões levantadas no Excurso I deste trabalho sobre a interação eletrônica e o conceito de uma ex-comunicação.

127 Uma das poucas exceções é a proposta de uma pesquisa metapórica, proposta por Ciro Marcondes Filho. Cf. MARCONDES FILHO, 2013, pp. 57-76. 
através dos seus conceitos e sistemas. A filosofia não possui objeto específico. Já o objeto de qualquer teoria da comunicação - por mais que alguns teóricos se neguem a afirmá-lo com receio de desmontar o castelo de vento da interdisciplinaridade - é bem claro: a criação de conceitos, modelos, figuras ou alusões que exibam, expliquem ou descrevam os mais variados aspectos do fenômeno comunicacional.

Esta pesquisa foi concebida não apenas como o ensaio para uma teoria negativa da comunicação, mas também como uma historiografia crítica do próprio conceito de comunicação. E para abordar essas duas dimensões foi necessário um método que se assemelhasse ao movimento da maré até a preia-mar: avançando e recuando, onda após onda, num avanço gradativo e no recolhimento súbito das vagas, num processo de diferença na iteração, na redundância. O movimento de retração das ondas não deixa de aludir à negatividade: tenta-se segurá-la com a mão, permanecem apenas seus vestígios na areia. Por isso o imperativo de uma abordagem indireta.

Uma outra escolha metodológica para a exposição da exterioridade radical da comunicação foi a opção pela escrita na voz neutra, passiva, que deseja indiciar a abertura para as várias vozes que já disseram as mesmas coisas que foram escritas até aqui ou que com-formaram todo o pensamento articulado neste trabalho. Não um "nós" que reclama uma coletividade ou comunidade imediata, mas um "se" de uma obra que fala por múltiplas vozes, tempos e espaços. A voz neutra e passiva sempre se apresenta como um bloqueio a qualquer tentativa de subjetivação.

O que este ensaio para uma ex-comunicação tentou exibir foi a incontornabilidade da dimensão mística recalcada no conceito de comunicação. Muito mais uma alusão que um conceito, a ex-comunicação buscou exemplificar a pertinência de uma teoria negativa da comunicação. Talvez o elemento mais importante desta despalavra seja seu hífen - o intervalo, o ausente, o deslocado, o inalcançável, o inexprimível. Ele marca a distância infinita entre os elementos da experiência e a finitude do ser-em-comunicação. Pausa e ligação precária entre dois termos que se retomam mutuamente. Instante em que o sujeito desaparece na absorção comunicacional. Transcendência na materialidade das coisas. $\mathrm{O}$ hífen descreve o momento de abandono ao outro: momento em que as medialidades realizam sua presentificação transparente e que a comunidade revela a existência: uma experiência comunicacional. É o momento em que todo o aparato se esvanece, em que o leitor se dissipa no livro, em que o espectador desaparece na imagem, em que o escritor se perde na obra, em que o ouvinte se afoga no som, em que o mim se torna abertura ao outro. 
A ex-comunicação é ainda a negação e o deslocamento que essa experiência implica: é transformação, é a obrigatoriedade da resposta, de ter que lidar com essa experiência, de ser responsável por esse outro diante de mim.

"Tudo é diferente do que tu imaginas, do que eu imagino

a bandeira ainda tremula,

os pequenos segredos ainda estão consigo, eles ainda lançam sombras, das quais

tu vives, eu vivo, nós vivemos" 128

\section{Paul Celan}

128 Es ist alles anders, als du es dir denkst, als ich es mir denke,/ die Fahne weht noch,/ die kleinen Geheimnisse sind noch bei sich,/ sie werfen noch Schatten, davon / lebst du, leb ich, leben wir. 


\section{REFERÊNCIAS BIBLIOGRÁFICAS}

ABRAM, J. A linguagem de Winnicott. Rio de Janeiro: Reunter, 2000.

AGAMBEN, G. A linguagem e a morte: um ensaio sobre o lugar da negatividade. Minas Gerais: Ed. UFMG, 2006.

ARISTÓTELES. Ética a Nicômaco. 2. ed. Lisboa: Quatzal Editores, 2006.

Sobre a alma. Tradução de Ana Maria Lóio. Lisboa: Imprensa Nacional-Casa da moeda, 2010.

AUSTIN, J. L. How to Do Things with Words. Cambridge: Harvard University Press, 1975.

BAECKER, D. Kommunikation. Leipzig: Reclam Verlag, 2005.

BARROS, M. de. Poesia completa. São Paulo: Leya, 2010.

BATAILLE, G. La experiencia interior: seguida de método de meditación y de post-scriptum 1953. Tradução de Fernando Savater. Madrid: Taurus Ediciones, 1973.

. Visions of excess: selected writings, 1927-1939. Minneapolis: Univ Of Minnesota Press, 1985.

O erotismo. Porto Alegre: L\&PM, 1987.

A literatura e o mal. Porto Alegre: L\&PM, 1989.

A experiência interior. São Paulo: Editora Ática, 1992.

Die innere Erfahrung nebst Methode der Meditation und Postskriptum 1953:

Atheologische Summe I. Tradução de Gerd Bergfleth. München: Matthes \& Seitz, 1999.

BATESON, G. Steps to an Ecology of Mind: Collected Essays in Anthropology, Psychiatry, Evolution, and Epistemology. Chicago: University of Chicago Press, 1972.

BAUMGARTEN, A. G. Estética: a lógica da arte e do poema. Rio de Janeiro: Vozes, 1993.

BECKER, H. A escola de Chicago. Mana, v. 2, p. 177-188, 1996.

BECKETT, S. Malone morre. Tradução de Paulo Leminski. São Paulo: Brasiliense, 1986.

Molloy. Tradução de Ana Helene Souza. Rio de Janeiro: Editora Globo, 2008.

O inominável. Tradução de Ana Helena Souza. Rio de Janeiro: Editora Globo, 2009.

Benjamin, W. Magia e Técnica, Arte e Política: ensaios sobre literatura e história da cultura. Tradução de Sérgio Paulo Rouanet. 3. ed. São Paulo: Editora Brasiliense, 1987. 
Das Kunstwerk im Zeitalter seiner technischen Reproduzierbarkeit: drei Studien zur Kunstsoziologie. 22. ed. Frankfurt am Main: Suhrkamp Verlag, 1992.

. Das Kunstwerk im Zeitalter seiner technischen Reproduzierbarkeit: Kommentar von Detlev Schöttker. 3. ed. Frankfurt am Main: Suhrkamp Verlag, 2007.

. Über Sprache überhaupt und über die Sprache des Menschen. In: TIEDEMANN, R. (Ed.). Walter Benjamin - Sprache und Geschichte: Philosophische Essays. Stuttgart: Reclam, 2010. p. 30-49.

BLANCHOT, M. La communauté inavouable. Paris: Les Éditions de Minuit, 1983.

. O espaço literário. Rio de Janeiro: Rocco, 1987.

. The unavowable community. Tradução de Pierre Joris. New York: Station Hill Press, 1988.

. A Conversa Infinita 1: A Palavra Plural. São Paulo: Escuta, 2005.

A Conversa Infinita 2: A Experiência Limite. São Paulo: Escuta, 2007.

BLUMER, H. Social Psychology. In: SCHMIDT, E. P. (Ed.). Man and Society: A Substantive Introduction to the Social Science. New York: Prentice-Hall, 1937. p. 144-198.

BLUTEAU, R. Vocabulario Portuguez E Latino: L-N [Vol. 5]. Coimbra: Collegio das Artes da Companhia de Jesus, 1716.

BODE, J. Was man nicht mitteilen kann: Sören Kierkegaard und indirekte Kommunikation. Wien: Universität Wien, 2009.

BOHRER, K. H. Ästhetik der Negativität. München: Carl Hanser Verlag, 2002.

BONSIEPEN, W. Negation und Negativität. In: Ritter, J. \& Gründer, K. (Org.). Historisches Wörterbuch der Philosophie [Mo - O]. Basel/Stuttgart: Schwabe \& Co, 1984.

BRAGA, L. Nem rara, nem ausente - tentativa. Revista Matrizes, v. Ano 4, n. 1, p. 65-81, 2010.

BUSCH, K. Passivität: Eine Einzelstimmung. Hamburg: Textem Verlag, 2012.

CAILLOIS, R. Man, Play, and Games. Tradução de Meyer Barash. Chicago: University of Illinois Press, 2001.

CATT, I. E. \& EICHER-CATT, D. Communicology: The New Science of Embodied Discourse. New Jersey: Fairleigh Dickinson University Press, 2010.

CATTEPOEL, J. Dämonie und Gesellschaft: Søren Kierkegaard als Sozialkritiker und Kommunikationstheoretiker. Praktische ed. München: Alber, 1992. 
CÉLAN, P. Die Gedichte: Kommentierte Gesamtausgabe. Frankfurt am Main: Suhrkamp, 2003a.

Die Niemandsrose. 13. ed. Frankfurt am Main: Fischer, 2003b.

COOLEY, C. H. Social organization: a study of the larger mind. New York: Charles Scribner's Sons, 1909.

Human Nature and the Social Order. New York: Charles Scribner's Sons, 1922.

COSTA LIMA, L. (Org.). A literatura e o leitor. Rio de Janeiro: Paz e Terra, 1979.

CUNHA, A. G. da. Dicionário Etimológico Nova Fronteira da Língua Portuguesa. Rio de Janeiro: Nova Fronteira, 1982.

DELEUZE, G. \& GUATTARI, F. O que é a filosofia? Rio de Janeiro: Editora 34, 1992.

Mil Platôs: Capitalismo e Esquizofrenia - Vol. 2. Tradução de Ana Lúcia De Oliveira e Lúcia Cláudia Leão. Rio de Janeiro: Editora 34, 1995.

DERRIDA, J. Margens da Filosofia. Campinas: Papirus, 1991.

. Writing and Difference. Tradução de Alan Bass. London: Routledge, 2002.

Gramatologia. São Paulo: Perspectiva, 2008.

A escritura e a diferença. São Paulo: Perspectiva, 2009.

DEVITO, J. A. Communicology: An Introduction to the Study of Communication. New York: Harper \& Row, 1978.

DIDI-HUBERMAN, G. Formlose Ähnlichkeit: oder die Fröhliche Wissenschaft des Visuellen nach Georges Bataille. Paderborn: Fink, 2010.

DISCHNER, G. Es wagen, ein Einzelner zu sein: Versuch über Kierkegaard. Bodenheim: Philo Verlagsgesellschaft, 1997.

ESPOSITO, R. Communitas: Origen y destino de la comunidad. Tradução de Carlo Rodolfo Mclinari Marotto. Buenos Aires: Arnorrortu, 2003.

FELINTO, E. Materialidades da Comunicação: por um Novo Lugar da Matéria na Teoria da Comunicação. Ciberlegenda (UFF), n. 5, 2001.

Passeando no Labirinto: Textos sobre as Tecnologias e Materialidades da Comunicação. Porto Alegre: EDIPUCRS, 2006.

FLUSSER, V. Kommunikologie. Frankfurt am Main: Fischer Taschenbuch Verlag, 1998. 
FREUD, S. Gesammelte Werke: Nachtragsband, Texte aus den Jahren 1885 bis 1938. Frankfurt am Main: S. Fischer Verlag, 1987.

. Das Unheimliche. In: Psychologische Schriften [Studienausgabe - Band IV]. Frankfurt am Main: Fischer, 2000. p. 241-274.

GADAMER, H.-G. Verdade e Método: traços fundamentais de uma hermenêutica filosófica. Petrópolis: Vozes, 1997.

GAMM, G. Flucht aus der Kategorie: Die Positivierung des Unbestimmten als Ausgang der Moderne. Frankfurt am Main: Suhrkamp, 1994.

Nicht nichts: Studien zu einer Semantik des Unbestimmten. Frankfurt am Main: Suhrkamp Verlag, 2000. p. 337

Der Deutsche Idealismus: Eine Einführung in die Philosophie von FIchte, Hegel und Schelling. Stuttgart: Reclam, 2012.

GOfFMAN, E. The Presentation of the Self in Everyday Life. Edinburgh: University of Edinburgh, 1956.

GÓRGIAS. Testemunhos e fragmentos. Lisboa: Colibri, 1993.

GREVE, W. Kierkegaards maieutische Ethik: Von "Entweder/Oder II" zu den "Stadien". Frankfurt am Main: Suhrkamp, 1999.

GRUBE, G. Vilém Flusser - Mundus ex machina. In: LAGAAY, A.; LAUER, D. (Eds.). Medientheorien. Eine philosophische Einführung. Frankfurt am Main: Campus Verlag $\mathrm{GmbH}, 2004$.

GRÜNEWALD, J. L. (Trad. e Org.). A Idéia do Cinema: Ensaios de Walter Benjamin, Eisenstein, Godard, Merleau-Ponty. Rio de Janeiro: Civilização Brasileira, 1969.

GUMBRECHT, H.-U. Flache Diskurse. In: GUMBRECHT, H. U.; PFEIFFER, K. L.; ELSNER, M. (Eds.). Materialität der Kommunikation. Frankfurt am Main: Suhrkamp, 1988.

EdUERJ, 1998.

Corpo e forma: ensaios para uma crítica não-hermenêutica. Rio de Janeiro:

Productions of Presence: what meaning cannot convey. California: Stanford University Press, 2004.

. Pequenas crises: experiência estética nos mundos cotidianos. In: GUIMARÃES, C.

(Ed.). Comunicação e Experiência Estética. Belo Horizonte: Ed. UFMG, 2006.

HABERMAS, J. Theorie des kommunikativen Handelns: Handlungsrationalität und gesellschaftliche Rationalisierung. Vol. 1. Frankfurt am Main: Suhrkamp, 1995. 
HARTMANN, F. Medienphilosophie. Wien: WUV/UTB, 2000.

. Medienphilosophische Theorien. In: WEBER, S. (Ed.). Theorien der Medien. Konstanz: UVK Verlagsgesellschaft, 2003.

HEGEL, G. W. F. Jenaer Systementwürfe III: Naturphilosophie und Philosophie des Geistes. Hamburg: Felix Meiner Verlag, 1987.

Wissenschaft der Logik: 1. teil, Die objektive Logik. Hamburg: eBook.de Edition, 2012a.

Phänomenologie des Geistes. Hamburg: eBook.de Edition, 2012b.

HEIDEGGER, M. Unterwegs zur Sprache - Gesamtausgabe I. Abteilung: Veröffentlichte Schriften 1910-1976. Vol. 12. Frankfurt am Main: Vittorio Klostermann, 1985.

Klostermann, 2003.

A caminho da linguagem. Tradução de Márcia Sá Cavalcante Schuback. 4. ed. Petrópolis: Vozes, 2008.

. Hegel - Gesamtausgabe III. Abteilung: Unveröffentlichte Abhandlungen (Vortäge - Gedachtes). Vol 48. 2. ed. Frankfurt am Main: Vittorio Klostermann, 2009.

HERDER, J. G. Abhandlung über den Ursprung der Sprache. Berlin: Reclam Verlag, 1986.

HETZEL, A. (Org.). Negativität und Unbestimmtheit: Beiträge zu einer Philosophie des Nichtwissens. Bielefeld: transcript Verlag, 2009.

HOFFMANN, S. Geschichte des Medienbegriffs. Hamburg: Felix Meiner, 2002.

HÖRL, E. Die heiligen Kanäle: Über die archaische Illusion der Kommunikation. Zürich-Berlin: diaphanes, 2005.

HÜBENER, W. Die Logik der Negation als ontologisches Erkenntnismittel. In: WEINRICH, H. (Ed.). Positionen der Negativität. München: Wilhelm Fink, 1977. p. 105-140.

HUIZINGA, J. Homo Ludens: o Jogo Como Elemento da Cultura. São Paulo: Perspectiva, 2000.

HUMBOLDT, W. VON. Über die Verschiedenheit des menschlichen Sprachbaues und ihren Einfluß auf die geistige Entwicklung des Menschengeschlechts: Über die Sprache. Wiesbaden: Marixverlag, 2003.

HUSSERL, E. Cartesianische Meditationen: Eine Einleitung in die Phänomenologie. 2. ed. Hamburg: Felix Meiner Verlag, 1987. 
IRIBARNE, J. V. Husserls Theorie der Intersubjektivität. Tradução de Menno-Arend Herlyn. Freiburg/München: Alber Verlag, 1994.

ISER, W. O Ato da Leitura: uma teoria do efeito estético. São Paulo: Editora 34, 1996.

JASPERS, K. Philosophie. 2. Existenzerhellung. Berlin - Heidelberg - New York: Springer-Verlag GmbH, 1973.

1984.

. Der philosophische Glaube angesichts der Offenbarung. 3. ed. München: Piper,

. Einführung in die Philosophie: zwölf Radiovorträge. 28. ed. München: Piper, 1989.

JAUS, H. R. O prazer estético e as Experiências Fundamentais da Poiesis, Aesthesis e Katharsis. In: COSTA LIMA, L. (Org.). A literatura e o leitor: textos de Estética da Recepção. Rio de Janeiro: Paz e Terra, 1979.

JAY, M. Songs of Experience: modern american and european variations on a universal theme. California: University of California Press, 2005.

KAMPER, D. \& WULF, C. (Org.). Schweigen: Unterbrechung und Grenze der menschlichen Wirklichkeit. Berlin: Reimer, 1992.

KANT, I. Kritik der Urteilskraft. Stuttgart: Reclam, 1991.

Kritik der reinen Vernunft: Zweite hin und wieder verbesserte Auflage (1787). München: GRIN Verlag, 2009.

KIERKEGAARD, S. Entweder-Oder: Ein Lebensfragment. München: Deutscher Taschenbuch Verlag, 1980.

Der Begriff der Angst: Eine schlecht und recht psychologisch-hinweisende Überlegung in Richtung auf das dogmatische Problem der Erbsünde von Vigilius Haufniensis. Tradução de Liselotte Richter. Frankfurt am Main: eva-Taschenbuch, 1984.

Abschließende unwissenschaftliche Nachschrift zu den philosophischen Brocken [Erste Teil]. Vol.1. München: Gütersloher Verlagshaus, 1994.

Die Krankheit zum Tode: Eine christlich-psychologische Darlegung zur Erbauung und Erweckung von Anti-Climacus. Stuttgart: Reclam, 1997.

Bodenheim: Philo Verlagsgesellschaft, 1997.

Die Wiederholung: Ein Versuch in der Experimentalpsychologie von Constantin Constantius. 2. ed. München: Deutscher Taschenbuch Verlag, 2007.

KRÄMER, S. Das Medium als Spur und als Apparat. In: KRÄMER, S. (Org.). Medien 
Computer Realität: Wirklichkeitsvorstellungen und Neue Medien. Frankfurt am Main: Suhrkamp Verlag, 1998. p. 73-94.

KRÄMER, S. Sprache, Sprechakt, Kommunikation: Sprachtheoretische Positionen des 20. Jahunderts. Frankfurt am Main: Suhrkamp Verlag, 2001.

Erfüllen Medien eine Konstitutionsleistung? Thesen über die Rolle medientheoretischer Erwägung beim Philosophieren. In: MÜNKER, S.,; ROESLER, A. \& SANDBOTHE, M. (Org.). Medienphilosophie. Beiträge zur Klärung eines Begriffs. Frankfurt am Main: Fischer Taschenbuch Verlag, 2003. p. 78-90.

(Org.). Performativität und Medialität. München-Paderborn: Wilhelm Fink, 2004.

. Medium, Bote, Übertragung: kleine Metaphysik der Medialität. Frankfurt am Main: Suhrkamp Verlag, 2008.

LAGAAY, A. \& LAUER, D. (Org.). Medientheorien: Eine philosophische Einführung. Frankfurt am Main: Campus Verlag, 2004.

LALANDE, A. Vocabulário técnico e crítico da filosofia. 3. ed. São Paulo: Martins Fontes, 1999.

LANIGAN, R. L. The Human Science of Communicology: A Phenomenology of Discourse in Foucault and Merleau-Ponty. Pittsburgh: Duquesne University Press, 1992.

LEVINAS, E. Existence and Existents. Dordrecht: Kluwer Academic Publishers, 1988.

Otherwise Than Being or Beyond Essence. Dordrecht: Kluwer Academic Publishers, 1991.

Is Ontology Fundamental? In: In: Basic Philosophical Writings. Ed. Peperzak, Adriaan T., Simon Critchley and Robert Bernasconi. Indianapolis: Indiana University Press, 1996. p. 1-10.

Totalidade e Infinito. Lisboa: Edições 70, 2008.

LISPECTOR, C. A maçã no escuro. Rio de Janeiro: Rocco, 1998.

LORENZER, A. Sprachzerstörung und Rekonstruktion. 2. ed. Frankfurt am Main: Suhrkamp, 1976.

LÜBKE, P. Kierkegaard and indirect communication. History of European Ideas, v. 12, n. 1, p. 31-40, 1990.

LYOTARD, J.-F. The Inhuman: Reflections on Time. Tradução de Geoffrey Bennington; Rachel Bowlby. Cambridge: Polity Press, 1991.

MARCONDES FILHO, C. O espelho e a máscara: o enigma da comunicação - Nova 
Teoria da Comunicação I. São Paulo: Ed. Unijui e Discurso, 2002.

MARCONDES FILHO, C. O escavador de silêncios: formas de construir e desconstruir sentidos na comunicação [Nova teoria da comunicação II]. São Paulo: Paulus, 2004.

O outro como um mistério e o feminino como a alteridade absoluta: Sobre a recuperação do face a face na comunicação em Emmanuel Lévinas. Revista Matrizes, v. 1, n. Outubro, 2007.

Paixão, erotismo e comunicação. Contribuições de um filósofo maldito, Georges Bataille. HYPNOS, v. 21, n. 2. Semestre, p. 208-230, 2008.

Comunicabilidade na rede: chances de uma alteridade medial. Anais do congresso Medienevolution, Interfaces und Infosozialität. Frankfurt am Main: 2009.

O princípio da razão durante: $O$ conceito de comunicação e a epistemologia metapórica [Nova Teoria da Comunicação III - Tomo V]. São Paulo: Paulus, 2010a.

. Princípio da Razão Durante: Comunicação para os antigos, a fenomenologia e o bergsonismo [Nova Teoria da Comunicação III - Tomo I]. São Paulo: Paulus, 2010b.

O princípio da razão durante: O círculo Cibernético - o observador e a subjetividade [Nova Teoria da Comunicação III - Tomo III]. São Paulo: Paulus, 2011.

. O rosto e a Máquina: $O$ fenômeno da comunicação visto pelos ângulos humano, medial e tecnológico [Nova Teoria da Comunicação - Vol. 1]. São Paulo: Paulus, 2013.

MARCONDES FILHO, C. (Org). Dicionário da comunicação. São Paulo: Paulus, 2009.

MARGREITER, R. Medienphilosophie: Eine Einführung. Berlin: Parerga Verlag, 2007.

MARIN, L. Die exkommunizierte Stimme: Erinnerungsversuche. Tradução de Bernhard Nessler. Berlin: diaphanes, 2002.

MARTINO, L. M. S. A disciplina interdisciplinar: ambivalências epistemológicas no ensino de Teoria(s) da Comunicação. Logos: Comunicação \& Universidade, v. 19, n. 2, p. 17-28, 2012.

MATZKER, R. Das Medium der Phänomenalität: Wahrnehmungs- und erkenntnistheoretische Aspekte der Medientheorie und Filmgeschichte. München: Wilhelm Fink Verlag, 1993.

MAYER, M. Humanismus im Widerstreit: Versuch über Passibilität. Paderborn: Fink Wilhelm, 2012.

MCLUHAN, M. Understanding Media: The Extensions of Man. New York: New American Library, 1964. 
MEAD, G. H. Mind, Self and Society from the Standpoint of a Social Behaviorist. Chicago: University of Chicago, 1934.

MENNINGHAUS, W. Walter Benjamins Theorie der Sprachmagie. Frankfurt am Main: Suhrkamp Verlag, 1995.

MERSCH, D. Was sich zeigt. Materialität, Präsenz, Ereignis. München: Fink, 2002.

. Ereignis und Aura: Untersuchungen zu einer Ästhetik des Performativen. Frankfurt am Main: Suhrkamp Verlag, 2002.

Wort, Bild, Ton, Zahl: Modalitäten medialen Darstellens. In: MERSCH, D. (Org.). Die Medien der Künste: Beiträge zur Theorie des Darstellens. München: Wilhelm Fink Verlag, 2003. p. 9-49.

Medialität und Undarstellbarkeit. Einleitung in eine "negative" Medientheorie. In: KRÄMER, S. (Org.). Performativitat und Medialität. München-Paderborn: Wilhelm Fink, 2004. p. $75-96$.

Gibt es Verstehen? In: ALBRECHT, J. \& HUBER, J. (Org.). Kultur Nicht Verstehen. Zürich: Springer, 2005. p. 109-126.

Medientheorien zur Einführung. Hamburg: Junius Verlag, 2006.

. Orte der Bedeutung: sechs Thesen zu Sprache und Alterität. In: BUBNER, R. \& HINRICHS, G. (Org.). Von der Logik zur Sprache: Stuttgarter Hegel-Kongreß 2005. Hamburg: Klett-Cotta, 2007a. p. 349-364.

Die Frage der Alterität: Chiasmus, Dlfferenz und die Wendung des Bezugs. In: DALFART, I. U. \& STOELLGER, P. (Org.). Hermeneutik der Religionen. Tübingen: Mohr Siebeck, 2007b. p. 35-57.

. Tertium datur: Einleitung in eine negative Medientheorie. In: MÜNKER, S. \& ROESLER, A. (Org.). Was ist ein Medium? Frankfurt am Main: Suhrkamp Verlag, 2008.

Posthermeneutik. Hamburg: Akademie-Verlag, 2010a.

- Meta/Dia Zwei unterschiedliche Zugange zum Medialen. Zeitschrift für Medien-und Kulturforschung, v. 2010, n. 2, p. 185-208, $2010 \mathrm{~b}$.

Einführung in die Medienkulturwissenschaft. Vorlesungen an der Universität Potsdam (EMW 2010-2011). Potsdam: Universität Potsdam, 2011.

Tertium datur: introdução a uma teoria negativa dos media. Tradução de Maurício Liesen. Revista Matrizes, v. 7, n. 1, p. 207-222, 2013.

MÖRES, C. Das kommunizierende Ich? Zum Kommunikationsbegriff in der Theologie mit Bezug auf die theologische Habermas-Rezeption. Berlin: Lit Verlag, 2006. 
MÜNKER, S. \& ROESLER, A. (Org.) Was ist ein Medium? Frankfurt am Main: Suhrkamp Verlag, 2008.

NANCY, J.-L. The Inoperative Community. Minneapolis: University of Minnesota Press, 1991.

. The Birth to Presence. Stanford: Stanford University Press, 1993.

. Being Singular Plural. Tradução de Robert D. Richardson; Anne O’Byrne. California: Stanford University Press, 2000.

Hegel: the restlessness of the negative. Tradução de Jason Smith; Steven Miller. Minneapolis: University of Minnesota Press, 2002.

. Die herausgeforderte Gemeinschaft. Tradução de Esther Von der Osten. Zürich-Berlin: diaphanes, 2007.

NIENTIED, M. Kierkegaard und Wittgenstein: "Hineintäuschen in das Wahre". Berlin: Walter de Gruyter, 2003.

NIETZSCHE, F. Über Wahrheit und Lüge: Ein Essay, Aphorismen und Briefe. Frankfurt am Main: Insel Verlag, 2000.

OTTMANN, H. Herr und Knecht bei Hegel. Bemerkungen zu einer mißverstandenen Dialektik. Zeitschrift für philosophische Forschung, v. 35, n. 3/4, Zum 150. Todestag von Georg Friedrich Wilhelm Hegel, p. 365-384, 1981.

PEIRCE, C. S. Colected Papers: Volume V (Pragmatism and Pragmaticism). Cambridge: Belknap Press of Harvard University Press, 1965.

PETERS, M. Pós-estruturalismo e filosofia da diferença. Belo Horizonte: Autêntica, 2000.

PIEPER, A. Sören Kierkegaard. München: C.H. Beck, 2000.

PINTO, L. M. DA S. Diccionario da Lingua Brasileira por Luiz Maria da Silva Pinto, natural da Provincia de Goyaz. Ouro Preto: Typographia de Silva, 1832.

PRECHTL, P. Edmund Husserl: zur Einführung. Hamburg: Junius Verlag, 1998.

PRICE, A. W. Love and friendship in Plato and Aristotle. Oxford: Oxford University Press, 1989.

PURKARTHOFER, R. Kierkegaard. Leipzig: Reclam, 2005.

RENTSCH, T. Negativität und praktische Vernunft. Frankfurt am Main: Suhrkamp Verlag, 2000. 
RITTER, J. \& GRÜNDER, K. (Org). Historisches Wörterbuch der Philosophie: I - K. V. 4. Basel/Stuttgart: Schwabe \& Co., 1976.

Historisches Wörterbuch der Philosophie: Mo - O. V. 6. Basel/Stuttgart: Schwabe \& Co., 1984.

ROESLER, A. (Org). Medienphilosophie: Beiträge zur Klärung eines Begriffes. Frankfurt am Main: Fischer, 2003.

ROMBACH, H., SEEBOHM, T. M. \& SOKOLOWSKI, R. Mensch, Welt, Verständigung : Perspektiven einer Phänomenologie der Kommunikation. Freiburg: Alber, 1977.

SAFATLE, V. O amor é mais frio que a morte: negatividade, infinitude e indeterminação na teoria hegeliana do desejo. Kriterion: Revista de Filosofia, v. 49, p. 95-125, 2008.

SANDBOTHE, M. Pragmatische Medienphilosophie: Grundlegung einer neuen Disziplin im Zeitalter des Internet. Weilerswist: Velbrück Wissenschaft, 2001.

SANDBOTHE, M. \& NAGL, L. (Org.). Systematische Medienphilosophie. Berlin: Akademie Verlag, 2005.

SAPIR, E. Language: An introduction to the study of speech. New York: Harcourt, Brace \& World, 1921.

Communication. In: Encyclopaedia of the Social Sciences. New York: Macmillan Publishers, 1935.

SAUSSURE, F. DE. Curso de linguística geral. São Paulo: Cultrix, 2008.

SCHÜSSLE, W. Jaspers zur Einführung. Hamburg: Junius Verlag GmbH, 1995.

SCHWARTE, L. (Org.). Bild-Performanz: Die Kraft des Visuellen. Paderborn: Fink Wilhelm, 2011. p. 391

SEESEMANN, H. Der Begriff Koinonia im Neuen Testament. Gießen: A. Töpelmann, 1933.

SHANNON, C. E. \& WEAVER, W. The Mathematical Theory of Communication. Urbana: University of Illinois Press, 1949.

SILVA, A. M. Diccionario da lingua portugueza: recompilado dos vocabularios impressos ate agora, e nesta segunda edição novamente emendado e muito acrescentado, por ANTONIO DE MORAES SILVA. Lisboa: Typographia Lacerdina, 1813.

SILVESTRE, J. P. Bluteau e as origens da lexicografia moderna. Lisboa: Imprensa nacional-Casa da moeda, 2008.

SIMÃO, L. M. Ensaios dialógicos: compartilhamento e diferença nas relações eu-outro. 
São Paulo: Ed. Hucitec, 2010.

SODRÉ, M. Comunicação: um campo em apuros teóricos. Matrizes, v. 2, n. jan./jun., p. 11-28, 2012.

SPITZ, R. Die Entstehung der ersten Objektbeziehungen. Stuttgart: Klett-Cotta, 1973.

Nein und Ja: die Ursprünge der menschlichen Kommunikation. Tradução de Käte Hügel. 4. ed. Stuttgart: Klett-Cotta, 1992.

STOEllgeR, P. Passivität aus Passion: Zur Problemgeschichte einer "categoria non grata”. Tübingen: Mohr Siebeck GmbH \& Company K, 2010.

THEUNISSEN, M. Negative Theologie Der Zeit. Frankfurt am Main: Suhrkamp, 1991.

VAZ, H. C. L. Senhor e escravo: uma parábola da filosofia ocidental. Síntese - Revista de Filosofia, v. 8, n. 21, p. 7-29, 1981.

VOGEL, M. Medien der Vernunft: Eine Theorie des Geistes und der Rationalität auf Grundlage einer Theorie der Medien. Frankfurt am Main: Suhrkamp Verlag, 2001.

VOLKE, A.-J. Les rapports avec autrui dans la philosophie grecque d'Arsitote à Panétius. Paris: Vrin, 1961.

WALDENFELS, B. Der Stachel des Fremden. Frankfurt am Main: Suhrkamp Verlag, 1990. . Antwortregister. Frankfurt am Main: Suhrkamp Verlag KG, 1994. p. 651

Topographie des Fremden: Studien zur Phänomenologie des Fremden I. Frankfurt am Main: Suhrkamp, 1997.

. Experimente mit der Wirklichkeit. In: KRÄMER, S. (Org.). Medien Computer Realität: Wirklichkeitsvorstellungen und Neue Medien. Frankfurt am Main: Suhrkamp Verlag, 1998. p. 213-243.

. Grundmotive einer Phänomenologie des Fremden. Frankfurt am Main: Suhrkamp, 2006.

. Grenzen der Normalisierung: Studien zur Phänomenologie des Fremden II. Frankfurt am Main: Suhrkamp Verlag, 2008.

. Responsive Ethik zwischen Antwort und Verantwortung. Deutsche Zeitschrift für Philosophie, v. 58, n. 1, p. 71-81, 1 fev. 2010.

Suhrkamp, 2012.

WALDENFELS, B. \& DÄRMANN, I. (Org.). Der Anspruch des Anderen: Perspektiven 
phänomenologischer Ethik. München: Fink, 1998.

WATZLAWICK, P., BEAVIN, J. H. \& JACKSON, D. D. Menschliche Kommunikation: Formen, Störungen, Paradoxien. 11. ed. Bern: Hans Huber, 2007.

WEIDTMANN, N. Erfahrung des Zwischen: Anmerkungen zu Waldenfels' Phänomenologie der Fremderfahrung. Etica \& Politica, n. XIII, p. 258-270, 2011.

WEINRICH, H. (Org.). Positionen der Negativität. München: Wilhelm Fink, 1975.

WELLERSHOFF, D. Die Verneinung als Kategorie des Werdens / Negation als Kommunikationsantrieb [Beitrag]. In: WEINRICH, H. (Org.). Positionen der Negativität. München: Wilhelm Fink, 1975.

WESCHE, T. Kierkegaard: Eine philosophische Einführung. Stuttgart: Reclam, 2003.

WIESING, L. Artifizielle Präsenz. Frankfurt am Main: Suhrkamp Verlag, 2005.

WINNICOTT, D. Communicating and not Communicating: leading to a study of certain opposites. In: The Maturational Process and the Facilitating Enviroment. London: Karnac Books, 1990.

WITTGENSTEIN, L. Tratactus logico-philosophicus. Tradução de José Arthur Giannotti. São Paulo: Edusp, 1968.

Werkausgabe in 8 Bänden - Band 1: Tractatus logico-philosophicus. Tagebücher 1914-1916. Philosophische Untersuchungen. 10. ed. Frankfurt am Main: Suhrkamp Verlag, 1995.

WULF, C. Präsenz des Schweigens. In: KAMPER, D. \& WULF, C. (Org.). Schweigen: Unterbrechung und Grenze der menschlichen Wirklichkeit. Berlin: Reimer, 1992. p. 7-16. 